\title{
In-Pile Instrumentation to Support Fuel Cycle Research and Development - FY12 Status Report
}

J. Rempe

J. Daw

D. Knudson

R. Schley

T. Unruh

B. Chase

J. Palmer

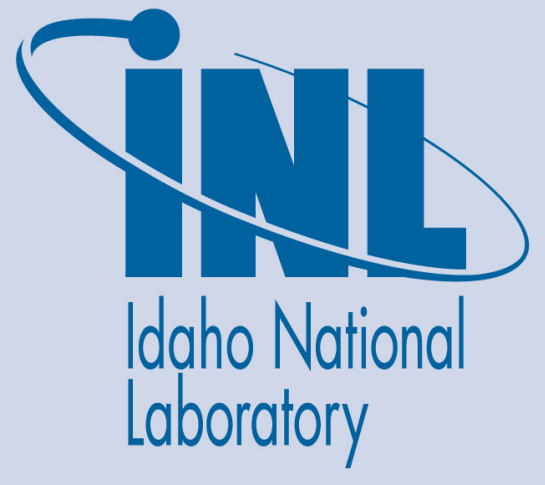

September 2012

The INL is a U.S. Department of Energy National Laboratory operated by Battelle Energy Alliance 
INL/EXT-12-26921

FCRD-FUEL-2012-000282

\title{
In-Pile Instrumentation to Support Fuel Cycle Research and Development - FY12 Status Report
}

\author{
J. Rempe \\ J. Daw \\ D. Knudson \\ R. Schley \\ T. Unruh \\ B. Chase \\ J. Palmer \\ September 2012
}

\section{Idaho National Laboratory \\ Fuel Cycle Research \& Development \\ Idaho Falls, Idaho 83415}

http://www.inl.gov

Prepared for the

U.S. Department of Energy

Office of Nuclear Energy

Under DOE Idaho Operations Office

Contract DE-AC07-05ID14517 


\section{DISCLAIMER}

This information was prepared as an account of work sponsored by an agency of the U.S. Government. Neither the U.S. Government nor any agency thereof, nor any of their employees, makes any warranty, expressed or implied, or assumes any legal liability or responsibility for the accuracy, completeness, or usefulness, of any information, apparatus, product, or process disclosed, or represents that its use would not infringe privately owned rights. References herein to any specific commercial product, process, or service by trade name, trade mark, manufacturer, or otherwise, does not necessarily constitute or imply its endorsement, recommendation, or favoring by the U.S. Government or any agency thereof. The views and opinions of authors expressed herein do not necessarily state or reflect those of the U.S. Government or any agency thereof. 


\section{EXECUTIVE SUMMARY}

The Office of Nuclear Energy in the Department of Energy funds fuel research and development that emphasizes an approach relying on first principle models to develop optimized fuel designs that offer significant improvements over current fuels. To facilitate this approach, high fidelity, real-time data are essential for characterizing the performance of new fuels during irradiation testing. A strategic research effort is underway to develop sensors of unprecedented accuracy and resolution for obtaining the data needed to characterize three-dimensional changes in fuel microstructure during irradiation testing. When implemented, this strategy will yield test capsule designs that are instrumented with new sensor technologies for irradiations at facilities primarily relied upon by the Fuel Cycle Research and Development (FCRD) program, the Advanced Test Reactor (ATR) and the High Flux Isotope Reactor (HFIR). As part of this effort, laboratory testing, and as needed, irradiation testing, of sensors in these capsules will be completed to give sufficient confidence that the irradiation tests will yield the required data.

At the onset of this effort, a strategic plan was developed to provide necessary background information related to fuel irradiation testing, desired parameters for detection, and an overview of currently available in-pile instrumentation. As part of developing this strategic plan, a workshop was held in which United States (US) and foreign experts from fuels, irradiation, and instrumentation fields ranked candidate sensor technologies. The strategic plan describes the consensus reached during the workshop with respect to recommendations for the path forward for accomplishing the goals of this research program. This document reports on the status of investigations in the sensor technologies identified by the expert panel as offering the most promise for meeting FCRD program objectives.

As noted within this report, Fiscal Year 2012 (FY12) research funding was limited. However, as summarized below, significant progress was still made in each technology area with respect to the developing and deploying new test rigs and sensors.

- Ultrasonics Based Sensors - During FY12, FCRD funding was primarily used to advance deployment of an ultrasonic thermometer (UT) and to support development of a successful ATR National Scientific User Facility (NSUF) proposal for addressing a key issue related to ultrasonic sensor deployment for in-pile irradiation testing, ultrasonic transducer survivability. This collaborative proposal, which was led by Pennsylvania State University, will include several piezoelectric and magnetostrictive transducers.

Laboratory testing was completed to assess the viability of using ultrasonics thermometers for multipoint temperature detection during irradiation testing. Although the accuracy and resolution will depend on the sensor selected, prior evaluations indicate that temperature measurements can be obtained with the required accuracy $\left(2-3{ }^{\circ} \mathrm{C}\right)$ at multiple locations with a single small diameter probe $(1 \mathrm{~mm})$. Results from FY12 tests have identified appropriate UT probe materials, a new magnetostrictive transducer design, a new damping method to reduce signal noise, and an enhanced signal processing method. As discussed within this document, temperature-dependent signal response evaluations indicate that stainless steel is the preferred probe for temperature measurements below $1000{ }^{\circ} \mathrm{C}$ and doped molybdenum is the preferred probe material for higher temperatures.

- Fiber Optics-Based Sensors - During FY12, FCRD funding was primarily used to advance deployment of a fiber-optics based elongation sensor and to support development of an ATR NSUF proposal for addressing a key issue related to fiber optics-based sensor deployment for in-pile irradiation testing, fiber optics survivability. 
Initial efforts in the fiber optics area are focusing on a sensor for measuring length. During FY11, a measurement technique based on an Extrinsic Fabry-Perot Interferometer was demonstrated in the laboratory. Measurements using this laboratory setup indicate elongations as small as $0.3 \mu \mathrm{m}$ can be detected for measurements ranging from 1.5 to $125 \mu \mathrm{m}$. Based on results from this technique demonstration, a conceptual probe design was developed and evaluated.

In FY12, efforts focused on developing a sealed probe that could be deployed in an irradiation test. A probe design was developed that incorporated a bellows to provide isolation from the environment and allow expansion of the probe. A number of obstacles were resolved in fabricating this probe, such as developing methods to bond inside the hypodermic tubing and developing methods to assemble and weld small probe components.

- Enhanced Existing United States Materials and Test Reactor Sensors - FY12 FCRD efforts in this area focused on completing characterization evaluations of a creep test rig that could be deployed in the newly reactivated ATR Pressurized Water Reactor (PWR) Loop 2A for measuring elongation during irradiation. In addition, a conceptual design for a creep test rig with variable loading was developed.

Building upon results from prior Idaho National Laboratory (INL) and the Institute for Energy Technology/Halden Reactor Project collaborative efforts to develop a creep test rig for use in the new PWR loop at the ATR, an initial prototype of this creep test rig was evaluated using an INL High Temperature Test Laboratory autoclave. Test results indicate that this test rig can be used to measure elongations as small as $10 \mu \mathrm{m}$. Results from these FY11 test rig evaluations were used to finalize recommendations for an enhanced design and fabricate an improved prototype design. During FY12, this enhanced creep test rig design was fabricated, characterized, and calibrated. The rig is now ready for deployment to measure specimen elongation in real time during irradiation testing in ATR Loop 2A.

During FY12, efforts were also initiated to develop a creep irradiation test rig with the ability to apply a variable load to a specimen. Completion of this design for variable specimen loading, will position INL as the second organization in the world capable of real-time creep testing in reactor coolant.

In summary, significant progress was made in each technology area of interest with respect to in-pile instrumentation development for FCRD irradiation testing. A creep test rig is now available for measuring elongation. In addition, progress continues for developing new ultrasonics and fiber optics based sensors. The innovation of the sensors being developed through this effort is evident from the fact that two invention disclosure records were filed and a paper summarizing interim research results was selected for "Innovations in Fuel Cycle Research Award" by the FCRD program. 


\section{CONTENTS}

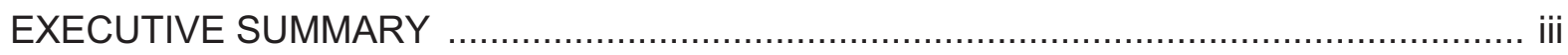

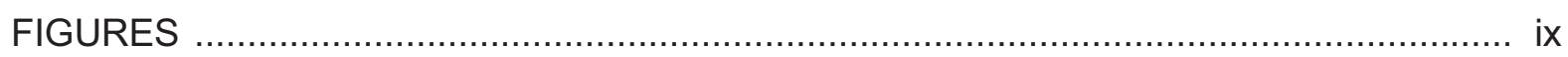

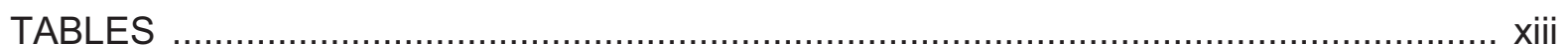

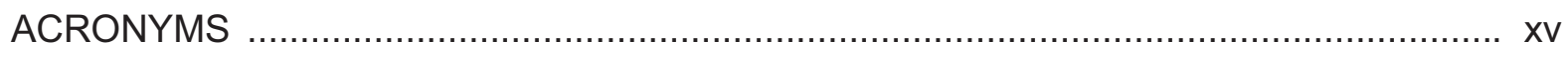

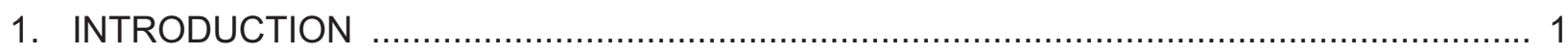

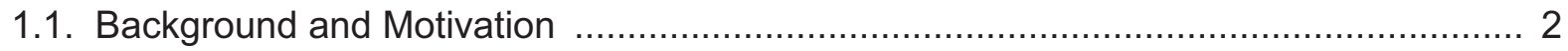

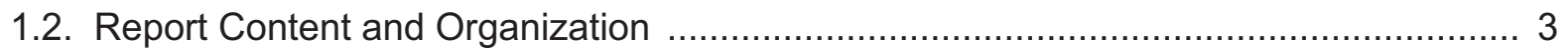

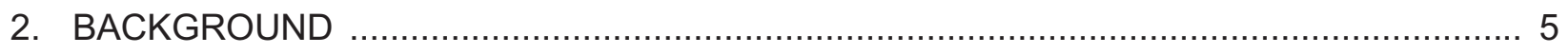

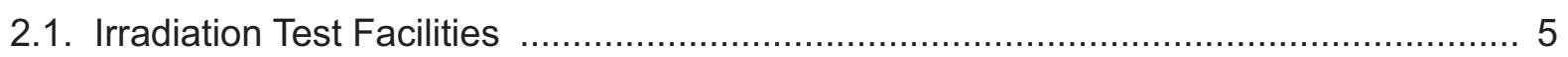

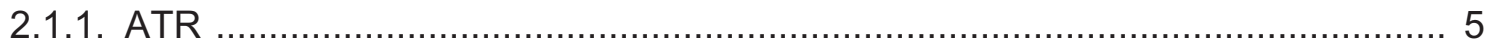

2.1.1.1. Reactor Design and18 Characteristics .................................... 5

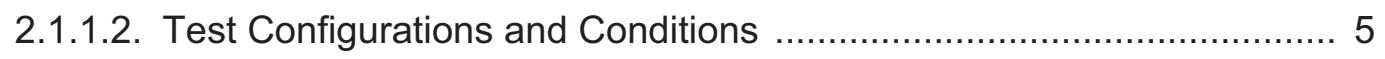

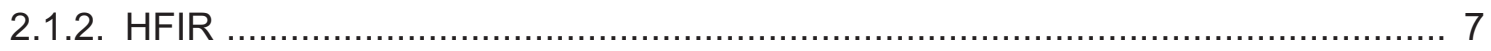

2.1.2.1. Reactor Design and Characteristics ........................................ 8

2.1.2.2. Test Configurations and Conditions ........................................ 8

2.2. Irradiation Test Conditions and Desired Parameters ....................................... 11

2.2.1. Currently Available Instrumentation to Provide Required Data ..................... 11

2.3. Expert Workshop Recommendations ........................................................ 11

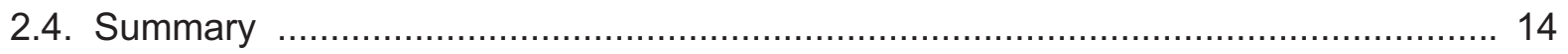

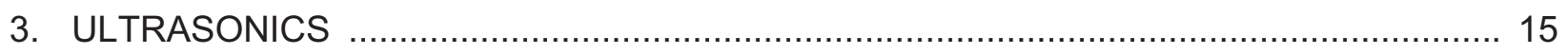

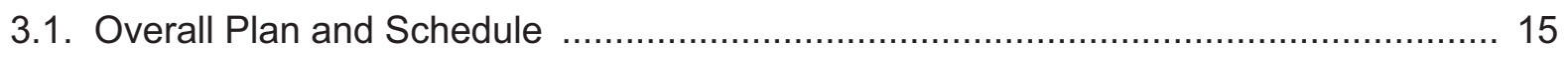

3.2. Task 1: Fuel Temperature (Ultrasonic Thermometry) ....................................... 15

3.2.1. Acoustic Velocity Measurement of Candidate Sensor Material ..................... 17

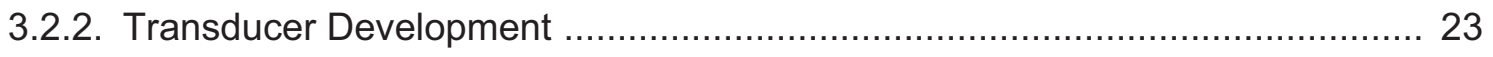

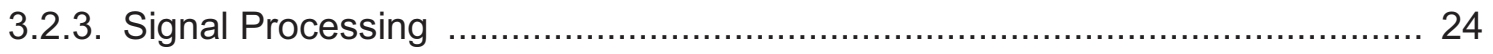

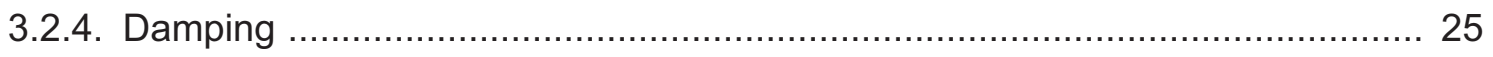

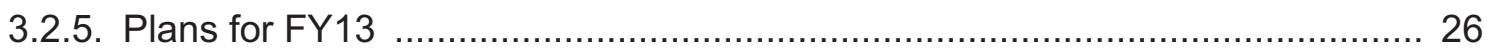

3.3. Task 2: Fuel Geometry/Morphology ......................................................... 26

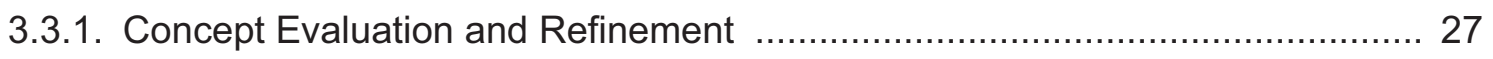

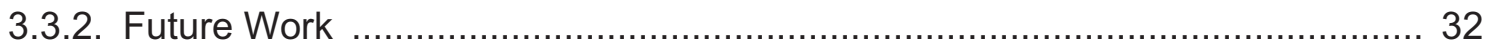

3.4. Task 3: Fission Gas Characteristics ....................................................... 32

3.5. Task 4: Cross-Cutting Research and Development (R\&D) ................................... 32

3.5.1. Irradiation Testing of Candidate Transducer Materials ............................... 33

3.5.1.1. Piezoelectric Materials ........................................................ 33 


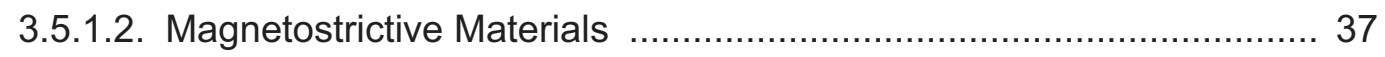

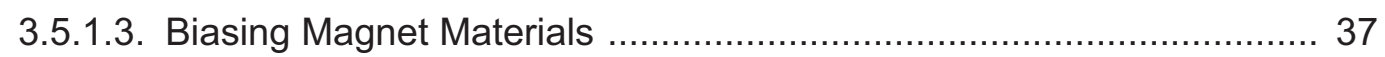

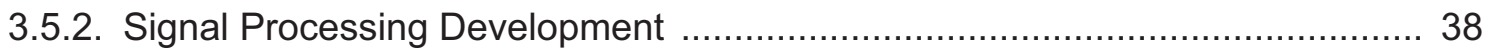

3.5.2.1. Signal Processing Needs ......................................................... 38

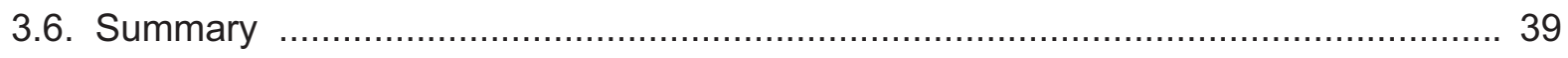

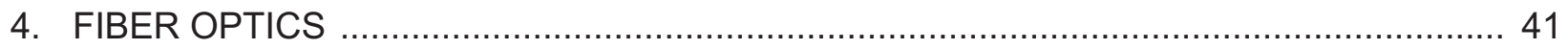

4.1. Overall Plan and Schedule .......................................................................... 41

4.2. Task 1: Fiber Optic Elongation Measurement .................................................... 41

4.2.1. Laboratory Evaluations to Assess Accuracy .............................................. 42

4.2.2. Probe Design and Fabrication .................................................................. 45

4.2.3. Elongation Sensor Technique Sensitivity ................................................ 47

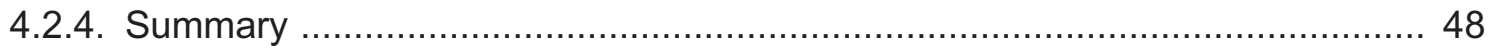

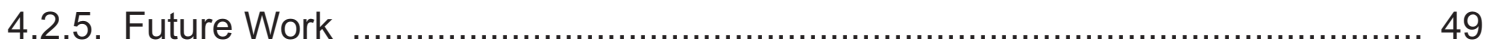

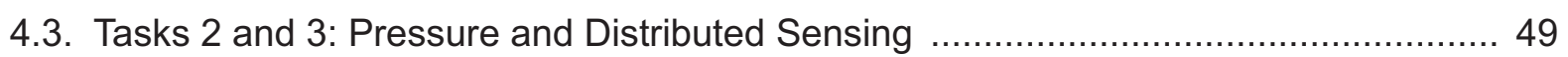

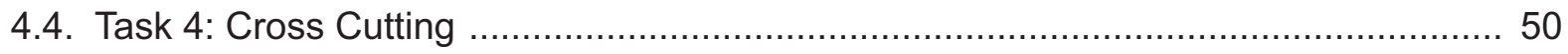

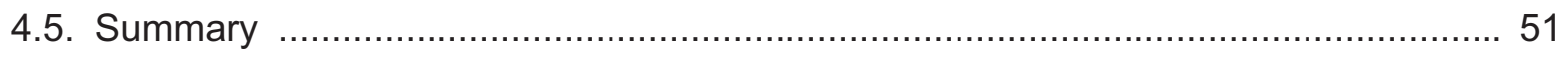

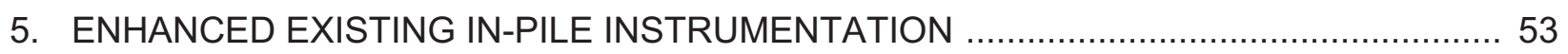

5.1. Overall Plan and Schedule .......................................................................... 53

5.2. Task 1: LVDT-based Elongation and Diameter Measurements .............................. 53

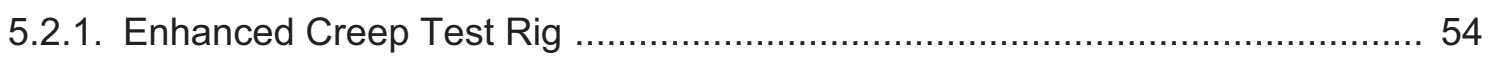

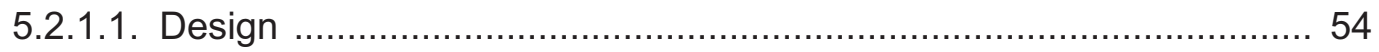

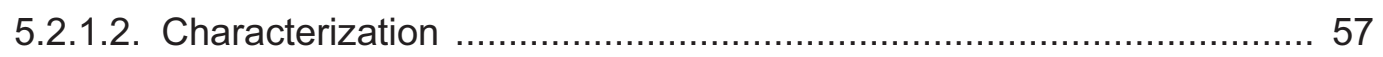

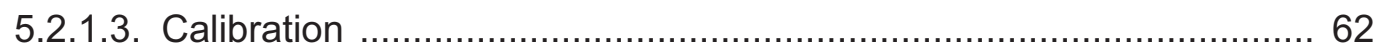

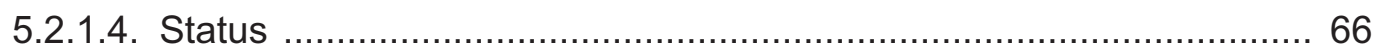

5.2.2. Enhanced Creep Test Rig with Variable Loading ....................................... 66

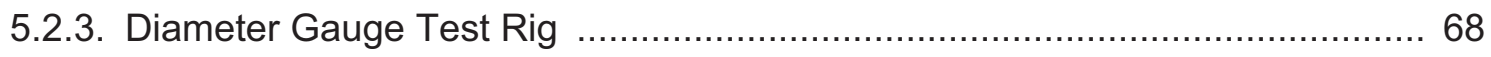

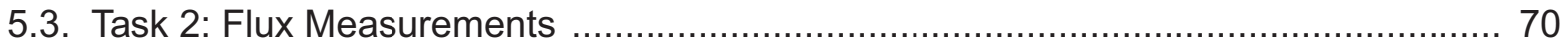

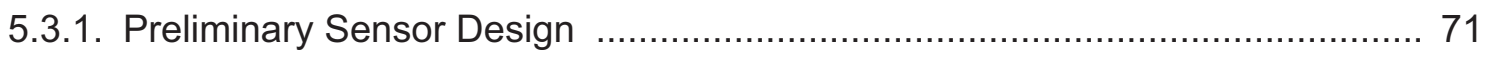

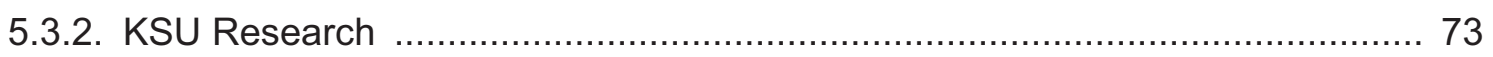

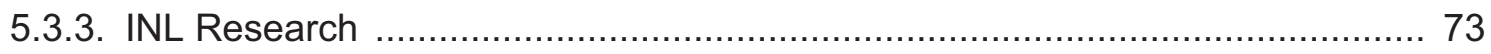

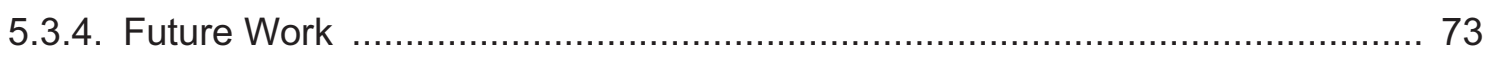

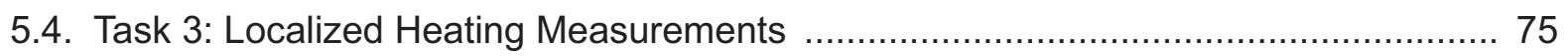

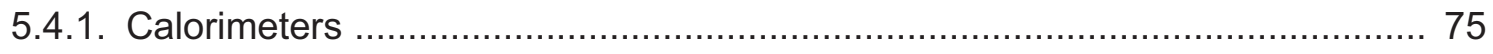

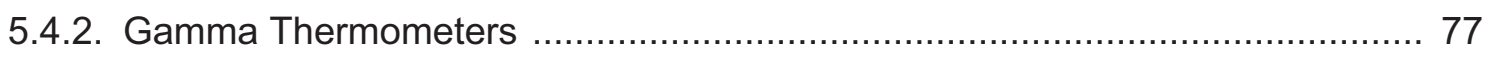

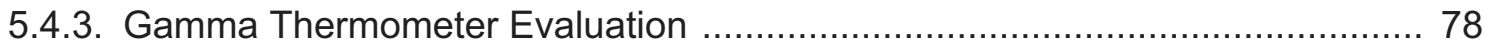

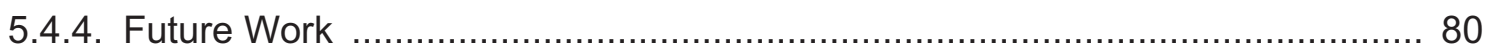

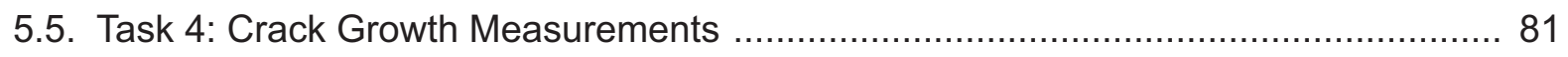

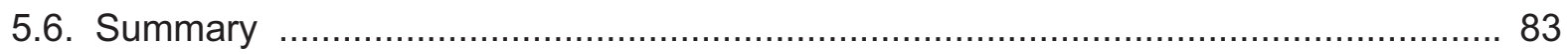


In-pile Instrumentation to Support Fuel Cycle Research and Development - FY11 Status Report

September 2012

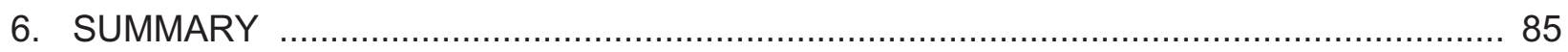

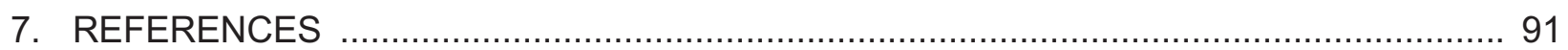


In-pile Instrumentation to Support Fuel Cycle Research and Development - FY11 Status Report 


\section{FIGURES}

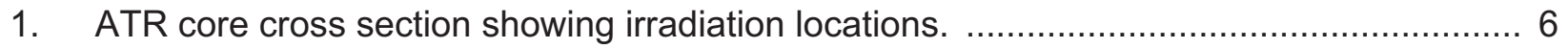

2. Schematic diagrams illustrating ATR irradiation locations. ...................................... 6

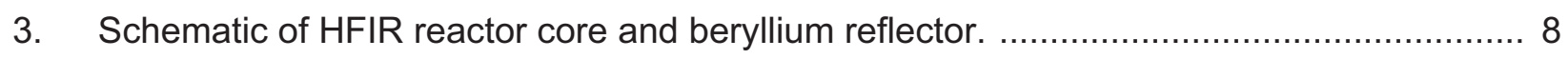

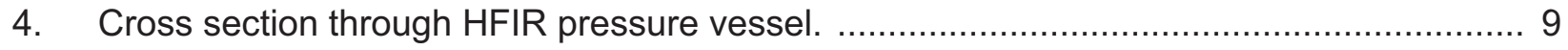

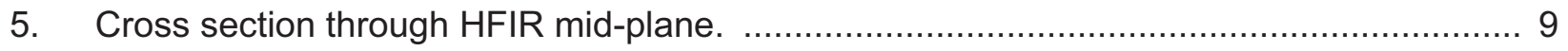

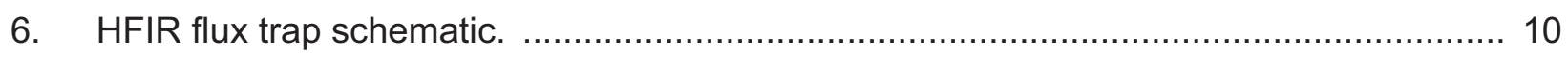

7. Overview of task to be completed as part of ultrasonic technology

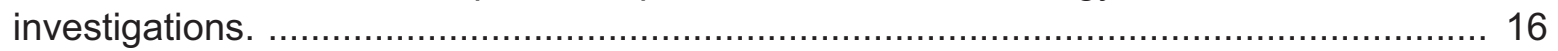

8. Schematic showing typical components of a UT and signal processing

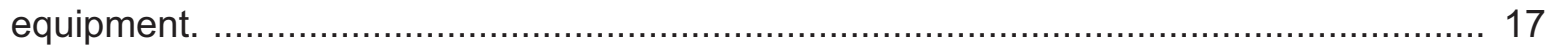

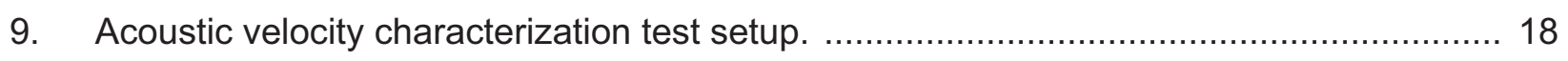

10. Comparison of measured acoustic velocity of stainless steel to calculated

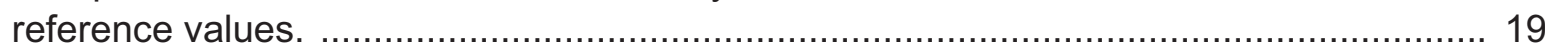

11. Comparison of measured acoustic velocity of molybdenum to calculated

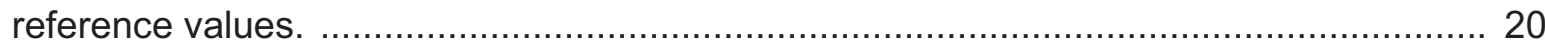

12. Comparison of measured acoustic velocity of Inconel 606 to calculated

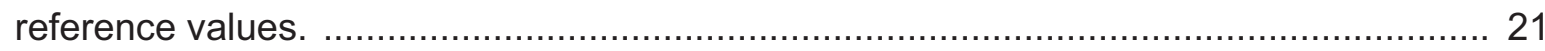

13. Progression of "sticking" observed for Inconel 606 sample. ...................................... 21

14. Comparison of measured acoustic velocity of $\mathrm{Nb}-1 \% \mathrm{Zr}$ to calculated reference

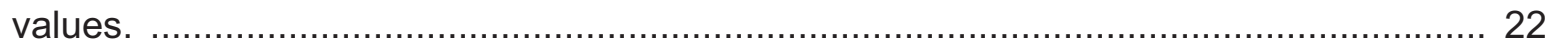

15. Time series data for $\mathrm{Nb}-1 \% \mathrm{Zr}$ sample showing increase in acoustic velocity with temperature.

16. Current multi-segment driving coil design with ring magnets and swaged

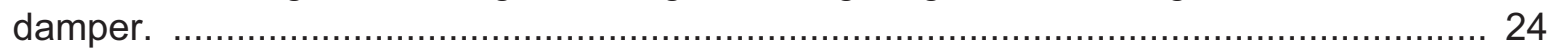

17. Graphical representation of data analysis process. ............................................... 25

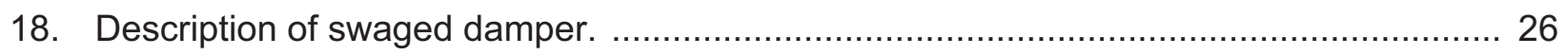

19. Initial ultrasonic approach for in-pile detection of elongation due to creep. ................... 27

20. Benchtop fixture for laboratory testing of elongation detection using ultrasonic

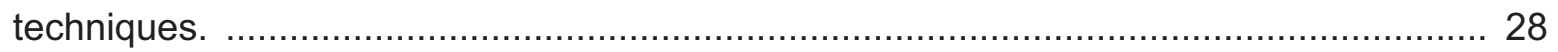

21. Typical pulse/echo results using the acoustic horn. ............................................... 29

22. The evolution of buttons used to apply a tensile load to the ultrasonic creep

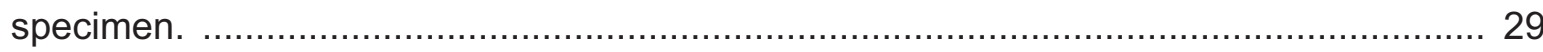

23. Typical pitch/catch results without use of the acoustic horn. .................................... 30

24. Coils developed and evaluated for use in sending and receiving transducers. ............... 31

25. Preliminary test capsule graphite sample holder design with sample and

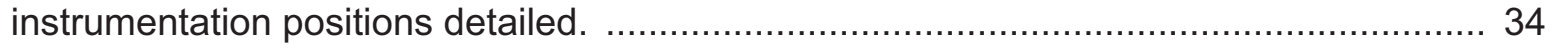

26. Diagram of signal processing system. ............................................................. 38

27. Overview of tasks to be completed as part of fiber optic sensor technology

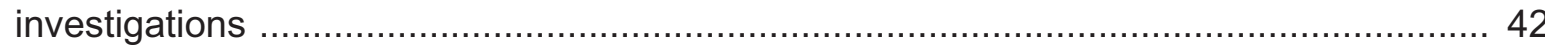

28. Cavity space measurement using EFPI. .......................................................... 42

29. Experiment configuration for EFPI technique evaluation. ..................................... 43 
30. Laboratory setup for initial evaluation of fiber optic in-pile elongation detection. ............ 44

31. Spectra showing EFPI fringe modulation at several cavity lengths. ........................... 44

32. Elongation probe concept using hypodermic tubing. .............................................. 46

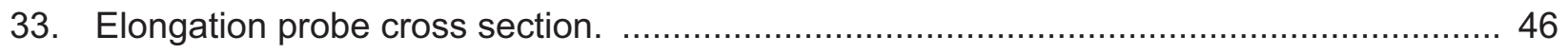

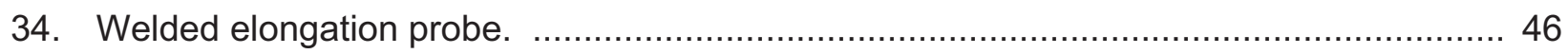

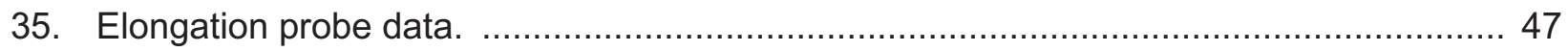

36. ATR fiber optic attenuation test schematic. ....................................................... 50

37. Overview of work to be completed as part of enhanced sensor deployment

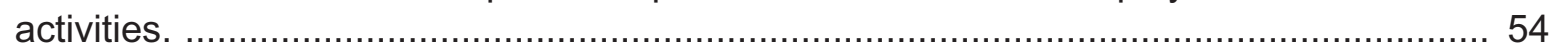

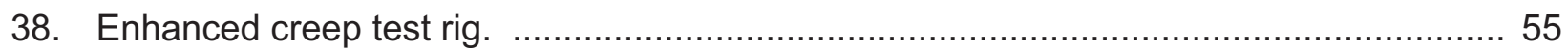

39. Original creep test rig positioned in an autoclave for testing. .................................. 55

40. Enhanced creep test rig (holder, three-dimensional model and schematic). .................. 56

41. Test configuration with an equivalent specimen load diagram. ................................ 57

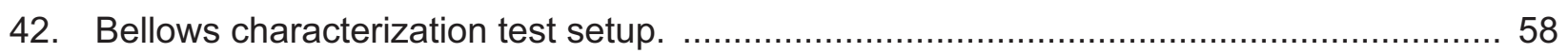

43. Depth micrometer configuration (without clamps) for measurement of the bellows

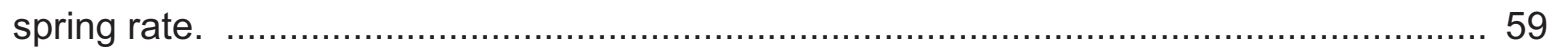

44. Bellows spring rates based on micrometer and rotational measurements in

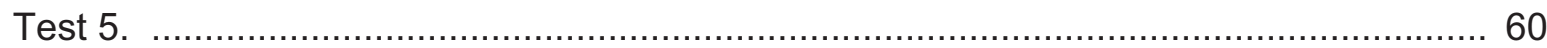

45. Bellows spring rates based on micrometer and rotational measurements in

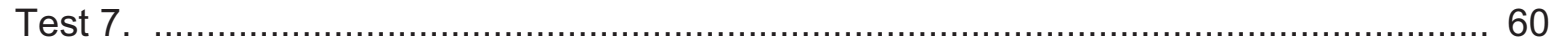

46. Bellows spring rates based on micrometer measurements in Test 8 . .......................... 61

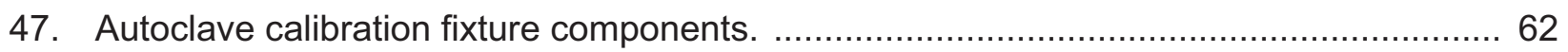

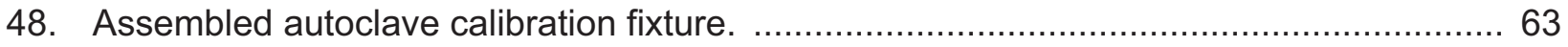

49. Bench top calibration results from Test 1 (at room temperature). ............................... 64

50. Autoclave calibration results from Test 3 (at room temperature). .................................. 64

51. Calibration results from IFE/HRP and INL. ...................................................... 65

52. Tensile test module irradiated in BR2 ( $a$ and b) with schematic of tensile test module (c) that includes: (1) gas line, (2) pneumatic loading unit, (3) firm specimen fixing point, (4) specimen, (5) movable specimen fixing point, (6) LVDT plunger, and (7) LVDT holder. ${ }^{55,56}$

53. LVDT / bellows assembly with provisions for internal pressurization of the bellows.

54. Creep test rig incorporating variable specimen loading capabilities. ........................... 69

55. IFE/HRP fuel pellet cladding interaction/crud deposition test rig (a) and diameter gauge (b).

56. Simplified diameter gauge; (a) finite element analysis showing magnetic field patterns; (b) inner body with coils; and (c) inner body. ....................................... 70

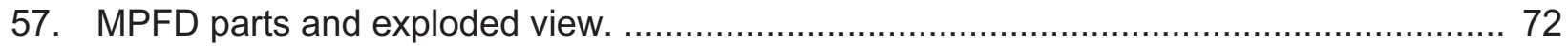

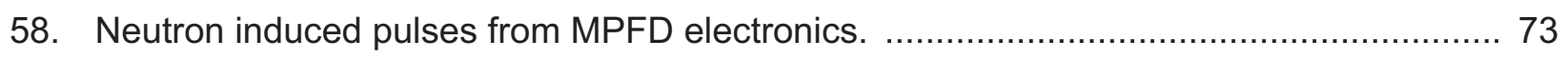

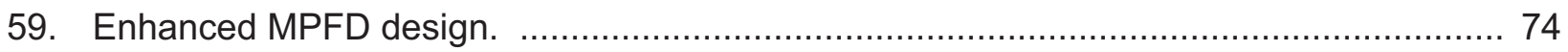


60. INL irradiation facilities for MPFD evaluation: (a) ATRC and (b) HPIL

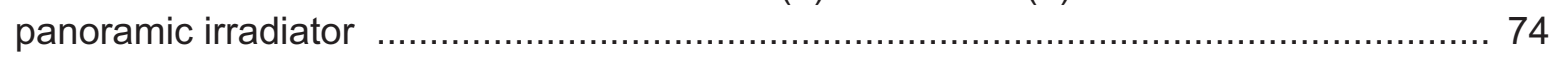

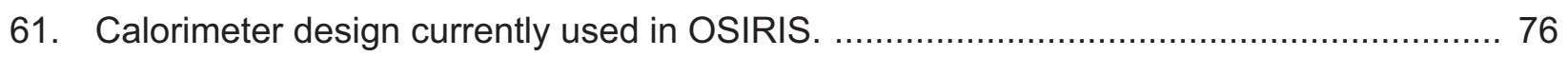

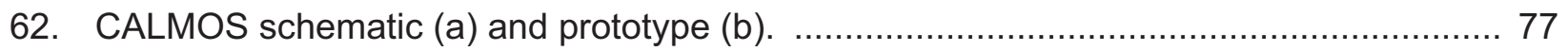

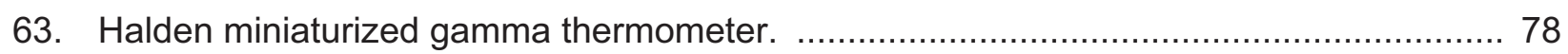

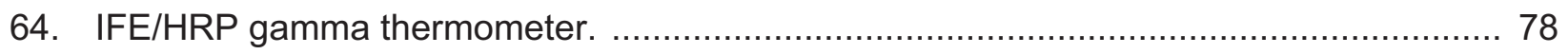

65. Insulated junction radiograph of IFE/HRP gamma thermometer. ……......................... 79

66. IFE/HRP gamma thermometer time constant evaluation. ......................................... 80

67. Essential hardware elements for implementing the DCPD method in-pile. .................... 81

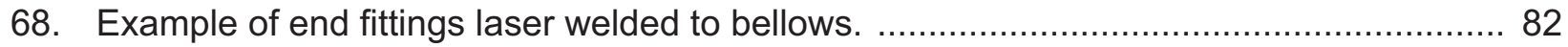

69. Prototype loading mechanism for in-pile DCPD testing - fabricated at INL. .................... 82

70. Response of probe materials exhibiting superior performance: (a) stainless steel for temperatures less than $1000^{\circ} \mathrm{C}$ and (b) doped molybdenum (KW-Mo) for

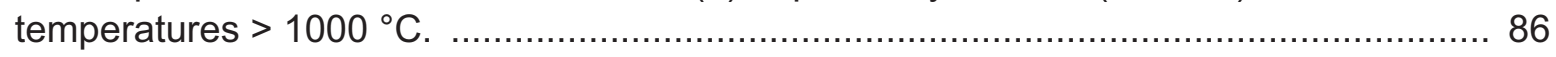

71. Conceptual design of proposed ultrasonics transducer test. ............................................ 86

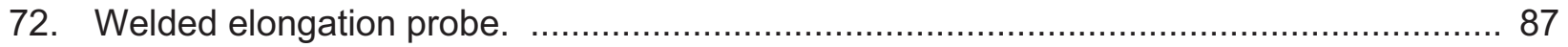

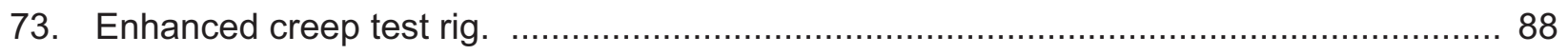

74. Conceptual design for variable load creep test rig. ................................................... 89 
In-pile Instrumentation to Support Fuel Cycle Research and Development - FY11 Status Report 


\section{TABLES}

1. Characteristics of vertical HFIR irradiation facilities. ............................................ 10

2. Summary of desired parameters for detection during fuel irradiation tests. ..................... 12

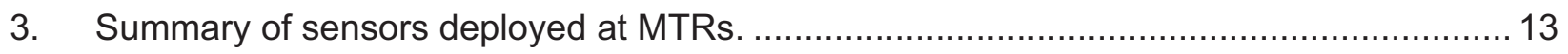

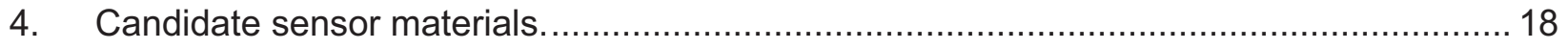

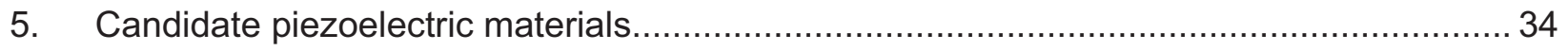

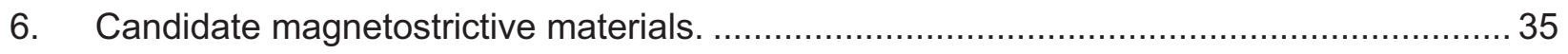

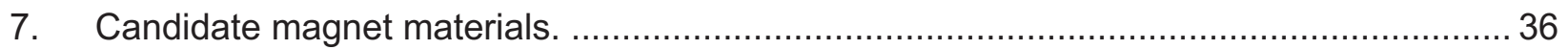

8. Comparison of measured cavity length versus length inferred from fringe

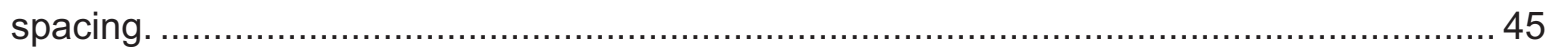

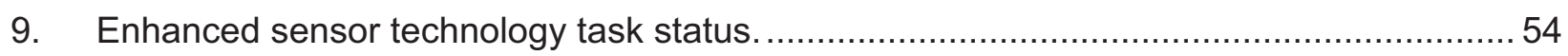

10. Summary description of components used in enhanced creep test rig.........................5 57

11. Results from bellows spring rate measurements................................................. 59

12. Results from bellows effective area measurements. .............................................. 61

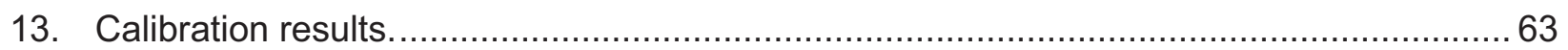

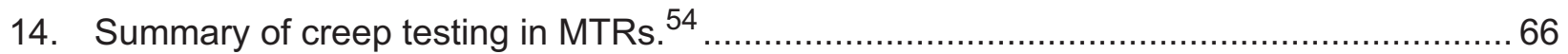


In-pile Instrumentation to Support Fuel Cycle Research and Development - FY11 Status Report 


\section{ACRONYMS}

\begin{tabular}{|c|c|}
\hline AISI & American Iron and Steel Institute \\
\hline ATR & Advanced Test Reactor \\
\hline ATRC & Advanced Test Reactor Critical (facility) \\
\hline BR2 & Belgian Reactor 2 \\
\hline CEA & Commissariat à l'Énergie Atomique et aux Energies Alternatives \\
\hline $\mathrm{CT}$ & Compact Tensile (specimen) \\
\hline DAQ & Data Acquisition \\
\hline $\mathrm{D}-\mathrm{A}$ & Digital to Analog \\
\hline $\mathrm{DC}$ & Direct Current \\
\hline DCPD & Direct Current Potential Drop \\
\hline DOE & (US) Department of Energy \\
\hline DOE-NE & Department of Energy, Office of Nuclear Energy \\
\hline EDL & (KSU) Electronics Design Laboratory \\
\hline EFPI & Extrinsic Fabry-Perot Interferometer \\
\hline FCRD & Fuel Cycle Research and Development \\
\hline FY & Fiscal Year \\
\hline HANARO & High Flux Advanced Neutron Application Reactor \\
\hline HBWR & Halden Boiling Water Reactor \\
\hline HFIR & High Flux Isotope Reactor \\
\hline HFR & High Flux Reactor \\
\hline HPIL & Health Physics Instrument Laboratory \\
\hline HTIR-TC & High Temperature Irradiation Resistant ThermoCouple \\
\hline HTTL & High Temperature Test Laboratory \\
\hline ID & Inner Diameter \\
\hline IDR & Invention Disclosure Record \\
\hline IFE/HRP & Institute for Energy Technology/Halden Reactor Project \\
\hline INL & Idaho National Laboratory \\
\hline JAERI & Japan Atomic Energy Research Institute \\
\hline JMTR & Japan Materials Test Reactor \\
\hline KAERI & Korea Atomic Energy Research Institute \\
\hline $\mathrm{KSU}$ & Kansas State University \\
\hline LDRD & Laboratory Directed Research and Development \\
\hline LVDT & Linear Variable Differential Transformer \\
\hline LWR & Light Water Reactor \\
\hline MIT & Massachusetts Institute of Technology \\
\hline MITR & Massachusetts Institute of Technology Reactor \\
\hline MPFD & Micro-Pocket Fission Detector \\
\hline MTR & Materials and Test Reactor \\
\hline NEET & Nuclear Energy Enabling Technologies \\
\hline
\end{tabular}




$\begin{array}{ll}\text { NGNP } & \text { Next Generation Nuclear Plant } \\ \text { NSUF } & \text { National Scientific User Facility } \\ \text { OBR } & \text { Optical Backscatter Reflectometry } \\ \text { OD } & \text { Outer Diameter } \\ \text { OTDR } & \text { Optical Time Domain Reflectometry } \\ \text { PC } & \text { Personal Computer } \\ \text { PSU } & \text { Pennsylvania State University } \\ \text { PWR } & \text { Pressurized Water Reactor } \\ \text { PZT } & \text { Lead Zirconate Titanate } \\ \text { RB } & \text { Large Removable Beryllium Facility } \\ \text { R\&D } & \text { Research and Development } \\ \text { SCK-CEN } & \text { Studiecentrum Voor Kernenergie Centre D'etude De L'energie Nucleaire } \\ \text { SFR } & \text { Sodium Fast Reactor } \\ \text { SPND } & \text { Self Powered Neutron Detector } \\ \text { TOF } & \text { Time of Flight } \\ \text { TRIGA } & \text { Training, Research, Isotopes, General Atomics } \\ \text { US } & \text { United States } \\ \text { UT } & \text { Ultrasonic Thermometer } \\ \text { VTT } & \text { Technical Research Centre (of Finland) } \\ \text { VXF } & \text { Vertical Experiment Facility }\end{array}$




\section{ADVANCED FUELS CAMPAIGN IN-PILE INSTRUMENTATION TO SUPPORT FUEL CYCLE RESEARCH AND DEVELOPMENT - FY12 STATUS REPORT}

\section{INTRODUCTION}

New and enhanced nuclear fuels are a key enabler for new and improved reactor technologies. For example, the goals of many advanced reactor concepts such as the next generation nuclear plant (NGNP), will not be met without irradiations successfully demonstrating the safety and reliability of new fuels. Likewise, fuel reliability has become paramount in ensuring the competitiveness of the commercial fleet of nuclear power plants. To address this need, the Office of Nuclear Energy in the Department of Energy (DOE-NE) funds a new direction in fuel research and development effort that emphasizes an approach relying on first principle models to develop optimized fuel designs that offer significant improvements over current fuels. To facilitate this approach, high fidelity, real-time, data are essential for characterizing the performance of new fuels during irradiation testing. A strategic research program has been initiated for developing the required test vehicles with sensors of unprecedented accuracy and resolution for obtaining the data needed to characterize three-dimensional changes in fuel microstructure during irradiation testing. When implemented, this strategy will yield test capsule designs that are instrumented with new sensor technologies for irradiations at facilities primarily relied upon by the Fuel Cycle Research and Development (FCRD) program, the Advanced Test Reactor (ATR) and the High Flux Isotope Reactor (HFIR). Prior laboratory testing, and as needed, irradiation testing of sensors in these capsules will have been completed to give sufficient confidence that the irradiation tests will yield the required data.

From the onset of this instrumentation development effort, it was recognized that obtaining these sensors must draw upon the expertise of a wide-range of organizations not currently supporting nuclear fuels research. Hence, a strategic plan ${ }^{1}$ was developed to provide necessary background information related to fuel irradiation testing, desired parameters for detection, and an overview of currently available in-pile instrumentation. Then, a workshop was held in which United States (US) and foreign experts from fuels, irradiation, and instrumentation fields participated. During the workshop, candidate sensor technologies to achieve the goals of this effort were discussed and ranked by experts using agreed upon criteria. The strategic plan was then updated to reflect the consensus reached during the workshop with respect to the path forward for accomplishing the goals of this research program.

Based on the activities completed to develop this strategic plan, it was recommended that the FCRD instrumentation development program be initiated as a multi-year effort focusing on the following three sensor technology areas:

- Ultrasonics-Based Evaluations - In this area, laboratory evaluations and necessary irradiations will be completed to demonstrate the viability of this technology for in-pile applications. Specifically, tasks have been be identified for obtaining the required signal processing upgrades, demonstrating the viability of ultrasonics to detect the parameters of interest under various anticipated test conditions (e.g., 
inert gas and sodium) with the required accuracy, and for developing test capsule(s) in which the proposed sensors could be deployed at the ATR and HFIR.

- Fiber Optics-Based Evaluations - In this area, laboratory evaluations and necessary irradiations will be completed to demonstrate the viability of this technology for in-pile applications. Specifically, tasks have been identified for obtaining the required signal processing, demonstrating the viability of fiber optics to detect the parameters of interest under various anticipated test conditions (e.g., inert gas and sodium) with the required accuracy (note that suitable coatings/sheaths must be identified for sodium applications and temperature limitations must be quantified). In addition, test capsule(s) designs will be developed in which the proposed sensors could be deployed at the ATR and HFIR.

- Upgrade US Materials and Test Reactor (MTR) In-Pile Instrumentation - In this area, laboratory evaluations and necessary irradiations will be completed to demonstrate the viability of enhanced detectors under anticipated ATR and HFIR irradiation conditions. Candidate instrumentation for enhancement include sensors for elongation and diameter evaluations, flux detectors, and thermal conductivity probes.

For each area, detailed project plans were developed with a schedule identifying what can be accomplished assuming the proposed funding level was initiated at $\$ 600 \mathrm{~K} / \mathrm{yr}$ and increased to approximately $\$ 1 \mathrm{M} / \mathrm{yr}$. Plans also identified 'off-ramps' at key decision points where the viability of the technology could be assessed prior to further research. In addition, project plans identified collaborations to ensure that research will take advantage of existing expertise for each technology. Although decreased funding availability has delayed some of the planned sensor development research, several sensor investigation activities were initiated in fiscal year 2011 (FY11). This report documents the FY12 status of each task agreed upon within the FCRD strategic plan. As documented in Reference 2 and in this report, these activities have already yielded sensors or test rigs that are ready for deployment or will be ready for deployment by FY14.

\subsection{Background and Motivation}

As noted in Reference 1, DOE-NE wishes to "move beyond incremental improvement of existing reactor and fuel cycle technologies to achieve transformational advances in knowledge and application." DOE-NE ${ }^{3}$ defined several goals with respect to advanced sustainable fuel performance:

- Reduce transuranic production,

- Perform fundamental analysis of fuel fabrication processes and their relation to fuel and cladding performance, and

- Evaluate very high burnup systems that require minimal or no chemical separations.

To move beyond incremental improvement of existing reactor and fuel cycle technologies and achieve transformational advances in knowledge and application, science-based research is emphasized.

The DOE-NE FCRD program places increased emphasis on advanced modeling and simulation tools to predict in-pile fuel behavior and to design innovative fuels that improve the performance of our existing commercial reactors and support new reactor designs. The goal of this FCRD Modeling and Simulation effort is to develop advanced tools that incorporate all of the relevant physics and chemistry, spanning phenomena from the macro-scale to the micro-structural level and over a large range of environmental variables, such as heat, pressure, and radiation. 
Improved modeling of the behavior of existing and advanced fuels faces several challenges. First, science-based models are needed to replace empirical correlations that are currently used to model major fuel behavior phenomena. However, these correlations were developed through existing databases of experimental data that are inadequate for developing science-based models. Second, there is a desire to predict fuel behavior with transuranics (TRU) added to the fuel. There are limited data for developing science-based models for these fuels. Last, there is the desire to develop models that can be used as a basis for extending fuel burnup to minimize waste. Those higher limits include higher burnups, linear powers, neutron fluences and operating temperatures. Again, there are limited data for developing and validating models for fuels exposed to these conditions. Though improved fuel modeling tools are potentially powerful vehicles of innovation and discovery, they have little value without a dedicated accompanying effort to validate them.

Clearly, a new paradigm for instrumented in-pile testing is needed to achieve the transformational goals outlined by DOE-NE. Historically, fuel characterizations from irradiation tests are primarily done using a 'cook and look' approach at selected intervals. The time and labor to remove, examine, and return irradiated samples for each measurement makes this approach very expensive. In addition, such techniques provide limited data and may disturb the phenomena of interest. Recently, several research organizations affiliated with MTRs have increased efforts to provide new in-pile sensors to support irradiation testing. However, none have started to develop the sensor technologies that would yield the data required to allow real-time observation of fuel microstructure and properties evolving during irradiation. The new data required to benchmark and validate models from DOE-NE's FCRD program must be of unprecedented precision and resolution for short term $(<24 \mathrm{hr}$ ) and longer duration irradiations. Developing and deploying new sensors capable of delivering such high-precision, in-pile data is a daunting task, but key to implementing DOE-NE goals.

\subsection{Report Content and Organization}

This document reviews key aspects of the strategic program developed to obtain desired data during FCRD irradiation tests. It describes representative fuel irradiation tests, identifies the needs for data obtained from these tests, and provides recommendations for in-pile instrumentation that could be used to obtain such data. As noted previously, it was recognized that this effort must draw upon input from a wide-range of experts not currently supporting nuclear fuels research. Hence, prior to initiating this research effort, a workshop was held in FY11 to obtain this input and gain consensus on the approach pursued. Reference 1 summarizes results from this workshop.

The remainder of this report is organized into six sections. Section 2 provides key background information, such as ATR and HFIR irradiation test options, representative FCRD test conditions and fuel types, desired physical parameters that must be detected during irradiation tests. Sections 3 through 5 provide details related to the FY12 progress in each sensor technology selected for study. Section 6 summarizes information reported in this document, emphasizing key FY12 accomplishments in each sensor technology area investigated. Section 7 lists references cited in this document. 
In-pile Instrumentation to Support Fuel Cycle Research and Development - FY12 Status Report 


\section{BACKGROUND}

This section summarizes background information related to irradiation facilities used by the FCRD program. In addition, Reference 1 information related to representative ceramic and metallic fuel types, irradiation test conditions, and physical parameters that must be detected during irradiation tests is summarized.

\subsection{Irradiation Test Facilities}

Most FCRD irradiations are performed in the ATR and HFIR. Design parameters and irradiation locations in these two facilities are summarized in this section.

\subsubsection{ATR}

The ATR is a unique facility for irradiation testing of nuclear fuel and materials. ${ }^{4}$ Designed to allow simulation of long neutron radiation exposures in a short time period, the ATR has a maximum power rating of $250 \mathrm{MW}_{\text {th }}$ with a maximum unperturbed thermal neutron flux of $1 \times 10^{15} \mathrm{n} / \mathrm{cm}^{2}-\mathrm{s}$ and a maximum fast neutron flux of $5 \times 10^{14} \mathrm{n} / \mathrm{cm}^{2}$-s. The ATR is cooled by pressurized $(2.5 \mathrm{MPa} / 360 \mathrm{psig})$ water that enters the reactor vessel bottom at an average temperature of $52{ }^{\circ} \mathrm{C}\left(126^{\circ} \mathrm{F}\right)$, flows up outside cylindrical tanks that support and contain the core, passes through concentric thermal shields into the open part of the vessel, then flows down through the core to a flow distribution tank below the core. When the reactor is operating at full power, the primary coolant exits the vessel at $71^{\circ} \mathrm{C}\left(160^{\circ} \mathrm{F}\right)$.

\subsubsection{Reactor Design and18 Characteristics}

As shown in Figure 1, the ATR core consists of 40 curved plate fuel elements in a serpentine arrangement around a $3 \times 3$ array of primary testing locations, or nine large high-intensity neutron flux traps. The unique ATR control device design permits large power variations among its nine flux traps using a combination of control cylinders (drums) and neck shim rods. The beryllium control cylinders contain hafnium plates that can be rotated toward and away from the core. Hafnium shim rods, which withdraw vertically, are inserted or withdrawn for minor power adjustments. Within bounds, the power level in each corner lobe of the reactor can be controlled independently to allow for different power and flux levels in the four corner lobes during the same operating cycle. The ratio of fast to thermal flux can be varied from 0.1 to 1.0. In addition to the nine large volume (up to $122 \mathrm{~cm} / 48 \mathrm{in}$. long and up to $13 \mathrm{~cm} / 5.0 \mathrm{in}$. diameter) high-intensity neutron flux traps, there are 66 irradiation positions inside the reactor core reflector tank, and there are two capsule irradiation tanks outside the core with 34 low-flux irradiation positions. A Hydraulic Shuttle Irradiation System (HSIS), more commonly referred to as the "Rabbit," was also recently installed in the ATR to restore the reactor's capability to perform irradiations of small capsules in the B-7 position of the reactor for materials research, rapid activations, and isotope production. ${ }^{5}$

\subsubsection{Test Configurations and Conditions}

Irradiated samples are enclosed in test capsules that are typically placed in a basket to facilitate positioning within the reactor. This section provides summary information about the three ATR primary test configurations, which are conceptually shown in Figure 2, and the HSIS. More detailed information can be found in References 4 and 5. 


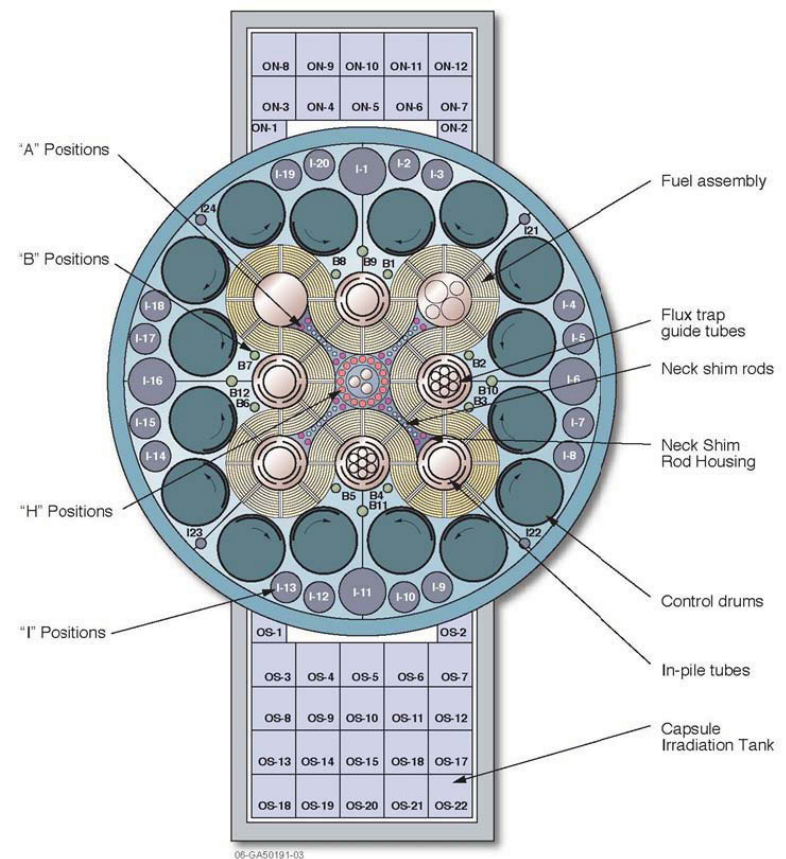

Figure 1. ATR core cross section showing irradiation locations.
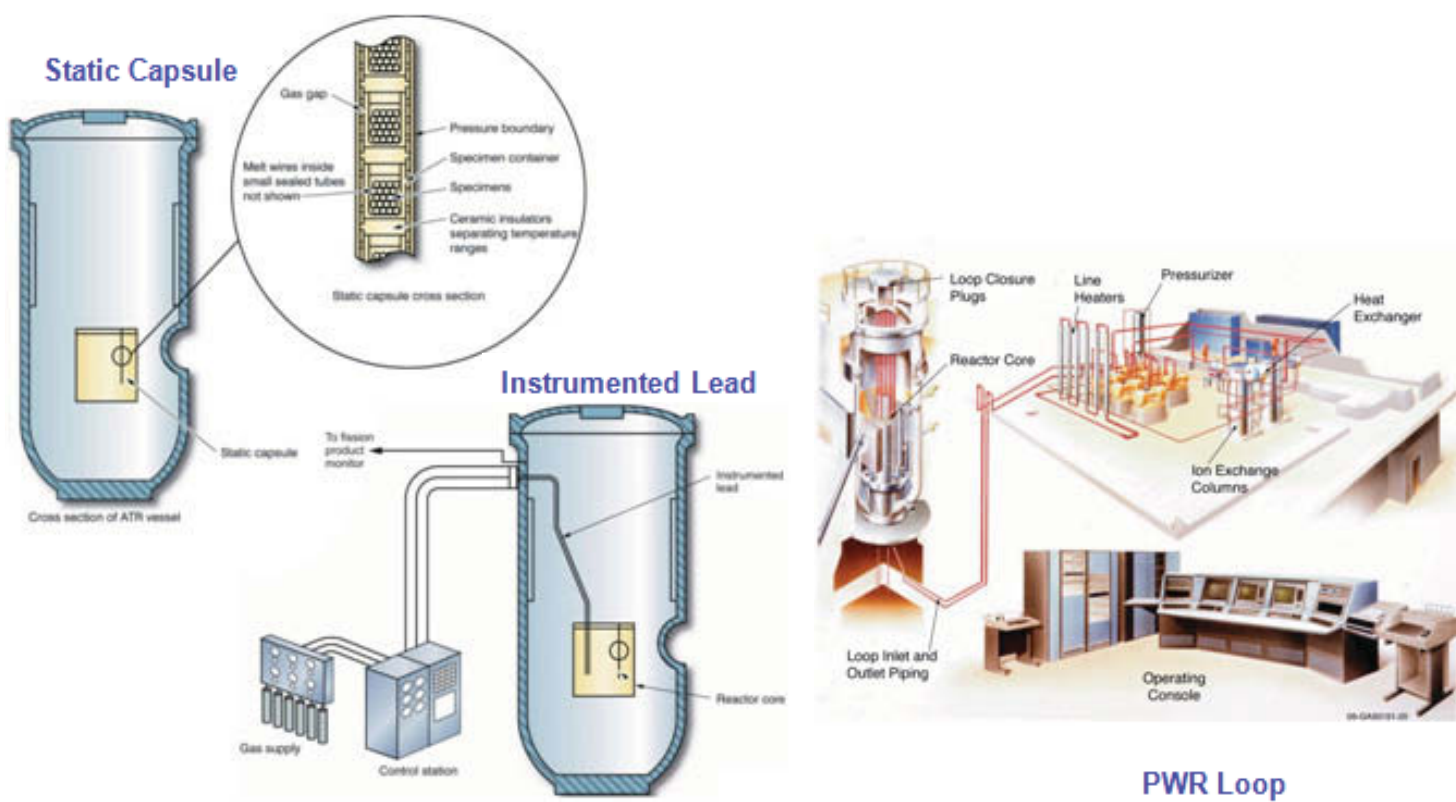

Figure 2. Schematic diagrams illustrating ATR irradiation locations. 
- Static Capsule Experiments - These capsules may contain a number of small samples or engineered components. Static capsule experiments may be sealed or may contain material that can be in contact with the ATR primary coolant (such capsules are in an open configuration without being sealed). Capsules may be any length, up to $122 \mathrm{~cm}$ (48 in.), and may be irradiated in any core position, including the flux traps. Irradiation temperature may be selected by providing a gas gap in the capsule with a known thermal conductance. Peak temperatures may be measured using a series of melt wires, temperature-sensitive paint spots, or silicon carbide temperature monitors. Accumulated neutron fluences may be verified using flux wires.

- Instrumented Lead Experiments - Active control of experiments and data from test capsules during irradiation is achieved using core positions with instrumentation cables and temperature control gases in ATR instrumented lead experiments. Such experiments can have instrumentation, such as thermocouples, connected to individual capsules or single specimens. This instrumentation can be used to control and sample conditions within the capsule. For example, temperature control in individual zones is performed by varying the gas mixture (typically helium and neon) in the gas gap that thermally links the capsule to the water-cooled reactor structure. In addition to temperature, instrumented lead experiments can be configured to monitor the gas around the test specimen. In a fueled experiment, the presence of fission gases due to fuel failures or oxidation can be detected via gas chromatography. Instrument leads allow real time display of experimental parameters in the control room.

- Pressurized Water Loop Experiments - Five of the nine ATR flux traps used for materials and fuels testing are equipped with pressurized water loops (at the NW, N, SE, SW, and W locations). A sixth loop, located in the center flux trap, began operational testing in 2012. Each of the water loops can be operated at different temperatures, pressures, flow rates, or water chemistry requirements. These loops can operate above the standard temperatures and pressure of a commercial pressurized water reactor (PWR) power plant. The great advantage of loop tests is the ease with which a variety of samples can be subjected to conditions specified for any PWR design. Each ATR pressurized loop is instrumented to measure and control coolant flows, temperatures, pressures and sample test data.

- Rabbit Tests - The HSIS or rabbit enables insertion and removal of experiment specimens during ATR during operational cycles. The HSIS is installed in the B-7 reflector position, which is one of the higher flux positions in the reactor with typical thermal and fast $(>1 \mathrm{MeV})$ fluxes of $2.8 \times 10^{14} \mathrm{n} / \mathrm{cm}^{2} / \mathrm{s}$ and $1.9 \times 10^{14} \mathrm{n} / \mathrm{cm}^{2} / \mathrm{s}$, respectively. The titanium experiment capsules, or shuttles, are approximately $16 \mathrm{~mm}$ in diameter and $57 \mathrm{~mm}$ in length, with interior usable dimensions of $14 \mathrm{~mm}$ in diameter and $50 \mathrm{~mm}$ in length. Up to 14 capsules can be used for irradiations simultaneously, although one does not need to fill all 14 capsules for a test. The maximum allowable weight of each shuttle contents is $27.0 \mathrm{gm}$.

\subsubsection{HFIR}

The HFIR is a beryllium-reflected, pressurized, light-water-cooled and moderated flux-trap-type reactor. The core, which consists of aluminum-clad involute-fuel plates, currently utilizes highly enriched ${ }^{235} \mathrm{U}$ fuel, that typically operates at $100 \mathrm{MW}_{\mathrm{t}}$. The HFIR was primarily designed (in the 1960s) to produce transuranic isotopes for use in the US heavy-element research program. Today, the reactor is a more versatile machine, producing medical and transuranic isotopes, and performing materials test experimental irradiations and neutron-scattering experiments, including the capability to conduct cold-source low-temperature neutron experiments. 


\subsubsection{Reactor Design and Characteristics}

The HFIR core, illustrated in Figure 3, consists of a series of concentric annular regions, each approximately $61 \mathrm{~cm}$ in height. The flux trap is $\sim 12.7 \mathrm{~cm}$ in diameter, and the outer fueled region is $\sim 43.5 \mathrm{~cm}$ in diameter. The fuel region is surrounded by a concentric ring of beryllium reflector approximately $30.5 \mathrm{~cm}$ in thickness. The beryllium reflector is in turn backed up by a water reflector of effectively infinite thickness. In the axial direction, the reactor is reflected by water. The reactor core assembly is contained in a $2.44 \mathrm{~m}$ diameter pressure vessel, which is located in a $5.5 \mathrm{~m}$ cylindrical pool of water. Figure 4 shows a cutaway of the reactor pressure vessel, its location in the reactor pool. Experiment facilities shown in this figure are discussed in Section 2.1.2.2.

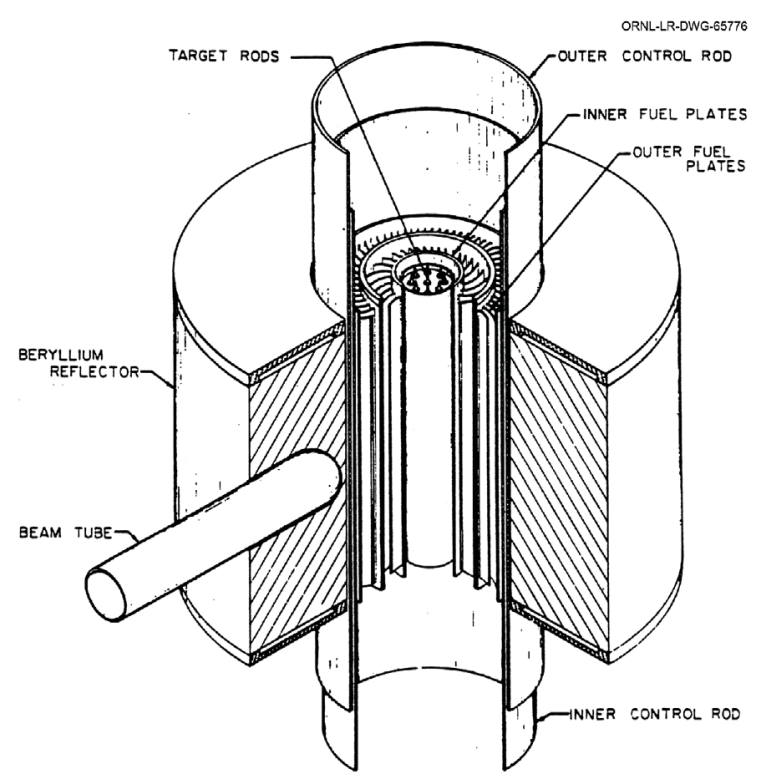

Figure 3. Schematic of HFIR reactor core and beryllium reflector.

\subsubsection{Test Configurations and Conditions}

Several facilities within the HFIR core and reflector are available for experimental use. These include (1) the flux trap, (2) three horizontal beam holes which originate in the reflector, (3) four slant access facilities which are located adjacent to the outer reflector at an angle with the vertical, and (4) 30 vertical facilities of various sizes located in the reflector. Figure 5, a cross section of the HFIR, illustrates these experimental facilities.

Table 1 contains the characteristics of the vertical irradiation facilities in HFIR. The facilities listed start with the flux trap (left column) and proceed outward to the large Vertical Experiment Facility (VXF) positions (right-most column). Going from the target region to the large VXF position, the fast flux decreases by a factor of 100 and the thermal flux (without shields) decreases by a factor of 5 . Also given in Table 1 are the characteristics for the Large Removable Beryllium Facility (RB*) position with and without thermal-neutron shields. Using the standard $\mathrm{RB}^{*} \mathrm{Eu}_{2} \mathrm{O}_{3}$ shield, the thermal neutron flux can be reduced by a factor of 50 without significantly affecting the fast flux, even after 8-10 cycles of operation. At beginning of life, the fast/thermal ratio is far higher. Thus, it is possible to tailor the neutron spectrum for specific experimental purposes and goals. 


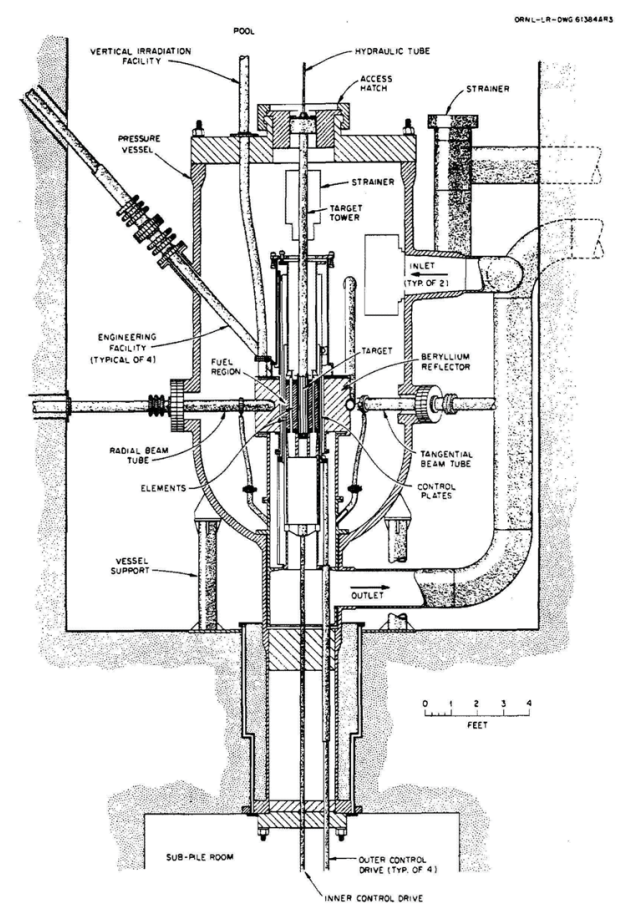

Figure 4. Cross section through HFIR pressure vessel.

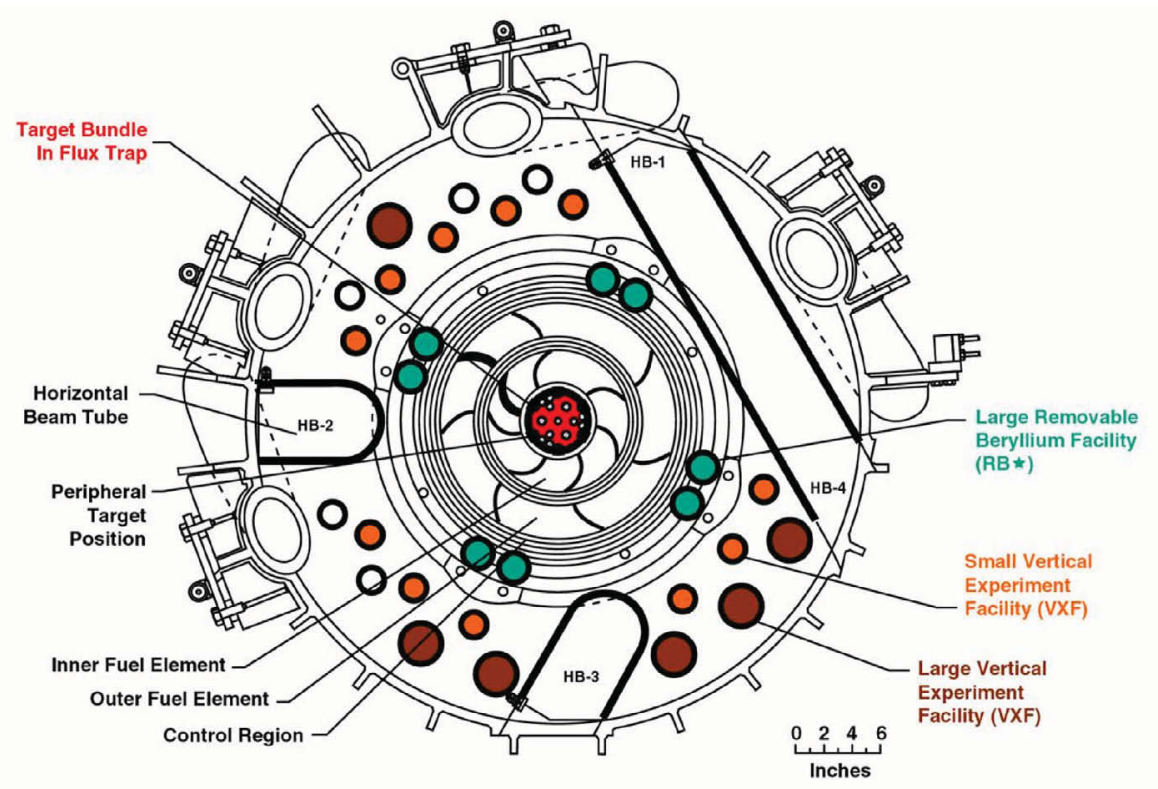

Figure 5. Cross section through HFIR mid-plane. 
Table 1. Characteristics of vertical HFIR irradiation facilities.

\begin{tabular}{|c|c|c|c|c|c|}
\hline Characteristic & Target & $\begin{array}{c}\text { RB* }^{*} \\
\text { unshielded }\end{array}$ & $\begin{array}{c}\mathrm{RB}^{*} \text { with } \\
\mathrm{Eu}_{2} \mathrm{O}_{3} \text { shield }\end{array}$ & $\begin{array}{l}\text { Small } \\
\text { VXF }\end{array}$ & $\begin{array}{l}\text { Large } \\
\text { VXF }\end{array}$ \\
\hline Fast flux, E $>0.1 \mathrm{MeV}\left(10^{14} \mathrm{n} / \mathrm{cm}^{2} \cdot \mathrm{sec}\right)$ & 11 & 5.3 & 4.9 & 0.5 & 0.13 \\
\hline Thermal flux, $\mathrm{E}<0.1 \mathrm{MeV}\left(10^{14} \mathrm{n} / \mathrm{cm}^{2} \cdot \mathrm{sec}\right)$ & 21 & 11 & 0.19 & 7.5 & 4.3 \\
\hline Peak displacements per atom (dpa) per cycle, stainless steel & 1.8 & 0.67 & 0.58 & & \\
\hline Typical capsule diameter $(\mathrm{mm})$ & 16 & 43 & 38 & 37 & 69 \\
\hline Number of available positions & 36 & 8 & 2 & 16 & 6 \\
\hline
\end{tabular}

The target region has the highest reactor neutron flux (thermal flux $[\mathrm{E}<0.5 \mathrm{eV}]$ of $2.1 \times 10^{15} \mathrm{n} / \mathrm{cm}^{2} \cdot \mathrm{s}$ and a fast flux $[\mathrm{E}>0.1 \mathrm{MeV}]$ of $\left.1.1 \times 10^{15} \mathrm{n} / \mathrm{cm}^{2} \cdot \mathrm{s}\right)$. A schematic of the target region is given in Figure 6 . The flux trap contains 36 positions plus the hydraulic tube (rabbit irradiation). Target positions may be irradiated for a cycle or multiple cycles (a cycle averages $\sim 23$ days but may vary from 21-26 days, depending on the power level and experiments loaded in the core). The target region may accommodate two fully instrumented experiments (the E3 and E6 locations). The target region also contains a hydraulic facility (location B3) which offers the unique opportunity to irradiate experiments for very low doses with irradiation times as short as 1 minute or as long as the full cycle.

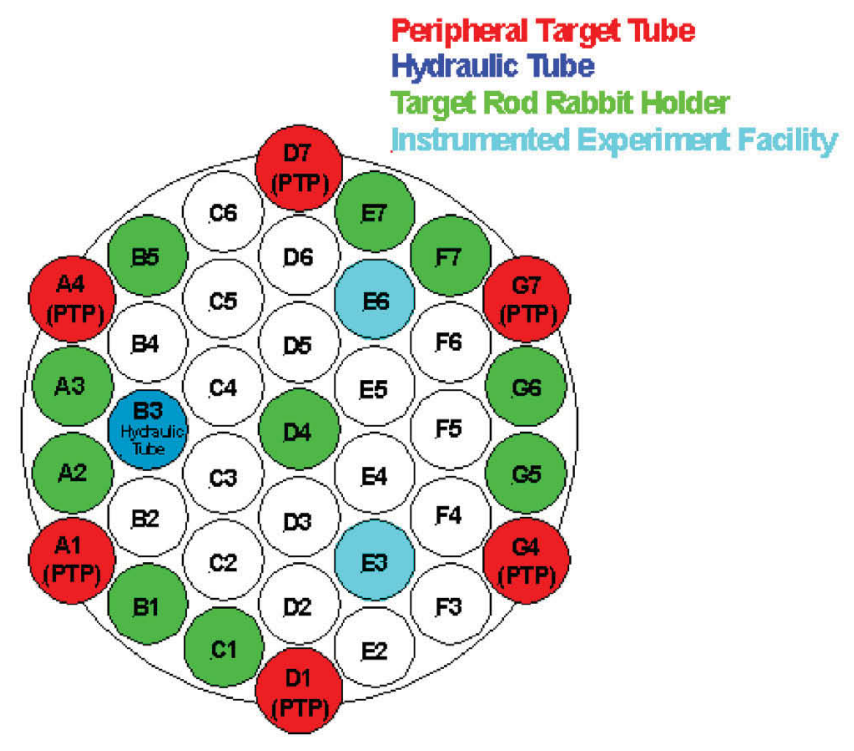

Figure 6. HFIR flux trap schematic.

The primary vertical test positions in the reflector (outside the core) are the "RB", "small VXF", and the "large VXF" positions (see Figure 5). The attributes (number of available positions, typical experimental capsule diameters, gamma heating and flux levels) for these positions are given in Table 1. Shielded designs are routinely used for these positions with highly instrumented assemblies normally being inserted in the RB positions. 


\subsection{Irradiation Test Conditions and Desired Parameters}

As discussed in Reference 1, the FCRD program focuses on three types of fuel irradiation conditions: ceramic fuel surrounded by helium gas for light water reactors (LWRs), ceramic fuel surrounded by helium gas for sodium fast reactors (SFRs), and metallic fuel surrounded by molten sodium for SFRs. Typical test conditions and geometries for each case are summarized in this section. Although it is recognized that some tests could be performed in non-prototypic conditions (e.g., metallic fuel surrounded by inert gas), experts at the FCRD workshop noted that such tests must be carefully planned to demonstrate their applicability. Hence, experts recommended that initial efforts in this instrumentation development program emphasize sensors that can provide data in prototypic conditions.

Initial discussions with fuel performance modeling experts indicate that the parameters listed in Table 2 should be measured with the desired accuracies and spatial resolution. Discussions with fuel modeling experts indicate that detection of thermal properties is of highest priority, followed by fuel internal pressure due to fission gas release, swelling, crack growth, and constituent migration. However, as noted in Reference 1, the FCRD program places the highest priority on sensors that can provide insights related to changes in fuel morphology because such insights are needed to clarify changes in other parameters, such as thermal conductivity, density, etc.

\subsubsection{Currently Available Instrumentation to Provide Required Data}

Sensors that are currently available at other MTRs (see Table 3) can be used in FCRD irradiations to obtain many of the desired parameters with the accuracies specified in Table 2. However, many of the sensors used at other MTRs require some enhancements before they can be successfully implemented in the higher flux, harsher conditions typical of ATR and HFIR tests. Once enhanced, these sensors can provide insights with respect to parameters, such as temperature, thermal conductivity, crack growth, and flux. However, in general, the resolution available with such sensors is limited due to the size of the irradiation test and the desire to minimize the impact of the sensor on test results. It should also be noted that existing and near-term sensor technologies do not provide any capability for detecting changes in fuel microstructure or constituent migration.

Nevertheless, several DOE-NE programs, including the FCRD, the ATR National Scientific Users Facility (NSUF), and Nuclear Energy Enabling Technologies (NEET) programs, have recognized the need to provide higher flux US MTRs access to in-pile instrumentation comparable to that available at foreign research reactors. Instrumentation development efforts are closely coordinated with DOE-NE to avoid duplication of efforts and ensure that program requirements are met.

\subsection{Expert Workshop Recommendations}

As noted in Section 1, a workshop was held at the beginning of this effort in which US and foreign experts from fuels, irradiation, and instrumentation fields participated. During the workshop, candidate sensor technologies were discussed and ranked by experts using agreed upon criteria. This section provides an overview of the process and summarizes recommendations from this workshop. 
Table 2. Summary of desired parameters for detection during fuel irradiation tests.

\begin{tabular}{|c|c|c|c|}
\hline \multirow{2}{*}{ Parameter } & \multirow{2}{*}{ Representative - Peak Value } & \multicolumn{2}{|r|}{ Desired } \\
\hline & & Accuracy & Spatial Resolution \\
\hline \multirow[t]{3}{*}{ fuel temperature } & Ceramic LWR - $1400^{\circ} \mathrm{C}$ & \multirow[t]{3}{*}{$2 \%$} & \multirow{3}{*}{$\begin{array}{l}1-2 \mathrm{~cm} \text { (axially); } \\
0.5 \mathrm{~cm} \text { (radially) }\end{array}$} \\
\hline & Ceramic SFR- $2600^{\circ} \mathrm{C}$ & & \\
\hline & Metallic SFR $-1100^{\circ} \mathrm{C}$ & & \\
\hline \multirow[t]{3}{*}{ cladding temperature } & Ceramic LWR $<400{ }^{\circ} \mathrm{C}$ & \multirow[t]{3}{*}{$2 \%$} & \multirow[t]{3}{*}{$1-2 \mathrm{~cm}$ (axially) } \\
\hline & Ceramic SFR $-650^{\circ} \mathrm{C}$ & & \\
\hline & Metallic SFR - $650^{\circ} \mathrm{C}$ & & \\
\hline \multirow[t]{3}{*}{ pressure in fuel rod plenum } & Ceramic LWR - 800 psi & $5 \%$ & \multirow[t]{3}{*}{$\mathrm{NA}^{\mathrm{a}}$} \\
\hline & Ceramic SFR-1250 psi & $5 \%$ & \\
\hline & Metallic SFR - $1250 \mathrm{psi}$ & $5 \%$ & \\
\hline $\begin{array}{l}\text { fission gas release (amount and } \\
\text { composition) }\end{array}$ & $0-100 \%$ of inventory & $10 \%$ & NA \\
\hline \multirow{3}{*}{$\begin{array}{l}\text { fuel and cladding dimensions } \\
\text { radial and axial (includes } \\
\text { fuel-cladding gap size) }\end{array}$} & Initial Length, $1 \mathrm{~cm}$ & $1 \%$ & $0.5 \mathrm{~cm}$ \\
\hline & Outer diameter/Strain, $0.5 \mathrm{~cm} / 5-10 \%$ & $0.1 \%$ & $0.25 \mathrm{~cm}$ (axially); $120^{\circ}$ (radially) \\
\hline & Fuel-Cladding Gap (0-0.1 mm) & $0.1 \%$ & $0.25 \mathrm{~cm}$ (axially); $120^{\circ}$ (radially) \\
\hline \multirow{3}{*}{$\begin{array}{l}\text { fuel morphology/ } \\
\text { microstructure/cracking/ } \\
\text { constituent migration }\end{array}$} & Grain size, $10 \mu \mathrm{m}$ & $5 \%$ & $1-10 \mu \mathrm{m}$ \\
\hline & Swelling/Porosity, 5-20\% & $2 \%$ & \\
\hline & Crack formation and growth & $2 \%$ & $10-100 \mu \mathrm{m}$ \\
\hline \multirow[t]{2}{*}{ fuel thermal properties } & $\begin{array}{c}\text { Thermal conductivity, } \\
\text { Ceramic: }<5 \mathrm{~W} / \mathrm{mK} ; \text { Metallic: }<50 \mathrm{~W} / \mathrm{mK}\end{array}$ & $4 \%$ & $<1 \mathrm{~cm}$ (radially) \\
\hline & $\begin{array}{l}\text { Density (estimated from changes in length, } \\
\text { diameter, porosity, etc.) }\end{array}$ & $2 \%$ & NA \\
\hline \multirow{2}{*}{$\begin{array}{l}\text { neutron flux for estimating } \\
\text { fluence and fuel burnup }\end{array}$} & Thermal neutron flux $-\sim 1-5 \times 10^{14} \mathrm{n} / \mathrm{cm}^{2}-\mathrm{s}$ & $1-10 \%$ & $5 \mathrm{~cm}$ (axially) \\
\hline & $\begin{array}{l}\text { Fast neutron flux }(\mathrm{E}>1 \mathrm{MeV})-\sim 1-5 \times 10^{14} \\
\mathrm{n} / \mathrm{cm}^{2}-\mathrm{s}\end{array}$ & $15 \%$ & $5 \mathrm{~cm}$ (axially) \\
\hline
\end{tabular}

a. NA-Not Applicable.

During the workshop, experts discussed possible criteria and ranked candidate technologies using the following five criteria:

- Potential to detect parameters with desired accuracy,

- Potential to detect desired parameters in prototypic conditions (environment, temperature, etc.),

- Versatility,

- Ease of Installation, and

- Technology Readiness (demonstrated in-pile experience to obtained desired accuracy under desired conditions).

For this assessment, experts ranked the above criteria using the following numeric scores:

1. Technology unable to meet most aspects of the criteria;

2. Technology may offer potential to meet some aspects of the criteria;

3. Technology may offer potential to meet most aspects of this criteria and some data available. 
Table 3. Summary of sensors deployed at MTRs.

\begin{tabular}{|c|c|c|c|}
\hline Parameter & Sensor $^{a}$ & Operating Conditions & Accuracy \\
\hline \multirow[t]{6}{*}{ Temperature } & Melt Wires & $100-1200^{\circ} \mathrm{C}$ & $\begin{array}{c}2-3{ }^{\circ} \mathrm{C} \text {, but limited by number of } \\
\text { wires with different melting } \\
\text { points included in test }\end{array}$ \\
\hline & SiC monitors & $100-800^{\circ} \mathrm{C}$ & $2 \%$ \\
\hline & Thermocouples (N, K) & $100-1000^{\circ} \mathrm{C}$ & $2 \%$ \\
\hline & $\begin{array}{l}\text { Thermocouples } \\
\text { (High Temperature } \\
\text { Irradiation Resistant } \\
\text { Thermocouples - } \\
\text { HTIR-TCs) }\end{array}$ & $100-1800^{\circ} \mathrm{C}$ & $2 \%$ \\
\hline & $\begin{array}{c}\text { Thermocouples - Type C, } \\
\text { D, R, and S }\end{array}$ & $100-2000^{\circ} \mathrm{C}$ & $\begin{array}{l}2 \% \text { or worse, decalibrate due to } \\
\text { transmutation }\end{array}$ \\
\hline & Ultrasonic Thermometers ${ }^{b}$ & $1300-3000{ }^{\circ} \mathrm{C}$ & $2 \%$ \\
\hline \multirow[t]{2}{*}{ Thermal Conductivity } & Multiple Thermocouple & $\begin{array}{l}100-2000{ }^{\circ} \mathrm{C} \text {, depending on } \\
\text { thermocouple type }\end{array}$ & $10 \%{ }^{6}$ \\
\hline & Hot Wire Needle Probe & $\begin{array}{l}100-1800{ }^{\circ} \mathrm{C} \text {, depending on } \\
\text { materials selected }\end{array}$ & $2-8 \%$ \\
\hline \multirow[t]{2}{*}{$\begin{array}{l}\text { Density / Geometry } \\
\text { Changes }\end{array}$} & $\begin{array}{c}\text { Length - Linear Variable } \\
\text { Differential Transformers } \\
\text { (LVDTs) }\end{array}$ & up to $500{ }^{\circ} \mathrm{C}^{\mathrm{C}}$ & $1-10 \mu \mathrm{m}$ \\
\hline & Diameter - Diameter Gauge & up to $500{ }^{\circ} \mathrm{C}^{\mathrm{c}}$ & $1-10 \mu \mathrm{m}$ \\
\hline Crack Initiation /Growth & $\begin{array}{l}\text { Crack Length - Direct } \\
\text { Current Potential Drop } \\
\text { (DCPD) Method }\end{array}$ & $350^{\circ} \mathrm{C} / 2250 \mathrm{psia}$ & $\sim 20 \%$ \\
\hline Young's Modulus & Loaded Creep Specimen & up to $500{ }^{\circ} \mathrm{C}^{\mathrm{c}}$ & $\sim 10 \%$ \\
\hline \multirow[t]{2}{*}{ Fission Gas/Pressure } & Sampling & Numerous isotopes & Unknown \\
\hline & Pressure gauge & $\begin{array}{c}15 \text { bar (220 psi) to } 70 \text { bar (1020 } \\
\text { psi) }\end{array}$ & $\begin{array}{c} \pm 0.2 \text { bar (2.9 psi) to } \pm 0.5 \text { bar ( } 7.3 \\
\text { psi) }\end{array}$ \\
\hline \multirow[t]{3}{*}{ Flux - Thermal } & Flux wires / Foils & Material dependent & $\sim 10 \%$ \\
\hline & SPNDs & Dependent on emitter & $\sim 1-10 \%{ }^{\mathrm{d}}$ \\
\hline & Fission Chambers & Dependent on fissile deposit & $\sim 1-10 \% \mathrm{~d}$ \\
\hline \multirow[t]{2}{*}{ Fast } & Flux wires / Foils & Material dependent & $\sim 1-10 \%$ \\
\hline & Fission Chambers & Dependent on fissile deposit & $\sim 1-10 \%$ \\
\hline
\end{tabular}

a. Color denotes status of sensor availability with respect to use in higher flux reactors, such as ATR or HFIR

(Black-available and demonstrated; Red - recently enhanced or developed and demonstrated; Magenta -lab testing completed and ready for irradiation testing; Blue - under investigation).

b. Prior in-pile use typically limited to short duration, fuel damage tests.

c. Some loss of accuracy at $350{ }^{\circ} \mathrm{C}$ due to Curie temperature effects, unless developmental LVDTs are deployed.

d. Accuracy decreases with use due to depletion of deposits within sensor.

Experts agreed that a simpler ranking system was appropriate due to the availability of information related to technologies with respect to various criteria.

As noted in Reference 1, ultrasonics and fiber optic technologies were ranked considerably higher than other candidate technologies considered. Discussion prior to the ranking process indicate that experts 
favored more mature technologies. Experts believed that existing research demonstrates that ultrasonic and fiber optics technologies offer the potential for some quick successes. For example, prior use of ultrasonic thermometers (UTs) suggest that a single probe could be used to obtain a temperature profile with accuracies and resolutions not possible with existing technologies.

In addition, experts favored technologies that could obtain the desired data under prototypic conditions and if they offered the potential to detect most, if not all, of the parameters requested by fuel modeling experts. For example, ultrasonic sensors were ranked higher because of their potential to detect desired parameters in metallic fuel surrounded by sodium and in oxide fuel surrounded by helium for the range of temperatures of interest.

Experts also ranked technologies more highly if they offered the potential for 'diverse' parameter detection. For example, initial research investments in ultrasonic and fiber optic technologies could lead to methods that could ultimately be used to detect a wide range of parameters (e.g., physical and environmental parameters). In addition, investments in ultrasonics and fiber optic technologies offer the potential for later achieving more advanced technologies, such as laser ultrasonics, that require these technologies for successful detection and/or transmission.

Experts emphasized the need for US researchers to work with organizations already possessing expertise in selected technologies. Where possible, the FCRD program should collaborate and/or learn from developments made by international nuclear instrumentation researchers and non-nuclear instrumentation researchers. In addition, any sensor in-pile deployment efforts should be coupled with post-irradiation examinations to maximize the insights obtained from any irradiation testing.

Experts also emphasized that sensor development efforts should focus on capsule design and sensor viability tasks. Experts noted that having sensors installed and functioning in a viable test capsule was as important as development of the sensor. Prior to starting any research, experts emphasized the need for developing detailed plans with 'off-ramps' at key decision points where the viability of the technology could be assessed prior to further research.

Last, experts emphasized the need for higher flux US MTRs to gain access to instrumentation available to users at foreign test reactors and to work toward improving the accuracy of existing sensors for detecting phenomena. It was noted that many of the sensors identified in Reference 1 are not currently available for use in the higher flux, harsher test conditions proposed for FCRD irradiations. In addition, experts noted that additional research was needed to reduce uncertainties associated with existing sensors.

\subsection{Summary}

In summary, a multi-year strategic research program is underway for developing the required test vehicles with sensors of unprecedented accuracy and resolution for obtaining the data needed to support FCRD irradiations. At the time that this research program was initially planned, it was anticipated that the funding levels would start at $\$ 600 \mathrm{~K}$ and increase to approximately $\$ 1 \mathrm{M} / \mathrm{yr}$. Although the funding for the first year of this effort was as planned, FY12 funding was significantly lower. Nevertheless, with the available funding, some of the planned research goals are progressing as planned. This document reports progress made during FY12. Specifically, Sections 3 through 5 report progress in each of the sensor technology areas deemed most promising. 


\section{ULTRASONICS}

Ultrasonics were identified in Reference 1 as a technology that will be developed for in-pile instrumentation to support FCRD irradiations. Ultrasonics can be deployed for measuring a range of parameters, including geometry changes, temperature, crack initiation and growth, gas pressure and composition, and microstructural changes. During FY11, funding was used to develop a long-term research plan to identify tasks that will be completed to demonstrate the viability of ultrasonics to provide needed FCRD in-pile instrumentation. In addition, efforts were initiated to evaluate the viability of using the first ultrasonic technique identified for investigation, ultrasonic thermometry, by FY14. As reported in this section, FY12 funding primarily focused on assessing the viability of using UTs for multipoint temperature detection by conducting research in the areas of component design, calibration/stabilization, material selection, fabrication, and accuracy evaluations. Progress made in each area is reported in this section. In addition, FY12 funding allowed development of a collaborative proposal for addressing a key concern related to ultrasonic sensor deployment for irradiation testing, ultrasonic transducer survivability. This collaborative proposal, which was led by Pennsylvania State University (PSU), has been selected by the ATR NSUF, and irradiation testing is expected to begin in FY13. Finally, this section reports progress funded by other programs on the deployment of ultrasonics sensors for measuring other parameters.

\subsection{Overall Plan and Schedule}

To accomplish the desired objectives, a task was defined for each type of ultrasonic sensor that will be deployed. In addition, a 'cross-cutting' task was defined to address issues that ultimately support all ultrasonic technology development tasks. Figure 7 provides an overview of the tasks that will be completed in the area of ultrasonics. As indicated in this figure, evaluations to support the use of ultrasonics for in-pile measurements are currently funded by several programs. The FCRD tasks are sequenced to first emphasize deployment of ultrasonic techniques for temperature detection (Task 1). In addition, Idaho National Laboratory (INL) Laboratory Directed Research and Development (LDRD) funding also allowed some research to explore the use of ultrasonics for use as an in-pile method for detecting length (Task 2). During FY13, tasks for continuing Task 2 length detection using ultrasonic techniques will be continued by the FCRD program if adequate funding is allocated, but efforts to explore ultrasonics for detecting fuel diameter and morphology changes and gas properties are not expected to be initiated until at least FY15 (unless funding levels are increased). For Tasks 1 through 3, laboratory evaluations are completed to assess the accuracy and resolution that the proposed ultrasonic techniques are capable of achieving and to verify that these methods can be used to measure the desired parameters. However, it was also recognized that all of the proposed ultrasonic techniques can benefit from research into cross-cutting areas, such as irradiation testing of selected components, and improvements in signal processing. During FY12, the NEET program funded cross-cutting research to enhance signal processing software for ultrasonics in-pile applications and research to support an ATR NSUF irradiation test of ultrasonics transducers. As documented in this section, the ATR NSUF has selected this project for an irradiation test in the Massachusetts Institute of Technology Reactor (MITR). Additional details about progress made and future plans for each of these tasks are documented in Sections 3.2 through 3.5.

\subsection{Task 1: Fuel Temperature (Ultrasonic Thermometry)}

The objective of this task is to deploy UTs in irradiations of ceramic and metallic fuels. UTs work on the principle that the speed at which sound travels through a material (acoustic velocity) is dependant on the 


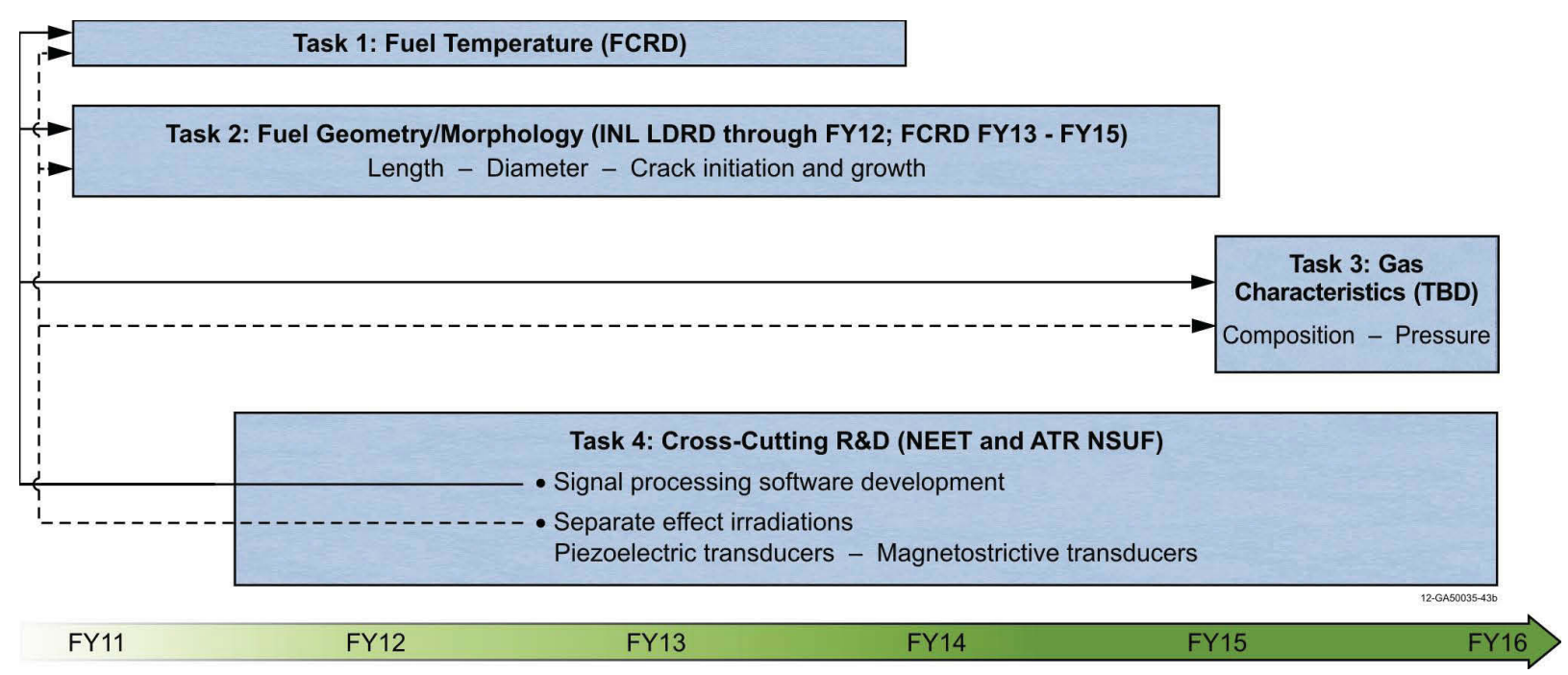

Figure 7. Overview of task to be completed as part of ultrasonic technology investigations.

temperature of the material. By introducing an acoustic pulse to the sensor and measuring the time delay of echoes, temperature may be derived. UTs offer several advantages over other temperature sensors. UTs can be made very small, as the sensor consists of only a small diameter rod which may or may not require a sheath. Measurements may be made near the melting point of the sensor material, as no electrical insulation is required; and shunting effects are avoided. Most attractive, however, is the ability to introduce acoustic discontinuities to the sensor, as this enables temperature measurements at several points along the sensor length (allowing temperature profiling with a single sensor).

A conceptual design of a 'notched-probe' UT, with key components identified, is shown in Figure 8. As indicated in this figure, a narrow ultrasonic pulse is generated in a magnetostrictive rod by a short duration magnetic field pulse produced by an excitation coil (though previous in-pile research utilized magnetostrictive transducers, piezoelectric transducers may potentially be used in this effort). The ultrasonic pulse propagates to the sensor wire, where a fraction of the pulse energy is reflected at each discontinuity (notches or diameter change). Each reflected pulse is received by the excitation coil, transformed into an electrical signal, amplified and evaluated in a start/stop counter system. The time interval between two adjacent echoes is evaluated and compared to a calibration curve to give the average temperature in the corresponding sensor segment. When a number of notches are available on the wire sensor, the various measurements give access to a temperature profile along the probe.

UTs have several advantages over other sensors. ${ }^{7}$ UTs can be made with very small diameters while maintaining a high level of durability, as the sensor consists simply of a small diameter rod (typical diameters range from $0.25 \mathrm{~mm}$ to $1 \mathrm{~mm}$, though a sheath may be required for some environments). ${ }^{8}$ In fact, a small diameter rod is desirable; as wave dispersion is avoided when the rod diameter is sufficiently smaller than the acoustic wavelength. ${ }^{9}$ Temperature measurements may be made near the melting point of the transducer material. As no electrical insulation is required, shunting effects found in thermocouples and resistance temperature devices are eliminated. A clear line of sight is not required, as is the case for most optical pyrometry applications. With proper selection of materials, UTs may be used in very harsh environments, such as high temperature steam or liquid metals. Perhaps the most appealing characteristic of UTs is the ability to make temperature measurements at several axial positions using a single sensor, thereby measuring a temperature profile. 


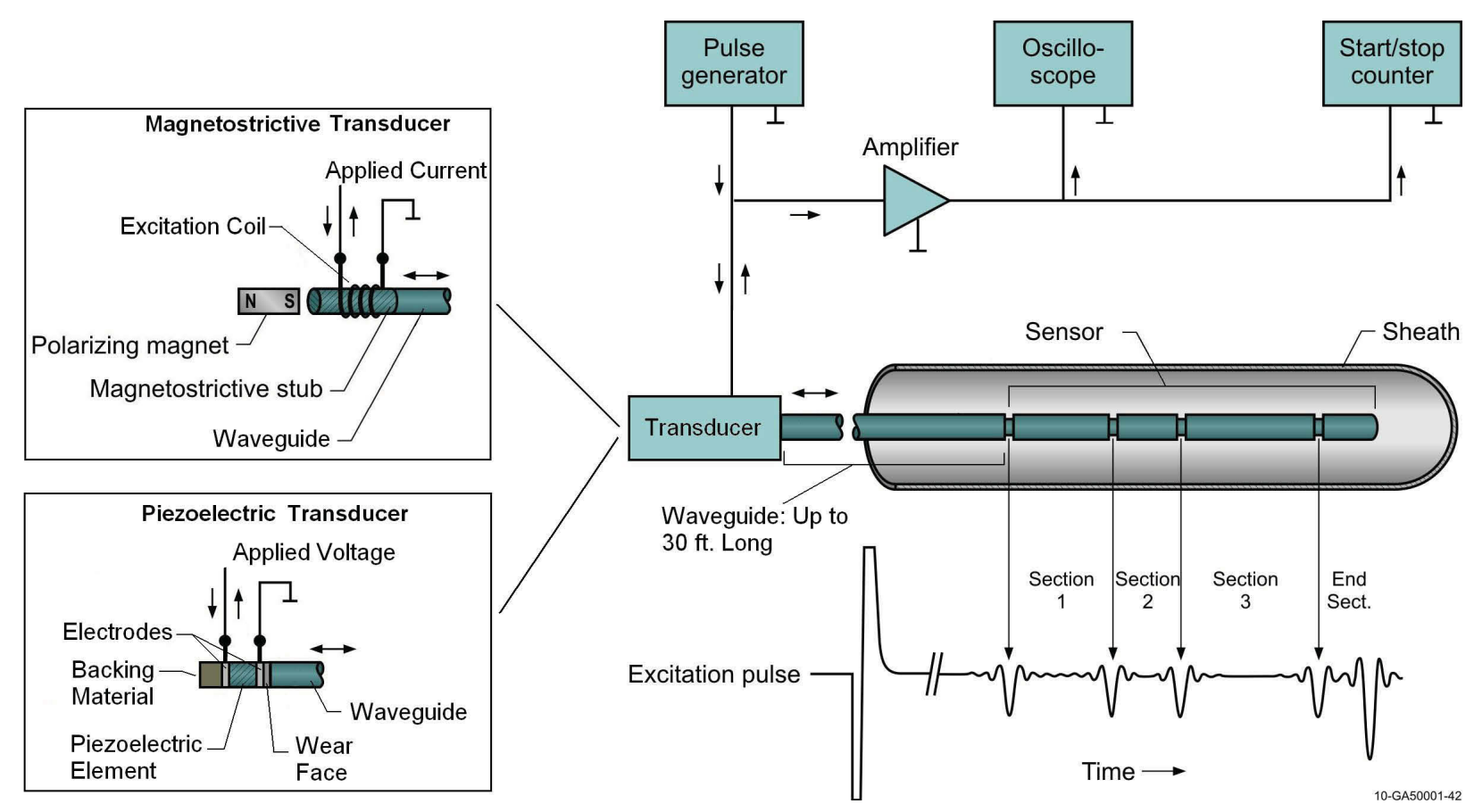

Figure 8. Schematic showing typical components of a UT and signal processing equipment.

Although UTs appear very promising for FCRD irradiation temperature measurement, research is needed before they are ready for deployment. FY12 UT research focused on resolving these deployment issues. Research was conducted to identify optimum designs, materials, and joining techniques for UT sensors and transducers in various FCRD fuel irradiations. In addition, efforts were completed to optimize the signal from UTs by investigating candidate methods to dampen signal noise and various signal processing options. Results from these efforts are presented in this section.

\subsubsection{Acoustic Velocity Measurement of Candidate Sensor Material}

As an initial step in the UT system development effort, acoustic velocity characterization tests were completed in order to reduce the number of candidate materials by comparing temperature response, ease of fabrication, transmitted signal quality, etc. The tests were also used to evaluate and make appropriate adjustments to a signal processing technique for UT applications. The steps required to perform these tests (candidate material selection, test sample fabrication, test setup, and signal processing adaptation) are detailed in the following sections.

The materials selected for initial evaluations are listed in Table 4 with relevant material properties and envisioned irradiation environments. Candidate sensor materials were selected based on melting temperature, thermal neutron capture cross section, and compatibility with likely in-pile test conditions. For higher temperature applications, such as inert gas-filled tests of oxide fuels, refractory metals are an obvious choice due to their high melting temperatures. Some refractory metals have been used successfully in similar tests for evaluating thermocouple components (both for short term use in tungsten-rhenium thermocouples and for longer term use in molybdenum-niobium based high temperature irradiation resistant thermocouples [HTIR-TCs] developed at INL). Tungsten and rhenium were not considered (despite high 
Table 4. Candidate sensor materials.

\begin{tabular}{|c|c|c|c|}
\hline Material & $\begin{array}{c}\text { Melting } \\
\text { Temperature, }{ }^{\circ} \mathrm{C}\end{array}$ & $\begin{array}{c}\text { Thermal Neutron } \\
\text { Capture Cross Section, } \\
\text { Barns }\end{array}$ & $\begin{array}{c}\text { Identified Irradiation } \\
\text { Test Application }\end{array}$ \\
\hline $\begin{array}{c}\text { 302 Stainless Steel } \\
\text { 304 Stainless Steel }\end{array}$ & 1510 & 3.02 & $\begin{array}{c}\text { Liquid Metal Bonded } \\
\text { Metallic Fuel } \\
\left(\mathrm{T}<1000^{\circ} \mathrm{C}\right)\end{array}$ \\
\hline Inconel 606 & 1510 & 3.03 & $\begin{array}{c}\text { Inert Gas Filled } \\
\text { Ceramic Fuel } \\
\left(\mathrm{T}>1000^{\circ} \mathrm{C}\right)\end{array}$ \\
\hline Molybdenum & 2620 & 2.51 & 2.51 \\
\hline
\end{tabular}

melting points and previous use in UTs for very short term measurements) due to their high thermal neutron capture cross sections, as both are known to be prone to decalibration due to transmutation. Molybdenum and niobium have high melting points and low thermal neutron capture cross sections. Variations of these materials, KW-molybdenum (molybdenum doped with small amounts of potassium, silicon, and tungsten) and niobium-1\% zirconium were selected for initial testing. Prior experience with these materials indicates that they retain ductility better than pure metals after heating. For lower temperature tests (less than $1000{ }^{\circ} \mathrm{C}$ ) in liquid metal or liquid sodium bonded metallic fuels, stainless steel and Inconel were selected for cost, corrosion resistance, and ease of fabrication.

Test specimens were isolated from each other in alumina tubes, which were installed in a tube furnace equipped with an argon purge gas system (note that Figure 9 shows a single installed sample, but a total of six were included in the test). Signals were generated using a commercial pulser/receiver system, and coils were fabricated in-house. Data were monitored and recorded using a high speed digital oscilloscope. Temperatures were monitored using a National Institute of Standards and Technology traceable Type-S thermocouple. Data were collected in $100{ }^{\circ} \mathrm{C}$ increments from room temperature to $1300{ }^{\circ} \mathrm{C}$.

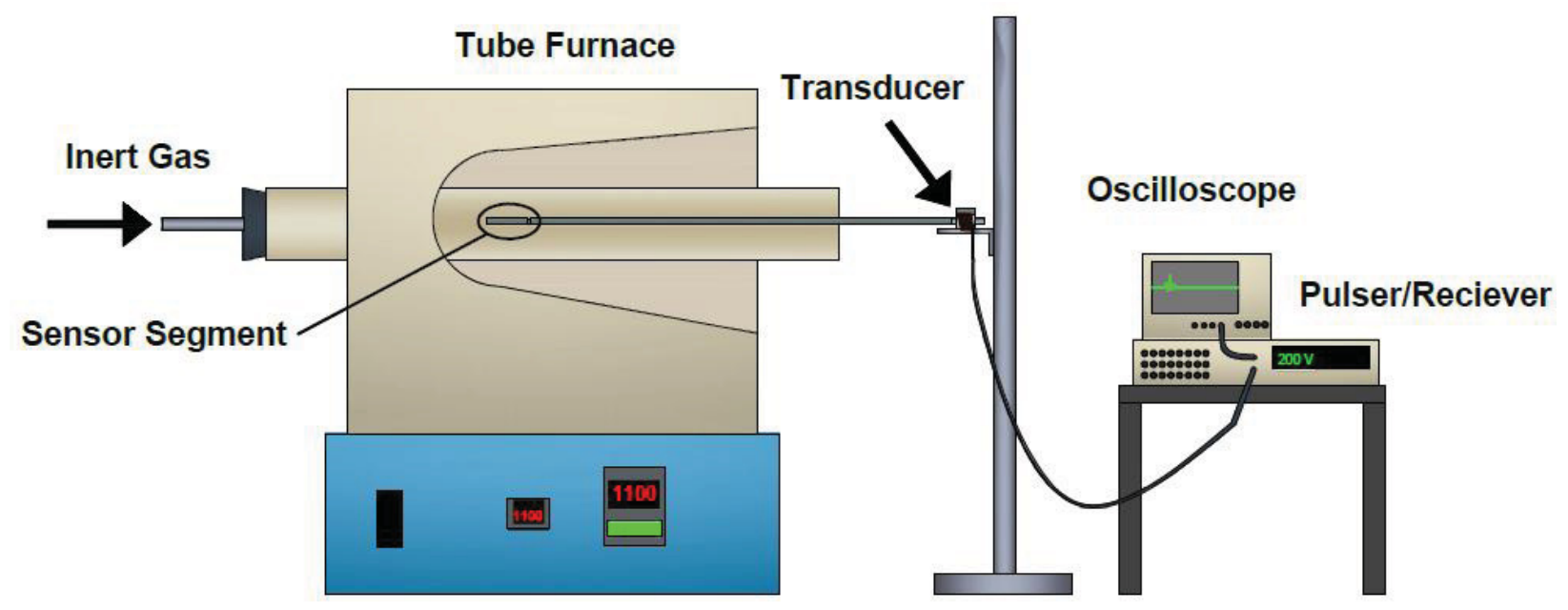

Figure 9. Acoustic velocity characterization test setup. 
Acoustic velocity was calculated from the delay time between the maxima in the filtered data and the known length of the sensor segment (after correcting for thermal expansion) using the following equation:

$c=\frac{2(l+\Delta l)}{\Delta t}$

where:

$c$ is the acoustic velocity,

$l$ is the initial sensor length at room temperature,

$\Delta l$ is the change in length due to thermal expansion, and

$\Delta t$ is the delay time between maxima.

\section{Stainless Steel}

Figure 10 compares measured acoustic velocities of 302 and 304 series stainless steel samples to values calculated from reference data. ${ }^{10,11}$ As shown in this figure, calculated velocities based on test data are somewhat higher than reference values found in the literature (about $5 \%$ for temperatures below $800{ }^{\circ} \mathrm{C}$ ). This difference can be attributed to differences in the manufacturing process used in production of the wires. However, the trend is appropriate for UT applications. High temperature attenuation increased signal noise and eventual loss of signal for temperatures above $1100{ }^{\circ} \mathrm{C}$ for the $0.254 \mathrm{~mm}$ diameter sample and above $1200{ }^{\circ} \mathrm{C}$ for the $1.58 \mathrm{~mm}$ diameter sample. It was also observed that the increased signal noise remained after cooling the sample.

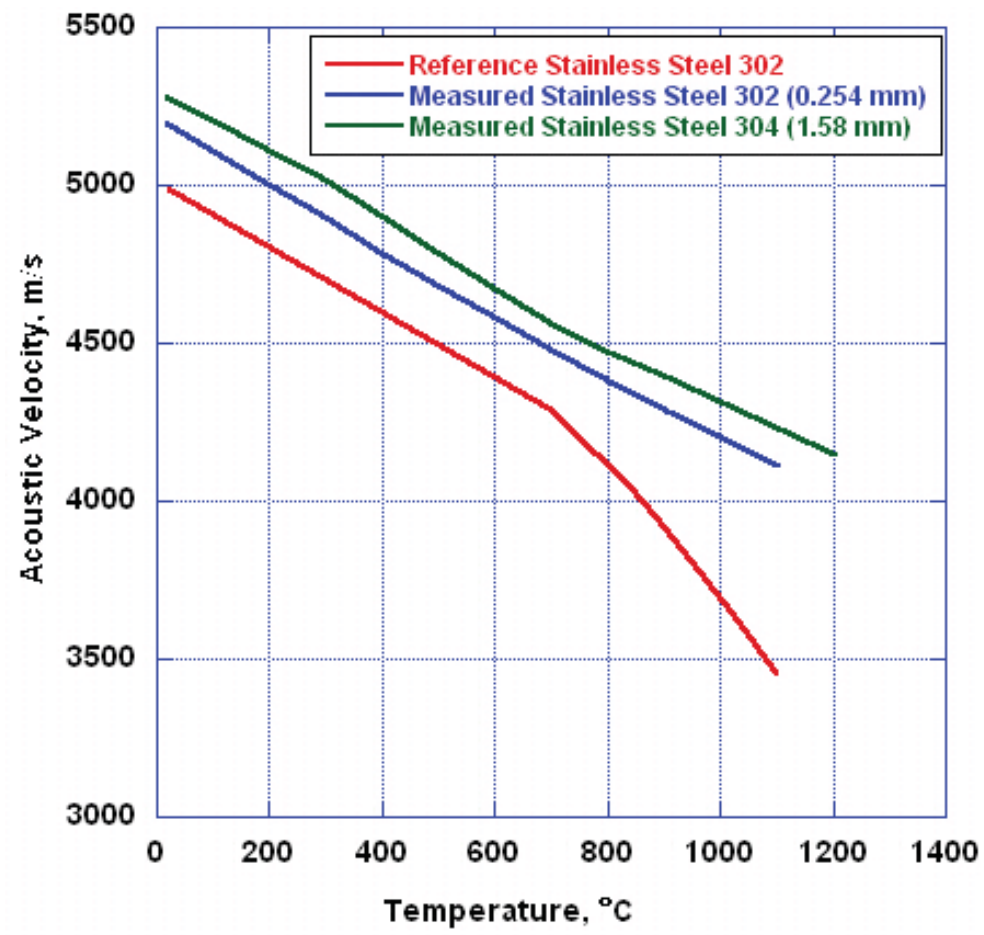

Figure 10. Comparison of measured acoustic velocity of stainless steel to calculated reference values. 


\section{Molybdenum}

Figure 11 compares measured acoustic velocities for pure molybdenum and KW-molybdenum samples to values calculated from reference data. ${ }^{10,12}$ The temperature response of the molybdenum samples is close to values inferred from the literature, except at the highest and lowest test temperatures. Signals for molybdenum samples did not attenuate significantly over the evaluated temperature range.

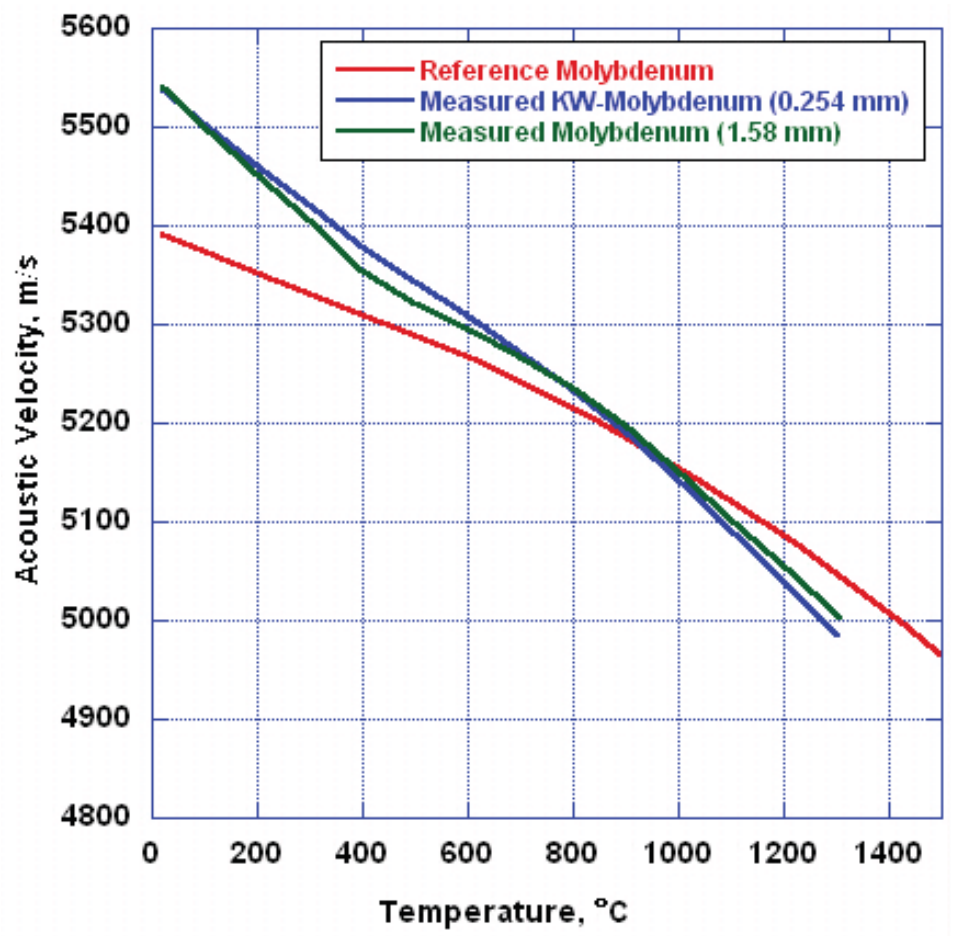

Figure 11. Comparison of measured acoustic velocity of molybdenum to calculated reference values.

\section{Inconel 606}

Figure 12 compares the acoustic velocity of Inconel 606 to values calculated from reference data. ${ }^{10,11}$ As with other materials evaluated, the velocity values of the tested samples are somewhat higher (better than $5 \%$ for temperatures up to $1100{ }^{\circ} \mathrm{C}$ ) than velocities calculated with reference data.

Sticking, a form of contact bonding between the sensor and its surroundings that can interfere with and obscure acoustic signals, occurred for Inconel 606 at temperatures above $1000{ }^{\circ} \mathrm{C}$. Sticking was only observed at temperatures above $1800^{\circ} \mathrm{C}$ in previous research. ${ }^{13,14,15}$ This sticking could have been due to contact bonding between the sample and the alumina tube. However, due to the relatively low test temperature, it is more likely due to binding between the sample and the tube caused by differential thermal expansion. An example of the effect of sticking is shown in Figure 13 for an Inconel sample tested at temperatures between $1000{ }^{\circ} \mathrm{C}$ and $1300{ }^{\circ} \mathrm{C}$. Sticking appears to begin at $1100{ }^{\circ} \mathrm{C}$ and has completely obscured the reflector signal at $1200^{\circ} \mathrm{C}$. Though the observed sticking obscured the signal at high test temperatures, Inconel 606 does appear to be a good candidate for lower temperature irradiation test use. However, the performance of candidate stainless steel materials appears superior. 


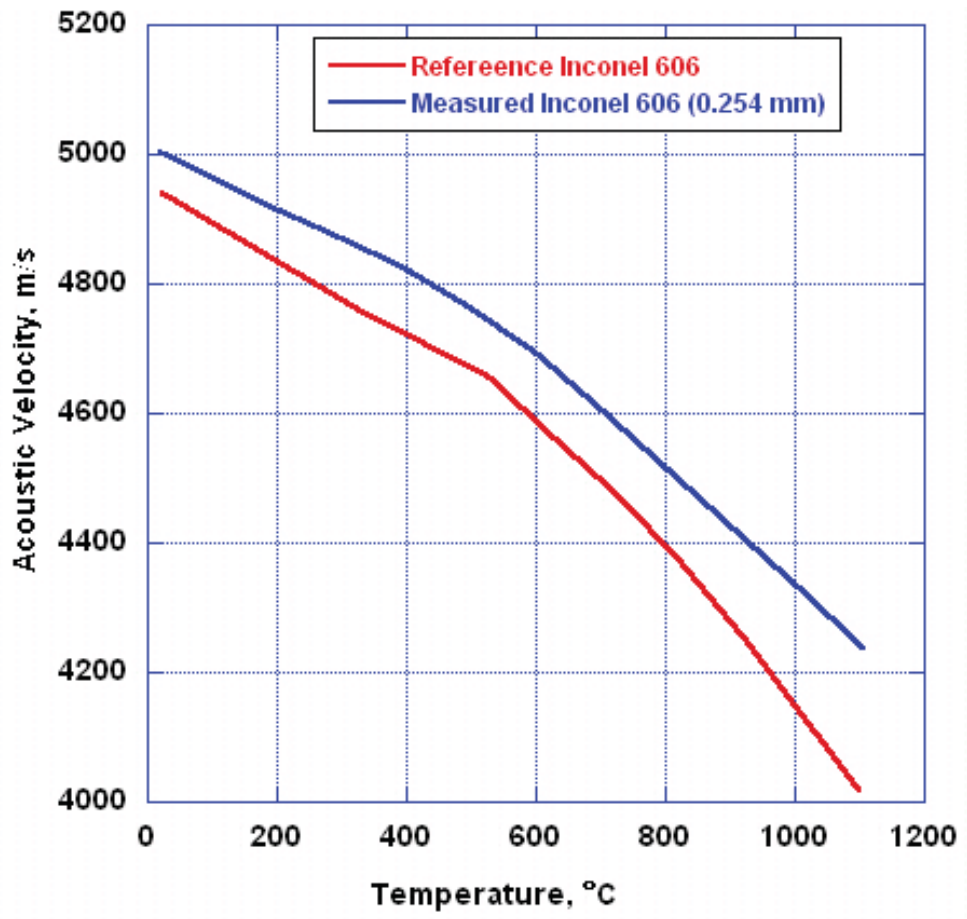

Figure 12. Comparison of measured acoustic velocity of Inconel 606 to calculated reference values.
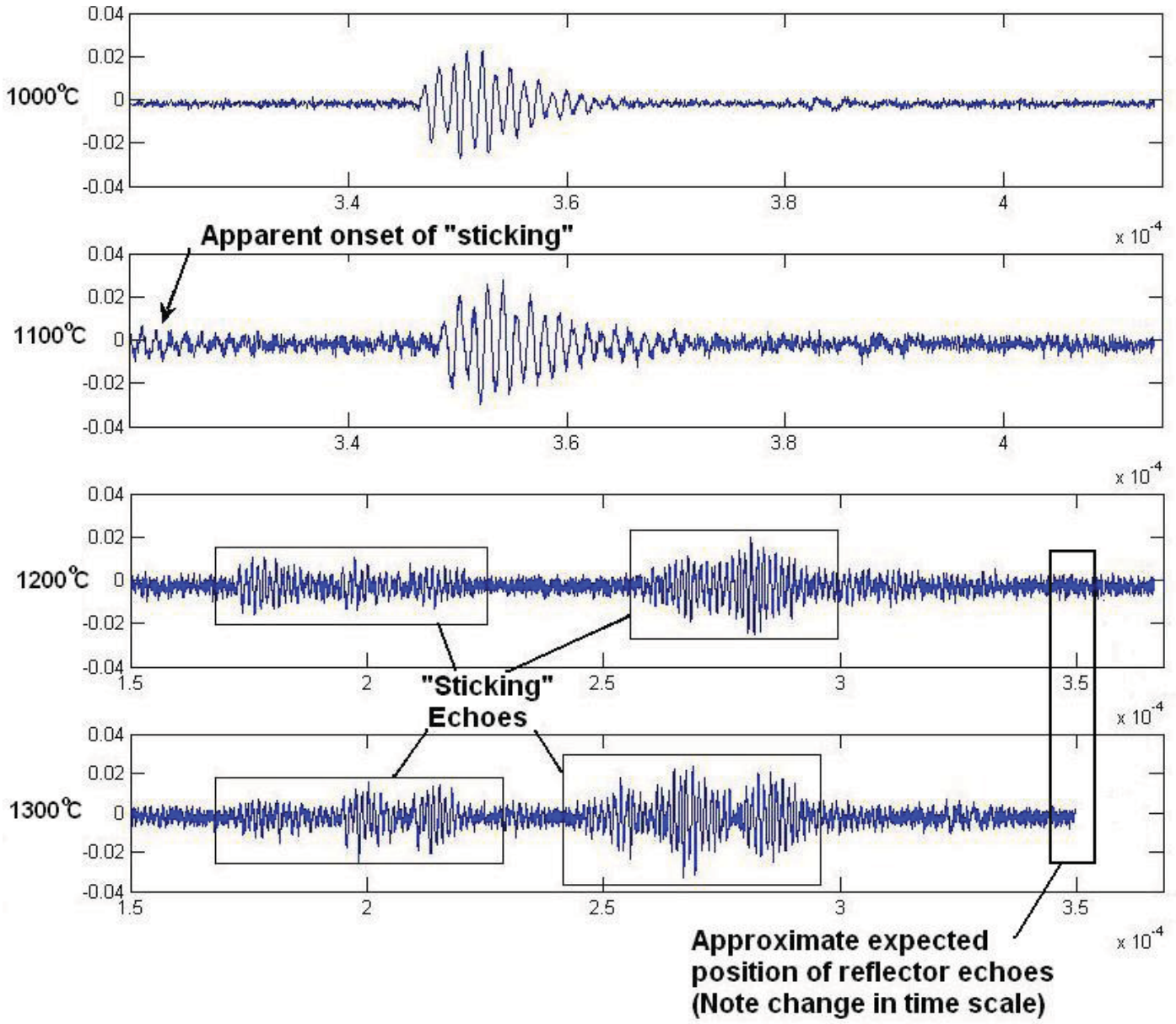

Figure 13. Progression of "sticking" observed for Inconel 606 sample. 


\section{Niobium-1\% Zirconium}

The temperature response of the niobium- $1 \%$ zirconium sample differed from values calculated from reference data, although the velocity values are close at room temperature. Reference data for density ${ }^{16}$ and elastic modulus ${ }^{17}$ predict a decrease in acoustic velocity with increasing temperature, as for the other tested samples. However, recorded data show a clear increase in velocity with temperature (see Figure 14).

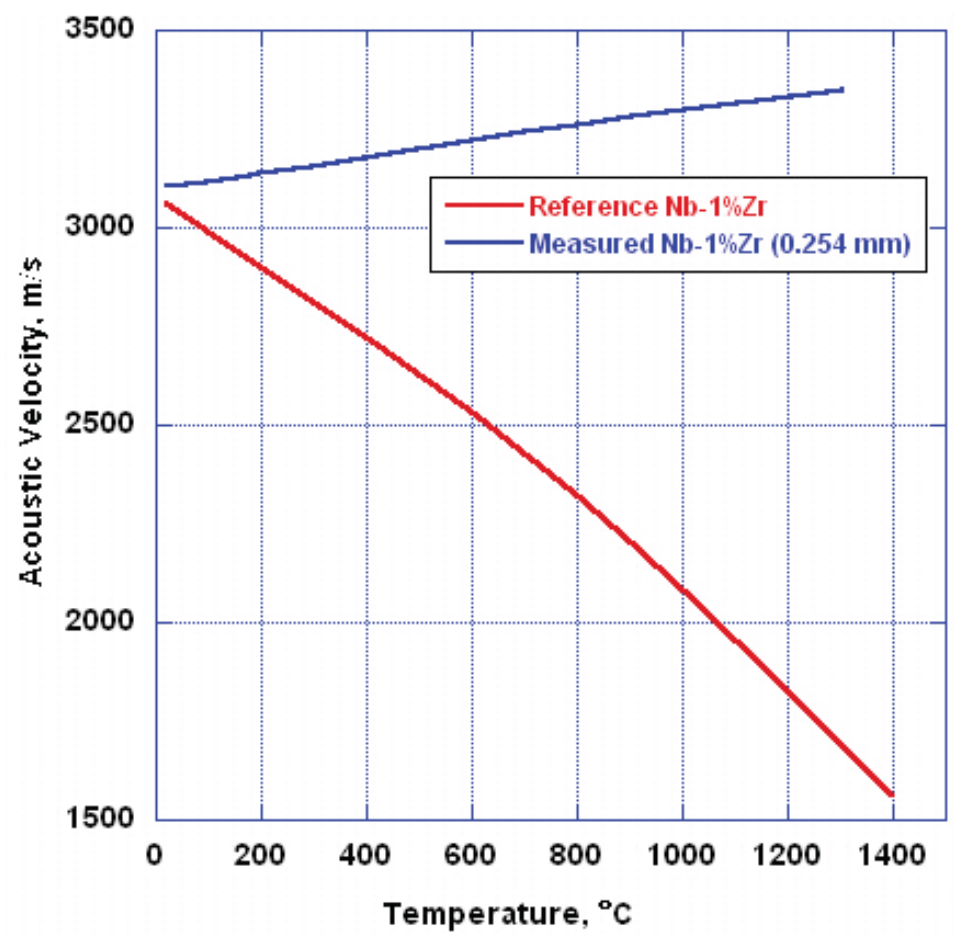

Figure 14. Comparison of measured acoustic velocity of $\mathrm{Nb}-1 \% \mathrm{Zr}$ to calculated reference values.

Difficulties in fabricating the niobium alloy sample may partially explain this discrepancy. For example, welding the niobium to the magnetostrictive stub with a laser welder was observed to significantly embrittle the wire. To overcome this, a small amount of nickel wire was melted onto the weld in order to strengthen the joint, causing a slight bulge. The embrittlement also made the "dilation" type reflector problematic and led to the use of a double bend in the wire as a reflector. Ringing in the magnetostrictive stub, due to the diameter increase, was observed to cause the acoustic pulse to spread. The double bend reflector, as it was not a sharp acoustic discontinuity, could have also increased measurement uncertainties. This "spread out" nature of the signals can be seen in Figure 15, which shows two reflection signals used to calculate acoustic velocity. Although the non-ideal signals could lead to increased error in the calculation of acoustic velocity, a comparison of signals recorded at different temperatures appears to verify the increase in velocity. Lines of equal slope were used to connect an easily identifiable feature common to both reflections starting at $20^{\circ} \mathrm{C}$. The line perfectly connects this feature in the leading reflection (at around $5 \times 10^{-4} \mathrm{~s}$ ). However a slight adjustment to the slope was required to fit the trailing reflection. This indicates a reduction in delay time with increasing temperature and, therefore, an increase in acoustic velocity. At this time, the increase in acoustic velocity is judged to be most likely due to the alloying of the base niobium with zirconium. This could cause a change in the relative effect of elastic modulus, compared to density, on the acoustic velocity by causing the sample to retain stiffness at elevated temperatures. 


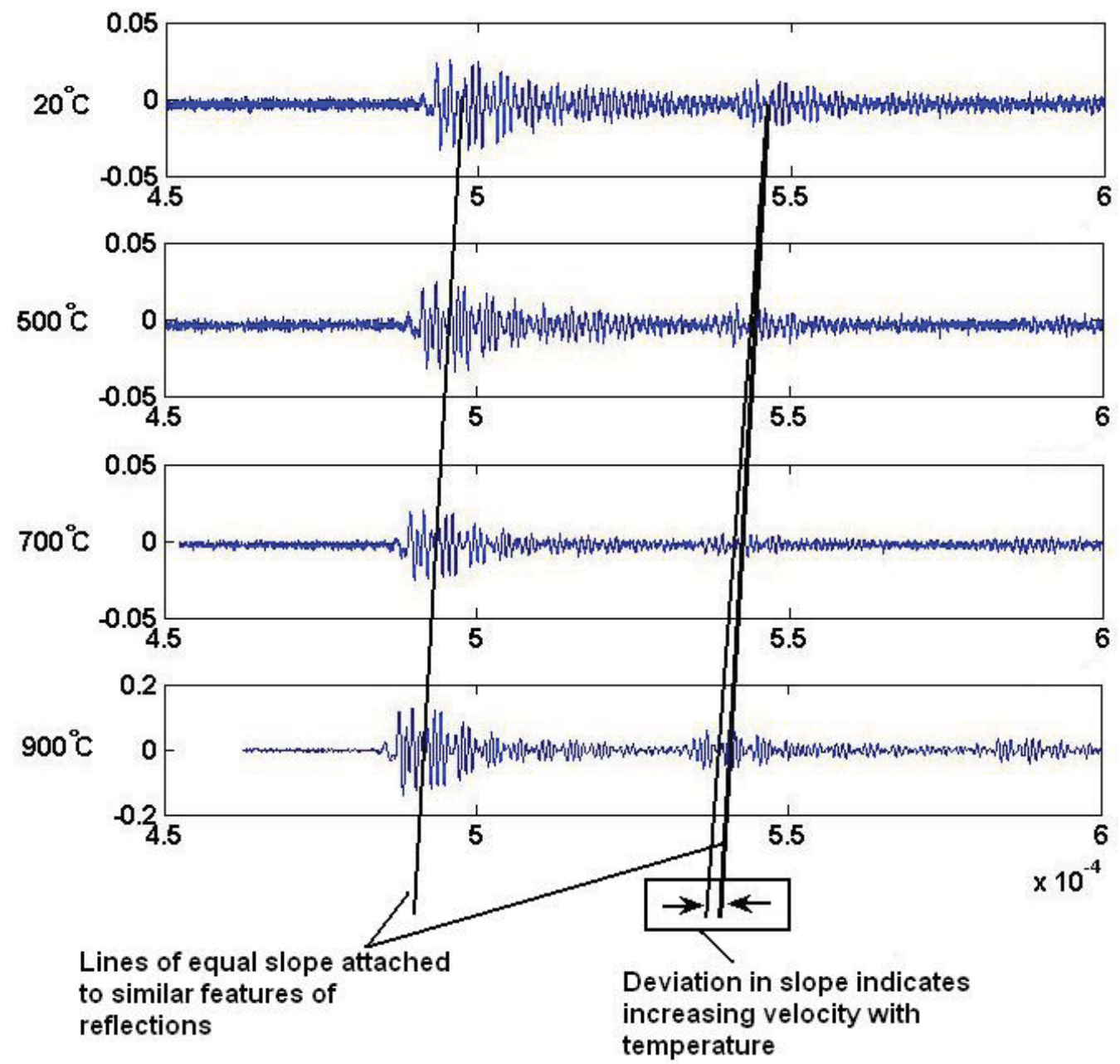

Figure 15. Time series data for $\mathrm{Nb}-1 \% \mathrm{Zr}$ sample showing increase in acoustic velocity with temperature.

\section{Recommendations}

Results from the acoustic velocity characterization test indicate that molybdenum and stainless steel are ideal candidates for the two temperature ranges considered in the current evaluations. Inconel 606 is also a good candidate, but does not offer any significant advantages over stainless steel. Due to difficulty in manufacturing the samples as well as poor temperature response, niobium-1\% zirconium is not a good candidate.

In summary, temperature-dependent signal response evaluations indicate that stainless steel is the preferred probe for temperature measurements below $1000{ }^{\circ} \mathrm{C}$ and doped molybdenum is the preferred probe material for higher temperatures. The upper limit for the use of doped molybdenum will be established in FY13 by performing tests in a higher temperature vacuum furnace at the High Temperature Test Laboratory (HTTL).

\subsubsection{Transducer Development}

The accuracy of an ultrasonic system is partially dependent on the operating frequency of the transducer. Higher frequencies allow resolution of smaller physical features (such as reflectors) as well as signal features (such as zero crossings). The frequency of a magnetostrictive transducer is primarily a function of the 
transducer (i.e. coil or rod) length, with the transducer length equating to one half of its acoustic wavelength. Increasing frequency necessarily requires decreasing length. However, decreasing transducer length also decreases signal strength. To overcome this, a new coil type was developed which utilizes a multi-segment design. This new coil design consists of several short coils wound from a single wire on a common bobbin. The coils are wound such that the spacing between coils is equal to the length of each coil segment. When the coil is energized, constructive interference of waves generated by each segment causes significant increase in signal strength compared to a single, short coil.

Magnetostrictive transducers require a biasing magnetic field to pre-align the magnetic moments within the magnetostrictive material. Without a biasing field, the signal does not have sufficient amplitude for detection. Typically, biasing is accomplished by placing a permanent magnet parallel to the driving coil and magnetostrictive rod. Asymmetric magnet placement can cause unwanted wave modes, primarily flexural waves. These wave modes travel at different velocities and may interfere with the waves being used for measurements, obscuring the desired information. To eliminate this effect, ring magnets were used, placed on each end of the coil. This results in a more uniform magnetic field, as well as reducing the overall transducer diameter.

A complete magnetostrictive transducer incorporating all current design enhancements is shown in Figure 16. Candidate materials for various components are also shown in this figure. During the next year, evaluations will be conducted to finalize the selection of component materials.

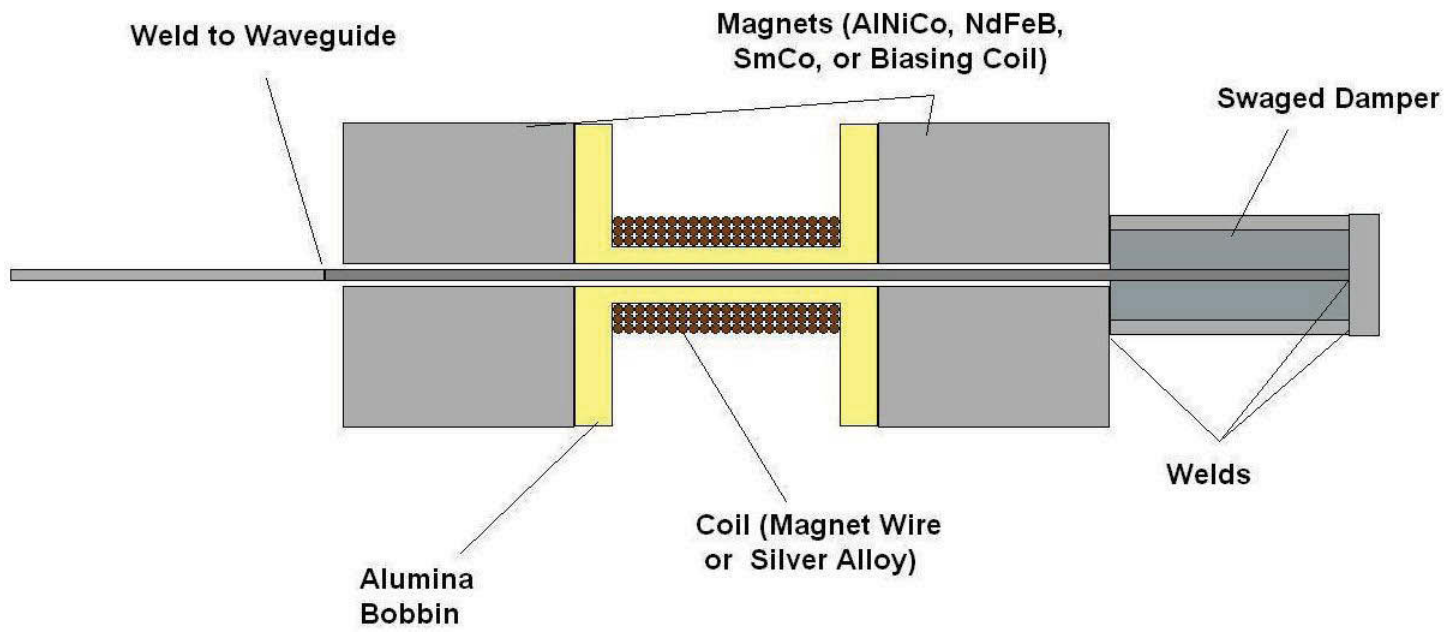

Figure 16. Current multi-segment driving coil design with ring magnets and swaged damper.

\subsubsection{Signal Processing}

A signal processing method described by Roberts, et al., ${ }^{18}$ was implemented in the acoustic velocity characterization test. This method consists of cross-correlating the time series data to a known signal (typically either the input signal or the expected reflection), then squaring and low pass filtering the correlated data. This method greatly increases the signal-to-noise ratio and simplifies identification of reflections, even in the presence of significant noise. This makes the technique especially useful when reflected wavelets are noisy and when reflection shape varies between test specimens. The input signal used in this test was a simple square pulse, and could not be used in the cross-correlation. The reflection signals were observed to vary from sample to sample, due to differences in material, reflector geometry, quality of welds between samples and the magnetostrictive wire used to generate signals, etc. Therefore, a computer program (using 
commercially available mathematics software) was developed that allows the graphical selection of a feature, ideally a relatively clear reflection, of the recorded data to use for cross-correlation. Conditioning of the data is then done automatically. Maxima of the filtered data can then be graphically selected, and the velocity is calculated from the delay time between these maxima. The correlation and filtering process cause a time shift in the signal. However, the acoustic velocity is calculated from the time difference from successive reflections, which does not change. This technique, and the code developed for it, may be easily adapted for temperature measurements, as the delay times used for calculating acoustic velocity are also used in calculation of temperature. A graphical example of the process is shown in Figure 17.
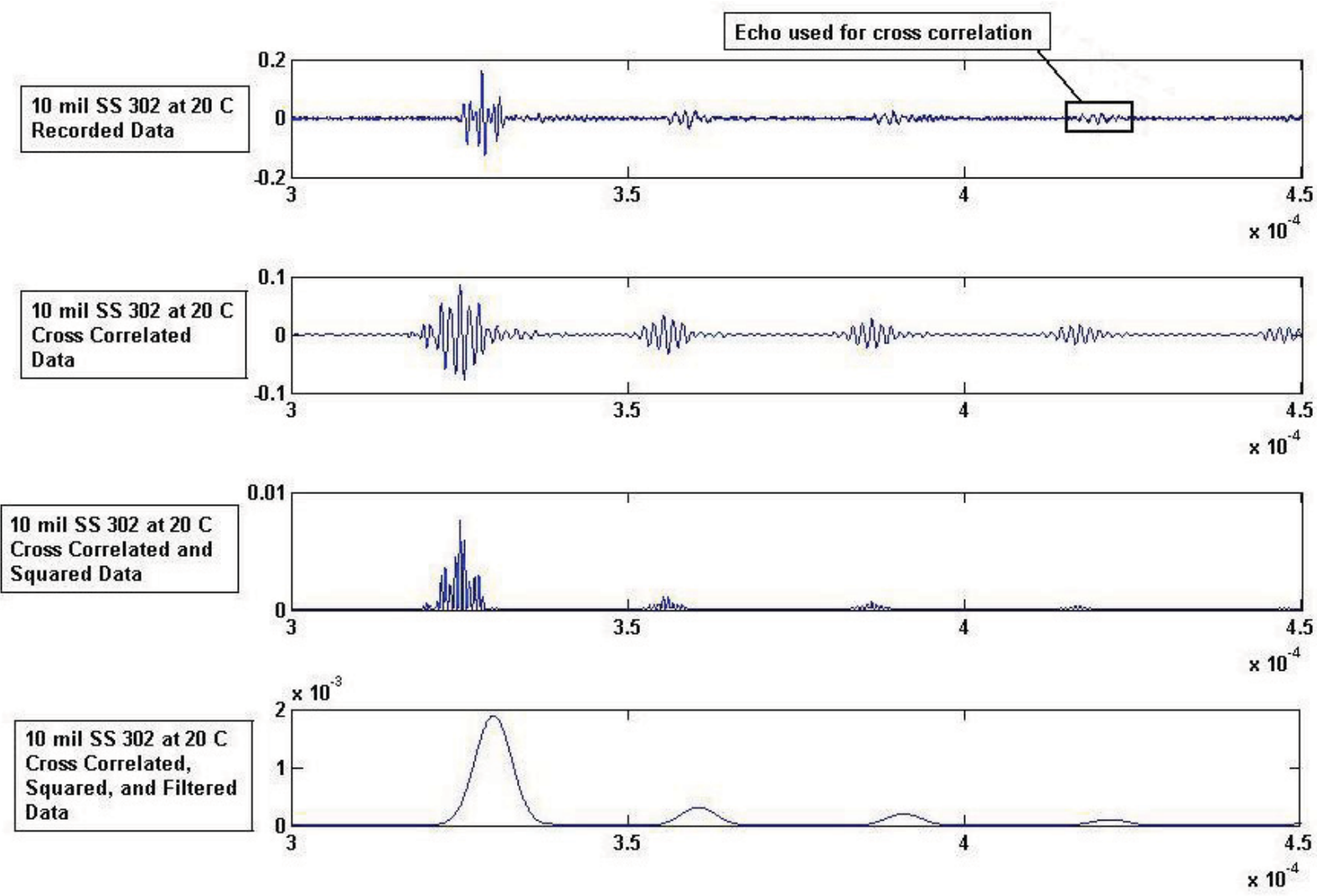

Figure 17. Graphical representation of data analysis process.

\subsubsection{Damping}

Ultrasonic transducers used to generate acoustic waves in a wire waveguide generate these waves in both directions along the wire (both toward and away from the sensor section of the waveguide). The waves propagating away from the sensor strike the free end of the waveguide and are reflected back toward the transducer, where they may interfere with the signals being used for measurement. In order to eliminate this problem, the free end of an ultrasonic transducer is damped. This is typically accomplished (in the case of piezoelectric transducers) by compressing a highly attenuative material against the free side of the transducer crystal. This is not an option with a small wire waveguide, as the area of the wire end is too small. A different damping method was developed that allows complete damping of the back end echo when used with a small waveguide (i.e., 0.010 inch diameter). This method becomes significantly less effective as waveguide diameter increases. For use with a thin wire waveguide, a short section of metallic tubing is filled with an attenuative material and swaged onto the free end of the waveguide, compressing the damping material, as shown in Figure 18. 


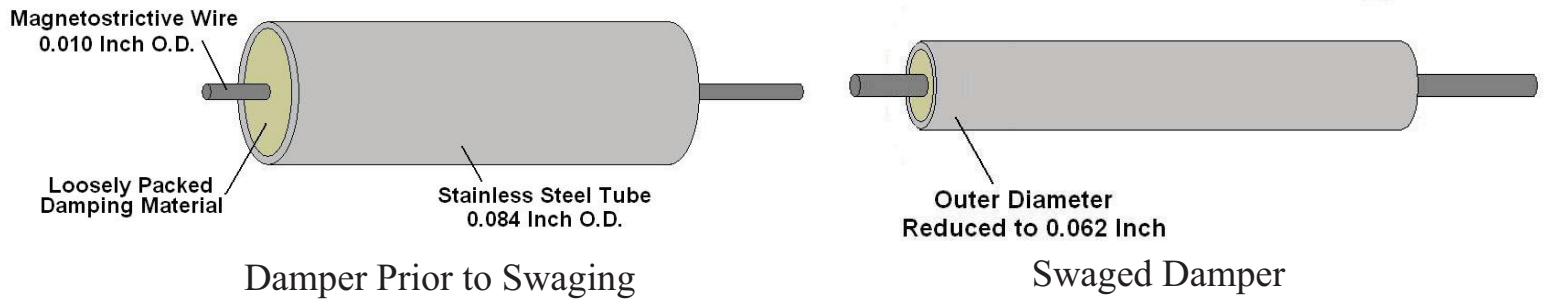

Figure 18. Description of swaged damper.

For in-pile testing with a stainless steel or Remendur waveguide, most damping materials (i.e. polymers and greases/gels) are not usable. Therefore, crushable oxides and stainless steel wool were selected as potential damping materials. It was determined that the signal improvement yielded by a swaged damper is primarily dependent on two properties; the acoustic impedance mismatch between the damping material and the waveguide, and the compression of the damper. For a $26 \%$ reduction in damper diameter ( 3 inch damper length), complete back-end echo attenuation was observed for dampers constructed with stainless steel wool or magnesium oxide powder.

\subsubsection{Plans for FY13}

Future work will include testing of molybdenum samples at higher temperatures (up to $2600{ }^{\circ} \mathrm{C}$ ) and development of a method to eliminate sticking. Further development of signal processing capabilities will also be required to overcome the problem of overlapping reflections. Finally a prototype system will be developed and tested to evaluate the potential accuracy and resolution possible with a UT system.

\subsection{Task 2: Fuel Geometry/Morphology}

During FY12, work under this task focused on laboratory development and evaluation of an approach using ultrasonic techniques for the in-pile detection of elongation due to creep. Although this work was funded through an INL LDRD, it is reported here because the FCRD program has interest in and will benefit from the availability of ultrasonic sensors for irradiation testing in US MTRs. To avoid duplication of sensor design, development, and evaluation, these efforts are monitored within the FCRD program. Such monitoring helps ensure that the sensors required by the FCRD program are ultimately developed.

The approach evaluated here was based on an initial concept for ATR irradiation testing as depicted in Figure 19. As indicated, the creep specimen consists of an arbitrary gauge length, which can be tensile loaded through a butt-end shoulder on one end and an acoustic horn with an integral butt-end shoulder on the other end. The creep specimen is connected to a very long $(\sim 9 \mathrm{~m})$ stainless steel waveguide, which allows specimen positioning in the core with transducer positioning outside the reactor vessel. A brass coupling is used to complete a connection between stainless steel and Remendur waveguides. Finally, a magnetostrictive transducer is placed on the end of the Remendur waveguide to send and receive ultrasonic pulses to and from the creep specimen. Those ultrasonic pulses rely on the magnetostrictive properties of the Remendur waveguide. Changes in the time of flight (TOF) for acoustic reflections associated with the specimen can then be used to infer changes in the gauge length.

A number of issues arose during laboratory evaluations of this initial approach for in-pile detection of elongation. Efforts during FY12 accordingly centered on the resolution of identified issues and refinement of the concept as described below. 


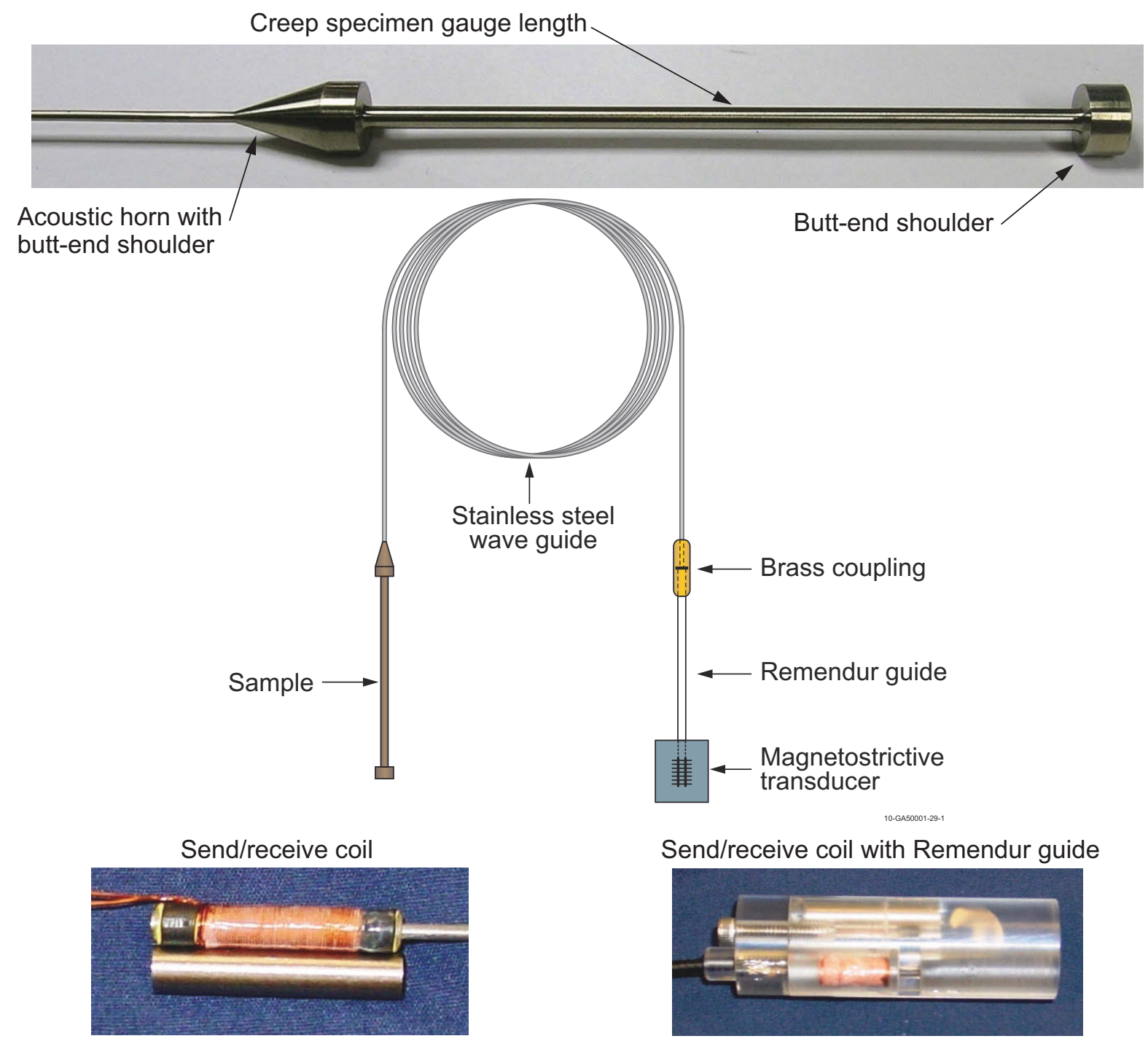

Figure 19. Initial ultrasonic approach for in-pile detection of elongation due to creep.

\subsubsection{Concept Evaluation and Refinement}

Although it was demonstrated that acoustic signals can be transmitted through the very long ( $\sim 9 \mathrm{~m})$ stainless steel waveguide under carefully controlled laboratory conditions, a number of potential problems were identified that raised concerns about use of this waveguide in any MTR irradiation test. Specifically, unwanted acoustic reflections can occur due to inadvertent contact with surrounding structures along the waveguide length, attenuation of the signal as a function of waveguide length is unavoidable, and the task of routing the waveguide from the core to a point outside the vessel without interference with other reactor components and test train structures would be difficult. Laboratory testing confirmed that unwanted acoustic reflections can completely mask the reflections that are needed to determine specimen elongation. In addition to acoustic reflections associated with inadvertent contact, generation of unwanted reflections by small bends, nicks, and other minor imperfections in the waveguide was also observed. For those reasons, it is clear that minimizing the stainless steel waveguide length is a very important design consideration for irradiation testing in MTRs. 
Based on the foregoing, laboratory testing was conducted with stainless steel waveguides $\sim 1 \mathrm{~m}$ long, or less. This length is sufficient to allow positioning of the creep specimen inside the ATR core and positioning of the magnetostrictive transducer above the core. At this time, planning for an ex-core position of the transducer (where the radiation dose is substantially lower than in-core positions) is appropriate given the current uncertainty with respect to the irradiation resistance of magnetostrictive transducers. Further reductions in the stainless steel waveguide length may be possible depending on results from an upcoming ATR NSUF irradiation test of magnetostrictive and piezoelectric transducers (see Section 3.5). Until results from this irradiation test are available, laboratory testing was completed using stainless steel waveguides limited to $1 \mathrm{~m}$ in length in the fixture shown in Figure 20. (Note that a 0.062 in OD stainless steel rod was used as both the specimen and the waveguide in this figure.)

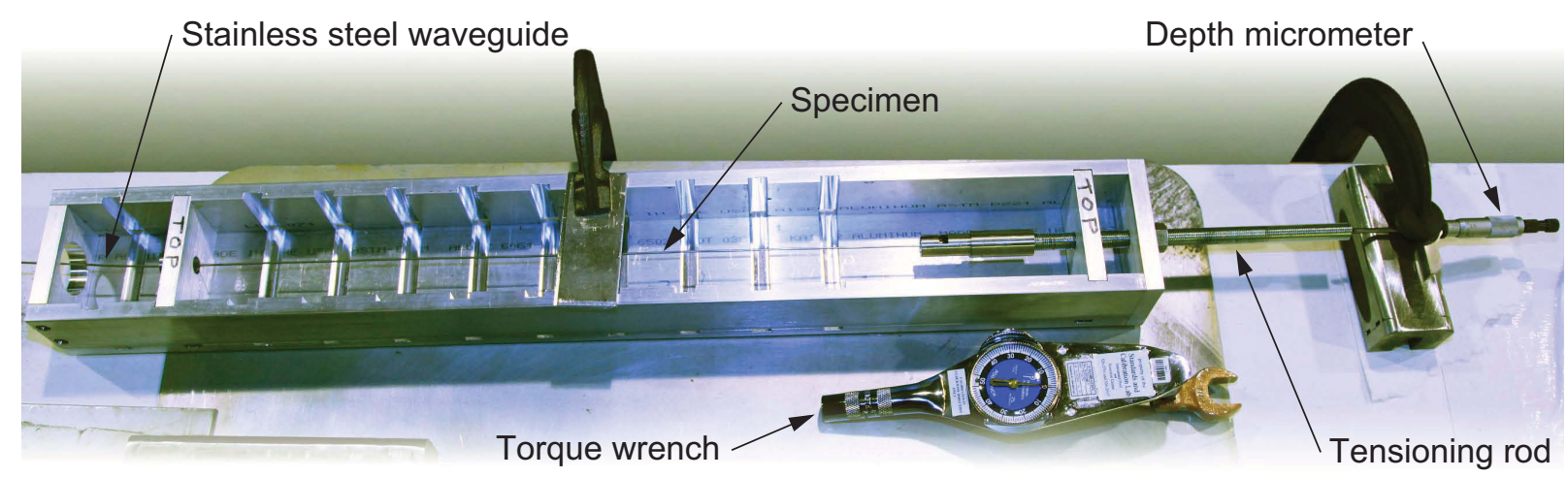

Figure 20. Benchtop fixture for laboratory testing of elongation detection using ultrasonic techniques.

As previously indicated, unwanted acoustic reflections can mask the reflections that are needed to complete ultrasonic evaluations. Reflections from the brass coupling, which are unavoidable given the mass added by the brass, certainly fall into the unwanted category. A number of direct stainless steel to Remendur joining techniques were therefore investigated in an effort to eliminate the coupling. Success was achieved using a tungsten inert gas butt welding process. The resulting joint was found to be durable and very close to ultrasonically transparent, which eliminated the need for use of the brass coupling.

Laboratory evaluations consistently indicated that multiple reflections are generated in the acoustic horn. As shown in Figure 21, those reflections make it difficult, if not impossible, to accurately determine TOF in the gauge length. This difficulty arises from the fact that there is no accurate way to identify any characteristic point within reflected waves (i.e., characteristic points such as peak values, zero crossings, or even the onset of refections cannot be identified without considerable uncertainty). Note that TOF uncertainties make it impossible to measure elongation accurately. Those results indicated the need to replace the horn.

Buttons were found to be an improvement over the acoustic horn. The buttons were similar to conventional butt-end shoulders used in tensile testing (see Figure 19), except the buttons were designed to slide onto the specimen instead of being a machined part of the specimen. Set screws were used to attach the first button to the specimen as indicated in Figure 22. Set screws were the first option tested to minimize reflections associated with the button by minimizing specimen-to-button contact (thereby minimizing the transfer of acoustic energy from the specimen to the button). However, this approach did not work because the set screws did not hold under tensile loading. 


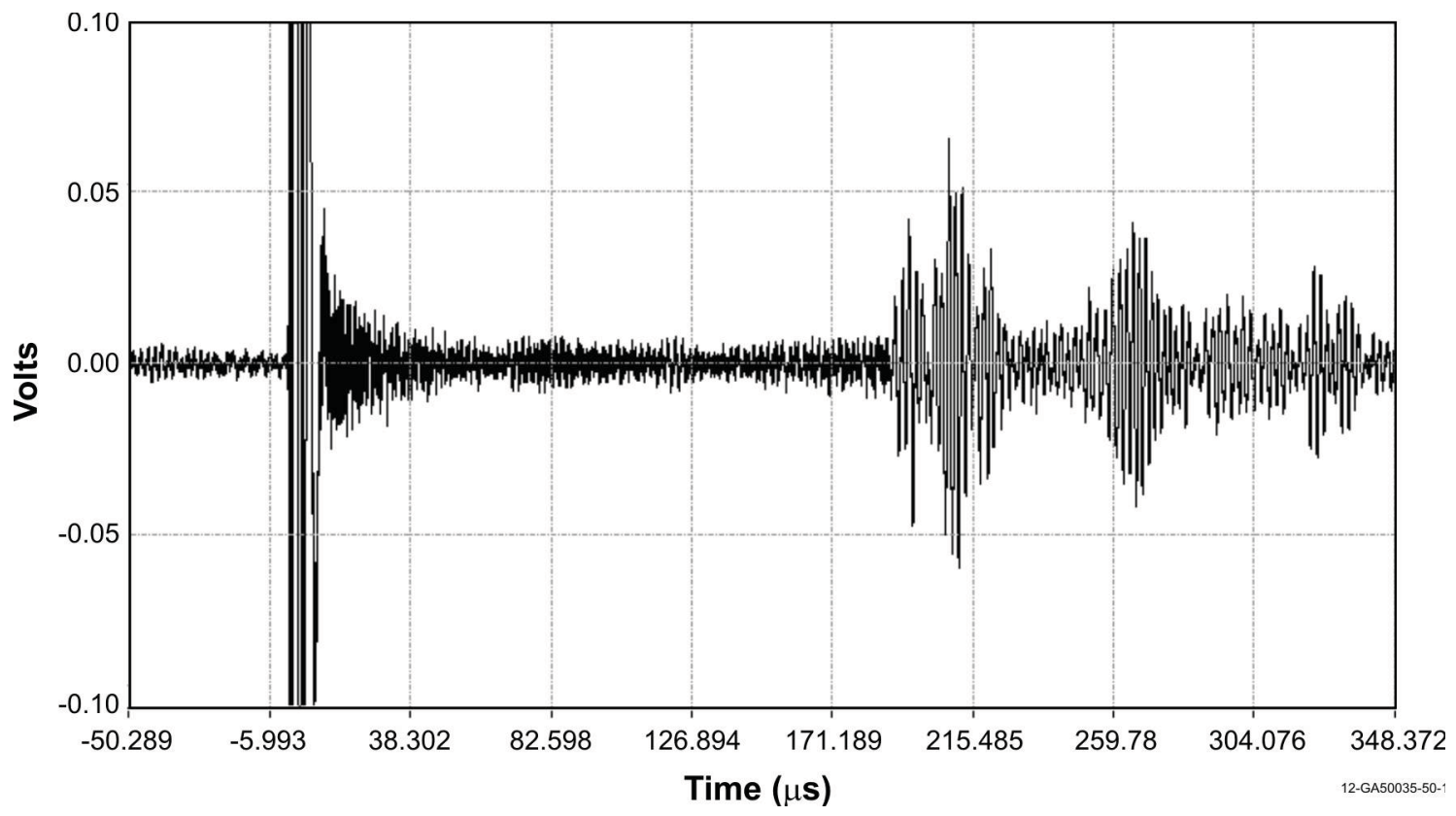

Figure 21. Typical pulse/echo results using the acoustic horn.
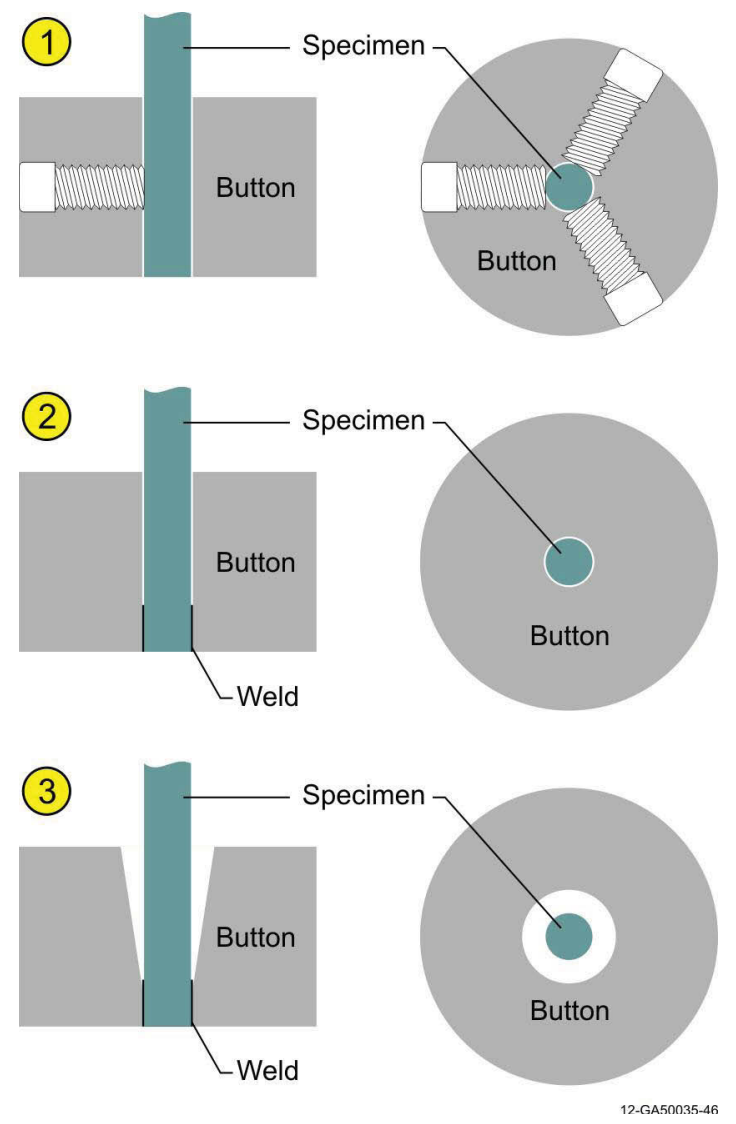

Figure 22. The evolution of buttons used to apply a tensile load to the ultrasonic creep specimen. 
The second attempt to use buttons in place of the acoustic horn involved use of a circumferential line weld to attach the button to the specimen. This line weld, completed with a laser welder, was also an attempt to minimize specimen-to-button contact. The weld held the tensile load and was quite effective at eliminating unwanted reflections as indicated in Figure 23.

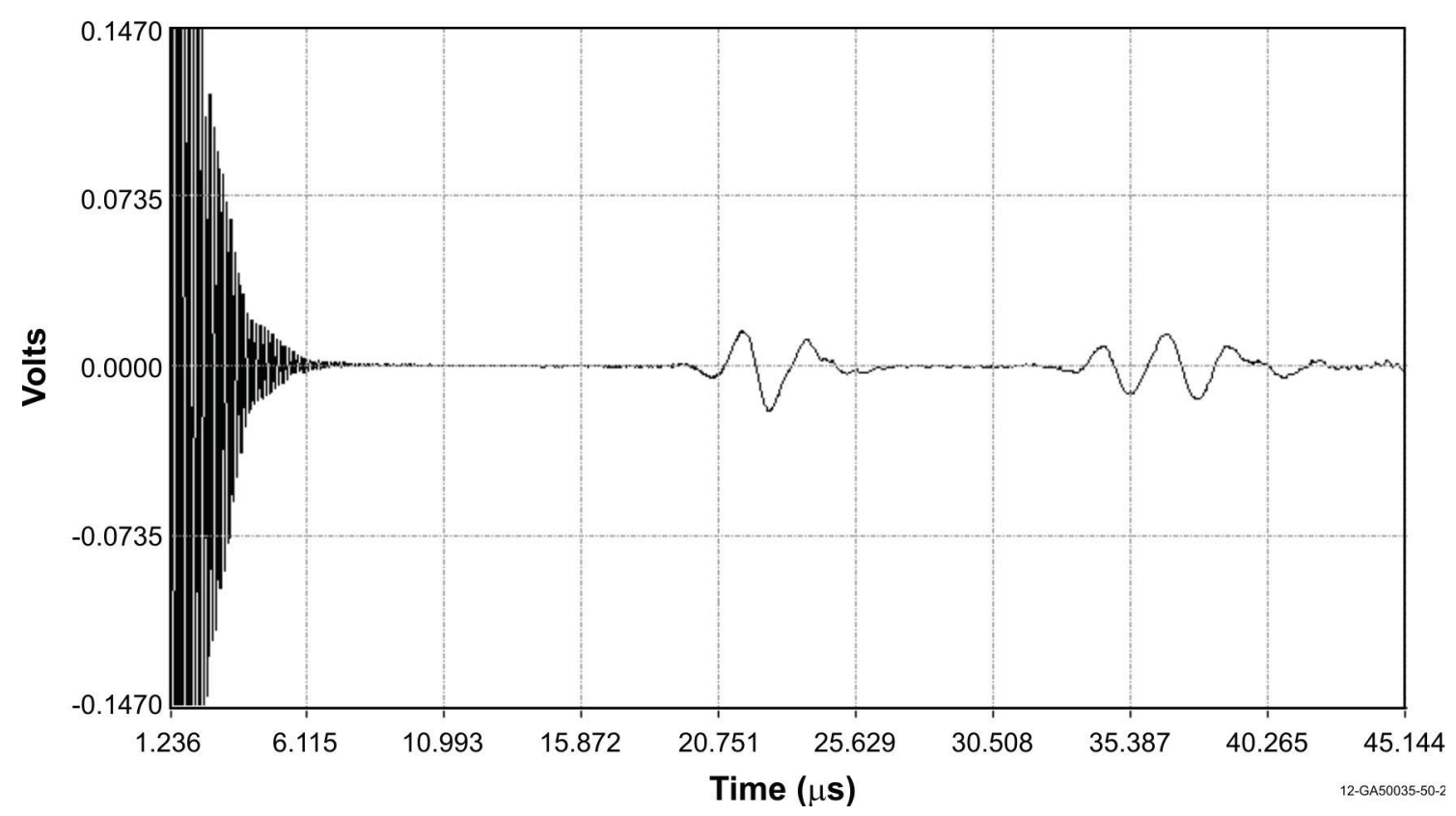

Figure 23. Typical pitch/catch results without use of the acoustic horn.

Although results shown in Figure 23 were remarkably clear compared to results shown in Figure 21, laboratory testing indicated problems with reflections in selected tests with the welded buttons. From those results, it appeared that specimen-to-button contact (other than along the circumferential line weld) could develop under tensile loading with only very minor misalignment of the specimen-to-button joint. On that basis, a conical recess was machined into buttons on the third attempt to replace the acoustic horn (see Figure 22). This button design proved to be a very good replacement for the horn because it did not promote unwanted acoustic reflections, it was strong enough to impart the desired tensile load, and it can be attached without rigorous measures to ensure perfect specimen-to-button alignment.

Efforts also were made to improve and optimize the design of the magnetostrictive transducer. Although the initial concept relied on a single transducer for sending and receiving ultrasonic pulses, the use of separate transducers for sending and receiving was evaluated. The motivation for these efforts stem from the fact that sending and receiving ultrasonic pulses tends to have conflicting requirements. Specifically, a low impedance transducer is desirable when sending an ultrasonic pulse while a high impedance transducer is desirable when receiving an ultrasonic pulse. A low impedance transducer, typically constructed using a relatively large diameter wire to form a coil with a relatively small number of turns, allows relatively high current flow (for a given voltage). High current flow is needed to generate a large magnetic field, which, in turn, produces a large magnetostrictive effect in the Remendur resulting in transmission of a strong acoustic pulse into the waveguide. On the other hand, a high impedance transducer, typically constructed using a relatively small diameter wire to form a coil with a relatively large number of turns, is best for transforming a magnetic field (associated with reflection of an acoustic pulse) into a relatively high voltage output signal. 
Figure 23 provides further motivation for the development and evaluation of separate send/receive transducers. Results shown in this figure (compared to Figure 21) indicate that significant reductions in unwanted reflections (i.e., noise) may be achieved using a pitch/catch mode (which requires separate send/ receive transducers) as opposed to a pulse/echo mode (which relies on a single transducer for sending/ receiving ultrasonic pulses). However, in a conventional pitch/catch configuration, the sending transducer and the receiving transducer are normally separated by the specimen being evaluated. In the case of ATR irradiation testing, that would mean that one of the transducers would normally be positioned in-core near the end of the specimen gauge length. As previously discussed, however, the irradiation resistance of magnetostrictive transducers remains unknown until completion of an ATR NSUF test program. This prompted a further refinement of the test concept, which places send and receive transducers next to each other in an ex-core position. The receiving transducer thereby detects acoustic reflections (from the buttons used to impart the specimen tensile load) instead of detecting acoustic transmission (through those buttons). The fact that reflections are detected improves resolution and accuracy (compared to conventional pitch/catch arrangements) because TOF is effectively doubled.

Laboratory evaluations also indicated that coil length can negatively extend the pulse width. Wider pulses (and corresponding increases in the reflected pulses) tends to reduce the accuracy of TOF measurements from point to point. For that reason, efforts were made to produce transducers with the shortest length physically possible. Send and receive coils consistent with that objective are shown in Figure 24 .

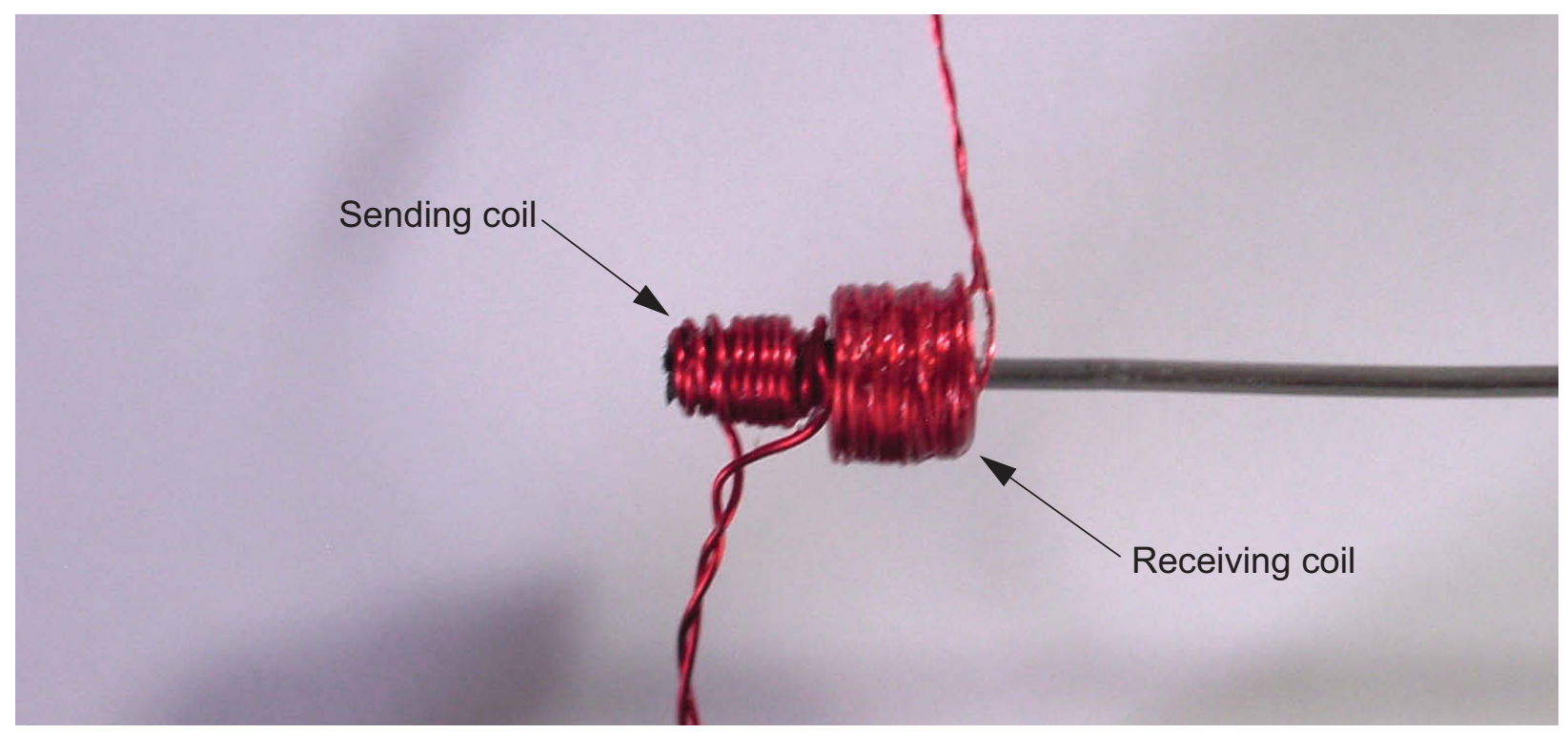

Figure 24. Coils developed and evaluated for use in sending and receiving transducers.

Finally, efforts were made to minimize acoustic reflections from the end of the Remendur. This was necessary because these reflections interfere with the waveforms needed to correctly interpret specimen response (like all other unwanted reflections). Although a wide variety of different damping mechanisms may conceivably work, a very simple approach was adopted for use during laboratory evaluations. Specifically, a long length of Remendur wire was welded to the stainless steel waveguide. The Remendur length was sufficient to ensure that acoustic reflections from the end of the Remendur will not arrive at the transducers until a time well past arrival of specimen acoustic reflections. In other words, TOF associated with the long Remendur wire eliminates interference by separating the Remendur reflections from the specimen reflections of interest. While this approach was perfectly acceptable for laboratory evaluations, a more compact solution may be preferable for irradiation testing in MTRs. 


\subsubsection{Future Work}

Significant progress was made with LDRD funding to examine the viability of using ultrasonic techniques for the in-pile measurement of elongation due to creep. Laboratory evaluations have resulted in enhanced designs for components that could be used for these in-pile measurements. However, several activities are still required to enable the in-pile use of ultrasonic techniques for the detection of elongation. Those activities include development of a pressure and water resistant case for magnetostrictive transducers, laboratory temperature/pressure testing of magnetostrictive transducers, monitoring results from the ATR NSUF irradiation testing of magnetostrictive and piezoelectric transducers, further elimination of acoustic reflections (including development of a more compact solution for handling Remendur reflections), and finalization of a creep test rig design.

\subsection{Task 3: Fission Gas Characteristics}

Work was not yet initiated in this area.

\subsection{Task 4: Cross-Cutting Research and Development (R\&D)}

As noted in Section 3.1, several activities in this area support more than one type of ultrasonics transducer. The NEET Advanced Sensor Initiative Project has funded the Ultrasonics Transducer Irradiation and Software Enhancements project because it will enable the use of ultrasonics-based sensors for irradiation testing. To ensure that NEET in-pile instrumentation research is relevant, sensor enhancements must be able to survive the irradiation conditions of interest to DOE-NE programs. It is also important that the enhancements be able to measure thermal and structural properties and irradiation test parameters with the desired accuracy and resolution required by these DOE-NE programs. This section summarizes information obtained from the various DOE-NE programs that is being used to guide NEET ultrasonic sensor investigations.

The first objective of this project is to evaluate ultrasonic transducer materials suitability for in-pile applications. Building upon recent results from ultrasonic sensor investigations, an in-depth assessment of prior piezoelectric and magnetostrictive transducer irradiations will be used to finalize a list of candidate materials for irradiation evaluation. In addition, researchers will collaborate with ATR NSUF staff to develop the design of an ATR instrumented-lead irradiation test capsule and a test plan for evaluating ultrasonic transducer materials. This test will include an irradiation evaluation of the most promising candidate piezoelectric and magnetostrictive transducer materials. To maximize the benefit of this irradiation test, input is solicited from appropriate individuals from various DOE-NE programs, such as Advanced Reactor Concepts, Light Water Reactor Sustainability, Small Modular Reactors, FCRD, NGNP and ATR NSUF programs. In addition, recent results from piezoelectric irradiation studies in foreign research reactors are considered. This test will be an instrumented lead test, such that real time signals are received from the transducers. Such a test will enable an accurate measure of the performance and possible degradation of candidate transducer materials under irradiation.

The second objective is to enhance software used to support various types of ultrasonic sensors. Researchers are contacting various ultrasonics experts from various DOE-NE programs, to define requirements for software to support various ultrasonic sensors. Ultrasonic instrumentation is a well developed technology widely used in non-nuclear applications; however, several improvements are required for successful implementation in irradiation tests. The harsh testing conditions that ultrasonic sensors will be exposed to 
are likely to reduce signal to noise ratio, complicating identification of signal features. Therefore, a primary goal of this effort will be the development of methods to improve signal to noise ratio. Ultrasonic sensors utilize several different signal characteristics (i.e. delay time, resonant frequency, attenuation, etc.) for monitoring the many parameters previously identified. Enhanced software, specific for in-pile ultrasonics applications will ultimately be developed in this effort that is capable of acquiring and processing signals specific to parameters of interest to DOE-NE programs.

\subsubsection{Irradiation Testing of Candidate Transducer Materials}

This project, which is a collaborative effort between INL, PSU, Argonne National Laboratory, and Pacific Northwest National Laboratory, supports efforts to develop a test capsule design and define irradiation conditions for evaluating most promising candidate piezoelectric and magnetostrictive transducer materials and designs. From the onset of this effort, an instrumented lead test was proposed, such that real time signals are received from the transducers being tested. Collecting real time signals will enable an accurate measure of the performance and possible degradation of candidate transducer and sensor materials under irradiation. In addition, laboratory testing will be completed to verify that transducer materials will survive anticipated thermal conditions and to characterize their pre-irradiation performance.

A preliminary test capsule design, which was developed as part of a collaborative effort led by PSU, is shown in Figure 25. The current design incorporates room for six piezoelectric and three magnetostrictive sample capsules as well as instrumentation for monitoring temperature, fast and thermal flux, and gamma heating. The design will be refined as the project continues.

Preliminary lists of candidate piezoelectric and magnetostrictive materials have been developed and are shown in Tables 5-7. As discussed in this section, materials are ranked based on the limited amount of space available, promising results from previous research, likely radiation tolerance, and Curie temperature. During FY13, the selection of materials that will be included in this test will be finalized.

\subsubsection{Piezoelectric Materials}

\section{Aluminum Nitride (AlN)}

Aluminum nitride is a relatively new material, as far as bulk single crystals are concerned. In fact, the work of Parks \& Tittmann ${ }^{19}$ with this material is the first of its sort. In the past, thin film AlN has been shown to be unaffected by gamma irradiation up to $18.7 \mathrm{MGy}^{20}$ and temperatures of $1000^{\circ} \mathrm{C} .{ }^{21,22}$ Moreover, this material has been explicitly cited in numerous independent studies as a highly radiation tolerant ceramic. ${ }^{23}$

Further, tests of bulk single crystal AlN in a Training, Research, Isotopes, General Atomics (TRIGA) nuclear reactor core showed this material to be completely unaffected by a fast and thermal neutron fluence of $1.85 \times 10^{18} \mathrm{n} / \mathrm{cm}^{2}$ and $5.8 \times 10^{18} \mathrm{n} / \mathrm{cm}^{2}$ respectively and a gamma dose of $26.8 \mathrm{MGy} .{ }^{19}$ This work along with that of Yano ${ }^{24}$ and Ito $^{25}$ have indicated that the ${ }^{14} \mathrm{~N}(\mathrm{n}, \mathrm{p}){ }^{14} \mathrm{C}$ is not of much concern, and AlN is an excellent candidate material.

\section{Bismuth Titanate Niobate (Bi3TiNbO9)}

The literature review has revealed bismuth titanate niobate to be the most promising material tested to date. ${ }^{26}$ However, this material lost roughly $60 \%$ of its one way piezoelectric response at a fast neutron fluence of $10^{20} \mathrm{n} / \mathrm{cm}^{2}$, which may preclude it from being used for longer duration in-pile irradiations. The decrease in the signal response is in agreement with the statements made by Trachenko, ${ }^{23}$ namely that disordered Ti-O-Ti bridges of highly covalent character form in titanates when subjected to ballistic radiation effects. Regardless, given that this material has shown the greatest promise to date, it has been selected as a baseline in the proposed research. 

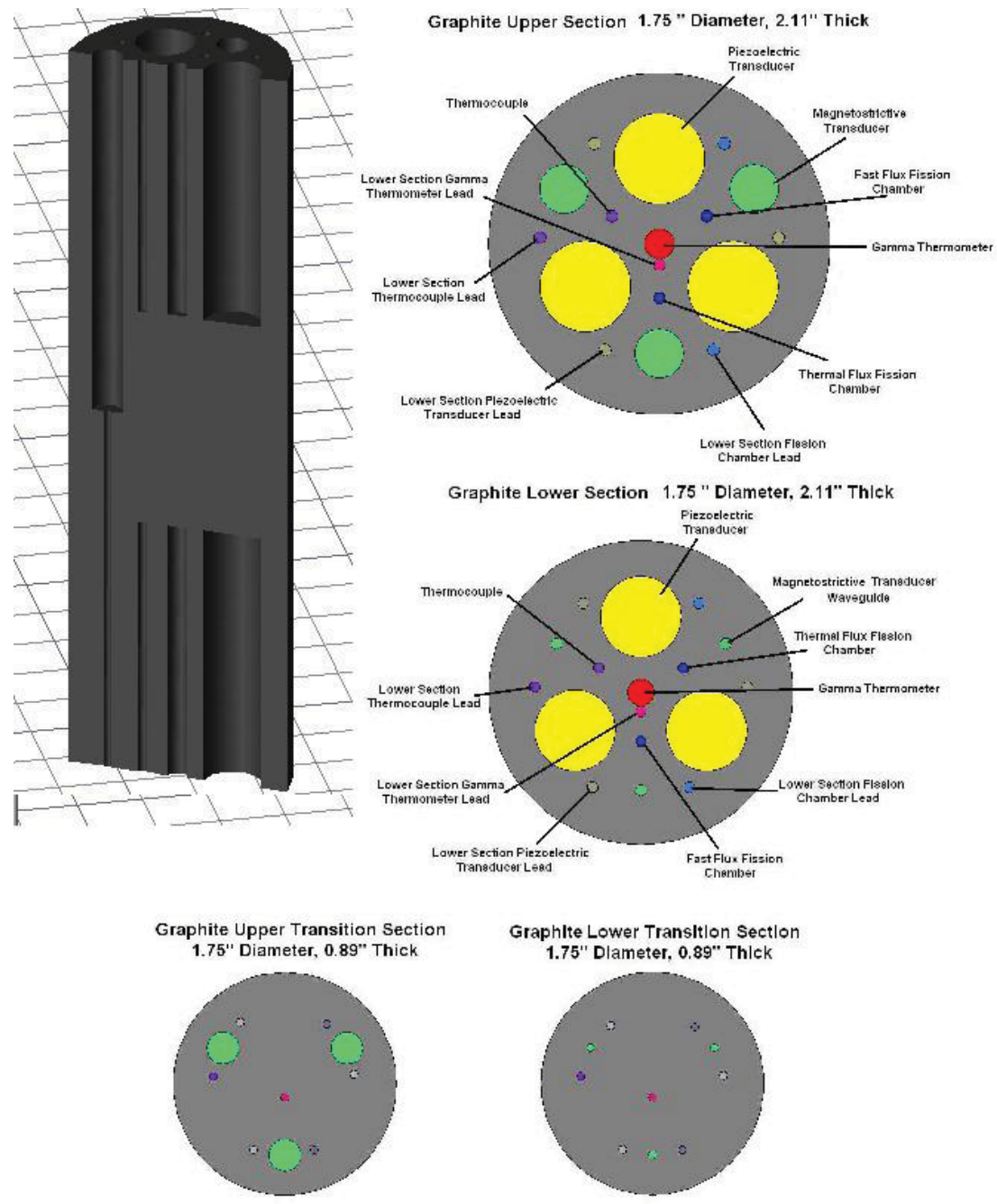

Figure 25. Preliminary test capsule graphite sample holder design with sample and instrumentation positions detailed.

Table 5. Candidate piezoelectric materials.

\begin{tabular}{|c|c|c|c|c|c|}
\hline Material & Composition & Dimensions & Key Properties & Comments & $\begin{array}{c}\text { Initial Rank (1: Most } \\
\text { Desirable, 3: Least } \\
\text { Desirable) }\end{array}$ \\
\hline $\begin{array}{c}\text { Lead Zirconate } \\
\text { Titanate (PZT) }\end{array}$ & $\mathrm{Pb}\left(\mathrm{Zr}_{\mathrm{x}} \mathrm{Ti}_{1-\mathrm{x}}\right) \mathrm{O} 3$ & Unknown & $\begin{array}{c}\text { Max. Operating } \\
\text { Temperature: } 330{ }^{\circ} \mathrm{C}, \\
\text { Coupling Coefficient: } 0.7\end{array}$ & $\begin{array}{c}\text { Most widely used out } \\
\text { of pile. Excellent } \\
\text { baseline comparator. }\end{array}$ & 3 \\
\hline Bismuth Titanate & $\mathrm{Bi}_{3} \mathrm{TiNbO}_{9}$, etc. & Unknown & $\begin{array}{c}\text { Max. Operating } \\
\text { Temperature: } 550-909 \\
\mathrm{C}, \text { Coupling Coefficient: } \\
0.0 .12-0.15\end{array}$ & $\begin{array}{c}\text { Thought to be radiation } \\
\text { tolerant. Most } \\
\text { promising previously } \\
\text { tested candidate. Good } \\
\text { baseline comparator. }\end{array}$ & 1 \\
\hline Lithium Niobate & $\mathrm{LiNbO}_{4}$ & Unknown & $\begin{array}{c}\text { Max. Operating } \\
\text { Temperature: } 700-1000 \\
\mathrm{C}, \text { Coupling Coefficient: } \\
0.46\end{array}$ & $\begin{array}{c}\text { High coupling factor. } \\
\text { High temperature } \\
\text { capability. Lithium } \\
\text { presence problematic. }\end{array}$ & 2 \\
\hline
\end{tabular}


Table 5. Candidate piezoelectric materials. (continued)

\begin{tabular}{|c|c|c|c|c|c|}
\hline Material & Composition & Dimensions & Key Properties & Comments & $\begin{array}{c}\text { Initial Rank (1: Most } \\
\text { Desirable, 3: Least } \\
\text { Desirable) }\end{array}$ \\
\hline Aluminum Nitride & AlN & Unknown & $\begin{array}{c}\text { Max. Operating } \\
\text { Temperature: } 1100^{\circ} \mathrm{C} \text {, } \\
\text { Coupling Coefficient: } \\
0.20\end{array}$ & $\begin{array}{l}\text { Thought to be highly } \\
\text { radiation tolerant. Very } \\
\text { high temperature } \\
\text { capability. }\end{array}$ & 1 \\
\hline $\begin{array}{c}\text { Rare Earth } \\
\text { Oxy-Borates }\end{array}$ & $\mathrm{RECa}_{4}\left(\mathrm{BO}_{3}\right)_{3}$ & Unknown & $\begin{array}{c}\text { Max. Operating } \\
\text { Temperature: } 750{ }^{\circ} \mathrm{C}, \\
\text { Coupling Coefficient: } \\
0.06-0.31\end{array}$ & $\begin{array}{l}\text { Boron presence } \\
\text { problematic. }\end{array}$ & 3 \\
\hline Zinc Oxide & $\mathrm{ZnO}$ & Unknown & -- & $\begin{array}{l}\text { Thought to be highly } \\
\text { radiation tolerant. }\end{array}$ & 1 \\
\hline Gallium Phosphate & $\mathrm{GaPO}_{4}$ & Unknown & $\begin{array}{c}\text { Max. Operating } \\
\text { Temperature: } 475^{\circ} \mathrm{C}, \\
\text { Coupling Coefficient: } \\
0.16\end{array}$ & $\begin{array}{l}\text { Not thought to be } \\
\text { radiation tolerant. } \\
\text { Amorphization at room } \\
\text { temperature observed. }\end{array}$ & 3 \\
\hline Langasite & $\mathrm{La}_{2} \mathrm{Ga}_{5} \mathrm{SiO}_{14}$ & Unknown & $\begin{array}{c}\text { Max. Operating } \\
\text { Temperature: } 735^{\circ} \mathrm{C}, \\
\text { Coupling Coefficient: }{ }^{\mathrm{a}}\end{array}$ & $\begin{array}{l}\text { Not thought to be } \\
\text { radiation tolerant. }\end{array}$ & 3 \\
\hline Lead Meta-Niobate & -- & Unknown & $\begin{array}{c}\text { Max. Operating } \\
\text { Temperature: } 200^{\circ} \mathrm{C}, \\
\text { Coupling Coefficient: }{ }^{\mathrm{a}}\end{array}$ & -- & 3 \\
\hline Quartz & $\mathrm{SiO}_{2}$ & Unknown & $\begin{array}{c}\text { Max. Operating } \\
\text { Temperature: } 275^{\circ} \mathrm{C} \text {, } \\
\text { Coupling Coefficient: }{ }^{\mathrm{a}}\end{array}$ & -- & 3 \\
\hline
\end{tabular}

a. To be determined.

Table 6. Candidate magnetostrictive materials.

\begin{tabular}{|c|c|c|c|c|c|}
\hline Material & Composition & Dimensions $\mathrm{s}^{\mathrm{a}, \mathrm{b}}$ & Key Properties & Comments & $\begin{array}{c}\text { Initial Rank } \\
\text { (1: Most } \\
\text { Desirable, } \\
\text { 3: Least } \\
\text { Desirable) }\end{array}$ \\
\hline Nickel & $100 \mathrm{Ni}$ & $\begin{array}{c}0.2 \text { inch diameter } X \\
3 \text { inch }\end{array}$ & $\begin{array}{l}25-50 \mathrm{~m} \text {-strain max. } \\
\text { magnetostriction, curie } \\
\text { temperature } 358^{\circ} \mathrm{C}\end{array}$ & & 2 \\
\hline Iron & $100 \mathrm{Fe}$ & $\begin{array}{c}0.2 \text { inch diameter } \mathrm{X} \\
3 \text { inch }\end{array}$ & $\begin{array}{l}10-20 \mathrm{~m} \text {-strain max. } \\
\text { magnetostriction, curie } \\
\text { temperature } 770^{\circ} \mathrm{C}\end{array}$ & $\begin{array}{c}\text { Pure metal, easy to acquire/ } \\
\text { manufacture, low magnetostriction }\end{array}$ & 3 \\
\hline Cobalt & $100 \mathrm{Co}$ & $\begin{array}{c}0.2 \text { inch diameter } X \\
3 \text { inch }\end{array}$ & $\begin{array}{l}50-60 \mathrm{~m} \text {-strain max. } \\
\text { magnetostriction, curie } \\
\text { temperature } 1130^{\circ} \mathrm{C}\end{array}$ & $\begin{array}{c}\text { Pure metal, easy to acquire/ } \\
\text { manufacture, low magnetostriction }\end{array}$ & 3 \\
\hline Remendur & $49 \mathrm{Fe}-49 \mathrm{Co}-2 \mathrm{Va}$ & $\begin{array}{c}0.2 \text { inch diameter } \mathrm{X} \\
3 \text { inch }\end{array}$ & $\begin{array}{l}70-100 \text { m-strain max. } \\
\text { magnetostriction, curie } \\
\text { temperature } 950^{\circ} \mathrm{C}\end{array}$ & $\begin{array}{c}\text { No longer manufactured, identical/ } \\
\text { similar alloys available, possible } \\
\text { activation of cobalt }\end{array}$ & 1 \\
\hline Vacoflux 17 & $81 \mathrm{Fe}-17 \mathrm{Co}-2 \mathrm{Cr}$ & $\begin{array}{c}0.2 \text { inch diameter } \mathrm{X} \\
3 \text { inch }\end{array}$ & $\begin{array}{l}25 \mathrm{~m} \text {-strain max. } \\
\text { magnetostriction, curie } \\
\text { temperature } 920^{\circ} \mathrm{C}\end{array}$ & Possible activation of cobalt & 3 \\
\hline Vacoflux 48 & $49 \mathrm{Fe}-49 \mathrm{Co}-2 \mathrm{Va}$ & $\begin{array}{c}0.2 \text { inch diameter } \mathrm{X} \\
3 \text { inch }\end{array}$ & $\begin{array}{l}70 \mathrm{~m} \text {-strain max. } \\
\text { magnetostriction, curie } \\
\text { temperature } 950^{\circ} \mathrm{C}\end{array}$ & Possible activation of cobalt & 1 \\
\hline
\end{tabular}


Table 6. Candidate magnetostrictive materials. (continued)

\begin{tabular}{|c|c|c|c|c|c|}
\hline Material & Composition & Dimensions ${ }^{\mathrm{a}, \mathrm{b}}$ & Key Properties & Comments & $\begin{array}{c}\text { Initial Rank } \\
\text { (1: Most } \\
\text { Desirable, } \\
\text { 3: Least } \\
\text { Desirable) }\end{array}$ \\
\hline Vacoflux 50 & $49 \mathrm{Fe}-49 \mathrm{Co}-2 \mathrm{Va}$ & $\begin{array}{c}0.2 \text { inch diameter } X \\
3 \text { inch }\end{array}$ & $\begin{array}{l}70 \mathrm{~m} \text {-strain max. } \\
\text { magnetostriction, curie } \\
\text { temperature } 950{ }^{\circ} \mathrm{C}\end{array}$ & Possible activation of cobalt & 1 \\
\hline Arnakrome 3 & $60 \mathrm{Fe}-30 \mathrm{Cr}-10 \mathrm{Co}$ & $\begin{array}{c}0.2 \text { inch diameter } \mathrm{X} \\
3 \text { inch }\end{array}$ & $\begin{array}{l}10-40 \text { m-strain max. } \\
\text { magnetostriction, curie } \\
\text { temperature } 625^{\circ} \mathrm{C}\end{array}$ & Possible activation of cobalt & 3 \\
\hline Arnakrome 4 & $95 \mathrm{Fe}-5 \mathrm{Cr}$ & $\begin{array}{c}0.2 \text { inch diameter } \mathrm{X} \\
3 \text { inch }\end{array}$ & $\begin{array}{l}10-40 \text { m-strain max. } \\
\text { magnetostriction, curie } \\
\text { temperature } 770^{\circ} \mathrm{C}\end{array}$ & Low magnetostriction & 1 \\
\hline Arnakrome 5 & $92 \mathrm{Fe}-8 \mathrm{Mn}$ & $\begin{array}{c}0.2 \text { inch diameter } X \\
3 \text { inch }\end{array}$ & $\begin{array}{l}10-40 \text { m-strain max. } \\
\text { magnetostriction, curie } \\
\text { temperature } 770{ }^{\circ} \mathrm{C}\end{array}$ & Low magnetostriction & 1 \\
\hline Galfenol & $81 \mathrm{Fe}-19 \mathrm{Ga}$ & $\begin{array}{c}0.2 \text { inch diameter } \mathrm{X} \\
3 \text { inch }\end{array}$ & $\begin{array}{l}100-400 \text { m-strain max. } \\
\text { magnetostriction, curie } \\
\text { temperature } 700{ }^{\circ} \mathrm{C}\end{array}$ & $\begin{array}{l}\text { Relatively new, small amounts of } \\
\text { data, may be difficult to acquire }\end{array}$ & 1 \\
\hline Terfenol-D & $\mathrm{Tb}_{0.3} \mathrm{Dy}_{0.7} \mathrm{Fe}_{1.95}$ & $\begin{array}{c}0.5 \text { inch diameter X } \\
3 \text { inch }^{\mathrm{c}}\end{array}$ & $\begin{array}{l}>1000 \mathrm{~m} \text {-strain max. } \\
\text { magnetostriction, curie } \\
\text { temperature } 360^{\circ} \mathrm{C}\end{array}$ & $\begin{array}{l}\text { Very brittle, strong biasing field/ } \\
\text { prestress required, presence of } \\
\text { terbium and dysprosium }\end{array}$ & 3 \\
\hline
\end{tabular}

a. Transducer size will depend strongly on magnet size, which in turn will depend on temperatures and allowed materials, Alnico magnets assumed.

b. Dimensions assume material can be manufactured to 0.010 inch diameter.

c. Terfenol-D rod from Etrema Inc. Listed as $13 \mathrm{~mm}$ minimum diameter.

Table 7. Candidate magnet materials.

\begin{tabular}{|c|c|c|c|}
\hline Magnet Type & $\begin{array}{c}\text { Chemical } \\
\text { Composition }\end{array}$ & Key Properties & Comments \\
\hline Alnico 5 & $\begin{array}{c}51 \mathrm{Fe}-24 \mathrm{Co}-14 \mathrm{Ni}-8 \mathrm{~A} \\
1-3 \mathrm{Cu}\end{array}$ & $\begin{array}{c}\text { Curie temperature } 860^{\circ} \mathrm{C} \text {, Max. Energy Product } 43.8 \mathrm{~kJ} / \mathrm{m}^{3} \text {, } \\
\text { Residual Induction } 12800 \text { gauss, Coercive force } 640 \\
\text { Oersteds }\end{array}$ & $\begin{array}{l}\text { High curie temperature, low } \\
\text { magnetic strength, demagnetize } \\
\text { over time, unusable due to cobalt }\end{array}$ \\
\hline Alnico 9 & $\begin{array}{c}34 \mathrm{Fe}-35 \mathrm{Co}-15 \mathrm{Ni}-7 \mathrm{~A} \\
1-4 \mathrm{Cu}-5 \mathrm{Ti}\end{array}$ & $\begin{array}{c}\text { Curie temperature } 860^{\circ} \mathrm{C} \text {, Max. Energy Product } 71.6 \mathrm{~kJ} / \mathrm{m}^{3} \text {, } \\
\text { Residual Induction } 10600 \text { gauss, Coercive force } 1500 \\
\text { Oersteds }\end{array}$ & $\begin{array}{l}\text { High curie temperature, low } \\
\text { magnetic strength, demagnetize } \\
\text { over time, unusable due to cobalt }\end{array}$ \\
\hline Nd-B-Fe & $\begin{array}{c}\mathrm{Nd}_{2} \mathrm{X}_{14} \mathrm{~B}, \mathrm{X}=\mathrm{Fe} \text { or } \\
\mathrm{Co}\end{array}$ & $\begin{array}{c}\text { Curie temperature } 310{ }^{\circ} \mathrm{C} \text {, Max. Energy Product } 190-400 \mathrm{~kJ} / \\
\mathrm{m}^{3} \text {, Residual Induction } 10000-14100 \text { gauss, Coercive force } \\
9600-13000 \text { Oersteds }\end{array}$ & $\begin{array}{l}\text { Low curie temperature, very } \\
\text { high magnetic strength, brittle, } \\
\text { presence of neodymium and } \\
\text { boron }\end{array}$ \\
\hline Sm-Co & $\mathrm{SmCo}_{5}$ & $\begin{array}{c}\text { Curie temperature } 750{ }^{\circ} \mathrm{C} \text {, Max. Energy Product } 130-180 \mathrm{~kJ} / \\
\mathrm{m}^{3} \text {, Residual Induction } 8300-11600 \text { gauss, Coercive force } \\
7500-10600 \text { Oersteds }\end{array}$ & $\begin{array}{l}\text { High curie temperature, high } \\
\text { magnetic strength, brittle, } \\
\text { presence of samarium and } \\
\text { cobalt, higher cost }\end{array}$ \\
\hline $\mathrm{Sm}-\mathrm{Co} / \mathrm{Sm}-\mathrm{Fe}$ & $\mathrm{Sm}_{2} \mathrm{X}_{17}, \mathrm{X}=\mathrm{Fe}$ or $\mathrm{Co}$ & $\begin{array}{c}\text { Curie temperature } 825^{\circ} \mathrm{C} \text {, Max. Energy Product } 190-240 \mathrm{~kJ} / \\
\mathrm{m}^{3} \text {, Residual Induction } 10000-11600 \text { gauss, Coercive force } \\
6000-10600 \text { Oersteds }\end{array}$ & $\begin{array}{l}\text { High curie temperature, high } \\
\text { magnetic strength, brittle, } \\
\text { presence of samarium and } \\
\text { cobalt, higher cost }\end{array}$ \\
\hline
\end{tabular}




\section{Zinc Oxide (ZnO)}

Zinc oxide is found in the Wurzite structure, as is $\mathrm{AlN}$, and has been cited as a highly radiation tolerant material. ${ }^{23}$ The evaluated nuclear data files (ENDF) do not show any detrimental nuclear cross sections, and this material possesses a high transition temperature and moderate piezoelectric coupling. If $\mathrm{ZnO}$ can be proven effective as a high temperature piezoelectric transducer, $\mathrm{ZnO}$ should be included in the proposed test.

\subsubsection{Magnetostrictive Materials}

\section{Remendur}

Remendur has the most history of use in nuclear applications of all the magnetostrictive alloys, having been used previously for short duration thermometry applications. ${ }^{27-31}$ Remendur has a high Curie temperature and high magnetostriction. Given this, and its previous use, Remendur is highly recommended for testing, despite the presence of cobalt. Although Remendur is no longer commercially available, several identical alloys are available under different names. INL also has a supply of Remendur which could be used for this test.

\section{Vacoflux $^{\circledR}$ (Vacuumschmelze ${ }^{32}$ )}

Vacoflux 50 is an alloy chemically identical to Remendur, which has been used in European ultrasonic thermometry applications. ${ }^{33}$ It is recommended as a possible alternative to Remendur.

Vacoflux 17 is essentially a reduced cobalt variant of Vacoflux 50. As such, it does still contain cobalt and has significantly reduced magnetostriction. Vacoflux 17 is not recommended, as Vacoflux 50/Remendur is clearly the preferable alternative.

\section{Arnokrome $^{T M}$ (Arnold Magnetics ${ }^{34-36}$ )}

Arnold Magnetics produces several magnetostrictive alloys, Arnokrome 3, Arnokrome 4, and Arnokrome 5. Arnokrome 3 contains cobalt and has much lower magnetostriction than Remendur, and is therefore not of interest in the current study. Arnokrome 4 and 5 have similar magnetostriction to Arnokrome 3, but without the presence of cobalt. Although not as promising as some candidates, it is recommended that either Arnokrome 4 or 5 be included in the irradiation test.

\section{Galfenol $^{37}$}

Galfenol is a relatively new alloy of iron and gallium. Galfenol is a member of the "giant" magnetostrictive alloys and has a very large saturation magnetostriction. It also has an appropriately high Curie temperature. Neither constituent element reacts strongly with neutron radiation. All of these factors appear to make Galfenol the most appealing magnetostrictive material candidate.

\subsubsection{Biasing Magnet Materials}

\section{Alnico}

Alnico magnets are considered primarily because they have a very high Curie temperature. The magnetic field strength is not high, compared to ceramic rare-earth magnets, but is sufficiently high for use as a biasing field source. Alnico magnets do have some history of testing in-pile, being tested to approximately half the target fluence of the current study with little loss of performance. ${ }^{38}$ The low coercive force is a concern as this indicates that the magnets lose strength over time. 


\section{Sm-Co}

Samarium-cobalt magnets have magnetic properties nearly as good as Nd-B-Fe magnets and Curie temperatures nearly as high as Alnico magnets. Although samarium has a high thermal neutron absorption cross section, previous irradiation testing indicates that neutron irradiation has a negligible effect on its magnetic properties. $^{39}$

\subsubsection{Signal Processing Development}

Initial progress on signal processing requirement definition and software development within the NEET-funded effort has been deferred to focus on the PSU-led irradiation in the MITR, which was recently selected for funding by the ATR NSUF program. However, discussions with team members have lead to the development of an organizational scheme for a signal processing system that could be used for measuring multiple phenomena with ultrasonic-based sensors (see Figure 26).

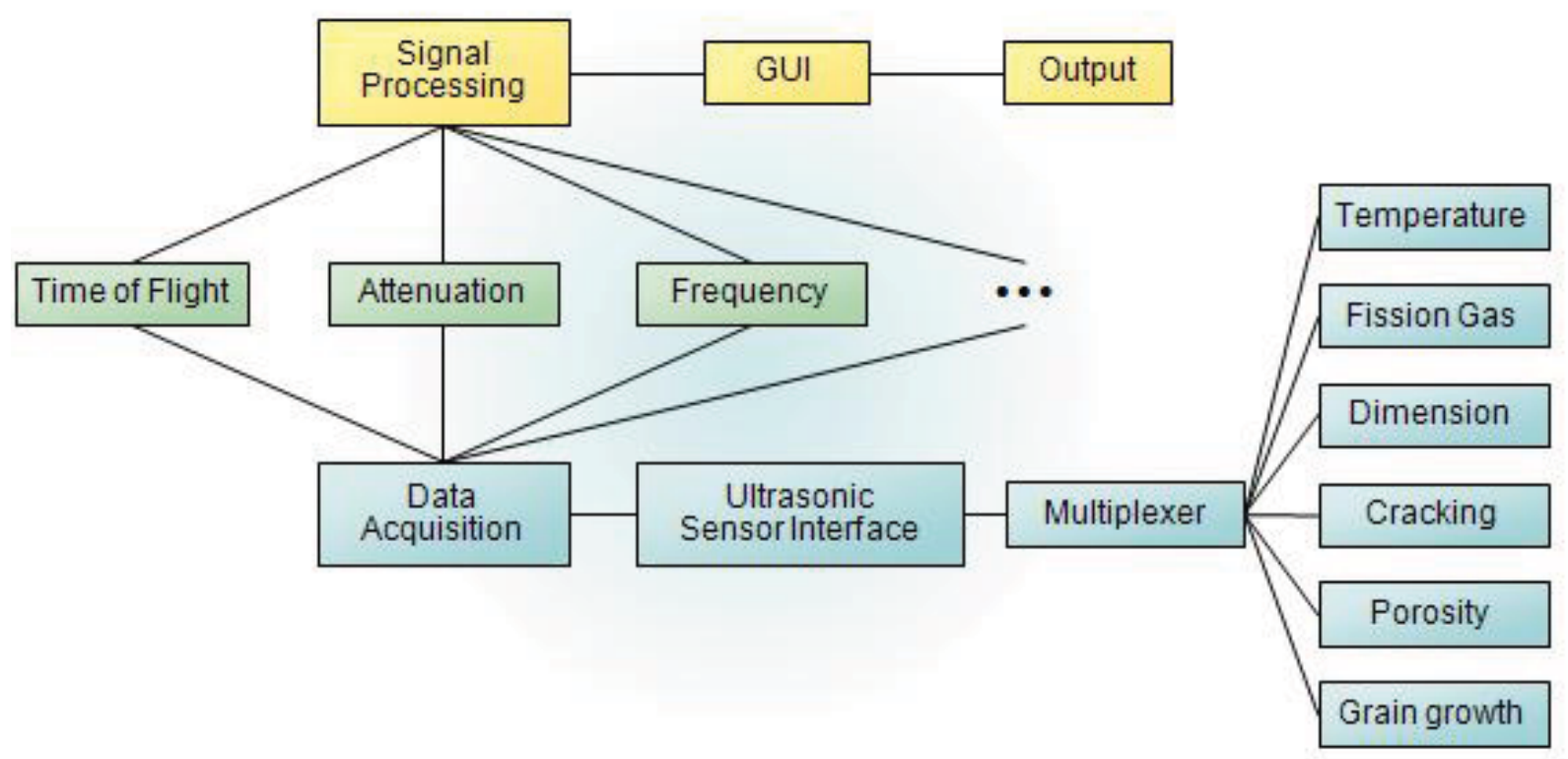

Figure 26. Diagram of signal processing system.

\subsubsection{Signal Processing Needs}

Regardless of the measured quantity, a common hardware platform will be required, which includes:

- High frequency ultrasonic system (frequency ranges are not yet determined, but will depend on the measurement type and wavelength relative to the feature size of interest) with adjustable amplitude and frequency. High power pulsers (tone burst excitation and pulse excitation) are available commercially.

- Digital-to-analog (D-A) conversion and data acquisition (DAQ) systems with high sample rate (1 GHz or greater) and bit depth (16 bits or greater). These DAQ cards are currently available commercially. The goal is to be able to acquire time-domain data (a-scans). On-board memory depth on the cards will need to be high (in excess of $16 \mathrm{MB}$ ) to enable acquisition of extended lengths (corresponding to long-duration signals). Ideally, the associated software will enable the averaging of multiple signals to reduce noise levels. 
- Software tools to enable control of the pulser/receiver system as well as the DAQ. While individual commercial units are typically available with computer controlled software, some software development will be needed to stitch the different modules together.

\subsection{Summary}

During FY12, FCRD funding was primarily used to advance deployment of one ultrasonics-based sensor, an UT. As discussed in this section, laboratory testing was completed to assess the viability of using ultrasonics thermometers for multipoint temperature detection during irradiation testing. Results from these tests have identified appropriate UT probe materials, a new magnetostrictive transducer design, a new damping method to reduce signal noise, and an enhanced signal processing method. Interim results were documented in Reference 40, which received an "Innovations in Fuel Cycle Research Award." In addition, an invention disclosure record (IDR) ${ }^{41}$ was filed related to the design of the enhanced design for magnetostrictive transducers. FY12 funding also allowed development of a collaborative proposal for addressing a key concern related to ultrasonic sensor deployment for irradiation testing, ultrasonic transducer survivability. This collaborative proposal, which was led by PSU, has been selected by the ATR NSUF, and irradiation testing is expected to begin in FY13. Finally, this section reports progress funded by other programs on the deployment of ultrasonics sensors for measuring other parameters, such as elongation. 
In-pile Instrumentation to Support Fuel Cycle Research and Development - FY12 Status Report

September 2012 


\section{FIBER OPTICS}

Fiber optic sensing technologies are one of the methods selected for development for in-pile instrumentation to support FCRD irradiations. Fiber optic sensing technologies can be used to measure a number of parameters, such as elongation, temperature, pressure and strain. Fiber optic sensors are small and some techniques allow multiple sensing locations along the length of the fiber. As documented in Reference 2, efforts were initiated in FY11 to investigate an elongation sensing technique in the laboratory to gain a better understanding of the technique and its viability for in-pile measurements. These efforts continued in FY12. In addition, INL collaborated on a university-led proposal to assess fiber optic survivability in a radiation environment during FY12. As documented in this section, other fiber-optics based sensing techniques will also be investigated to demonstrate their viability to meet the needs for in-pile instrumentation. Successful demonstration of the initial fiber optic sensors for in-pile measurements will lead to the development of more sophisticated fiber based measurements for material properties in subsequent years.

\subsection{Overall Plan and Schedule}

To accomplish the desired objectives, a task has been defined for each type of fiber optic sensor that will be investigated. In addition, a 'cross-cutting' task has been defined to address issues that support optical fiber sensor deployment in general. Figure 27 provides an overview of the tasks that will be completed in this effort. As shown in the figure, the first task is the development of a fiber optic sensor for the measurement of elongation (Task 1). The tasks are scheduled such that the simplest and least expensive sensors are developed first so that expertise gained during initial sensor development can be used to expedite development of subsequent sensors. Where commercially available sensors exist, modification for use in high radiation environments will be investigated and collaborations will be sought. Sensing techniques will then be setup and demonstrated in the laboratory to gain a firm understanding of the sensor parameters prior to developing a probe incorporating the sensor. Evaluations will then be conducted to determine the accuracy and precision of each fiber optic sensor and verify its suitability for deployment. The cross cutting Task 4 will investigate implementation issues relevant to all of the optical fiber sensors such as optical fiber temperature limitations and pressure boundary seals. A key issue related to the use of fiber optics sensors for irradiation testing is the ability of fiber optics to resist degradation from gamma and neutron exposure. To address this issue, INL collaborated on a university-led ATR NSUF proposal for a high fluence irradiation test to evaluate the survivability of fiber optics in an irradiation test. As results from cross-cutting task activities become available, additional laboratory tests may be performed prior to the technique being recommended for deployment as an in-pile instrumentation technique.

\subsection{Task 1: Fiber Optic Elongation Measurement}

As noted above, the objective of this task is to develop and deploy an optical fiber elongation/displacement sensor for the measurement of fuel rod elongation. The sensing method for this sensor is based on the Extrinsic Fabry-Perot Interferometer (EFPI) using a low coherence white light source. In order for any fiber optic technique to be deployed in-pile, the following parameters of the sensing technique and probe must be determined or developed:

- The accuracy of the proposed approach must meet objectives (e.g., selecting appropriate system components to obtain measurement with desired accuracy),

- A probe design that can be deployed in a MTR instrumented lead capsule must be developed, and 


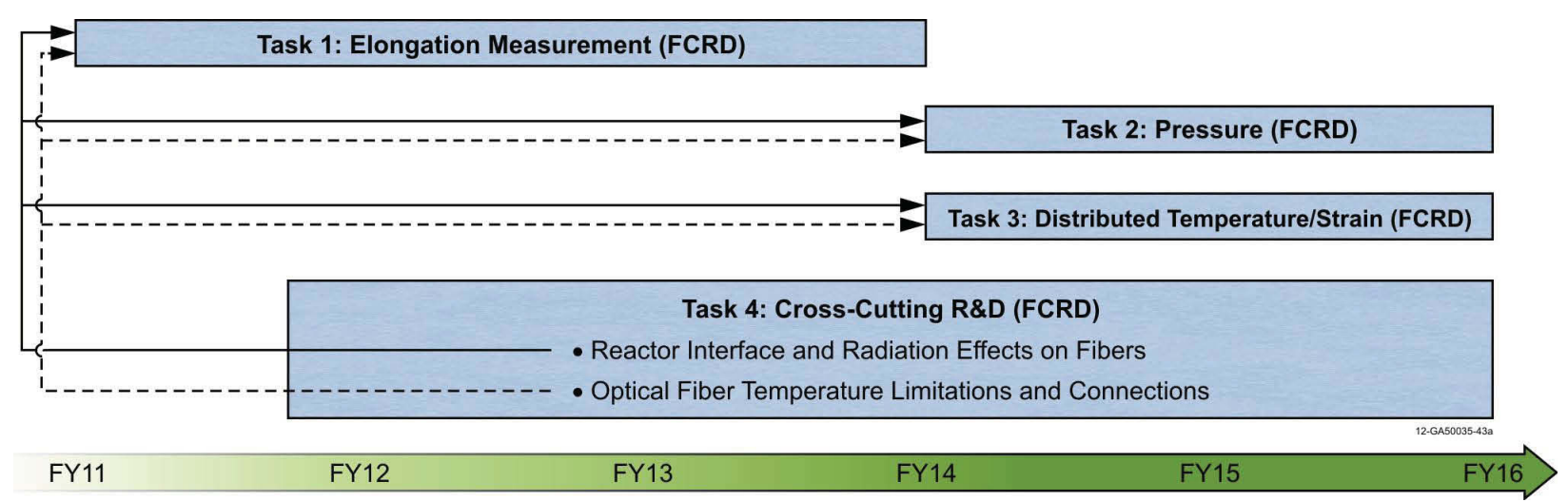

Figure 27. Overview of tasks to be completed as part of fiber optic sensor technology investigations

- The life expectancy requirements under irradiations at proposed test conditions.

During FY11, efforts were initiated to gain insights about the first two parameters. The technique was demonstrated in the lab, and the accuracy and limitations of the sensing methodology were evaluated. FY12 efforts focused on the development and testing of a sensing probe.

\subsubsection{Laboratory Evaluations to Assess Accuracy}

Initial laboratory investigations extended the concept presented by the CEA/SCK-CEN Joint Laboratory. ${ }^{42}$ In this technique, the distance between the end of an optical fiber and a reflecting surface is determined using the interference of the light reflected from the end of the fiber, "R1," and that reflected from surface on the opposite side of the cavity space, "R2," as shown in Figure 28.

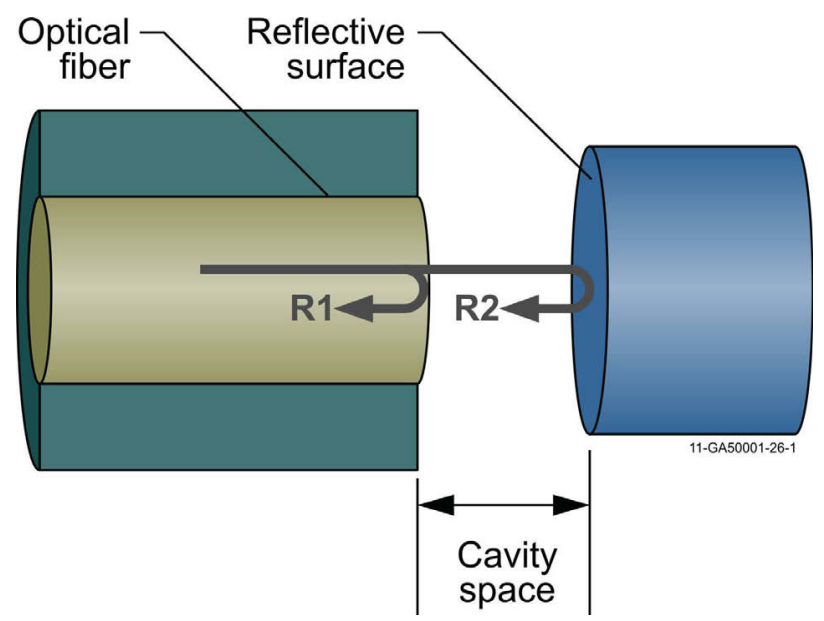

Figure 28. Cavity space measurement using EFPI.

The interference of these two beams produces a fringe pattern when viewed using a spectrometer, which displays the returning light intensity versus wavelength. The length of the cavity space can then be determined from the wavelength of two adjacent fringe peaks by using the following equation ${ }^{43}$ 
$d=\frac{\lambda_{1} \lambda_{2}}{2\left(\lambda_{1}-\lambda_{2}\right)}$

where:

$d$ is the cavity length, and

$\lambda_{1}$ and $\lambda_{2}$ are the wavelengths of adjacent fringe peaks.

During FY11, a laboratory experiment was setup to test and gain experience using this measurement technique. The technique is implemented by introducing broadband light into an optical fiber. The light in the fiber passes through a 50/50 fiber splitter in which 50\% of the light continues to the probe at the end of the fiber. The probe contains a variable cavity space as previously outlined. Reflected probe light returns through the fiber to the beam splitter which delivers $50 \%$ of this returning light to the spectrometer as shown in Figure 29. A grating in the spectrometer separates the returning light into a spectrum of the wavelengths of light present. The interference creates a modulation of the spectrum intensity as described above.

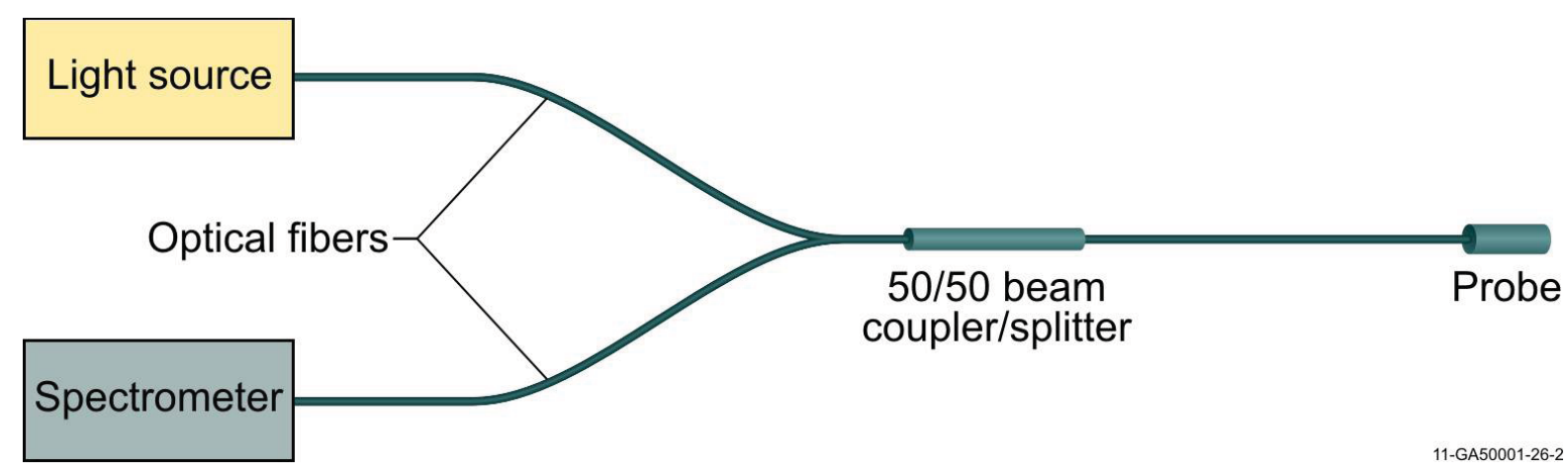

Figure 29. Experiment configuration for EFPI technique evaluation.

The FY11 evaluations included testing multiple light sources and fiber core sizes. It was determined that a broadband halogen light source was both cost effective and provided a wide usable light spectrum. Multimode fibers with small core sizes $(50 \mu \mathrm{m})$ produced better results than larger core $(200 \mu \mathrm{m})$ fibers. It was also determined that for maximum fringe modulation, the light intensity reflected from the fiber tip should be equal to the light intensity from the reflector (R1 and R2 in Figure 28). This can be accomplished by using a polished fiber for the reflector or by applying a partial reflective coating to the fiber tip and using polished metal for the reflector. The equipment used for the final FY11 technique evaluations and subsequent FY12 testing included: an Ocean Optics halogen light source (HL-2000-FHSA), an Ocean Optics model QE65000 spectrometer, and a Thor Labs model FCMM50-50A-FC 50/50 fiber optic splitter. The ability to measure elongation was evaluated using a Newport VP-25X stage with a Newport ESP301 driver for control and position readout. This setup is shown in Figure 30.

Initial technique evaluation was accomplished using an optical fiber for delivery and a quartz window for the reflector. The resulting fringe modulation using the halogen light source is shown in Figure 31, and the cavity spacing versus the stage readout is shown in Table 8.

Minor differences in the absolute cavity length calculated from the fringes versus the readout from the stage controller were attributed to the inability to zero the stage exactly where the cavity length was zero. However, the change in cavity space versus the change in stage position from point to point were in very good agreement (typically less than $0.3 \mu \mathrm{m}$ ). It should be noted that a simple routine of graphically picking 


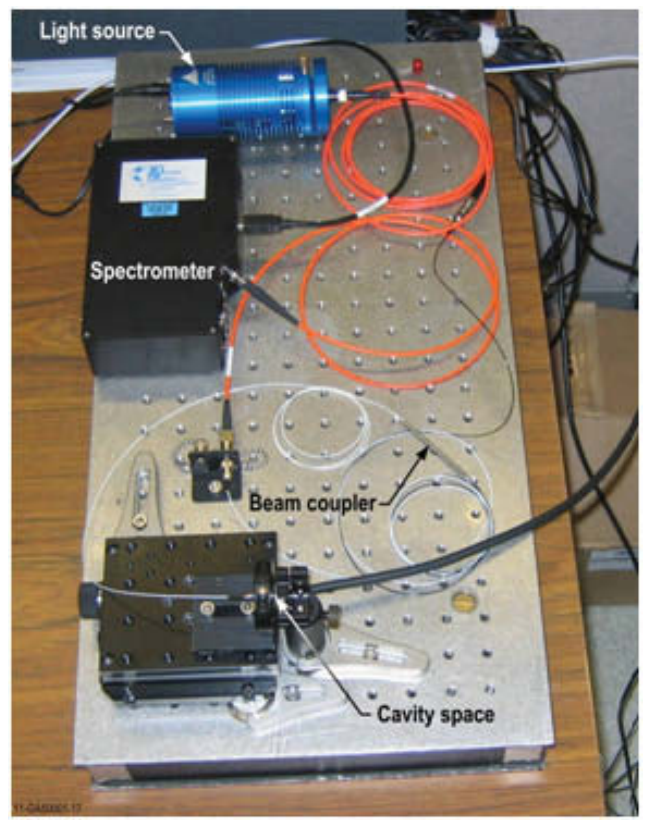

Figure 30. Laboratory setup for initial evaluation of fiber optic in-pile elongation detection.

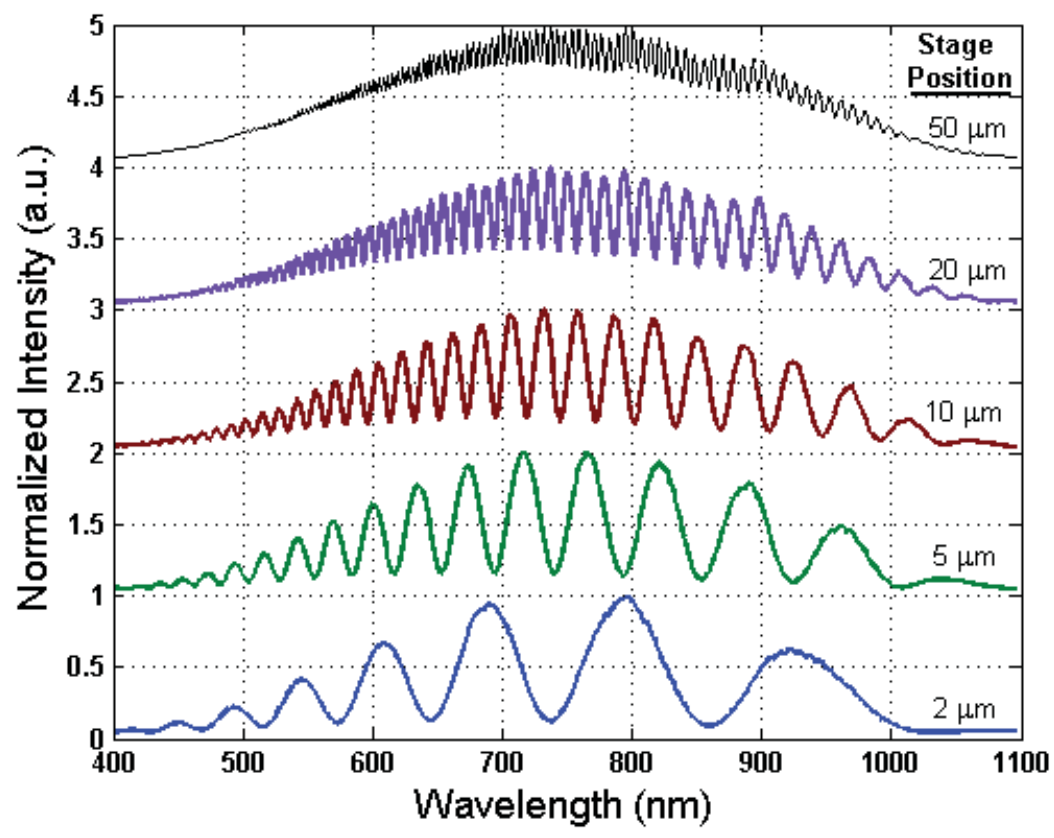

Figure 31. Spectra showing EFPI fringe modulation at several cavity lengths.

fringe peak wavelengths and calculating an average cavity space using Equation (2) was used. In future evaluations, a more sophisticated analysis for determining the fringe spacing will be employed to enhance accuracies. 
Table 8. Comparison of measured cavity length versus length inferred from fringe spacing.

\begin{tabular}{|c|c|c|c|}
\hline $\begin{array}{c}\text { VP-25X Stage Position } \\
(\mu \mathrm{m})\end{array}$ & $\begin{array}{c}\text { Cavity Based on Measured } \\
\text { Fringe Spacing }\end{array}$ & $\begin{array}{c}\text { Change in Measured } \\
\text { Cavity }(\mu \mathrm{m})\end{array}$ & $\begin{array}{l}\text { Difference Between Change in Stage } \\
\text { Position and Measured Cavity }(\mu \mathrm{m})\end{array}$ \\
\hline 0 & 0.73 & - & - \\
\hline 1 & 1.63 & 0.901 & 0.10 \\
\hline 2 & 2.64 & 1.010 & -0.01 \\
\hline 3 & 3.55 & 0.911 & 0.09 \\
\hline 4 & 4.55 & 0.995 & 0.00 \\
\hline 5 & 5.54 & 0.991 & 0.01 \\
\hline 7 & 7.45 & 1.917 & 0.08 \\
\hline 10 & 10.46 & 3.009 & -0.01 \\
\hline 15 & 15.45 & 4.988 & 0.01 \\
\hline 20 & 20.59 & 5.141 & -0.14 \\
\hline 25 & 25.61 & 5.023 & -0.02 \\
\hline 30 & 30.55 & 4.934 & 0.07 \\
\hline 35 & 35.48 & 4.933 & 0.07 \\
\hline 40 & 40.70 & 5.219 & -0.22 \\
\hline 45 & 45.57 & 4.871 & 0.13 \\
\hline 50 & 50.77 & 5.196 & -0.20 \\
\hline 60 & 60.82 & 10.057 & -0.06 \\
\hline 70 & 70.73 & 9.904 & 0.10 \\
\hline 80 & 80.75 & 10.017 & -0.02 \\
\hline 90 & 90.78 & 10.035 & -0.03 \\
\hline 100 & 101.06 & 10.277 & -0.28 \\
\hline 125 & 126.06 & 25.002 & 0.00 \\
\hline
\end{tabular}

\subsubsection{Probe Design and Fabrication}

Once the technique was successfully demonstrated, work on conceptual probe designs was begun. In FY11, an initial probe was fabricated using stainless steel hypodermic tubing. In this design, the optical fiber was bonded inside of a short length of stainless steel tube, and the reflecting side of the cavity was fabricated by bonding a short length of larger core optical fiber into a small piece of the same stainless steel tubing. The fiber ends were polished and inserted into a larger diameter sleeve such that the space between the tips created the measurement cavity. The sleeve served to maintain axial alignment between the fibers as the cavity space was changed. A schematic of the probe design is shown in Figure 32.

Evaluations of this concept probe yielded promising results. In FY12 efforts were focused on developing a sealed probe that could be deployed in an irradiation test. A probe design was developed that was functionally similar to the concept probe, but incorporated a bellows, which would provide isolation from the environment and allow expansion of the probe. A cross-section of the probe design is shown in Figure 33.

A number of obstacles were resolved in fabricating this probe. Bonding of the optical fiber in the stainless steel hypodermic tubing presented problems as initial attempts at stripping the fiber coating and bonding in the tube resulted in fracture of the fiber at moderate temperatures. It was found that gold coated fiber, which can withstand temperatures of $700{ }^{\circ} \mathrm{C}$, could be bonded inside the hypodermic tube using Cotronics Resbond 907TS Green threadlocker without fiber fracture at elevated temperatures. Another issue was 


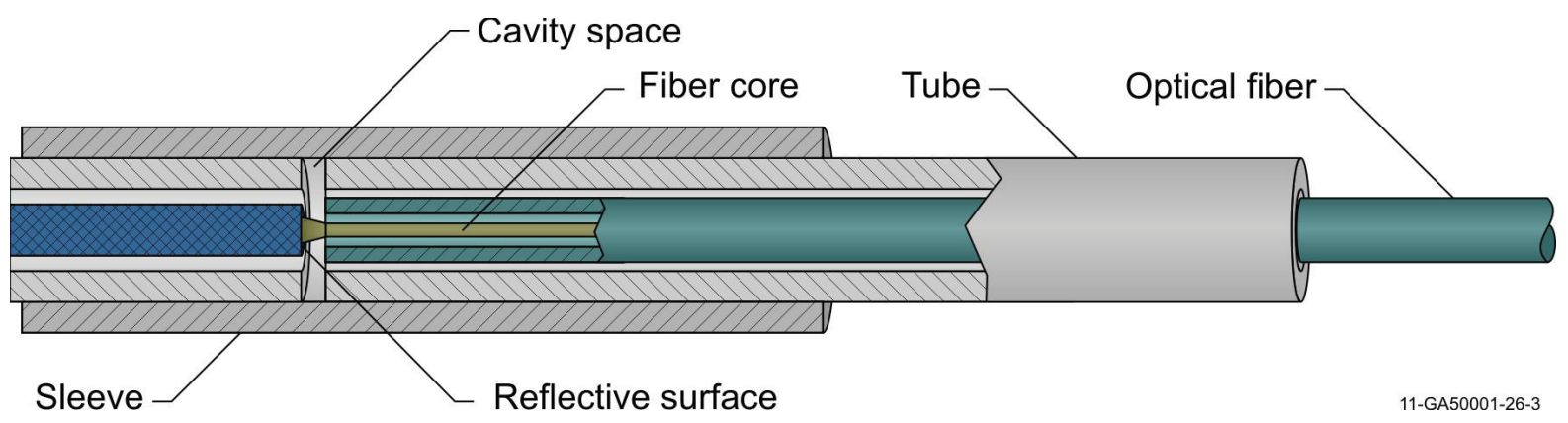

Figure 32. Elongation probe concept using hypodermic tubing.

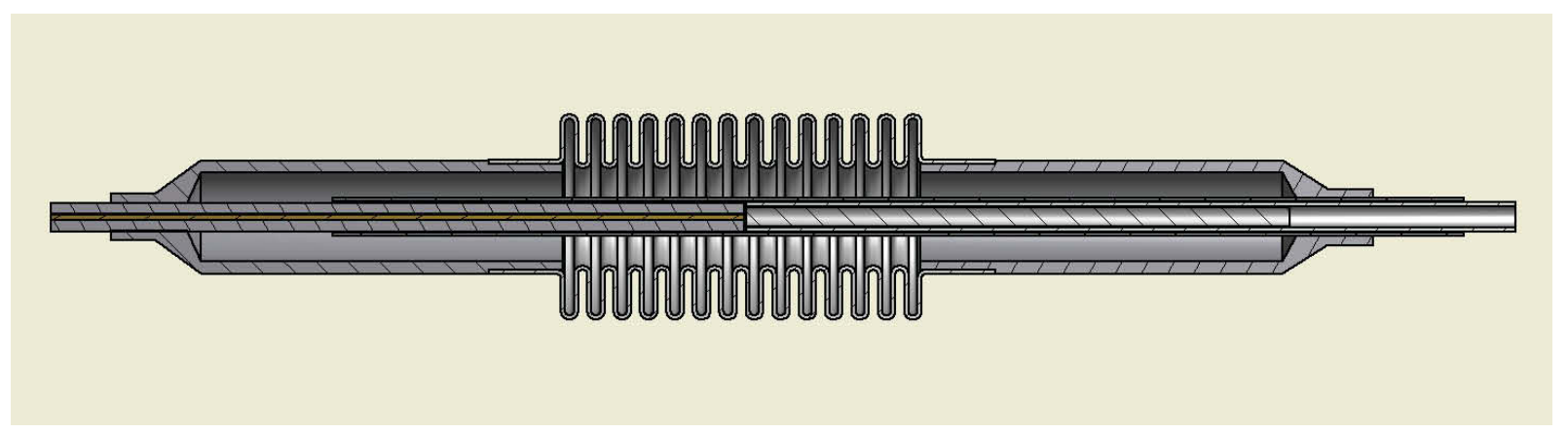

Figure 33. Elongation probe cross section.

developing the ability to assemble and weld the small probe components. The smallest readily available stainless steel bellows was a MiniFlex Corporation Model SS-125-46-168. An adapter was developed which could be welded to the bellows on one end and the hypodermic tubing on the other end. Welding of these components was accomplished using a laser welding system. A photo of the completed sensor is shown in Figure 34.

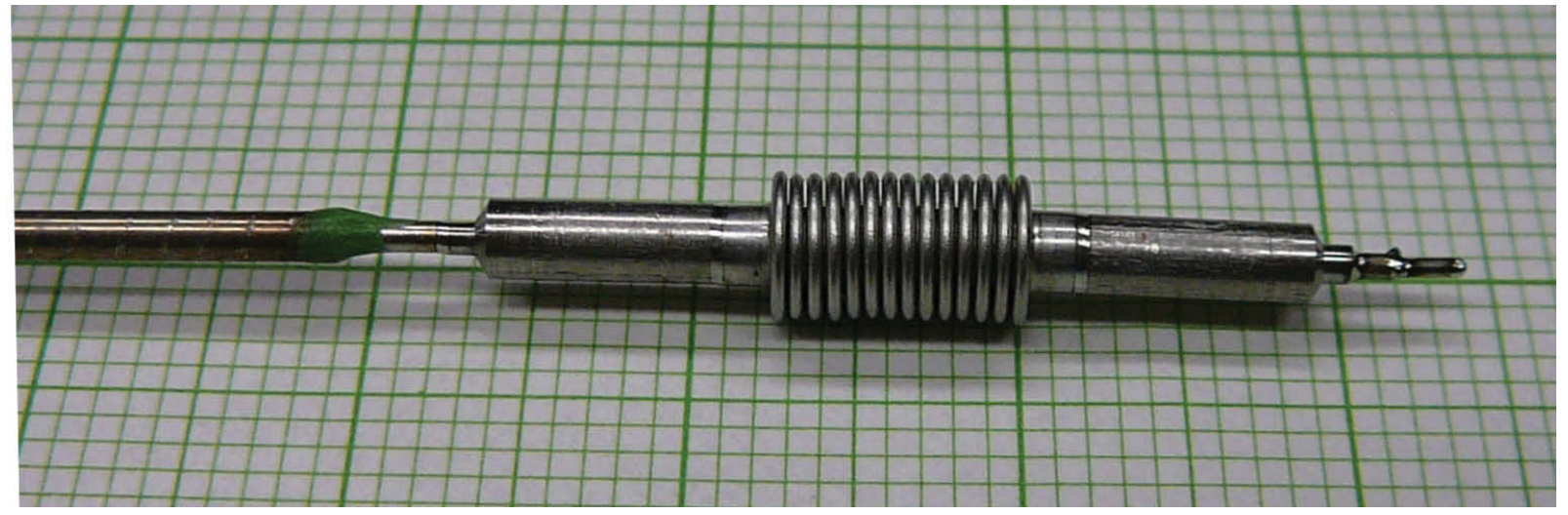

Figure 34. Welded elongation probe. 
Initial testing of the probe revealed an increasing discrepancy between the readings from the stage and the probe. However, it was determined the discrepancy was due to flexing of the support posts. A more substantial test fixture was fabricated, and the probe was retested. For the first test, the probe was clamped in position, and the stage was first zeroed and then moved from $0 \mu \mathrm{m}$ to $150 \mu \mathrm{m}$ in increments from 1 to $10 \mu \mathrm{m}$. This test yielded very good results with the discrepancy between the stage position reading and the probe being generally less than $0.3 \mu \mathrm{m}$ up to a $90 \mu \mathrm{m}$ displacement. The increased error observed with displacements greater than $100 \mu \mathrm{m}$ was primarily due to difficulty reading the fringe pattern. Repeatability was then evaluated by randomly moving the stage between 3 and $92 \mu \mathrm{m}$. Position readings from both the stage and probe were plotted, and a linear fit performed. The data and linear fit are shown in Figure 35. The linear fit slope was 1.0037, which is close to a perfect match of 1.00; and the intercept was $0.50 \mu \mathrm{m}$. The intercept is simply a measure of how close the stage zero was to the probe zero. The average difference between probe measurements and the stage readings (adjusted for the zero offset) was less than $0.2 \mu \mathrm{m}$.

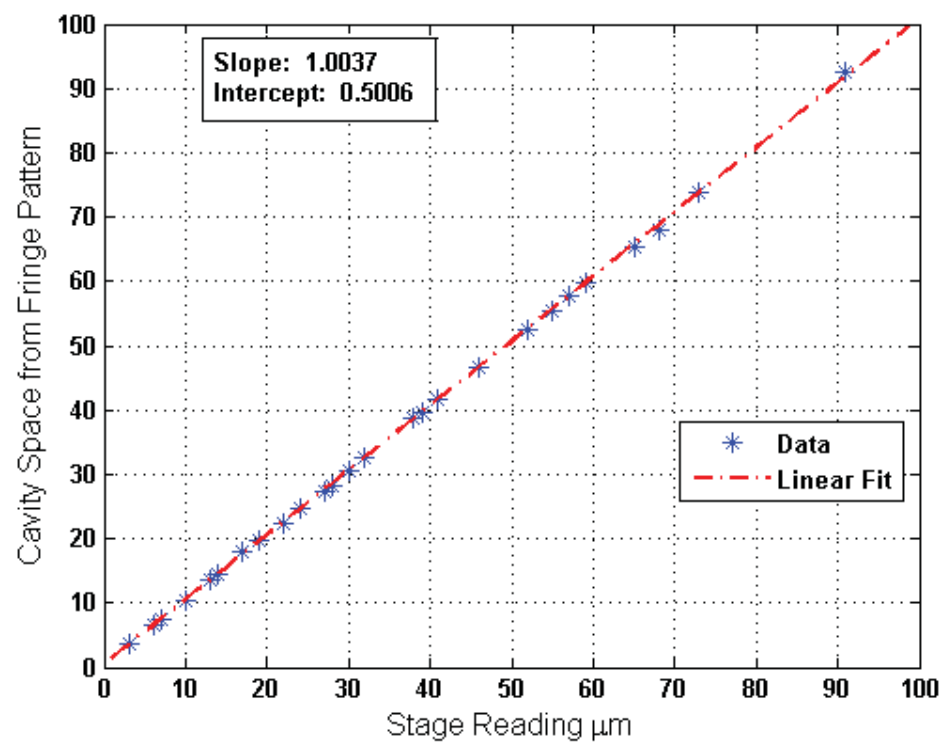

Figure 35. Elongation probe data.

\subsubsection{Elongation Sensor Technique Sensitivity}

Evaluation of the EFPI technique and testing of an elongation probe based on this method have led to a better understanding of the sensitivity and cavity length range of this technique. On a closer inspection of Equation (2) and observation of the recorded spectrum, it can be seen that the fringe spacing is long for a small cavity length and short for a longer cavity length. Consequently, as the cavity length increases the sensitivity decreases. It has been shown that the radiation induced attenuation of optical fibers is the lowest in the near IR wavelength, particularly in the range from about 800 to $1300 \mathrm{~nm} .{ }^{42}$ If the probe were designed to operate in this window and two fringe peaks were required within this range to determine fringe spacing, the minimum detectable cavity space would be approximately $1.5 \mu \mathrm{m}$. The maximum detectable cavity space is based on the resolution of the spectrometer. As the cavity space increases and the fringe peaks get closer together, the ability to resolve individual peaks becomes the limiting factor. The Ocean Optics QE65000 used in these tests had a resolution of about $0.8 \mathrm{~nm}$ which resulted in a maximum measurable cavity space of about $125 \mu \mathrm{m}$. Testing of the probe revealed high precision for measurements between approximately 3 and $100 \mu \mathrm{m}$. Measurement errors increased above this range. Some improvements for longer displacements may be possible by using a spectrometer which is sensitive to longer wavelengths than the QE65000. 


\subsubsection{Summary}

Work on the elongation probe has lead to a number of observations about the technique which are summarized below:

- The technique is viable and has demonstrated an accuracy on the order of $0.3 \mu \mathrm{m}$.

- Small core, low numerical aperture fibers tend to work better.

- Return light from the reflections at the end of the fiber and the mirrored surface should be approximately the same intensity for good fringe modulation depth. If a highly reflective surface is used opposite the fiber end face, the fiber end face should be coated with a $38 \%$ reflective coating for best results.

- The fiber face should be polished flat and alignment of the fiber axis perpendicular to the reflective surface must be maintained.

- The sensitivity of the probe is a function of the spectrometer resolution and the fringe modulation depth.

- The minimum detectable cavity space is based on the bandwidth of the light source and "transmission window" of the irradiated optical fiber. The best transmission range for irradiated optical fibers extends from approximately $800 \mathrm{~nm}$ to $1300 \mathrm{~nm}$.

- The approximate measurement range of a probe based on this technique is 1.5 to $125 \mu \mathrm{m}$ (based on the fiber transmission window and a spectrometer resolution of $0.8 \mathrm{~nm}$ ).

Work during FY11 and FY12 has demonstrated the viability of a fiber optic elongation sensor based on the EFPI technique. A probe has been fabricated and tested and an IDR was filed related to its design. ${ }^{44} \mathrm{How}-$ ever, continued development will be required to produce an in-pile service ready sensor. The following list outlines the status of activities required to bring the desired sensor to fruition.

- Optimization of probe design parameters - During FY12 an elongation probe was fabricated and tested. Many improvements were made over the initial concept probe. Optimization will continue throughout the development process. Probes using fibers with lower numerical apertures and smaller core diameters will be investigated. Coating the end of the fiber with a partially reflective coating and using a highly reflective surface on the opposite side of the cavity space may be advantageous. This aspect of the probe design will also be optimized.

- Develop a seal - The probe developed during FY12 is a sealed design.

- Fabrication Capabilities- Capabilities at the INL were sufficient to fabricate the initial elongation probe. Improved commercial processes may be used for the final sensors.

- Radiation Resistance - Work to date has been conducted using standard commercially available fibers and components. Radiation resistant fibers and fiber to tube bonding materials/methods need to be incorporated into the design. A broadband light source operating in the 800 to $1300 \mathrm{~nm}$ range also needs to be identified or developed.

- Signal Analysis Software - During the current evaluation phase of the sensor development the signal from the probe is displayed as a modulated wavelength spectrum on the screen of a PC. This is not convenient for an operator. Automated signal analysis software will be developed so that cavity length or elongation can be provided directly to the user.

- Final Design \& Testing - Once the probe has been optimized it will still need to be attached to the sample and incorporated into a test capsule. This final design configuration will then be tested in a simulated reactor environment prior to deployment. 
Work during FY11 and FY12 has demonstrated the viability of a fiber optic elongation sensor based on the EFPI technique. A probe has been fabricated and tested and an IDR was filed related to its design. ${ }^{44}$ However, continued development will be required to produce an in-pile service ready sensor.

\subsubsection{Future Work}

The following list outlines the status of activities required to bring the desired sensor to fruition:

- Optimization of probe design parameters - During FY12, an elongation probe was fabricated and tested. Many improvements were made over the initial concept probe. Optimization will continue throughout the development process. Probes using fibers with lower numerical apertures and smaller core diameters will be investigated. The use of smaller diameter bellows will also be evaluated. Coating the end of the fiber with a partially reflective coating and using a highly reflective surface on the opposite side of the cavity space may be advantageous.

- Develop a seal - The probe developed during FY12 is a sealed design.

- Fabrication Capabilities - Capabilities at the INL were sufficient to fabricate the initial elongation probe. Improved commercial processes may be used for the final sensors.

- Radiation Resistance - Work to date has been conducted using standard commercially available fibers and components. Radiation resistant fibers and fiber to tube bonding materials/methods need to be incorporated into the design. A broadband light source operating in the 800 to $1300 \mathrm{~nm}$ range also needs to be identified or developed. As discussed in Section 4.4, results from an irradiation test are required before this probe can be deployed.

- Signal Analysis Software - During the current evaluation phase of the sensor development the signal from the probe is displayed as a modulated wavelength spectrum on the screen of a PC. This is not convenient for an operator. Automated signal analysis software will be developed so that cavity length or elongation can be provided directly to the user.

- Final Design \& Testing - Once the probe has been optimized it will still need to be attached to the sample and incorporated into a test capsule. This final design configuration will then be tested in a simulated reactor environment prior to deployment.

Although development efforts were planned to enable deployment of this probe by FY14, development has been delayed due to funding limitations. In addition, deployment will be delayed until completion of the irradiation test discussed in Section 4.4.

\subsection{Tasks 2 and 3: Pressure and Distributed Sensing}

Limited funding has been available for work on Tasks 2 and 3, which concern fiber optic pressure sensing and distributed sensing. A brief survey of commercially available sensors was conducted. A number of single point optical fiber based pressure sensors are commercially available, and some testing of pressure sensors in high radiation environments has also been reported. ${ }^{45}$ Fiber optic distributed sensing systems based on fiber Bragg gratings, optical time domain reflectometry (OTDR), or optical backscatter reflectometry (OBR) are readily available commercially, but the commercial distributed sensing systems identified to date operate at optical wavelengths outside the 800 to $1300 \mathrm{~nm}$ range which offers the lowest radiation induced attenuation for optical fibers. Work at universities on radiation resistant distributed sensing systems is on-going, but work on Tasks 2 and 3 for this program will not be started until FY15 unless funding levels increase. 


\subsection{Task 4: Cross Cutting}

The objective of the cross cutting task is to address optical fiber implementation issues that apply to all fiber optic sensors. For example, pressure boundary seals are necessary to transition the optical fiber into the reactor environment. An INL-developed method of addressing this issue has been reported previously, ${ }^{46}$ and commercial off the shelf seals and feed throughs are becoming more readily available. Optical fiber temperature limitations are also an issue. Copper and gold coated fibers are available which can endure long term temperatures in the 600 to $700{ }^{\circ} \mathrm{C}$ range. Fiber optic sensing applications in temperatures over $1000{ }^{\circ} \mathrm{C}$ have been reported but longevity may only be a few hours. ${ }^{47}$ This temperature limitation may preclude the use of optical fibers from in-situ direct fuel measurements. The temperature capabilities of fiber optic sensors would be sufficient for measurements near the fuel cladding or in cases where the fiber could be used to direct light to or collect light from the fuel surface.

Radiation effects on optical fibers and the probe components are an important issue for the long term survivability of fiber based sensors. A summary of the fiber issues and related research has been reported previously. ${ }^{42}$ Irradiation testing of the optical fiber and components is paramount to quantitatively determining the effects on the sensor accuracy and lifetime. Collaborations with Ohio State University and Texas A\&M University have led to development of an ATR NSUF proposal for fiber optic radiation testing, which is planned for submission in early FY13. The objective of the proposal would be the measurement of radiation induced attenuation in several optical fibers in an ATR instrumented lead experiment. A schematic of the proposed experiment is shown in Figure .

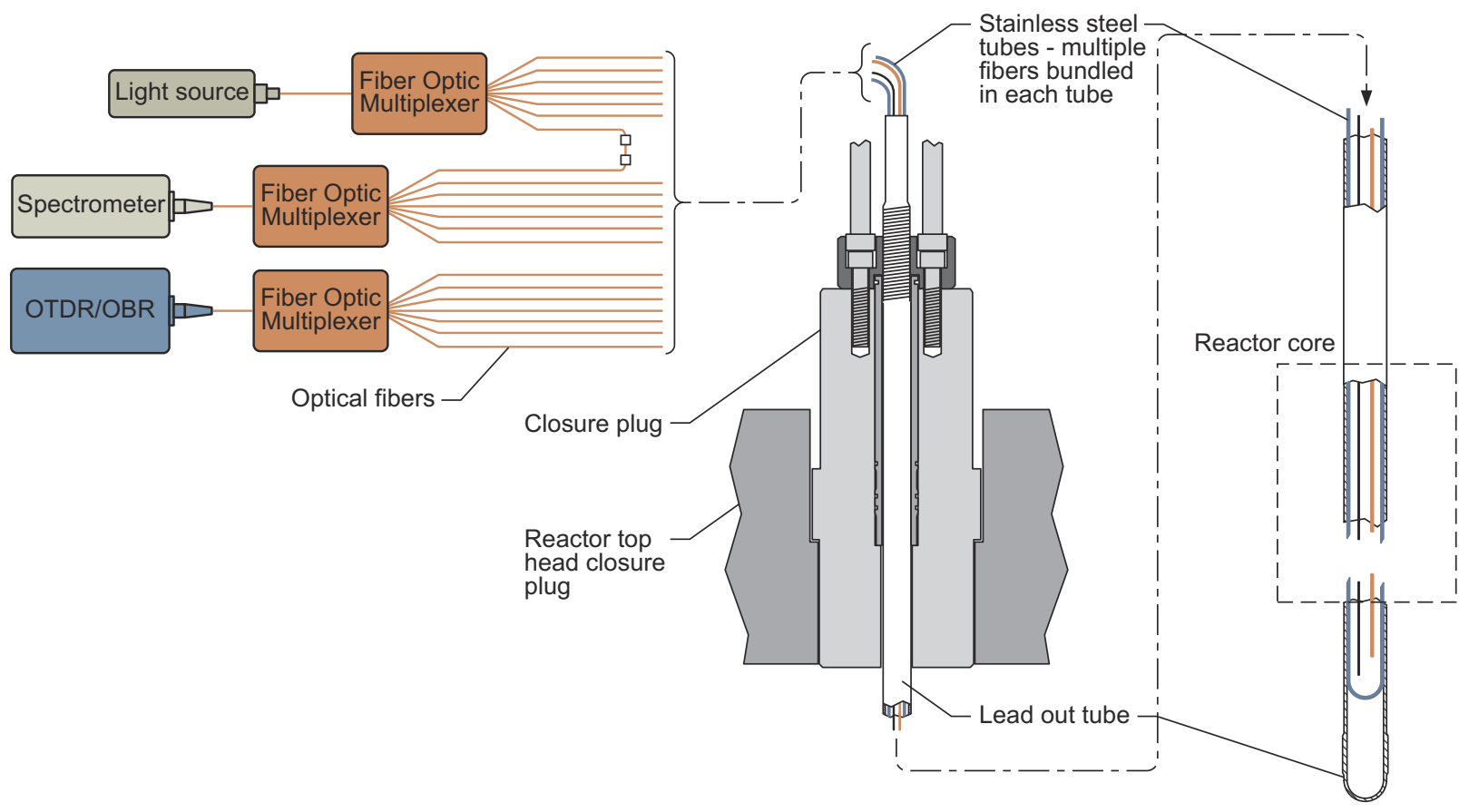

Figure 36. ATR fiber optic attenuation test schematic.

The test methodology would involve both through transmission testing using a spectrometer and single ended fiber testing using either OTDR or OBR. In the through transmission test, the fiber would be routed down to the reactor core and back essentially forming a long "U". Light from a broadband source would be coupled into one end of the fiber and the opposite end would be connected to a spectrometer. This would allow attenuation across a broad wavelength range to be continuously monitored. As the tight bend radius necessitated by the small test positions could be detrimental to the fibers, OTDR or OBR instruments 
would also be employed. These instruments allow attenuation measurements to be made from one end of a fiber but are limited to discrete wavelengths. Fiber optic multiplexers would be implemented in both test methods to allow multiple fibers to be tested using the same instrument.

The design concept uses a lead out tube which would be inserted through the reactor top head closure plate and down into the test position. The lead out tube would serve as the primary pressure boundary. Individual optical fibers would be bundled inside separate small diameter stainless steel tubes. These smaller tubes could be hard mounted in the lead out tube to maintain proper positioning and added protection for the fibers. If funded, the proposal would help answer long standing questions on the longevity of optical fiber based sensors in the ATR.

\subsection{Summary}

This section has reported progress in the development of an optical fiber based elongation sensor for in-pile instrumentation. During FY12 an elongation sensor based on an EFPI was designed, fabricated and tested in the laboratory. Measurements using this laboratory setup were typically within $0.3 \mu \mathrm{m}$ of the corresponding stage read out and had a measurement range of approximately 1.5 to $125 \mu \mathrm{m}$. Based on the technique demonstration setup, a concept probe was developed. The probe had an outside diameter of less than $1 \mathrm{~mm}$ and yielded results similar to the initial laboratory setup. Optimization and refinement of the probe and investigation of fiber optic pressure and distributed sensing will continue in FY13 so that, depending upon funding availability, the probe is ready for deployment in FY14 (with the exception of fiber optic survivability irradiation testing). 
In-pile Instrumentation to Support Fuel Cycle Research and Development - FY12 Status Report 


\section{ENHANCED EXISTING IN-PILE INSTRUMENTATION}

“Upgrade US MTR In-Pile Instrumentation" was identified in Reference 1 as a key objective needed to support FCRD irradiation testing. Enhancing existing in-pile instrumentation available at other MTRs is fundamental aspect of that objective. However, information reported in Reference 1 also indicated that sensors available for irradiation testing at other MTRs may not survive in the higher flux, higher temperature environments associated with FCRD irradiations in the ATR and the HFIR. Consequently, high flux, high temperature design, development, and evaluation of existing instrumentation is needed to deploy sensors in US MTRs comparable to those existing at other facilities. The status of that work is described in this section.

It should be noted that a long-term research plan was developed during FY11 to identify sensors that are needed for FCRD irradiations. It was recognized that several DOE-funded programs (e.g., ATR NSUF, NGNP, NEET, and FCRD) are interested in (and will benefit from) the availability of those sensors for irradiation testing in US MTRs. During FY12, the FCRD program continued the lead in tasks to develop linear variable differential transformer (LVDT)-based sensors for detecting elongation and diameter changes during irradiation. As discussed herein, other DOE programs (and INL LDRD initiatives) are assuming, or have expressed interest in assuming, the lead role for research required to develop sensors needed for FCRD irradiations. To avoid duplication of sensor design, development, and evaluation, these efforts are monitored by INL within the FCRD program to ensure that all of tasks are completed and the ultimate goal of having required sensors to support FCRD irradiation testing at US MTRs is achieved.

\subsection{Overall Plan and Schedule}

As discussed in Section 2, sensors for measuring several key parameters of interest during FCRD fuel irradiations are not currently available at US MTRs. To ensure that appropriate sensors are available at US MTRs, a proposed path forward (with a schedule) for addressing the needs is illustrated in Figure 37. Funding sources currently leading the efforts (or the planned efforts) for ensuring that these sensors are developed and deployed are also identified. Additional details related to the status of research efforts for each type of sensor are provided in Table 9. As indicated in this table, efforts are generally limited to initial viability evaluations. The status of each of these tasks will continue to be monitored within the FCRD program to ensure that all of these tasks are completed, and the ultimate goal of having comparable sensors to support irradiation testing at US MTRs is achieved. In cases where a task may stall due to a lack of funding, FCRD funds may be required to ensure that these sensors are available for FCRD irradiations.

\subsection{Task 1: LVDT-based Elongation and Diameter Measurements}

The objective of this task is to deploy LVDT-based test rigs capable of detecting changes in fuel elongation and diameter in US MTRs. For decades, the Institute for Energy Technology/Halden Reactor Project (IFE/HRP) has successfully developed and deployed such test rigs at the Halden Boiling Water Reactor (HBWR) and other MTRs. However, none have been deployed in the high flux and high temperature levels that exist at the ATR and HFIR. In this task, test rig designs that are capable of detecting diameter and length changes of fuels (and materials) during irradiation are developed and evaluated. Laboratory evaluations are completed using autoclaves at INL's HTTL. As test rigs are deployed in ATR PWR loops, data will also be collected under this task to assess their in-pile performance. Ultimately, insights gained from laboratory and irradiation testing will be used to develop standard LVDT-based test rig designs for irradiation testing in ATR and HFIR. 


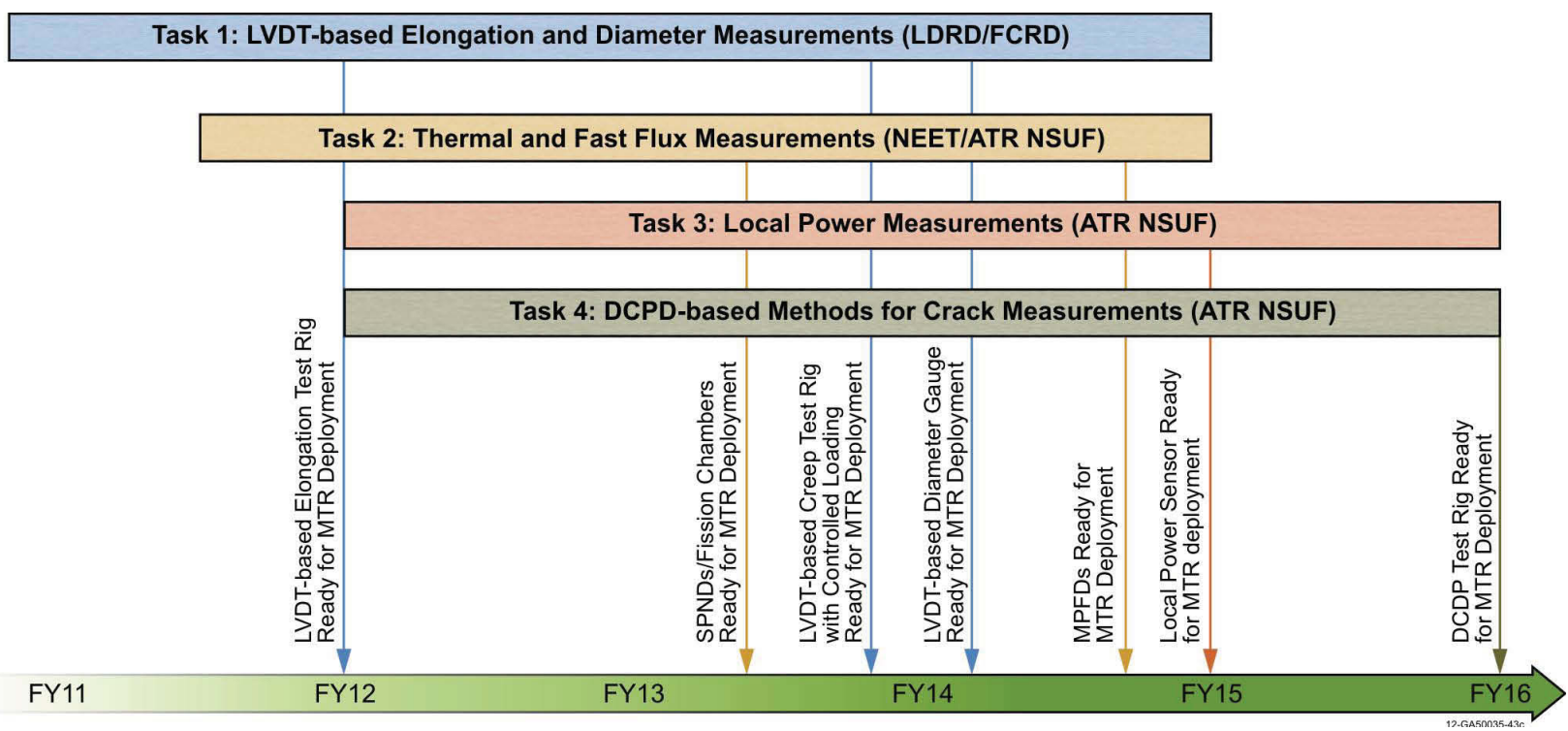

Figure 37. Overview of work to be completed as part of enhanced sensor deployment activities.

Table 9. Enhanced sensor technology task status.

\begin{tabular}{|l|c|l|}
\hline \multicolumn{1}{|c|}{ Task Number and Title } & Funding Source & \multicolumn{1}{c|}{ Status } \\
\hline $\begin{array}{l}\text { Task1: LVDT-based Elongation and } \\
\text { Diameter Measurements }\end{array}$ & $\begin{array}{c}\text { LDRD/ FCRD } \\
\text { (ATR NSUF } \\
\text { for irradiation } \\
\text { testing) }\end{array}$ & $\begin{array}{l}\text { Builds upon results from an INL LDRD to develop an enhanced } \\
\text { LVDT for higher flux, higher temperature irradiations at US } \\
\text { MTRs. Final evaluations required for deploying a creep test rig in } \\
\text { an ATR PWR loop completed in FY12. Efforts to develop an } \\
\text { enhanced creep test rig (with variable loading) initiated in FY12. }\end{array}$ \\
\hline $\begin{array}{l}\text { Task 2: Thermal and Fast Flux } \\
\text { Measurements }\end{array}$ & $\begin{array}{c}\text { ATR NSUF / } \\
\text { NEET }\end{array}$ & $\begin{array}{l}\text { ATR NSUF funding efforts to develop recommendations for flux } \\
\text { detectors for ATR based on evaluations of selected SPNDs and } \\
\text { fission chambers in ATRC. NEET funding efforts to develop and } \\
\text { evaluate a MicroPocket Flux Detector. }\end{array}$ \\
\hline Task 3: Local Power Measurements & ATR NSUF & $\begin{array}{l}\text { ATR NSUF funded initial viability evaluations of gamma } \\
\text { thermometers for measurements in US MTRs. }\end{array}$ \\
\hline $\begin{array}{l}\text { Task 4: DCDP-based Methods for Crack } \\
\text { Measurements }\end{array}$ & ATR NSUF & $\begin{array}{l}\text { ATR NSUF funding initial viability INL/MIT evaluations to } \\
\text { deploy DCDP technology, based on IFE/HRP approach, in US } \\
\text { MTRs. }\end{array}$ \\
\hline
\end{tabular}

\subsubsection{Enhanced Creep Test Rig}

During FY12, all efforts were focused on completing work needed to support deployment of an enhanced creep test rig in Loop 2A of the ATR. Accordingly, the design (including prototype fabrication), characterization, and calibration of the test rig were completed as outlined in this section.

\subsubsection{Design}

The enhanced creep test rig design shown in Figure 38 was derived through a previously-documented evaluation of the original creep test rig shown in Figure 39. As indicated in both figures, major components include a tensile specimen, a bellows, an LVDT, and the fixturing needed to connect these components within a supporting frame. (In a pressurized water environment [i.e., an autoclave or a PWR test loop], external water pressures tend to collapse the bellows producing a tensile load on the specimen.) IFE/HRP 


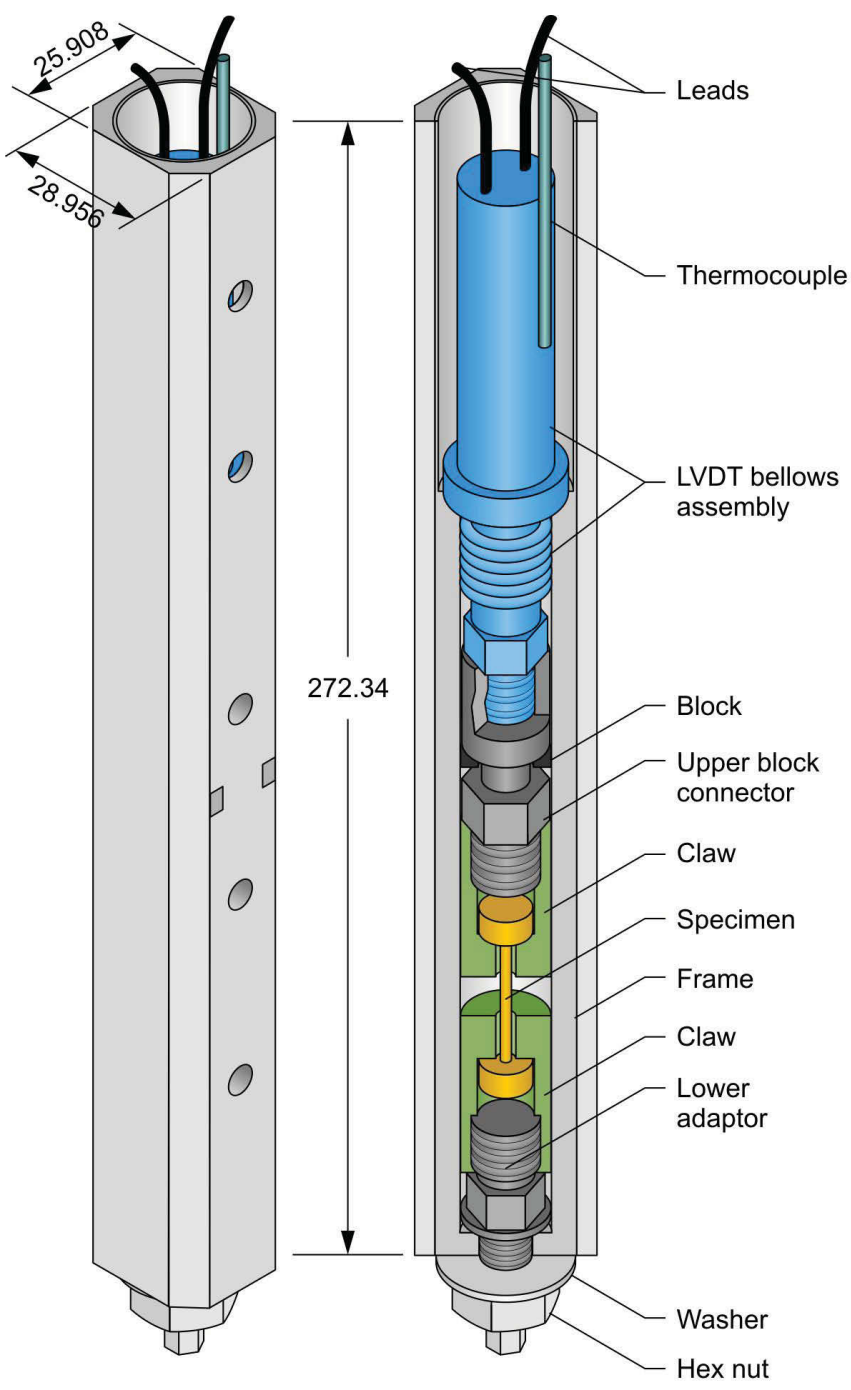

Dimensions in $\mathrm{mm}$

Figure 38. Enhanced creep test rig.
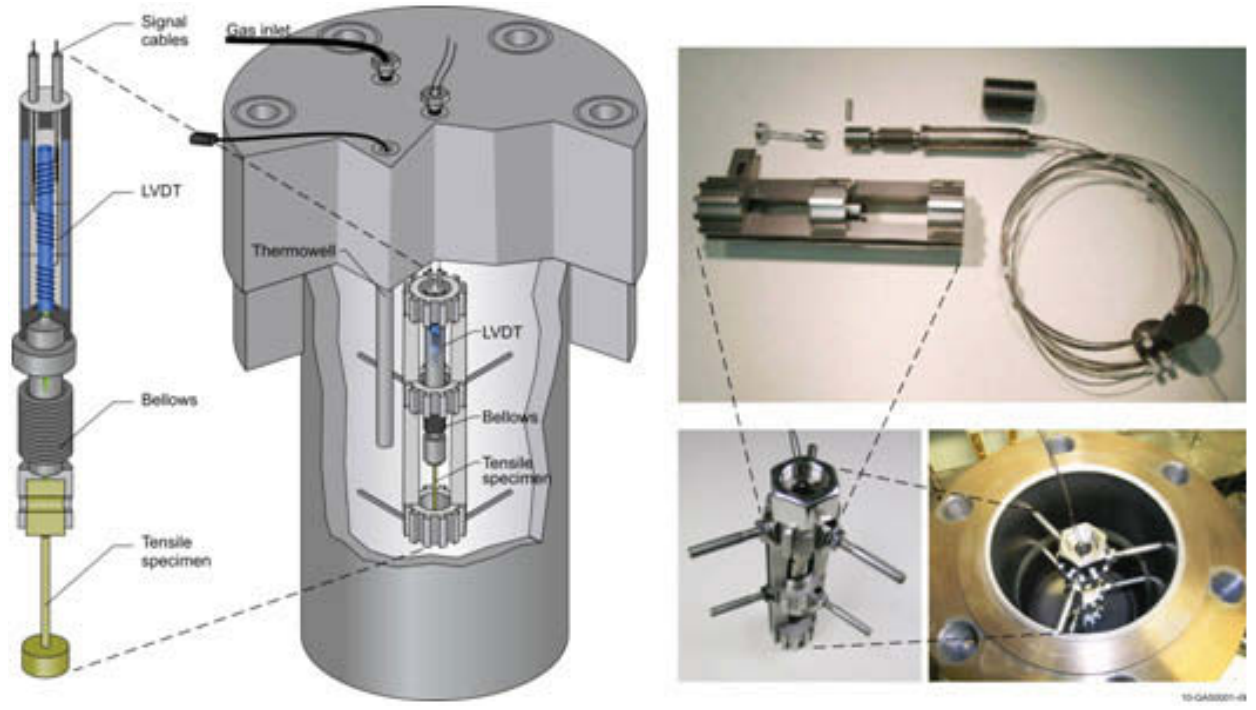

Figure 39. Original creep test rig positioned in an autoclave for testing. 
provided the LVDT and welded the LVDT, bellows, and the associated connecting fixturing in both test rigs using e-beam welding techniques.

The primary refinements embodied in the enhanced creep test rig (relative to the original creep test rig), and the factors motivating those modifications, include changes in the:

- LVDT - Coil wires are made from a silver alloy rather than a copper-nickel alloy to eliminate Curie-point temperature instabilities associated with earlier versions of the IFE/HRP LVDT (see Reference 48).

- Connecting Fixturing - Specimen to fixture interfaces were designed to minimize potential mating mismatch while promoting easier assembly/disassembly. In addition, the lower adaptor was fitted with a hex nut to allow pre-loading sufficient to minimize the effects of compliance issues.

- Frame - The mass of stainless steel was reduced to minimize gamma heating. The frame was also re-designed for compatibility with established ATR test configurations for PWR Loop 2A (see Figure 40).

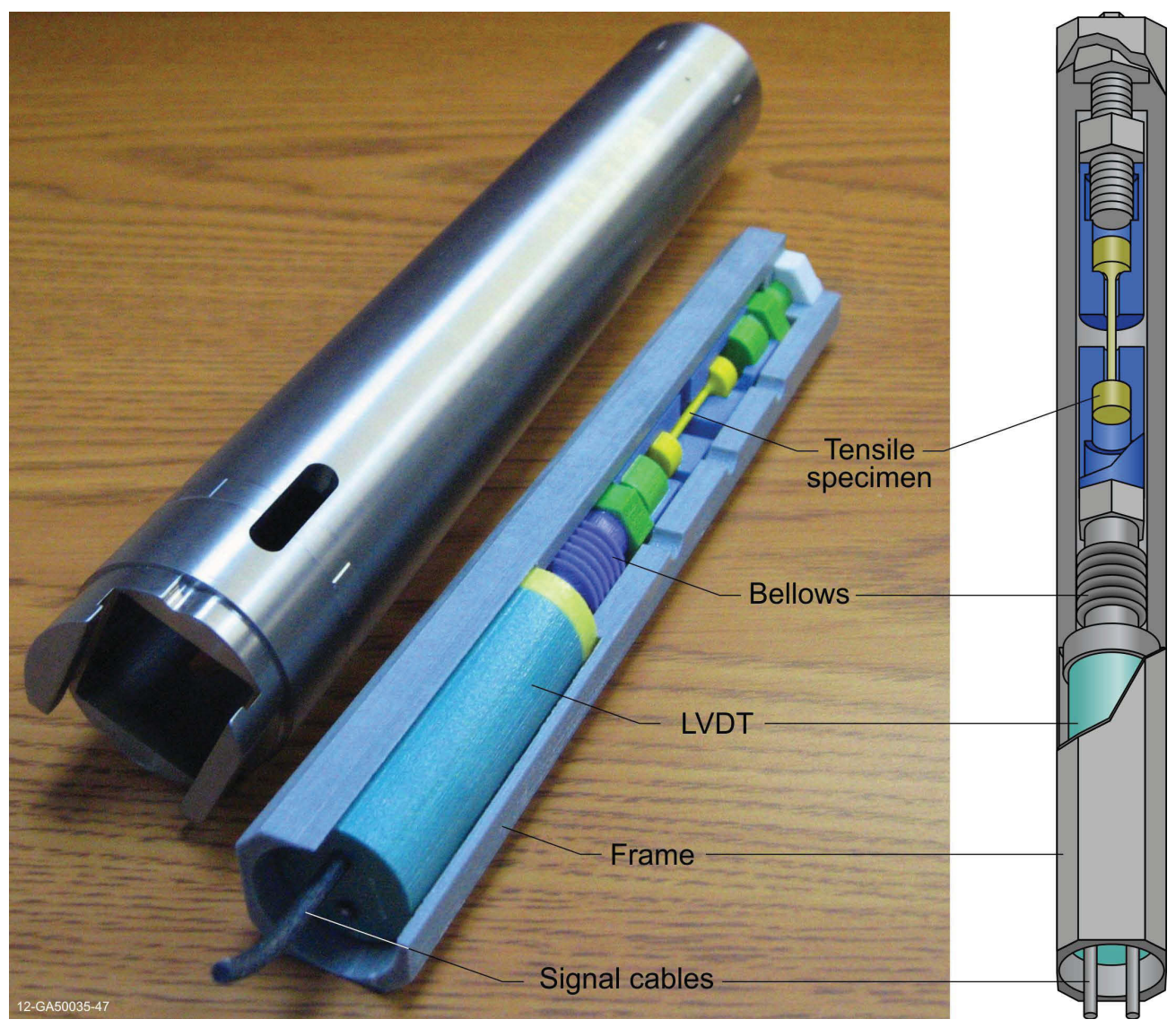

Figure 40. Enhanced creep test rig (holder, three-dimensional model and schematic).

Key components in the enhanced test rig design are listed in Table 10. Note that an aged Inconel 718 bellows was selected because of its higher strength, ${ }^{49}$ although the bellows may be fabricated from other materials (e.g., Inconel 625, Inconel X-750, or stainless steel). More detailed information regarding the enhanced creep test rig can be found in References 50, 51, and 52. 
Table 10. Summary description of components used in enhanced creep test rig.

\begin{tabular}{|c|c|c|c|}
\hline Component & Manufacturer & Model Number & Material \\
\hline Bellows & Mini-Flex & I718-320-110-790, Rev: -- C & Inconel 718, aged \\
\hline LVDT & IFE/HRP & Type 5 & $\begin{array}{c}\text { Inconel 600; Core - AISI 403; } \\
\text { Coils - Silver Alloy (Alloy 406; } \\
\text { Alcal Type E Insulation) }\end{array}$ \\
\hline Connecting Fixturing & IFE/HRP & & Inconel 600 \\
\hline Tensile Specimen & INL & NA $^{\text {a }}$ & 304 stainless steel and copper \\
\hline
\end{tabular}

a. Although no model number is applicable, detailed IFE/HRP specifications can be found in Reference 50.

\subsubsection{Characterization}

Characterization was needed to determine the bellows spring rate and effective area. These bellows characteristics must be known to quantify the load applied to any given specimen as outlined below.

Based on the configuration shown in Figure 41, the specimen load $\left(F_{S}\right)$ is given by

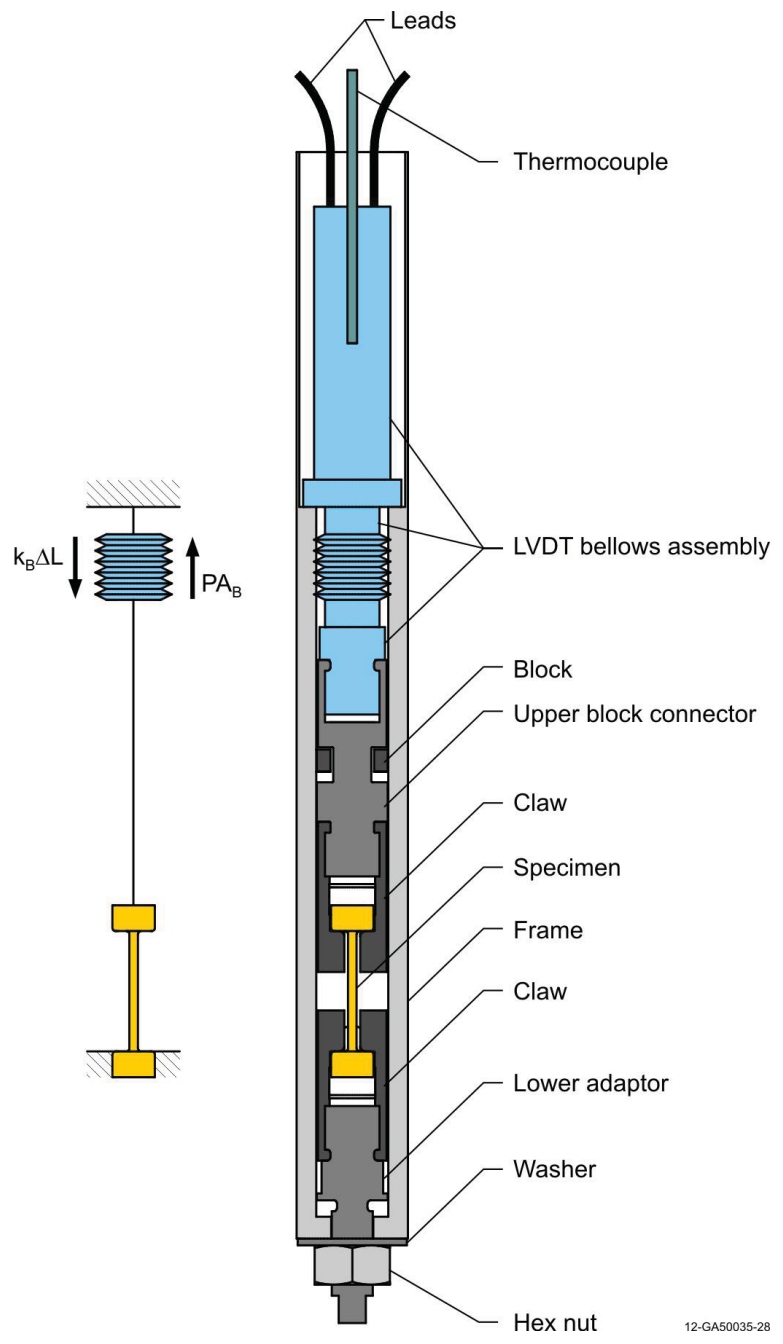

Figure 41. Test configuration with an equivalent specimen load diagram. 


$$
F_{s}=P A_{B}-k_{B} \Delta L
$$

where

$P \quad=$ pressure acting on the exterior surface of the bellows,

$A_{B}=$ bellows effective area,

$k_{B} \quad=$ bellows spring rate, and

$\Delta L=$ displacement of the bellows (and the specimen) as detected by the LVDT.

If the spring rate and effective area have been characterized, the specimen load can be readily determined as a function of pressure and displacement measurements. Spring rate and effective area characterization required use of a specialized fixture as shown in Figure 42.

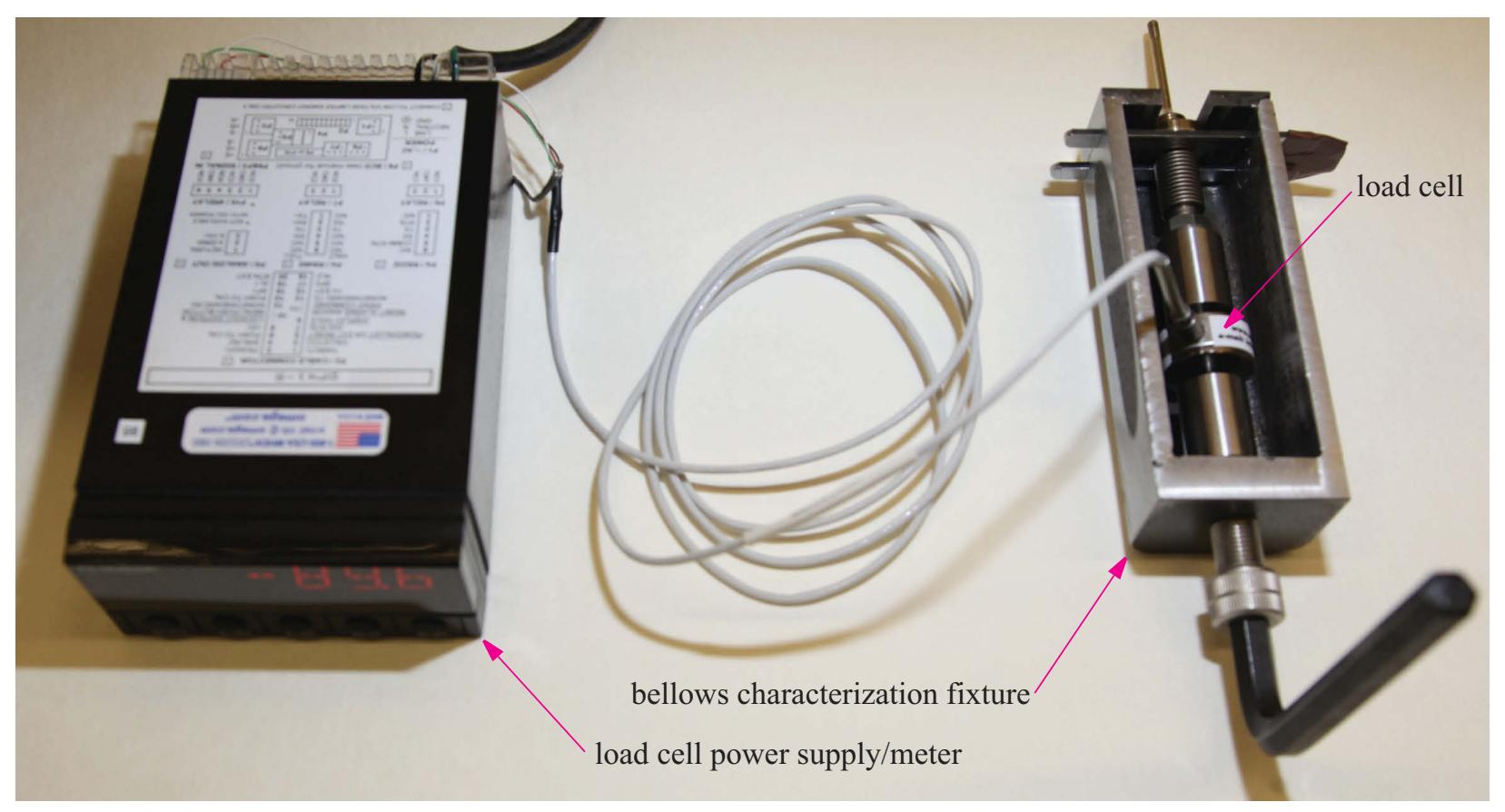

Figure 42. Bellows characterization test setup.

The bellows spring rate was determined through a series of bench top measurements where the probe assembly was constrained by one end of the fixture so that the bellows could be collapsed by incrementally tightening the Allen bolt into threads in the opposite end of the fixture. (Note that the adaptor mating with the Allen bolt is not threaded so the Allen bolt simply pushed the adaptor toward the bellows with each rotation.) As the Allen bolt was tightened, an ever increasing force was registered by the (calibrated) load cell consistent with the bellows spring rate and displacement. Displacement of the bellows was periodically measured during incremental bolt tightening, using a depth micrometer and/or by converting the revolutions of the Allen bolt into an equivalent linear movement based on the bolt pitch. The depth micrometer was clamped in line with the fixture and the micrometer was simply advanced to touch the head of the hex bolt each time the bolt was tightened as indicated in Figure 43. Relative to Equation (3), $P$ was effectively zero and $\left(F_{S}\right)$ was registered through the load cell while $\Delta L$ was measured. That allowed direct calculation of the bellows spring rate $\left(k_{B}\right)$ based on the measured values. Results from this effort are provided in Table 11. (Note that all bench top measurements were completed at room temperature with the assumption that the spring rate is temperature independent.) 


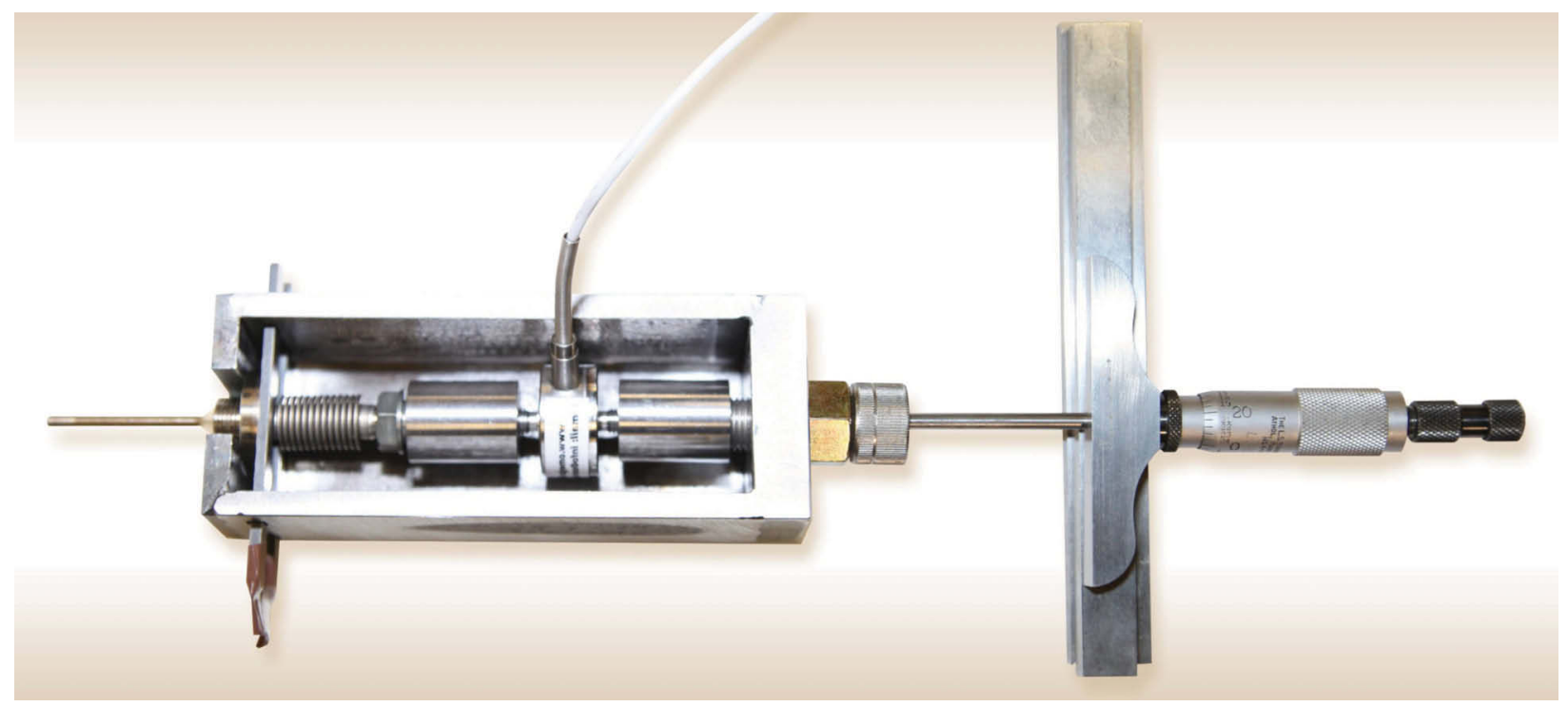

Figure 43. Depth micrometer configuration (without clamps) for measurement of the bellows spring rate.

Table 11. Results from bellows spring rate measurements.

\begin{tabular}{|c|c|c|c|c|}
\hline \multirow{2}{*}{ Test } & \multirow{2}{*}{$\begin{array}{c}\text { Description } \\
\text { (relative to calibration) }\end{array}$} & \multirow{2}{*}{ Measurement Method } & \multicolumn{2}{|c|}{ Spring Rate (N/mm) $)^{\mathbf{a}}$} \\
\cline { 4 - 5 } & & micrometer & bolt rotation \\
\hline 1 & before & micrometer / bolt rotation & 154 & 150 \\
\hline 2 & before & micrometer / bolt rotation & 186 & 168 \\
\hline 3 & before & micrometer / bolt rotation & 149 & 154 \\
\hline 4 & after & micrometer & 150 & \\
\hline
\end{tabular}

a. From a best-fit linear approximation of the measured data.

Results from Tests 1, 3, and 4 are provided in Figures 44, 45, and 46, respectively. These data are judged to be the best representation of the bellows spring rate. (Results from Test 2 were ignored because those results seem to be outliers relative to all other measurements.) From these figures (and Table 11), the average bellows spring rate was found to be $151 \mathrm{~N} / \mathrm{mm}$. This result can be compared with the manufacturer's nominal specification of 138 to $175 \mathrm{~N} / \mathrm{mm}$. The variation in the manufacturer's specification primarily depends on the nature of the bellows heat treatment. Although the bellows was heat treated, specifics of that heat treatment are unknown so any value within the specified range (i.e., $151 \mathrm{~N} / \mathrm{mm}$ ) is reasonable.

The bellows effective area was determined through a series of measurements in an argon atmosphere in an autoclave using a configuration very similar to that shown in Figure 42. In this case, however, the fixture and a threaded bolt adaptor were used to eliminate all movement of the bellows. As autoclave pressures were increased, the (constrained) bellows imparted an ever increasing force in the (calibrated) load cell.

The effective area characterization process consisted of incrementally increasing the autoclave pressure and recording that pressure along with the associated load cell output. Relative to Equation (3), it should be clear that $\Delta L$ was held at zero while $\left(F_{S}\right)$ was registered through the load cell and $P$ was measured. That allowed direct calculation of the bellows effective area $\left(A_{B}\right)$ based on the measured values. Results from this effort are listed in Table 12. (Note that all autoclave measurements were completed at room temperature with the assumption that the effective area is temperature independent.) 


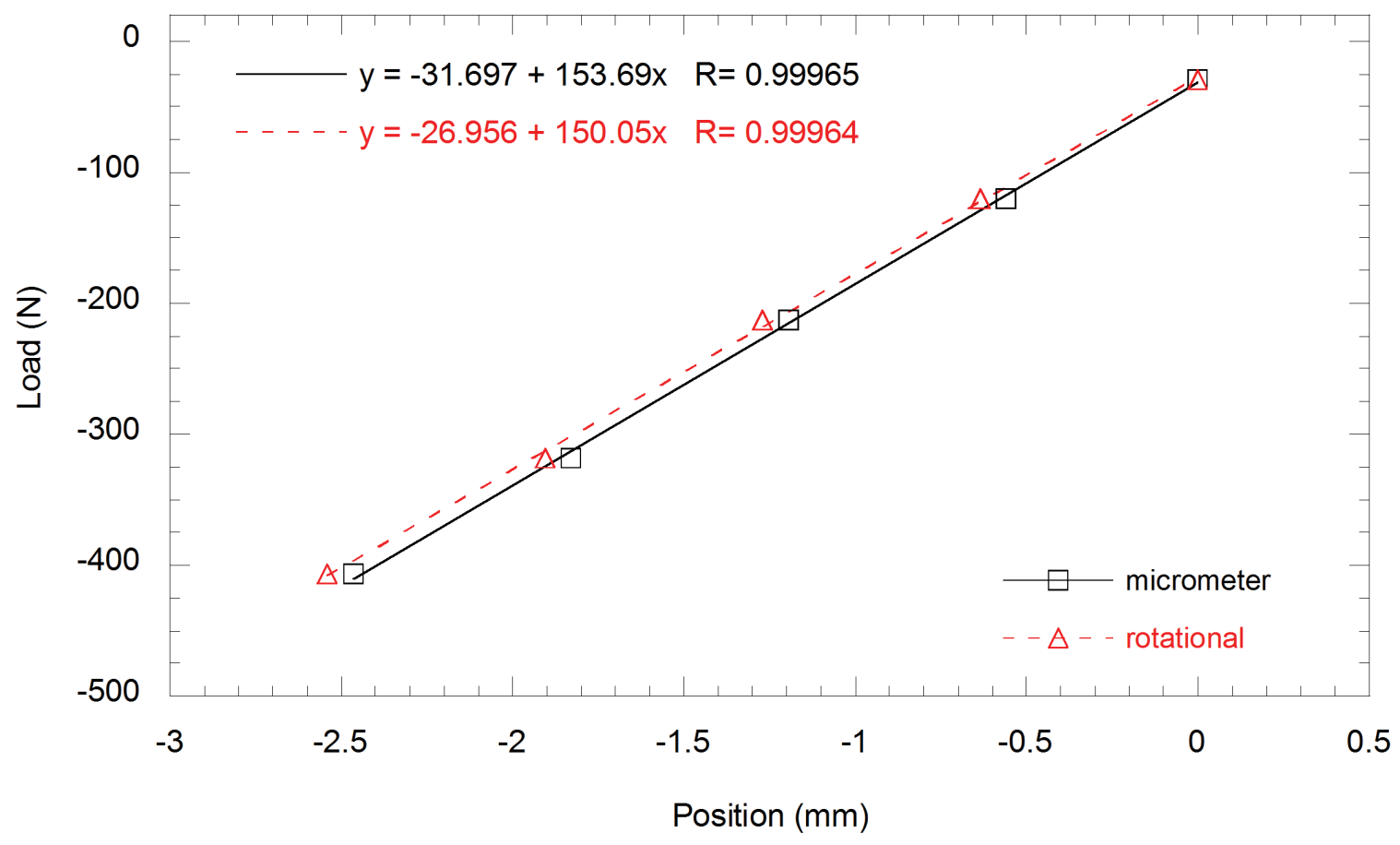

Figure 44. Bellows spring rates based on micrometer and rotational measurements in Test 5.

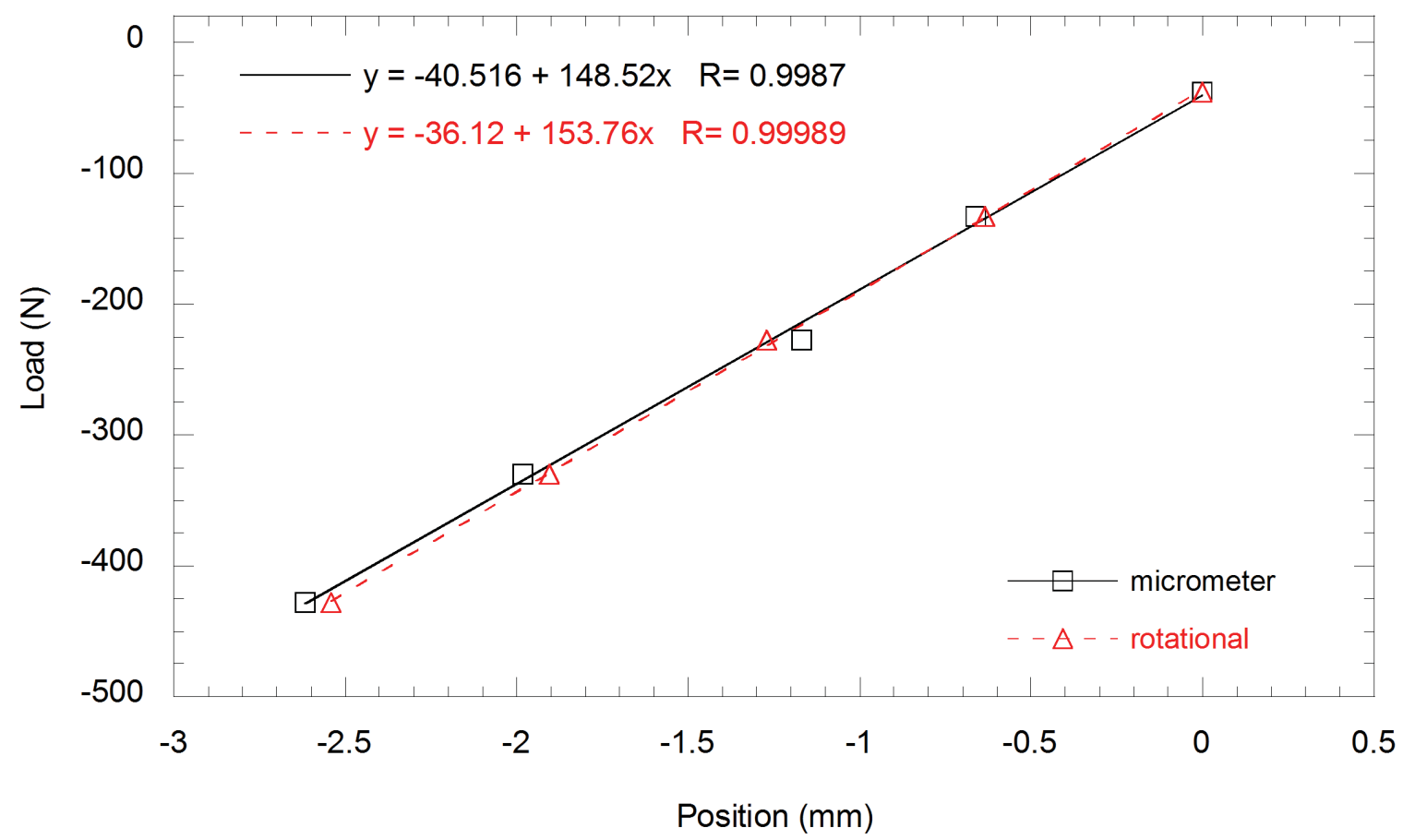

Figure 45. Bellows spring rates based on micrometer and rotational measurements in Test 7. 


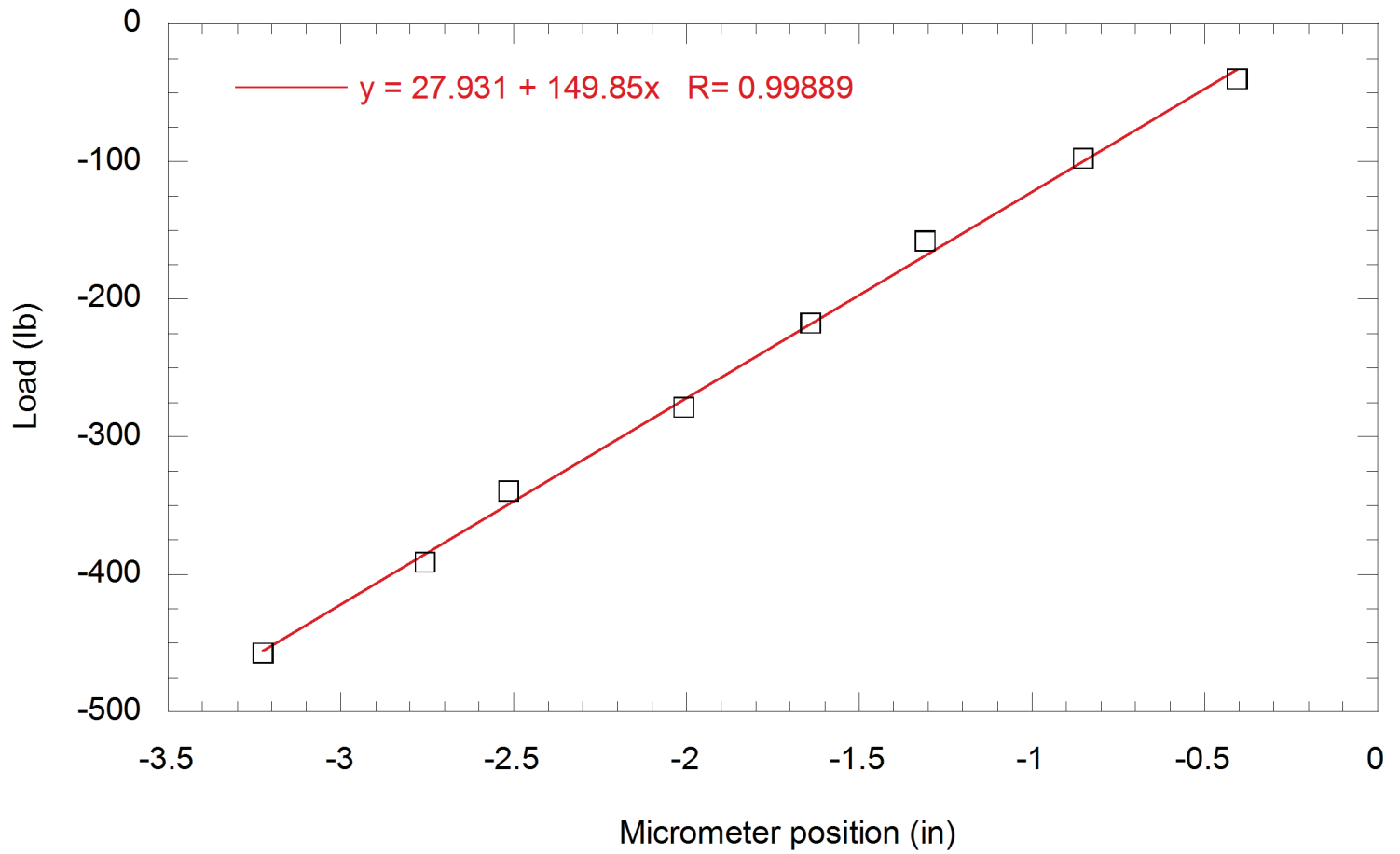

Figure 46. Bellows spring rates based on micrometer measurements in Test 8.

Table 12. Results from bellows effective area measurements.

\begin{tabular}{|c|c|c|c|}
\hline Test & Load (N) & Pressure (MPa) & Area $\left(\mathbf{m m}^{\mathbf{2}}\right)$ \\
\hline \multirow{4}{*}{1} & 297.3 & 3.930 & 75.64 \\
\cline { 2 - 4 } & 536.1 & 7.033 & 76.23 \\
\cline { 2 - 4 } & 807.5 & 10.411 & 77.56 \\
\cline { 2 - 4 } & 997.3 & 12.962 & 76.94 \\
\cline { 2 - 4 } & 791.8 & 10.549 & 75.06 \\
\cline { 2 - 4 } & 548.1 & 7.308 & 74.99 \\
\hline \multirow{5}{*}{2} & 250.8 & 3.516 & $71.33^{\mathrm{a}}$ \\
\cline { 2 - 4 } & 267.2 & 3.585 & 74.52 \\
\cline { 2 - 4 } & 528.2 & 6.964 & 75.84 \\
\cline { 2 - 4 } & 817.7 & 10.618 & 77.02 \\
\cline { 2 - 4 } & 1010.2 & 13.100 & 77.12 \\
\cline { 2 - 4 } & 805.7 & 10.480 & 76.88 \\
\cline { 2 - 4 } & 549.0 & 7.377 & 74.41 \\
\cline { 2 - 4 } & 265.8 & 3.723 & $71.40^{\mathrm{a}}$ \\
\hline
\end{tabular}

a. Ignored as an outlier. 
As indicated in the table, some of the data at low pressure appeared to be inconsistent with respect to all other data. It is believed that this inconsistency was related to hysteresis effects associated with decreasing autoclave pressures. If those outliers are ignored, the bellows average effective area was found to be $76.0 \mathrm{~mm}^{2}$. Relative to the manufacturer's nominal reported area of $79.4 \mathrm{~mm}^{2}$, this measured discrepancy (of $\sim 4 \%$ ) is believed to be within normal manufacturing tolerances.

\subsubsection{Calibration}

As discussed in Reference 52, the LVDT bellows assembly was calibrated at room temperature and at 150 , 250 , and $350{ }^{\circ} \mathrm{C}$, which covers the range of temperatures expected during deployment in the ATR Loop 2A. This calibration provides the means to relate any measured LVDT output voltage to a corresponding displacement. Although IFE/HRP provided calibration as part of their LVDT delivery agreement with INL, their calibration could differ from INL data based primarily on potential differences in signal conditioning electronics. INL calibration was therefore required.

Bench top and autoclave calibrations at room temperature were completed. Bench top measurements (at room temperature) provided a way to check results that were subsequently obtained through (room temperature) autoclave testing. That way, a degree of confidence was achieved relative to the validity of all autoclave testing, which was deemed the best method to obtain higher temperature calibration results.

The bench top setup was essentially identical to Figure 43. The addition of the LVDT to the end of the probe assembly was the only difference relative to the figure. With the LVDT in place, each advancement of the Allen bolt (which was measured with the depth micrometer) was accompanied by a change in the LVDT output voltage. The bench top calibration process consisted of incrementally tightening the Allen bolt, recording the LVDT output voltage, and measuring the associated displacement.

Autoclave testing was considerably more complex than bench top testing because of difficulties measuring displacement inside the autoclave. Those difficulties were addressed through the design and fabrication of a specialized fixture with positive mechanical stops to accurately define a displacement. Components in that fixture are shown in Figure 47 while the (semi-)assembled fixture is shown in Figure 48.

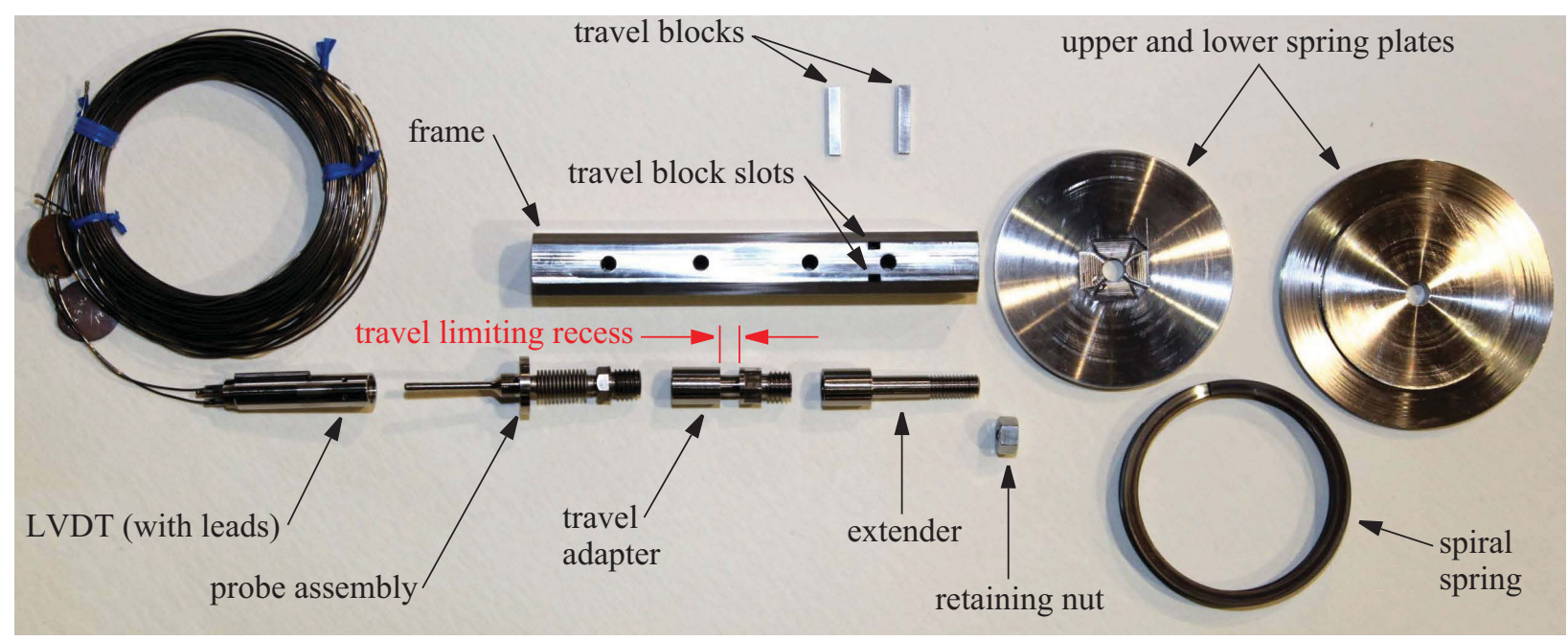

Figure 47. Autoclave calibration fixture components. 


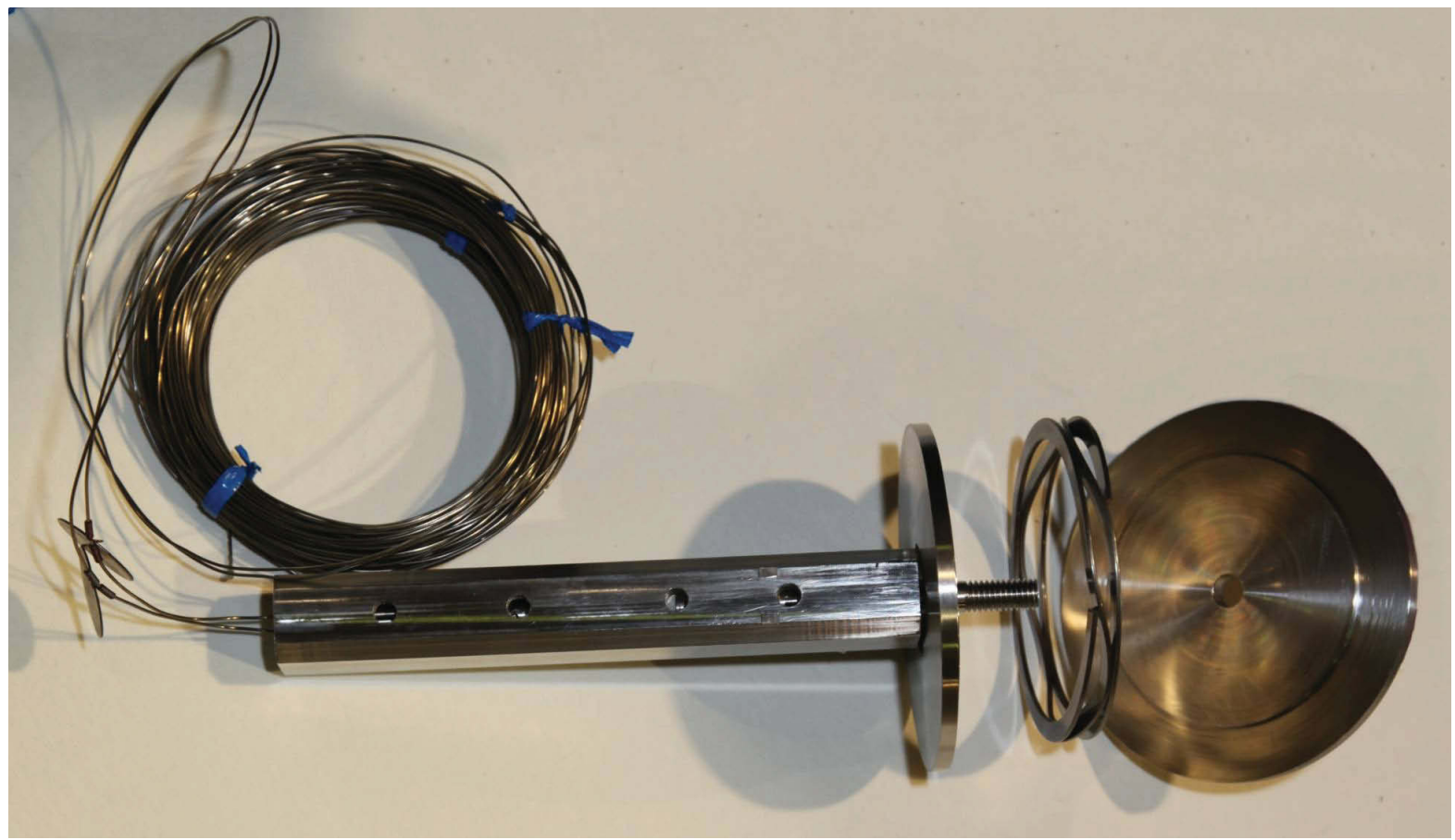

Figure 48. Assembled autoclave calibration fixture.

The specialized autoclave calibration fixture was assembled with the retaining nut tightened just enough to (slightly) stretch the bellows and pull the top of the travel limiting recess (in the travel adapter) into contact with the travel blocks. That provides the initial position of the LVDT for all autoclave testing. As the pressure is increased during each test, the bellows contracts, which collapses the spiral spring and allows movement of the travel adapter. At some autoclave pressure, bellows contraction is sufficient for the bottom of the traveling limit recess to contact the travel blocks, which defines the final LVDT position for all autoclave testing. (Note that the travel limit is the difference between the travel limit recess of $7.34 \mathrm{~mm}$ and the travel block height of $5.08 \mathrm{~mm}$ for a total of $2.26 \mathrm{~mm}$, which is within the bellows maximum travel limit of $3.7 \mathrm{~mm}$.)

All autoclave calibration testing was conducted in a pressurized argon environment where autoclave heaters were used to achieve the desired temperature for each test. This was a practical way to complete the calibration as a function of temperature. Results from calibration tests at room temperature and at 150, 250, and $350{ }^{\circ} \mathrm{C}$ are listed in Table 13. As indicated in the table, room temperature tests were conducted on the bench top and in an autoclave. Results from Test 1 are shown in Figure 49, which are typical of the room temperature bench top data. Corresponding room temperature autoclave results are provided in Figure 50.

Table 13. Calibration results.

\begin{tabular}{|c|c|c|c|}
\hline Test & Description & Temperature $\left({ }^{\circ} \mathbf{C}\right)$ & Sensitivity (mV/mm) \\
\hline 1 & bench top & room & 1687 \\
\hline 2 & bench top & room & 1678 \\
\hline 3 & autoclave & room & 1694 \\
\hline 4 & autoclave & 150 & 1719 \\
\hline 5 & autoclave & 250 & 1749 \\
\hline 6 & autoclave & 350 & 1767 \\
\hline
\end{tabular}




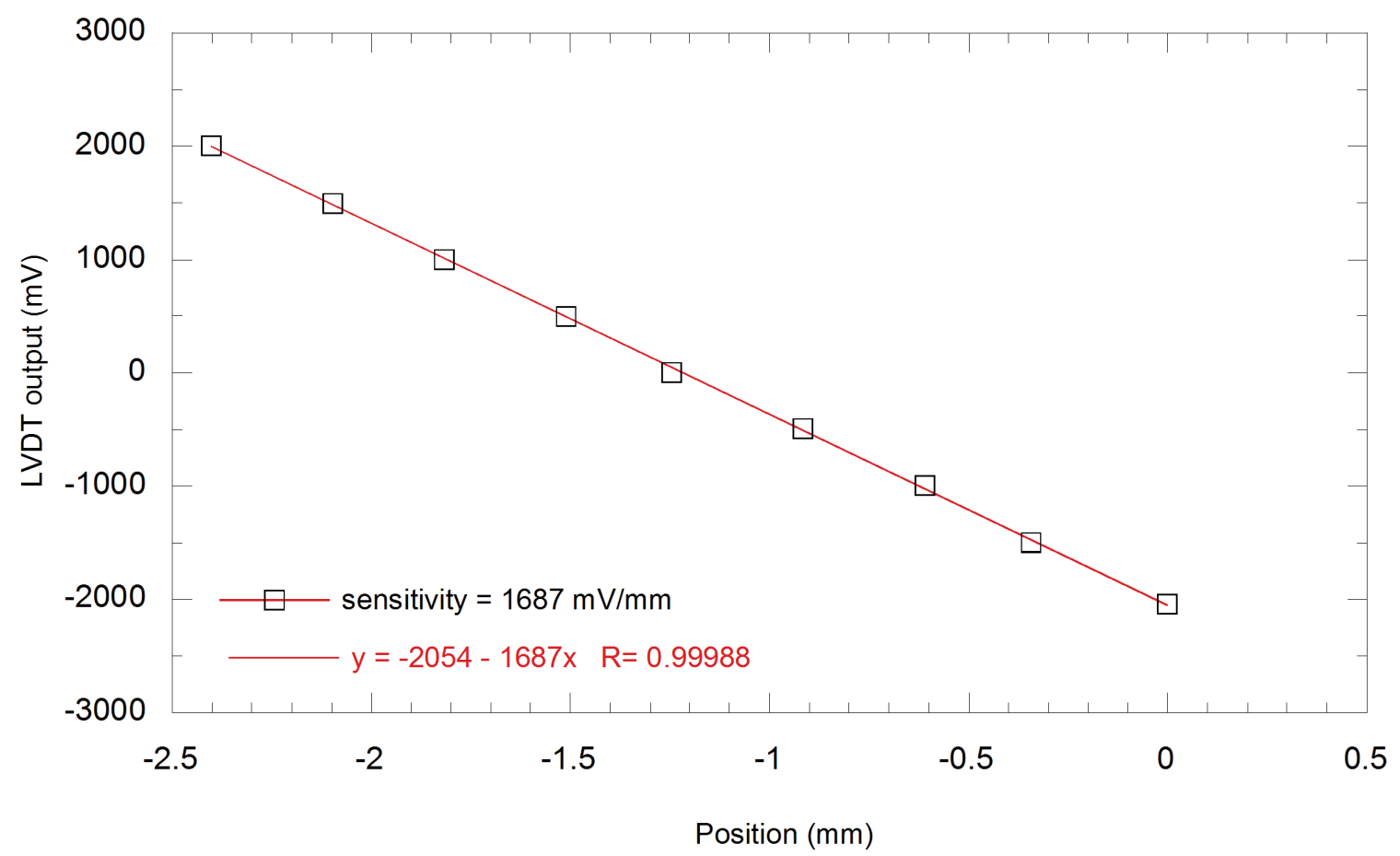

Figure 49. Bench top calibration results from Test 1 (at room temperature).

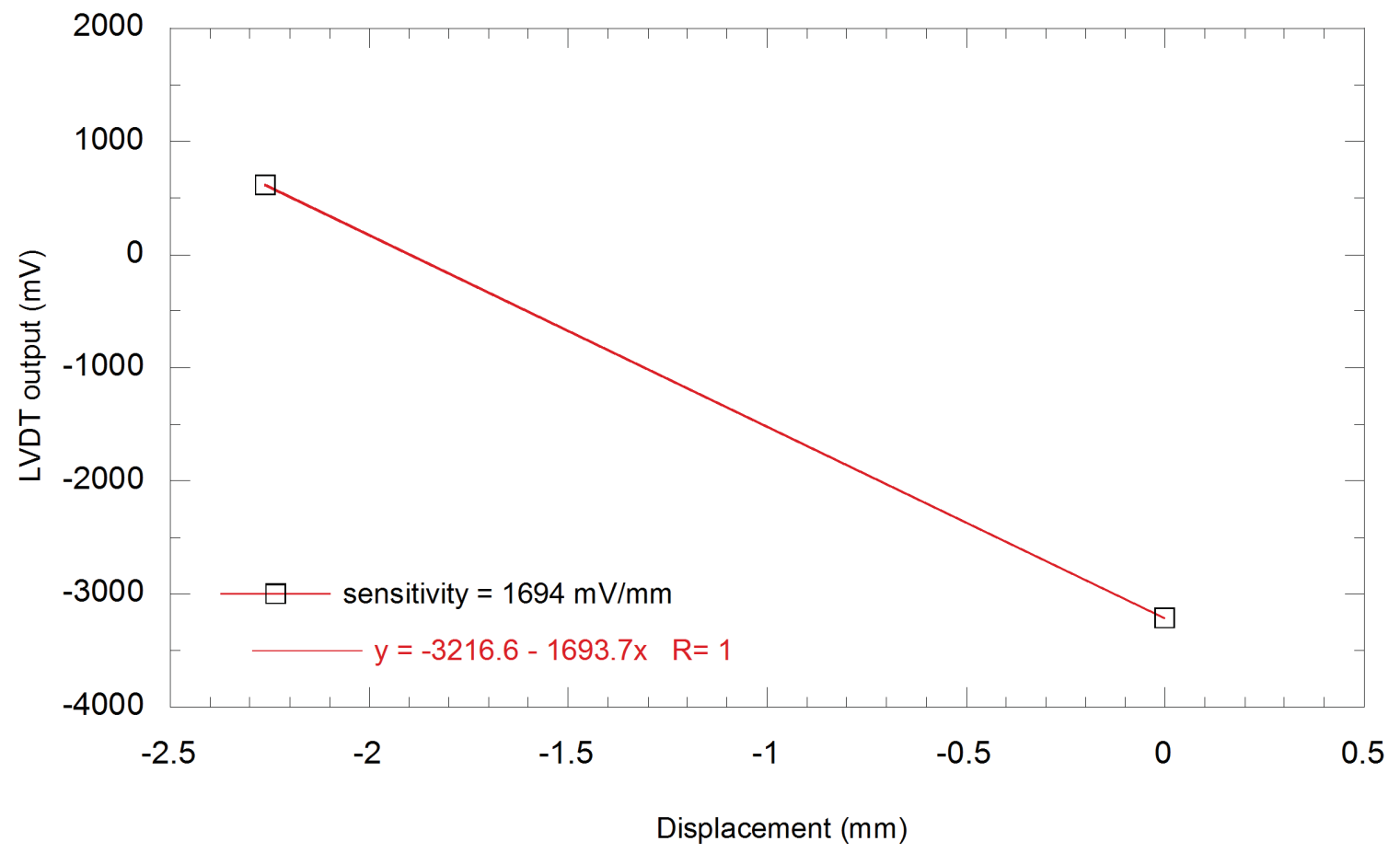

Figure 50. Autoclave calibration results from Test 3 (at room temperature). 
As indicated in Figure 49, the LVDT output voltage and the associated displacement were collected as the Allen bolt was incrementally tightened (yielding a total of 9 data points in this case). In contrast, autoclave data shown in Figure 50 were limited to just 2 points; one where the travel adapter was pulled downward (with the retaining nut) to contact the top of the travel blocks and one where bellows compression (due to autoclave pressurization) pulled the travel adapter upward to contact the bottom of the travel blocks.

Regardless of these differences in the method for data collection, the room temperature results were found to be consistent. This indicates that the specialized autoclave fixture can be used to accurately collect calibration data inside the autoclave.

Averaging all room temperature calibration data yields a value of $1686 \mathrm{mV} / \mathrm{mm}$. It is worth noting that averaging appears to be justified because differences in the measured calibration values do not translate to any appreciable travel discrepancy. Specifically, the maximum discrepancy for bellows travel across all room temperature data is (at most) $0.035 \mathrm{~mm}$.

In addition to room temperature calibration data, measurements were also completed at 150,250, and $350{ }^{\circ} \mathrm{C}$ as indicated in Table 13. This provides the means to relate any measured LVDT output voltage to a corresponding displacement over the range of temperatures anticipated in ATR deployment. These measurements can be compared to IFE/HRP calibration data as shown in Figure 51. Although the general trends in the data sets are very similar, there is clearly a shift (or an offset bias) between the data sets. All reason(s) behind this shift are unknown; however, differences between INL and IFE/HRP LVDT signal conditioning electronics have been identified as the major contributor.

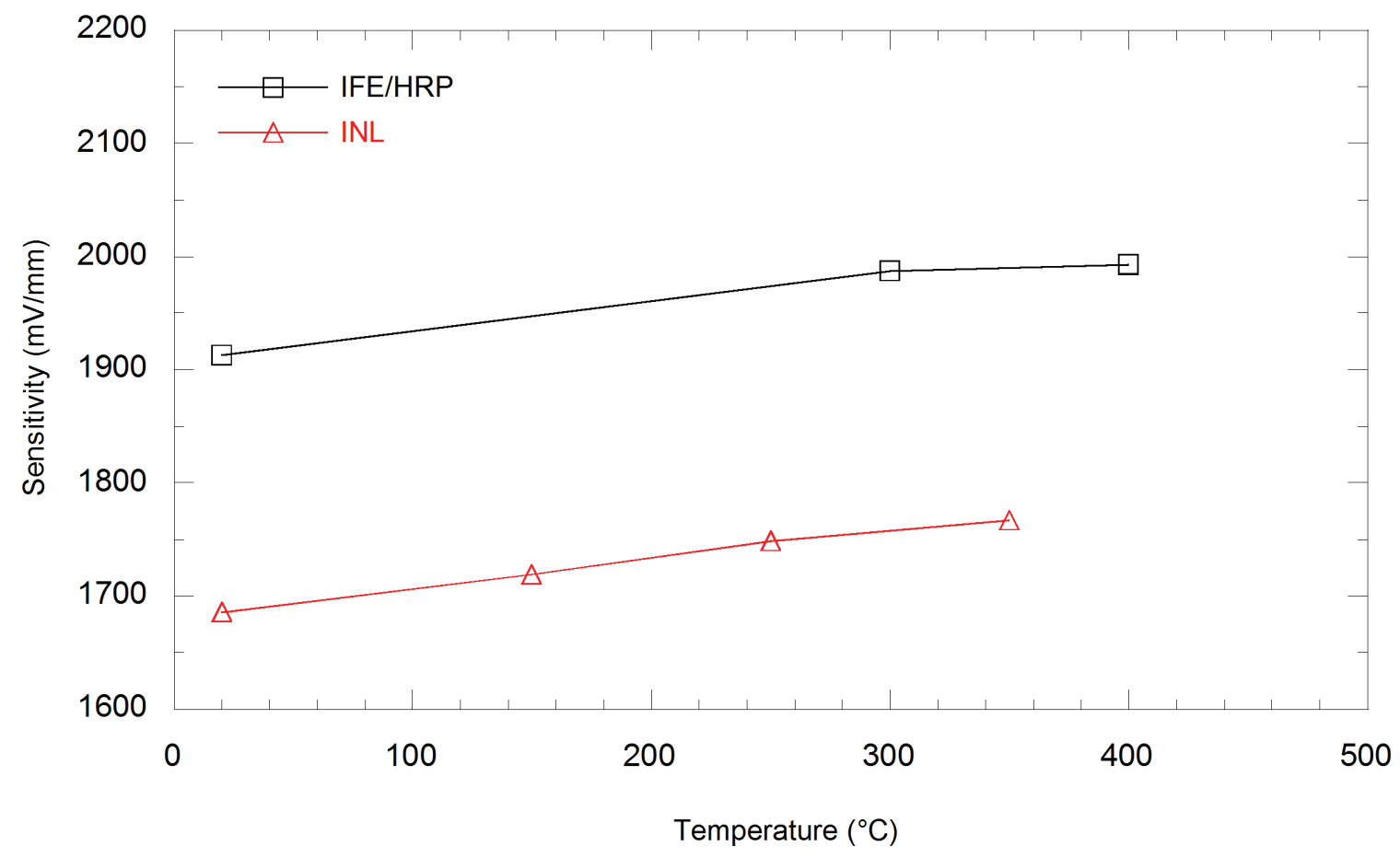

Figure 51. Calibration results from IFE/HRP and INL. 


\subsubsection{Status}

An enhanced creep test rig has been designed, characterized, and calibrated. The rig is ready for deployment to measure specimen elongation in real time during irradiation testing in ATR Loop 2A. Once it is deployed in the ATR, data from this test rig will be evaluated to assess its performance and refine the design (if appropriate) to develop standard LVDT-based test rig designs for irradiation testing in ATR and HFIR.

\subsubsection{Enhanced Creep Test Rig with Variable Loading}

As discussed in References 1, 53, and 54, several MTRs (e.g., BR2 with assistance from VTT Technical Research Center of Finland, HANARO with assistance from KAERI, JMTR with assistance from JAERI, and OSIRIS with assistance from CEA) have deployed creep test rigs with a bellows to apply a variable load to a specimen and LVDTs to detect growth of the specimen. Selected aspects of these various creep test setups are compared in Table 14. In most cases, test pressures external to the bellows are offset by internal bellows pressurization to produce the variable loads. As indicated, however, most of the setups are designed to test specimens in inert gas. A notable exception is specimen testing in reactor coolant conducted in BR2.

Table 14. Summary of creep testing in MTRs. ${ }^{54}$

\begin{tabular}{|c|c|c|c|c|c|}
\hline Country/MTR & Test Conditions & $\begin{array}{l}\text { Real Time } \\
\text { Load } \\
\text { Control }\end{array}$ & Method & $\begin{array}{c}\text { Real Time } \\
\text { Elongation } \\
\text { Detection }\end{array}$ & Method \\
\hline $\begin{array}{l}\text { Belgium/BR2 with } \\
\text { assistance from VTT } \\
\text { Technical Research } \\
\text { Center of Finland }\end{array}$ & $\begin{array}{l}\text { Stagnant reactor coolant } \\
\qquad\left(\sim 90^{\circ} \mathrm{C}\right)\end{array}$ & Yes & $\begin{array}{l}\text { Internally } \\
\text { pressurized } \\
\text { bellows }\end{array}$ & Yes & Monitored LVDT \\
\hline France/OSIRIS ${ }^{\mathrm{a}}$ & $\begin{array}{c}\text { Inert gas, water, and } \mathrm{NaK} \\
\text { (from room temperature } \\
\text { up to } 380^{\circ} \mathrm{C} \text { ) }\end{array}$ & Yes & $\begin{array}{l}\text { Internally } \\
\text { pressurized } \\
\text { bellows }\end{array}$ & $\begin{array}{c}\text { Yes } \\
\text { (also external } \\
\text { diameter gauges) }\end{array}$ & Monitored LVDT \\
\hline Norway/HBWR & $\begin{array}{c}\text { Inert gas } \\
\left(240-400^{\circ} \mathrm{C}\right)\end{array}$ & Yes & $\begin{array}{l}\text { Internally } \\
\text { pressurized } \\
\text { bellows }\end{array}$ & $\begin{array}{c}\text { Yes } \\
\text { (also external } \\
\text { diameter gauges) }\end{array}$ & $\begin{array}{l}\text { Monitored LVDT } \\
\text { (under development } \\
\text { for } 600{ }^{\circ} \mathrm{C} \text { and } \\
250 \text { bar) }\end{array}$ \\
\hline Japan/JMTR & $\begin{array}{l}\text { Inert gas } \\
\left(550^{\circ} \mathrm{C}\right)\end{array}$ & Yes & $\begin{array}{l}\text { Internally } \\
\text { pressurized } \\
\text { bellows }\end{array}$ & Yes & Monitored LVDT \\
\hline Netherlands/HFR & $\begin{array}{l}\text { Inert gas and } \mathrm{NaK} \\
\quad\left(300-600^{\circ} \mathrm{C}\right)\end{array}$ & Yes & $\begin{array}{l}\text { Self-contained } \\
\text { spring-washer } \\
\text { system }\end{array}$ & $\begin{array}{c}\text { Yes } \\
\text { (semi-continuous) }\end{array}$ & Monitored LVDT \\
\hline Korea/HANARO & $\begin{array}{c}\text { Inert gas } \\
\text { (up to } 600{ }^{\circ} \mathrm{C} \text { ) }\end{array}$ & Yes & $\begin{array}{l}\text { Internally } \\
\text { pressurized } \\
\text { bellows }\end{array}$ & Yes & Monitored LVDT \\
\hline
\end{tabular}

a. In upcoming tests. Previous tests relied on out-of-pile measurements with strain gauges.

The rig developed by VTT and tested in BR2 is shown in Figure 52. The materials used in the irradiation test were thin $(0.3 \mathrm{~mm})$ sheets of oxygen free high conductivity copper containing trace amounts of $\mathrm{Ag}, \mathrm{Si}$, $\mathrm{Fe}, \mathrm{Mg}$, and $\mathrm{CuCrZr}$ alloy because these materials are expected to be exposed to thermal and mechanical loads in International Thermonuclear Experimental Reactor. The test rig includes a pneumatic loading unit, which applies a tensile load on the test specimen using inert gas to pressurize a metallic bellows and a 
LVDT from IFE/HRP to measure the resulting displacement produced in the specimen. The load generated by the pneumatic unit is calculated from the pressure differential applied to the bellows. The stiffness and effective cross section of the bellows also impacts the load exerted on the specimen. However, the stiffness of the pneumatic loading unit differs from the stiffness of the bellows. Hence, VTT developed a calibration unit to correlate the applied gas pressure in the bellows with the actual load acting on the specimen. Test results demonstrated that it is technically feasible to carry out well-defined, controlled, dynamic in-pile tensile tests, making it possible to investigate the intrinsic role of applied stress and displacement damage acting concurrently in determining the global deformation behavior of the specimen under dynamic irradiation conditions. (Additional details related to the design and operation of this unit may be found in References 55 and 56.)
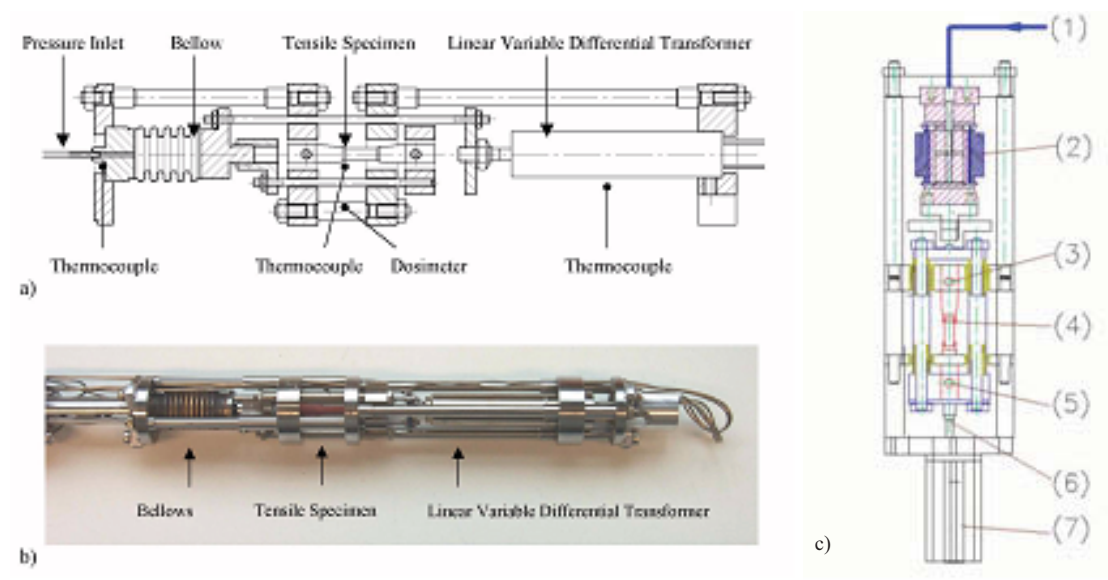

Figure 52. Tensile test module irradiated in BR2 ( $a$ and $b$ ) with schematic of tensile test module (c) that includes: (1) gas line, (2) pneumatic loading unit, (3) firm specimen fixing point, (4) specimen, (5) movable specimen fixing point, (6) LVDT plunger, and (7) LVDT holder. ${ }^{55,56}$

Based on VTT concepts and the INL enhanced creep test rig (described in Section 5.2.1), efforts were initiated under the FCRD program during FY12 to develop a conceptual design for a creep test rig for deployment in US MTRs with the ability to apply a variable load to a specimen. Like the enhanced creep test rig, this design will allow testing in reactor coolant at PWR conditions. As indicated in Table 14, the enhanced creep test rig, and completion of this design for variable specimen loading, will position INL as the second organization in the world capable of real-time creep testing in reactor coolant.

During FY12, an LVDT was procured from IFE/HRP. An LVDT / bellows assembly was then designed with provisions for internal pressurization of the bellows via an Inconel tube (with an OD of $1.59 \mathrm{~mm}$ ) as shown in Figure 53. The key to internal pressurization lies in a small diameter hole ( $\sim 1 \mathrm{~mm}$ ID) that will be drilled through the edge of the flange separating the LVDT from the bellows. This hole will tap into an annular gap between the LVDT core and the core guide tube (inside the LVDT). The small hole provides the means for pressurization because the annular gap accessed by the hole also extends beyond the flange to regions inside the bellows. The Inconel pressurization tube, which will be seal welded to the flange, will connect will the small hole to a high pressure inert gas supply with an appropriate control system. (Note that the penetration of the small hole through the edge of the flange will also be seal welded.)

The LVDT / bellows assembly was designed so that it can be used interchangeably with the enhanced creep test rig described in Section 5.2.1. As indicated in Figure 54, the LVDT / bellows assembly, and the hardware associated with connections to the specimen, fit in the frame for the enhanced creep test rig. As previously discussed, this frame also fits inside the test holder as shown in Figure 40. Ultimately, this 


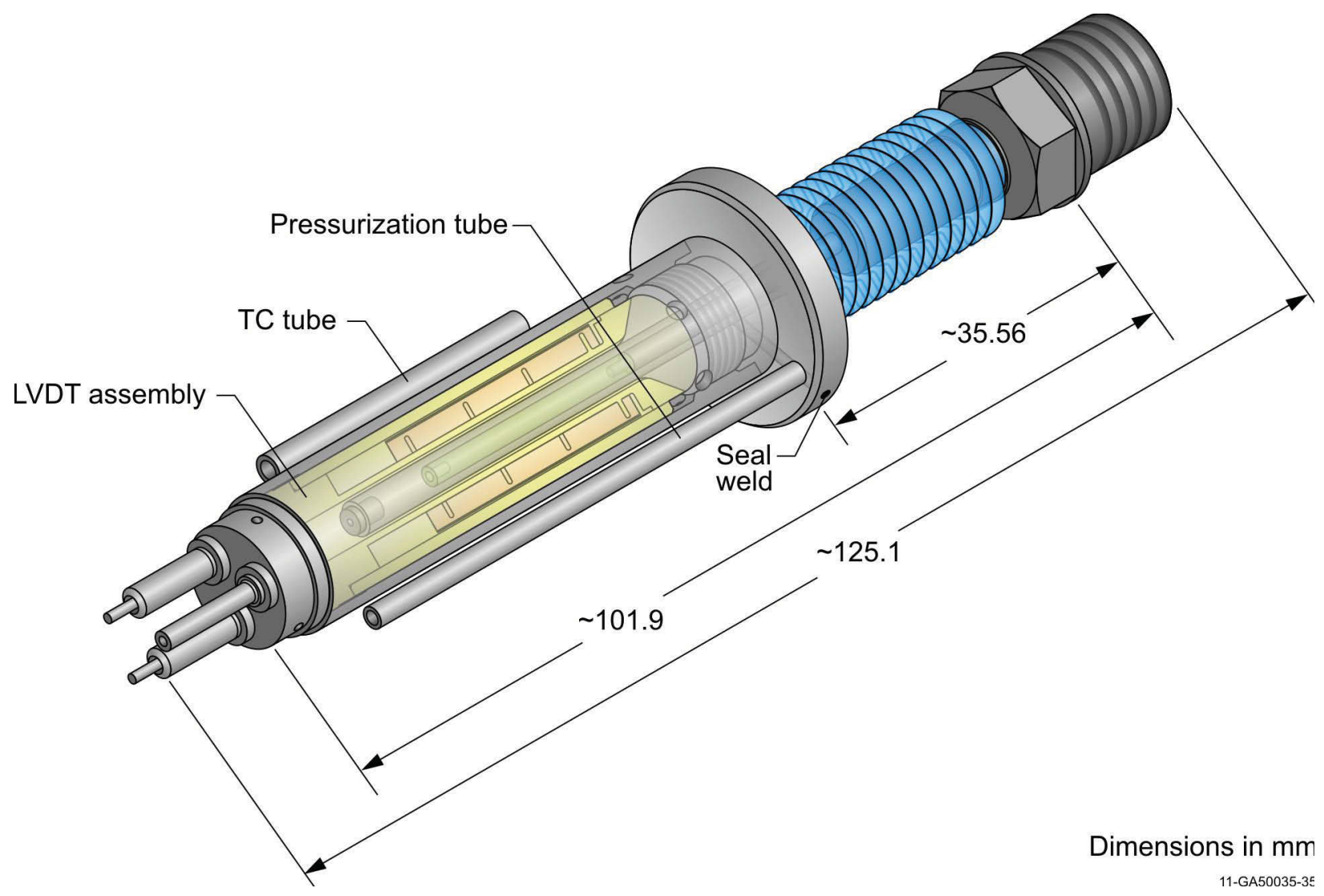

Figure 53. LVDT / bellows assembly with provisions for internal pressurization of the bellows.

means that enhanced creep test rigs, with or without variable specimen loading capabilities, can be deployed in established ATR test configurations for PWR Loop 2A. Depending on funding availability in FY13, the creep test rig design with variable specimen loading capabilities will be completed, fabricated, and tested from room temperature and pressure conditions up to PWR temperature and pressure conditions in an HTTL autoclave. This testing will be used to calibrate the rig as a function of temperature while verifying all test rig functions.

\subsubsection{Diameter Gauge Test Rig}

As discussed in Reference 1, the IFE/HRP currently uses a gauge for measurement of cladding diameter to assess cladding creep, fuel pellet-cladding mechanical interaction, fuel creep / relaxation, and the accumulation of fuel rod crud deposits. This diameter gauge will be evaluated (and enhanced as needed) within the FCRD program for deployment in US MTRs.

The gauge is a key component in the IFR/HRP representative test rig shown in Figure 55(a), which provides real-time in-pile detection of fuel diameter changes, temperature, and neutron exposure, cladding elongation, and loop coolant temperature, flow, and chemistry (concentration, $\mathrm{pH}$, etc.). The test rig relies on LVDT-based technology, although the diameter gauge differs from a typical LVDT in several ways. First, the two primary coils and the two secondary coils are wound on a ferritic bobbin as opposed to the Inconel bobbin used in an LVDT. Second, the diameter gauge uses an armature instead of the magnetically-permeable core used in the LVDT. Finally, the position of the armature relative to the two secondary coils changes the balance between the secondary voltages in the diameter gauge while the balance between the secondary voltages is determined by the position of the magnetically-permeable core in an LVDT. (The output of both devices is proportional to the balance between the secondary voltages.) 


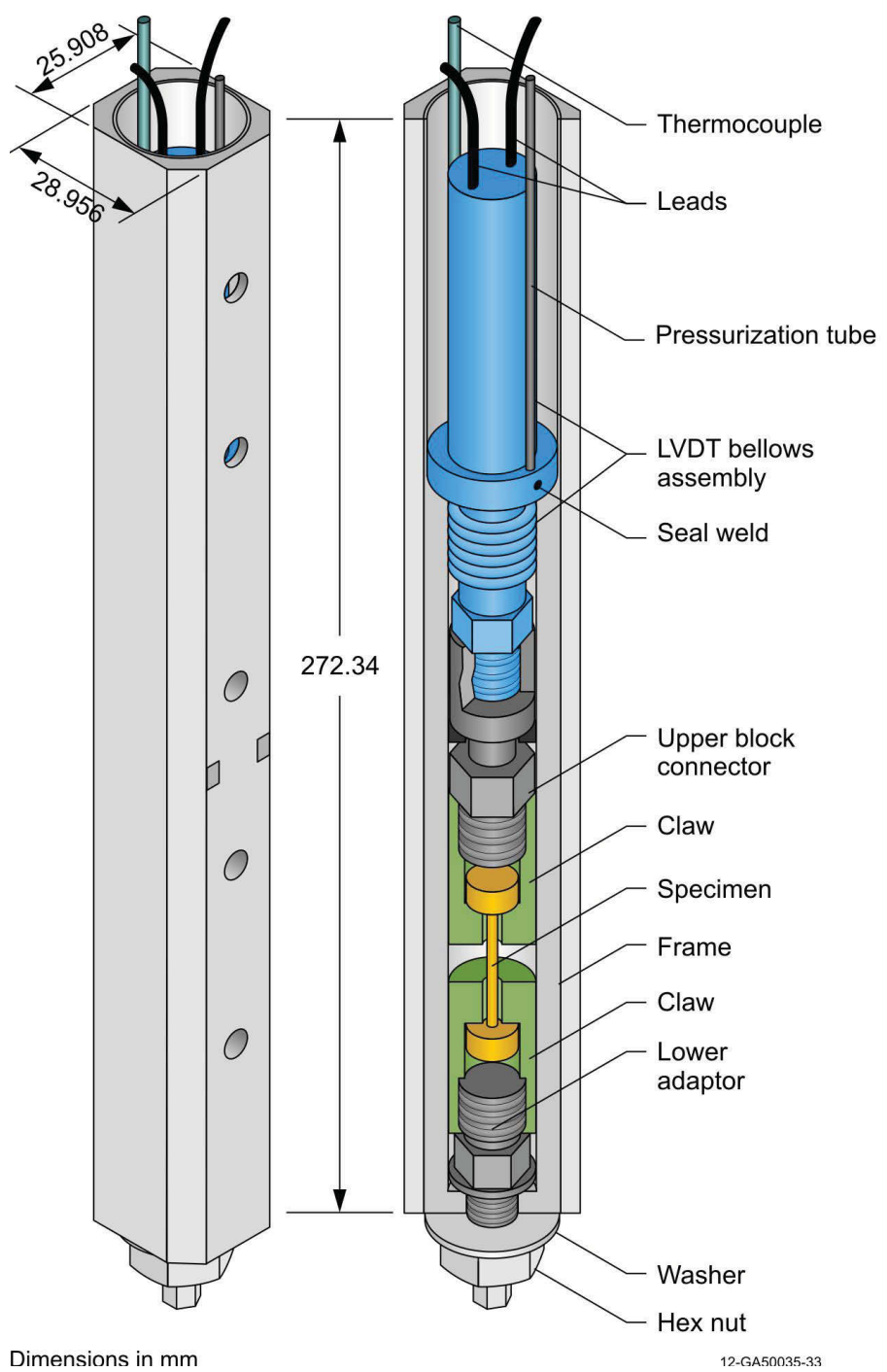

Figure 54. Creep test rig incorporating variable specimen loading capabilities.

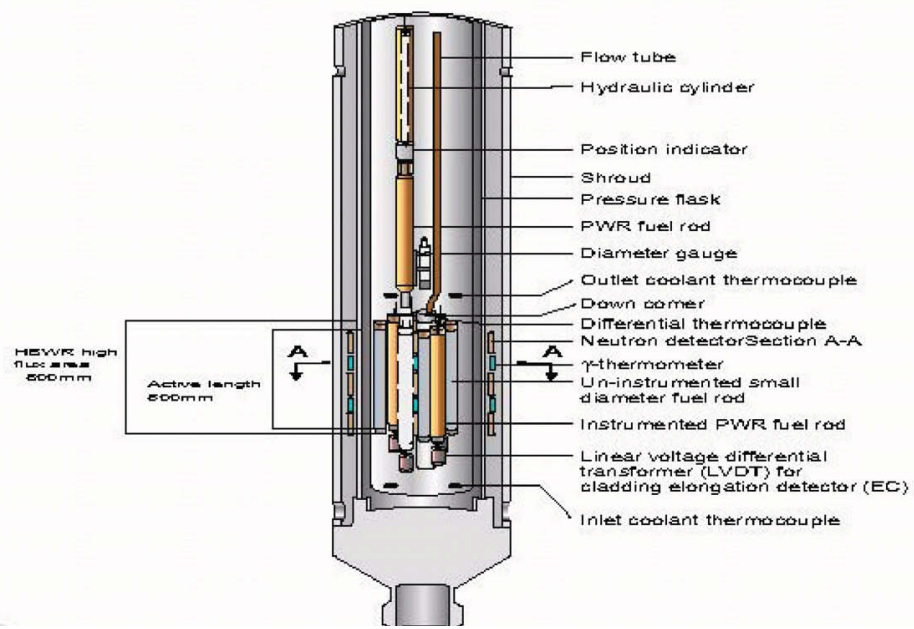

(a)

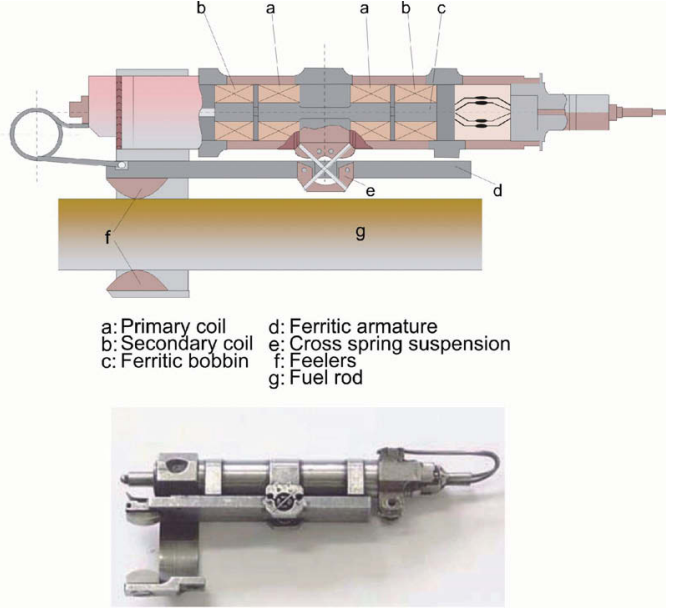

(b)

Figure 55. IFE/HRP fuel pellet cladding interaction/crud deposition test rig (a) and diameter gauge (b). 
As shown in Figure 55(b), the diameter gauge contains two feelers on opposite sides of the fuel rod. During testing, the diameter gauge travels along the fuel rod using an in-core hydraulic drive and positioning system. A calibration is performed in conjunction with each diameter measurement via machined calibration blocks attached to the fuel rod end plugs. The diameter gauge is accurate to $\pm 2 \mu \mathrm{m}$ at coolant conditions up to 165 bar and $325^{\circ} \mathrm{C}$. However, as discussed in Section 5.2.1.1, IFE/HRP collaborations with INL have led to an enhanced LVDT (using silver alloy coil materials and alternate fabrication processes) that have increased temperature limits and accuracy. IFE/HRP is currently investigating options that would further increase LVDT operating temperatures. ${ }^{57}$

As seen in Figure 55(b), the design of the diameter gauge is somewhat complicated in that sections of nonmagnetic material have to be welded to sections of magnetic material. Therefore, IFE/HRP is investigating a new design in which the outer wall of the sensor consists of a single tube of Inconel $600 .{ }^{58}$ As shown in Figure 56(a), the new design has been optimized using finite element calculations. The inner body is now made from one piece where the coil separators are integral parts of the body [see Figure 56(b and c)]. In order to prevent flux linkage between the (magnetic) coil separators and the ferritic armature, the part of the separators facing the armature is shaved off making a large air gap between coil separators and the housing. Tests show that the new diameter gauge, operated in self-compensating mode, has a linear response over the range $\pm 0.9 \mathrm{~mm}$, which is much longer than the $0.2 \mathrm{~mm}$ range typically required for in-pile applications. The accuracy of the new diameter gauge is the same as the original design at approximately $\pm 2 \mu \mathrm{m}$.

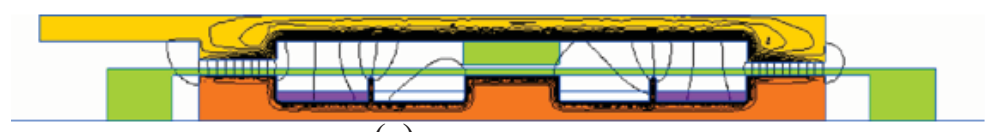

(a)

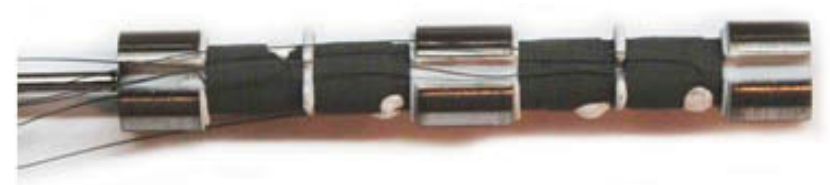

(b)

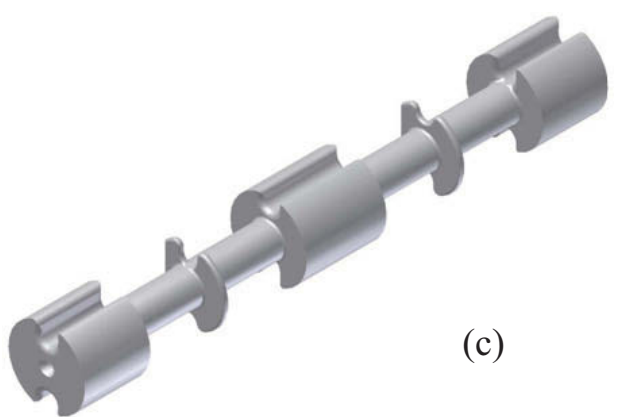

Figure 56. Simplified diameter gauge; (a) finite element analysis showing magnetic field patterns; (b) inner body with coils; and (c) inner body.

If FCRD funding is available, activities will be initiated during FY13 to procure and perform laboratory evaluations to assess the viability of using a diameter gauge in higher flux, higher temperature US MTRs.

\subsection{Task 2: Flux Measurements}

Real-time in-pile flux measurements are generally performed using self powered neutron detectors (SPNDs) or fission chambers. An ATR NSUF instrumentation project at the Advanced Test Reactor Critical (ATRC) facility is investigating use of such sensors for online flux and power measurements. Initial investigations have demonstrated the sensors to be a viable candidate for use in higher flux environments, such as ATR or HFIR irradiations; however it is recognized that a more robust, smaller, multi-purpose sensor is desirable for FCRD irradiations. Efforts are underway to develop a robust sensor, known as a micro-pocket fission detector (MPFD), that has the ability to simultaneously measure thermal flux, fast flux, and temperature all within a single compact sensor package. 
The objective of this joint INL, Kansas State University (KSU), and CEA collaborative task, which is funded by the NEET program, is to develop a MPFD. Miniature fission chambers and thermocouples have been used in-pile at research and test reactors throughout the world; however, none have been deployed in a single compact package to survive the harsh conditions that exist in high performance reactors. In this task, sensors are developed and evaluated that are capable of simultaneously measuring thermal neutron flux, fast neutron flux, and temperature in a single package.

Within the last decade, efforts have been initiated by KSU to develop MPFDs that have the potential to simultaneously detect thermal and fast flux along with temperature in a single miniature sensor. Initial evaluations to demonstrate the proof of concept have already been performed at the KSU TRIGA reactor. However, prior to deployment of these new MPFDs in a high pressure, high temperature and high flux environment in a test reactor, such as the ATR or the HFIR, it is recognized that a more robust sensor design should be developed. The new design will use fabrication techniques perfected by INL's HTTL staff during development of other high temperature irradiation sensors, such as their doped molybdenum/niobium alloy HTIR-TCs as well as the expertise in miniature fission chamber design possessed by CEA.

Deployment of MPFDs in current and future R\&D projects will address several challenges including:

- Current fission chamber technologies do not offer the ability to measure fast flux, thermal flux and temperature within a single compact probe, MPFDs offer this option. The real-time, high accuracy data from a MPFD will significantly enhance various development and qualification efforts and new multi-physics code validation efforts.

- MPFD construction is very different then current fission chamber construction; the use of high temperature materials allow MPFDs to be specifically tailored to survive harsh conditions encountered in the core of high performance MTRs.

- New high-fidelity reactor physics codes will need a small, accurate, multipurpose in-pile sensor to validate the codes without perturbing the validation experiment, MPFDs fill this requirement.

- MPFDs can be built with variable sensitivities to survive the lifetime of an experiment or fuel assembly in some MTRs; allowing for more efficient and cost effective power monitoring.

- The small size of the MPFDs allows multiple sensors to be deployed to accurately visualize the flux and temperature profiles in the reactor.

The MPFD project consists of two research tasks. The objective for the first task is to develop an enhanced MPFD design and prototype and test its performance in a laboratory setting, while the objective for the second task is to construct an enhanced MPFD prototype with fissile deposits and evaluate it in reactor facilities. If the requested NEET funding for completing these tasks is provided, it is anticipated that they will be completed within approximately three years. The work in FY12 has been devoted to enhancing the MPFD design to accommodate INL-developed HTIR-TCs and improve robustness for high temperature, high flux, long-duration ATR and commercial applications. Readout electronics have been built and prototype fabrication is underway.

\subsubsection{Preliminary Sensor Design}

Fission chambers are typically constructed with two coaxial cylindrical electrodes, one of which has a fissile material deposit that is sensitive to neutron interactions. The gap between the electrodes is filled with a gas, typically argon, and a voltage potential is applied between the electrodes. After a neutron interacts with the fissile material, a fission product is ejected into the gas and a large number of charge pairs are created in the device. These charges are separated and collected at their respective electrode which leads to a current pulse being generated. MPFDs utilize the same concept, but with a different geometry that uses 
parallel plate electrodes instead of coaxial cylinders. This design is known as a parallel plate fission chamber. However, the MPFD design is set apart from other fission chamber designs because their signal is obtained by capturing only part of the available fission product energy deposition whereas all of the energy deposition must be captured in a classical fission chamber. This departure from conventional fission chamber design and operating characteristics allows the MPFDs to have a much smaller chamber size with a much lower fill gas pressure. The design has excellent discrimination characteristics because the energy deposited by the fission products is much greater then that of other types of background radiation interactions in the detector. As another added benefit, the small size allows them to have a faster response time, and thus have the potential to achieve higher count rates then conventional fission chamber designs. As such, MPFDs offer the potential for in-pile applications, and for instrumenting the fuel itself.

As shown in Figure 57, the MPFDs are unique because of their ability to measure three reactor parameters at very nearly the same location in the reactor core with a single compact detector that is the approximate size of either SPNDs or CEA-developed subminiature fission chambers that can only detect thermal or fast flux. MPFDs utilize two miniature parallel plate ionization chambers that contain a deposit of U-235 for thermal flux detection and a deposit of Th-232 for fast neutron detection. The design also includes a provision to install a thermocouple directly above the fission chambers. Initial MPFD testing at the KSU TRIGA reactor demonstrates that material selection minimizes local flux perturbations and that response time is sufficiently fast to provide time-dependent monitoring of the fission reaction rate or fast and thermal flux during a high power reactor transient. However, initial MFPD prototypes did not include temperature sensors, and testing was completed in an uncharacterized flux distribution at the KSU TRIGA Mark-II nuclear reactor at low temperatures and low fluence.

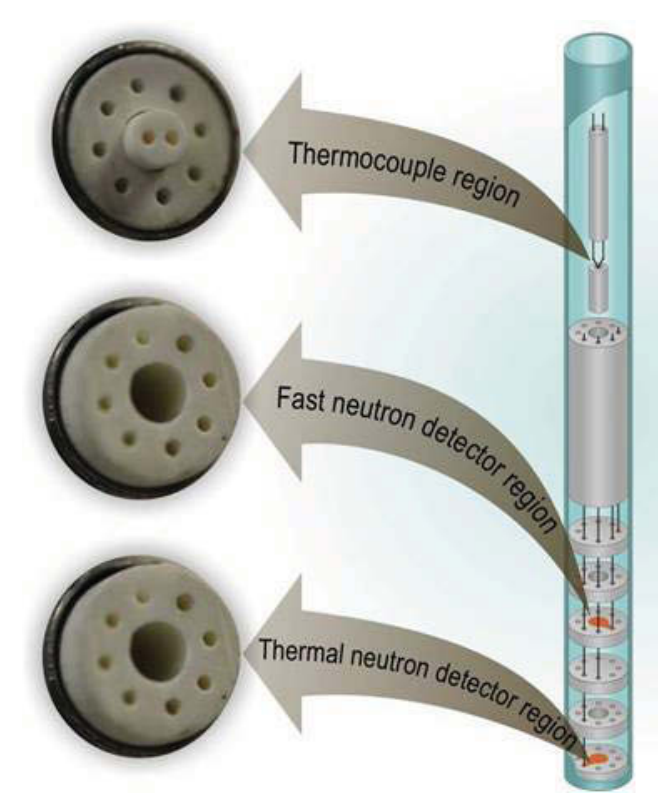

Figure 57. MPFD parts and exploded view.

In response to the need to make the MPFDs more robust and more easily deployed in test reactors, such as ATR and HFIR, the design was changed from a flat geometry to a cylindrical geometry that are more easily contained within leak-tight tubes using methods and equipment already in place at the HTTL. 


\subsubsection{KSU Research}

KSU focused on two tasks to aid in MPFD development. The first task developed new detector electronics for the new MPFD design. The amplifiers were designed, built, and tested at KSUs Electronics Design Laboratory (EDL). After initial testing at EDL was complete, the amplifiers were connected to an older fission chamber installed in the KSU TRIGA Mark II nuclear reactor and tested to verify the amplifier would capture neutron induced pulses. The amplifier captures the expected pulses as demonstrated by the pulse shown in Figure 58.

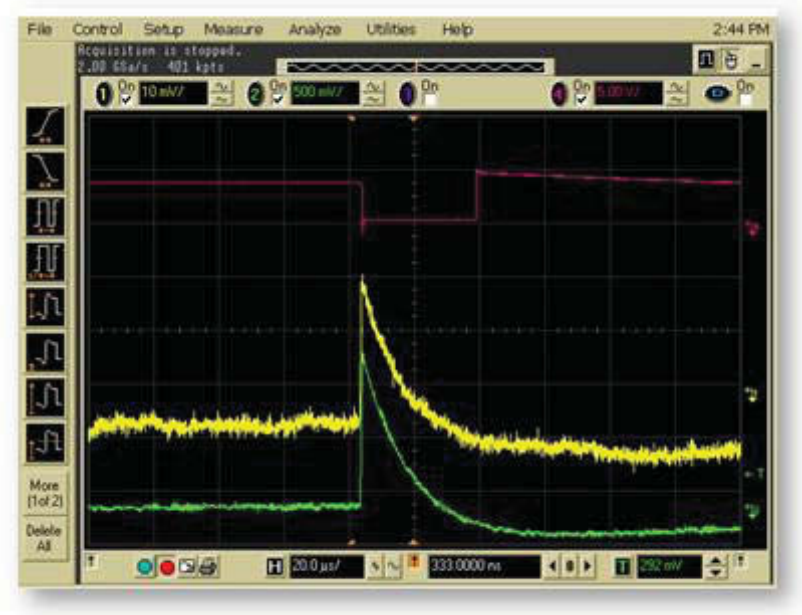

Figure 58. Neutron induced pulses from MPFD electronics.

KSU's second task focused on developing an enhanced plating system for deposition of the electrical contacts and fissile material on the MPFDs. Initial work included fabricating tooling required to deposit the electrical contacts via electron beam evaporation. The fissile material deposition evaluation is considering two methods; the first method is to use standard electroplating, while the second is to use electro-less plating. Ultimately, the deposition method that produces the most consistent deposit will be chosen for final MPFD fabrication.

\subsubsection{INL Research}

INL work focused on redesigning the MPFD layout to be more robust and be more easily deployable in high performance reactors, such as the ATR and the HFIR. The new design, as shown in Figure 59, uses a cylindrical geometry that will be inserted into a leak-tight tube. The design places the sensors on top of each other while moving the wire connections to the edge of the detector electrodes. The signal wires will run inside the insulators for the entire length of the detector and extension cable. The materials used for the MPFD are end-use dependent; for prototype construction, the materials chosen were alumina insulators, stainless steel tubes, and alumel and chromel wires. The active region of the prototype detector will be fabricated using loose assembly techniques used by INL's HTTL staff during development of other high temperature irradiation sensors. The 6 wire extension cable uses drawing and swaging construction methods.

\subsubsection{Future Work}

During FY13, detector prototype fabrication and high temperature and neutron flux evaluations will be completed at INL and KSU. High temperature evaluations will be performed in the HTTL. Simple response testing will be performed at KSU using their 1 MW TRIGA Mark II research reactor and at the 


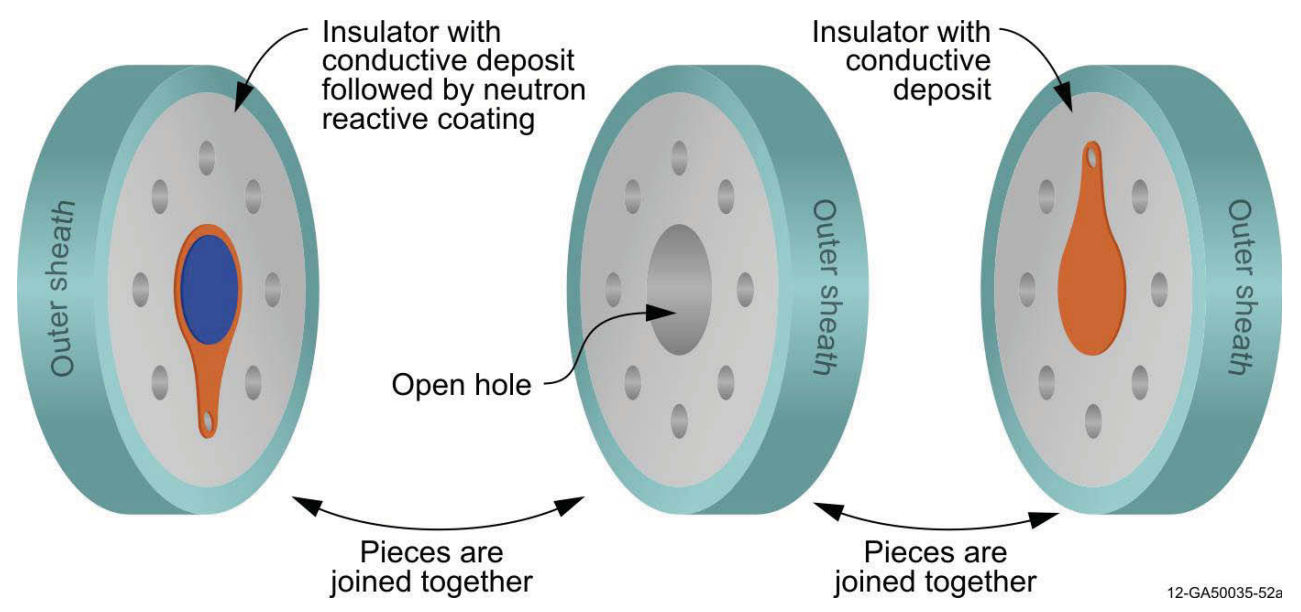

Figure 59. Enhanced MPFD design.

INL Health Physics Instrument Laboratory (HPIL) neutron and gamma panoramic irradiators. More complex evaluations will utilize the INL's ATRC using specialized fixturing installed at the ATRC shown in Figure 60. This fixturing is used to characterize and cross-calibrate a wide range of flux detectors, including SPNDs, CEA-developed fission chambers, and specially-developed back to back fission chambers. CEA will model the detector response and compare to actual results. This data will be used to develop a smaller, improved design of MPFD that will be constructed and evaluated in FY14. Ultimately, it is anticipated that the ATR NSUF program will deploy a MPFD in a higher flux reactor irradiation test at an appropriate NSUF facility.

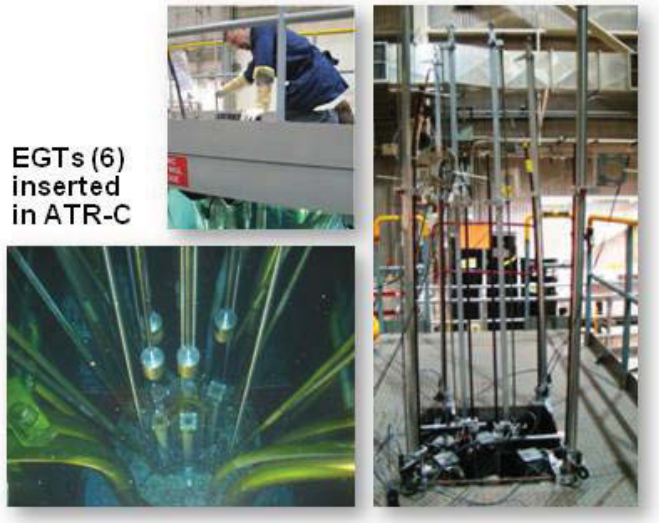

(a)

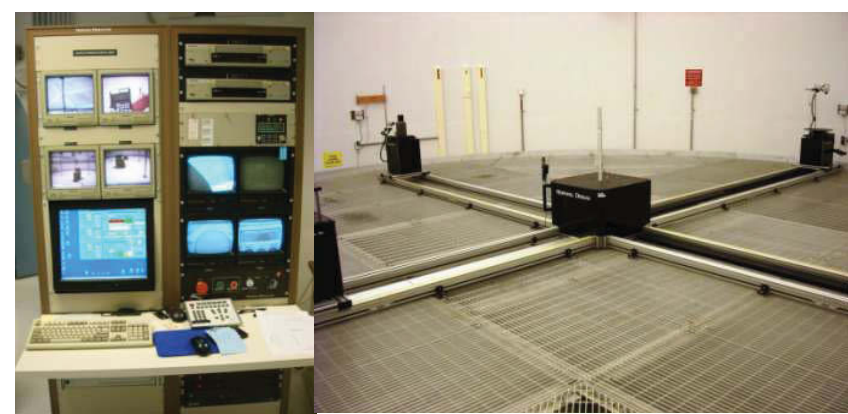

(b)

Figure 60. INL irradiation facilities for MPFD evaluation: (a) ATRC and (b) HPIL panoramic irradiator

The testing and analysis completed in this project will provide the necessary 'proof-of-concept' data to demonstrate the viability of MPFDs for higher fluence irradiations, offering ATR and HFIR users enhanced capabilities for real-time measurement of the thermal and fast flux and of temperature with a single, miniature detector. 


\subsection{Task 3: Localized Heating Measurements}

Initial evaluations of localized heating measurement methods was funded in FY12 by the ATR NSUF program. The objective of this effort was to research the methods used for local gamma heating measurements and to commence testing of a gamma heating sensor. After investigating the sensors currently available, gamma thermometers and calorimeters were selected for further review. The operation of these local power measurement sensors is discussed in this section. Due to the less complex design of the gamma thermometer, it was selected for initial laboratory evaluation. An IFE/HRP gamma thermometer was acquired, and initial tests were performed to develop greater understanding of gamma thermometer operation and the applicability for US MTRs.

Gamma heating sensors have several advantages over neutron detectors. The main advantage is that gamma heating signals are constant with fuel burnup. Gamma heating devices can also be quite versatile since they can be used to measure some thermal characteristics of coolant and core materials as well as local power. Some commercial and test reactors utilize vertical stacks of gamma thermometers to provide water level and other data related to the coolant properties. ${ }^{59}$ The characteristics of CEA calorimeters and IFE/HRP gamma thermometers are discussed in more detail in this section.

\subsubsection{Calorimeters}

CEA has pursued calorimetric techniques for local power measurements. ${ }^{60}$ Currently-used calorimeters to measure local power in OSIRIS consist of two pairs of aluminum cells, fixed onto the same aluminum base. The cells of each pair are similar except that one contains a graphite sample and the other a corresponding volume filled with nitrogen (see Figure 61). The two pairs of cells are diametrically opposed on the same aluminum base in order to avoid any gradient effect in the calorimeter. The entire structure is enclosed inside a tube in contact with the external water flow for heat removal. The pedestal between the upper part of the cell and the base in contact with the external sleeve is a thermal resistance through which the deposited energy inside the cell is transferred. The energy deposit is calculated using a calibration curve obtained from experiments with different electric energy inputs and measured temperature differences between empty and full cells located at the same axial position along the core height. Note that the heating rate unit $(\mathrm{W} / \mathrm{g})$ is written as $\mathrm{W} / \mathrm{g}(\mathrm{C})$ to emphasize the fact that the sample is graphite. Current devices for OSIRIS in-pile measurements consist of five different calorimeters (each one made of four cells), piled-up along the core height leading to five measurement points, from which the heating profile curve is fitted. Even though these calorimeters are reliable, they have inherent drawbacks, due to the static nature of this technology.

To improve the current differential method, a new system, CALMOS, is being developed and tested in OSIRIS. The key point of this new device is to put only two cells (one empty and one equipped with the graphite sample) coaxially inside a same external sleeve and then to move the probe using a displacement system. Hence, this new system will be able to measure the heating rate data at any level in the core and determine more accurately the heating profile inside and above the core (which was not possible with the current technology).

This new CALMOS design includes several new features. Specifically, it:

- allows continuous axial heating rate distribution measurements instead of selected point wise measurements,

- extends measurements to locations above the core, where heating levels are sufficiently high that they must be taken into account to design any new experimental device, 


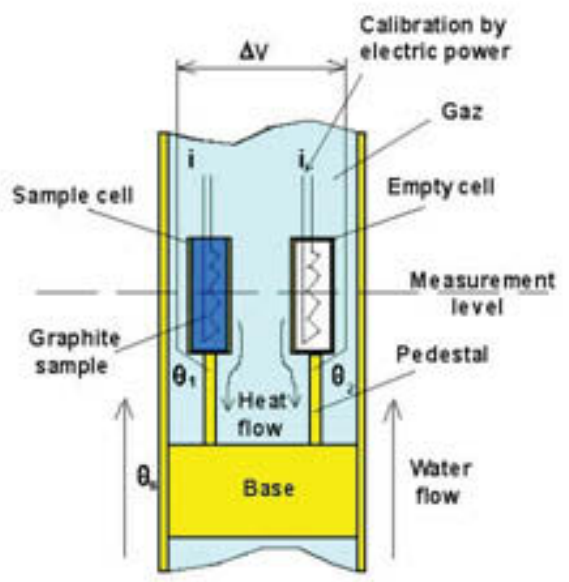

Figure 61. Calorimeter design currently used in OSIRIS.

- reduces the irradiation aging of the cells. The probe is exposed to the irradiation field only during measurement periods. As a consequence, the aging of heater wires is limited, and calibrations can be performed during the whole calorimeter life for periodic verifications,

- facilitates point measurements because of the small size of the calorimeter $(18 \mathrm{~mm})$, and

- minimizes the radial gradient effect in probe vicinity (e.g., coaxial configuration and smaller size).

Two identical cells are included in the CALMOS conceptual design shown in Figure 62. The upper cell (the sample cell) contains a graphite specimen, whereas the lower cell (the reference cell) is empty. Each cell is surrounded by a gas gap (nitrogen) and set on a base surrounded by a stainless external tube in contact with the reactor water flow. A thermocouple (Type K) is embedded on the top of each pedestal (hot temperature), whereas a second one is located on the external surface of the aluminum base (cold temperature). Two heating elements, made of constantan wire embedded in alumina, are inserted inside the cells, thus allowing the calorimeter's calibration. The calorimeter works in a continuous mode, i.e., the energy deposit in each cell is flowing through the pedestal and then through the external sleeve. The temperature difference " $\Delta \mathrm{T}_{\text {sample }}$ " between the two thermocouples is proportional to the energy deposit in the graphite and cell structure; whereas " $\Delta \mathrm{T}_{\text {reference" }}$ is proportional to the deposit in the empty cell structure. There-

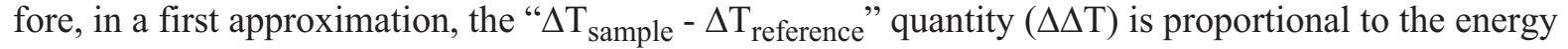
deposit inside the only graphite sample. This new nuclear heating measurement method has been patented by CEA. ${ }^{61}$

The following functional criteria were defined for CALMOS:

- a large sensitivity range is needed to be able to perform measurements above the core down to $0.1 \mathrm{~W} / \mathrm{g}(\mathrm{C})$ and inside the core up to $13 \mathrm{~W} / \mathrm{g}(\mathrm{C})$ [As noted previously, the heating rate unit $(\mathrm{W} / \mathrm{g})$ is written as $\mathrm{W} / \mathrm{g}(\mathrm{C})$ to emphasize the fact that the sample is graphite],

- the cell external diameter is limited to $18 \mathrm{~mm}$ in order to be able to insert and move the calorimetric probe inside an external sleeve representative of OSIRIS standard experimental devices,

- the overall length of the probe should not exceed $220 \mathrm{~mm}$ with regard to the core fissile height $(630 \mathrm{~mm})$,

- good linearity of $\Delta \Delta \mathrm{T}\left[\Delta \mathrm{T}_{\text {sample }}-\Delta \mathrm{T}_{\text {reference }}\right]$ versus heating rate in the range of 0.1 to $13 \mathrm{~W} / \mathrm{g}(\mathrm{C})$ is required. A maximum of $20 \%$ from linearity for $13 \mathrm{~W} / \mathrm{g}(\mathrm{C})$ was set for the design, and

- the highest temperature inside the cell structure should not exceed $500{ }^{\circ} \mathrm{C}$ in order to have a significant margin with respect to the aluminum melting point. 


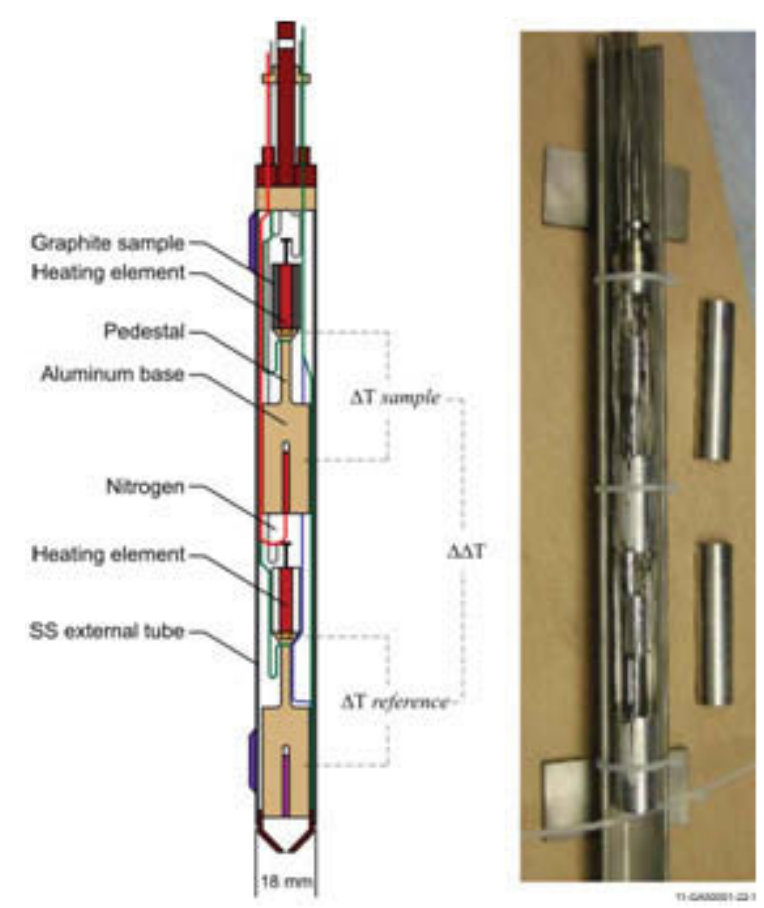

Figure 62. CALMOS schematic (a) and prototype (b).

Key geometric parameters of both cells are the height and diameter of the aluminum base, height and diameter of the pedestal, height and diameter of the upper part of the cell determining the sample volume. During design steps, a trade-off had to be found between thermal optimization and technological constraints. Main structural evolutions during the design phase led to the addition of polished stainless steel screens to limit radiative losses. Furthermore, a highly conductive aluminum alloy $\left(230 \mathrm{~W} / \mathrm{m}-{ }^{\circ} \mathrm{C}\right)$ was selected to decrease the peak temperatures of the sensor. A CALMOS prototype is shown in Figure 62.

\subsubsection{Gamma Thermometers}

Local power measurements have been made at the HBWR since 1962 using a compact (3.9 mm OD) gamma thermometer that detects heat produced by fission and fission product gamma rays. ${ }^{62}$ Heat is transferred to the coolant sink along a closely controlled conduction path while the temperature drop is measured by a differential thermocouple. The generated signal, which is proportional to the fuel power, is strong and constant with fuel burn-up. The gamma thermometer is made of a Type K differential thermocouple where the hot junction is insulated from the moderator by a gas-filled cylinder (see Figure 63). Heat produced by gamma absorption in an inner, thermally insulated, body results in a local rise in temperature. The temperature increase and the time constant of the gamma thermometer are used to calculate the actual gamma irradiation. The gamma thermometer can be re-calibrated in-core by applying a low DC voltage to the differential thermocouple. The inner body of the gamma thermometer is heated by the current applied to the thermocouple for a short period of time. The decay of temperature is monitored, and a relationship between temperature and decay time is used to recalibrate the gamma thermometer.

Gamma thermometers have been deployed in the US commercial nuclear industry. Delta M Corporation has manufactured gamma thermometers and supplied them to commercial plants to provide local gamma heating measurements as well as other parameters discussed previously. 


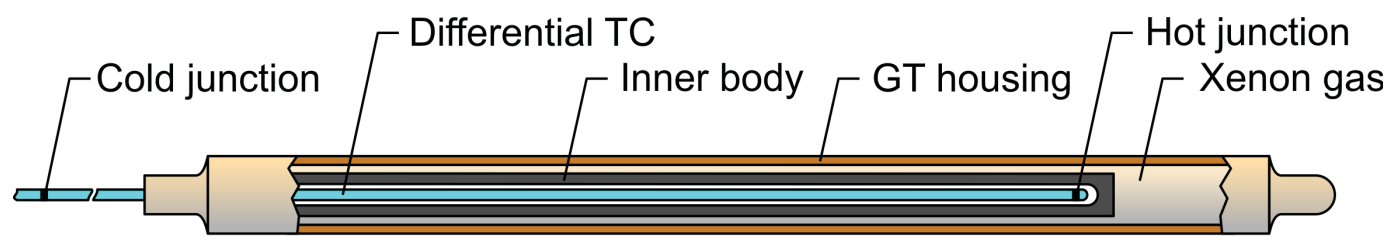

10-GA50001-78-3

Figure 63. Halden miniaturized gamma thermometer.

\subsubsection{Gamma Thermometer Evaluation}

Because of their simpler design and thermocouple-like construction, the gamma thermometer was selected for evaluation as a viable local gamma heating sensor in US MTRs. Commercially-available gamma thermometer designs were evaluated, and vendors were contacted to determine the best gamma thermometer for evaluation at the HTTL. Due to design features, cost, irradiation testing history, and other logistical factors, the IFE/HRP gamma thermometer design was selected for evaluation. The IFE/HRP gamma thermometer is shown in Figure 64.

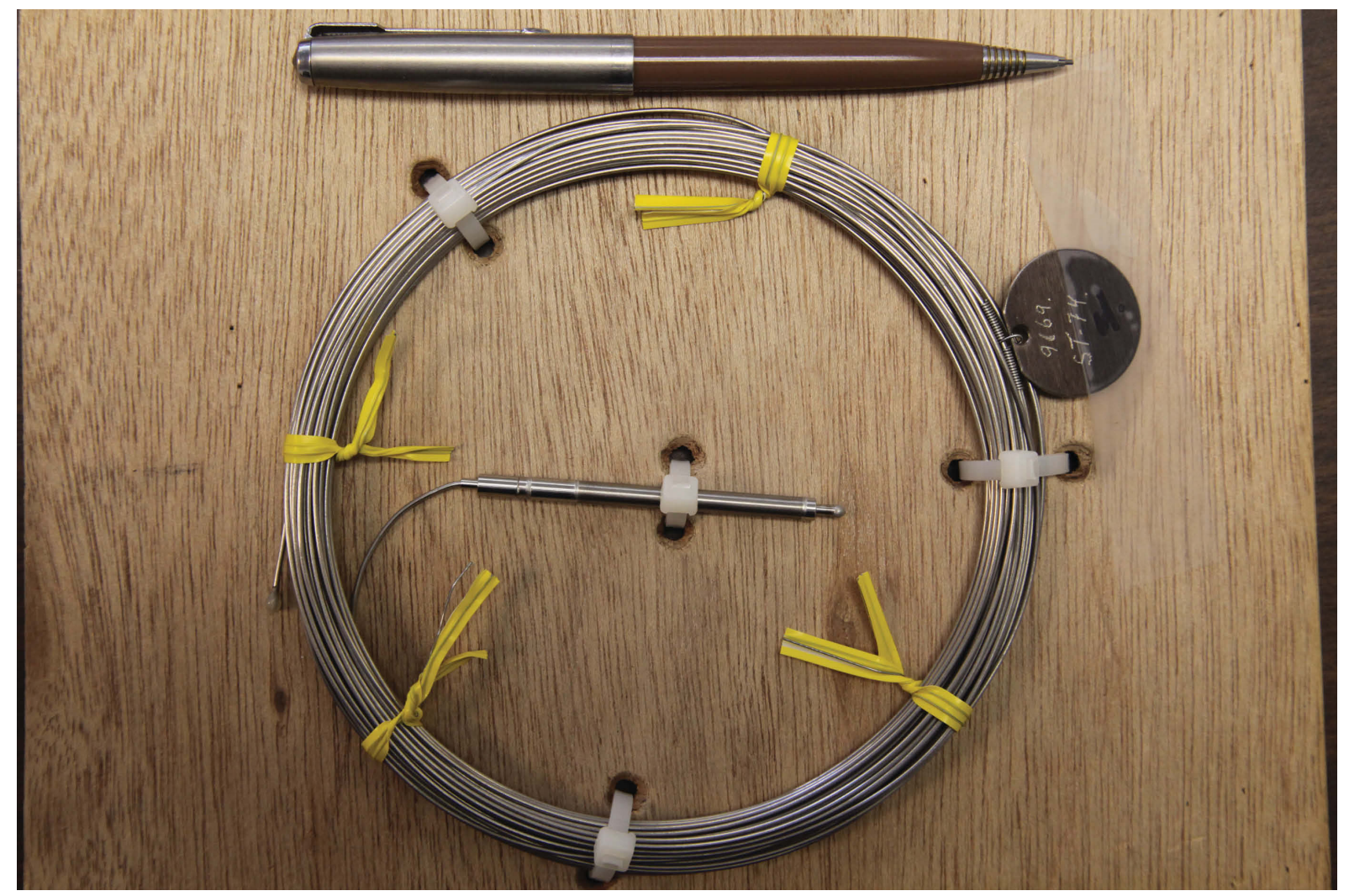

Figure 64. IFE/HRP gamma thermometer.

Once the IFE/HRP gamma thermometer arrived, it was X-rayed to determine the internal composition. Figure 65 is one of the radiographs of the IFE/HRP gamma thermometer. The distance between the insulated junction and the cold junction is an important quantity to know for the experimental setup; however, the cold junction could not be located in the radiographs. IFE/HRP was contacted and provided drawings that specified that the distance between the junctions is $75 \mathrm{~mm} .{ }^{63}$ 


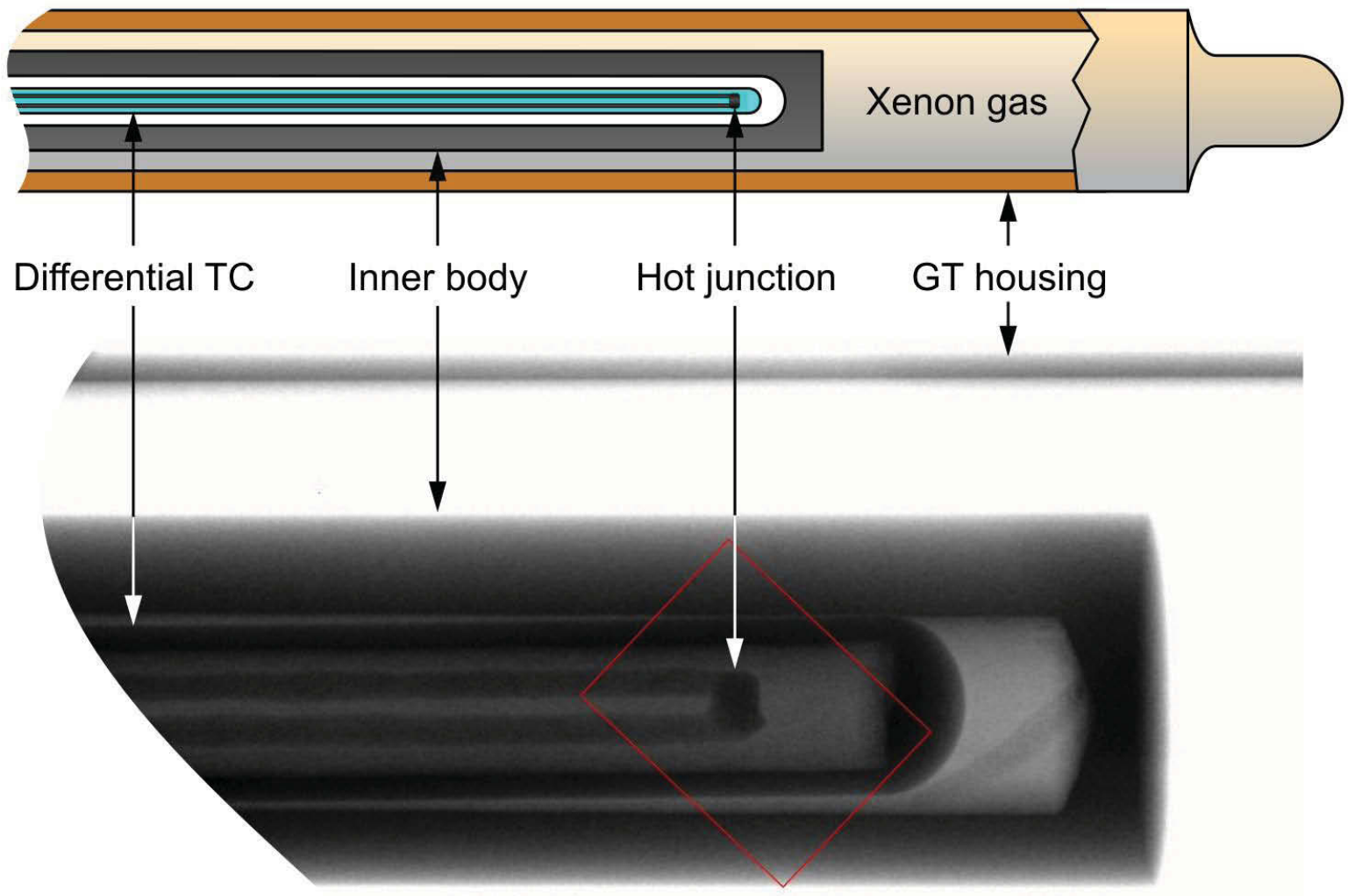

Xenon gas

12-GA50035-53

Figure 65. Insulated junction radiograph of IFE/HRP gamma thermometer.

Initial FY12 evaluation of the gamma thermometer focused on reproducing the time constant that was provided by IFE/HRP. The experimental setup to perform time constant measurements consists of a beaker of ice-water and a beaker of boiling water on a hot plate. The gamma thermometer is transferred between the two states of water with known temperatures. At the moment the gamma thermometer is switched from one state to the next, an electric potential is established between the junctions of the differential thermocouple. The non-insulated junction reacts to the change in temperature immediately however the insulated junction has a delayed reaction. Data are logged as the insulated junction heats or cools to the same temperature as the non-insulated junction at which point the potential difference between the two junctions returns to zero. Once the equilibrium temperature is attained, the data logging is terminated and the data are evaluated. In order to obtain the time constant, the data are converted from a voltage signal to a temperature. This is done by utilizing the linear relationship between temperature and voltage for a Type $\mathrm{K}$ thermocouple. Once the temperature is plotted, a curve fit can be applied to the data using Equation (4).

$T=T_{0} e^{-\frac{t}{\tau}}$

where

$T=$ temperature, 


$$
\begin{array}{ll}
T_{0} & =\text { initial temperature } \\
t & =\text { time, and } \\
\tau & =\text { time constant. }
\end{array}
$$

The resulting curve fit contains the information needed to extract the time constant. A graph with the curve fit is shown in Figure 66. The data for the case where the gamma thermometer is transferred from the boiling water to the ice water have less variation and produced a time constant similar to the value provided by IFE/HRP. The IFE/HRP time constant is $57.83 \mathrm{~s}$, and the value inferred from the graph in Figure 66 is $58.53 \mathrm{~s}$.

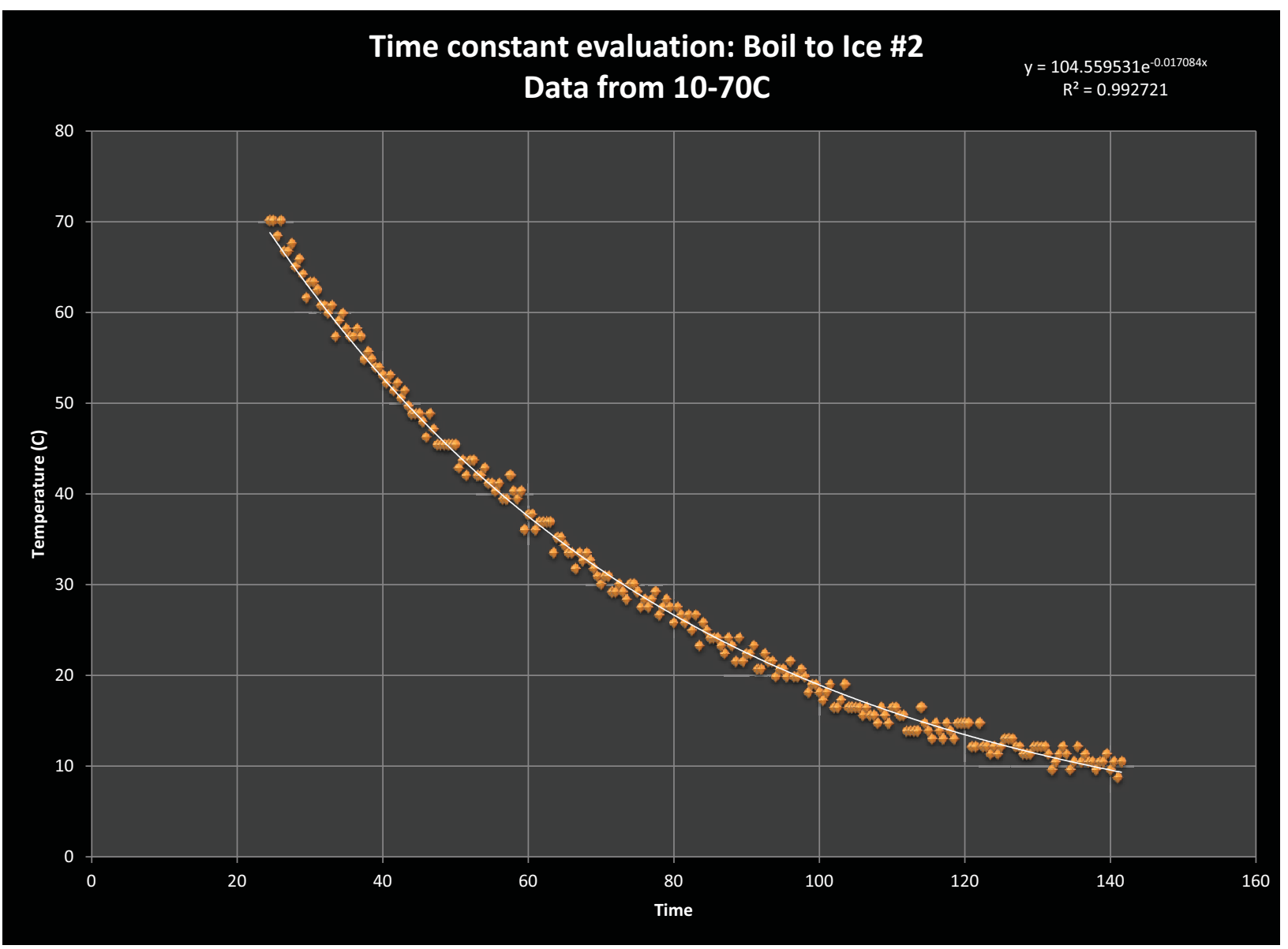

Figure 66. IFE/HRP gamma thermometer time constant evaluation.

\subsubsection{Future Work}

As evaluations continue in FY13, an improved understanding of the gamma thermometer operation will be gained. Plans for future testing include utilizing gamma fields in INL facilities to understand the sensitivity and calibration of the gamma thermometer. Further research will elicit improvements that can be implemented in the design of an improved gamma heating sensor that could be deployed for use in US MTR applications. 


\subsection{Task 4: Crack Growth Measurements}

The purpose of this task is to adapt in-pile material testing technology developed at the HBWR to high flux MTRs in the US, such as INL's ATR and the HFIR. Currently, the HBWR performs irradiations with on-line crack propagation monitoring. HBWR tests employ a reversing direct current potential drop (DCPD) method, which consists of introducing a precisely controlled current across a loaded specimen and measuring the drop in voltage at different locations across the crack mouth (which changes as a function of crack growth).

Figure 67 shows the essential features of the in-pile hardware used at HBWR. A loading mechanism is used to stress the crack in a compact tensile (CT) specimen. The mechanism utilizes a miniature high pressure bellows, which expands to apply the force required to propagate the crack. The CT specimens are fabricated with "ears" above the loading holes to provide locations for current and voltage connections.

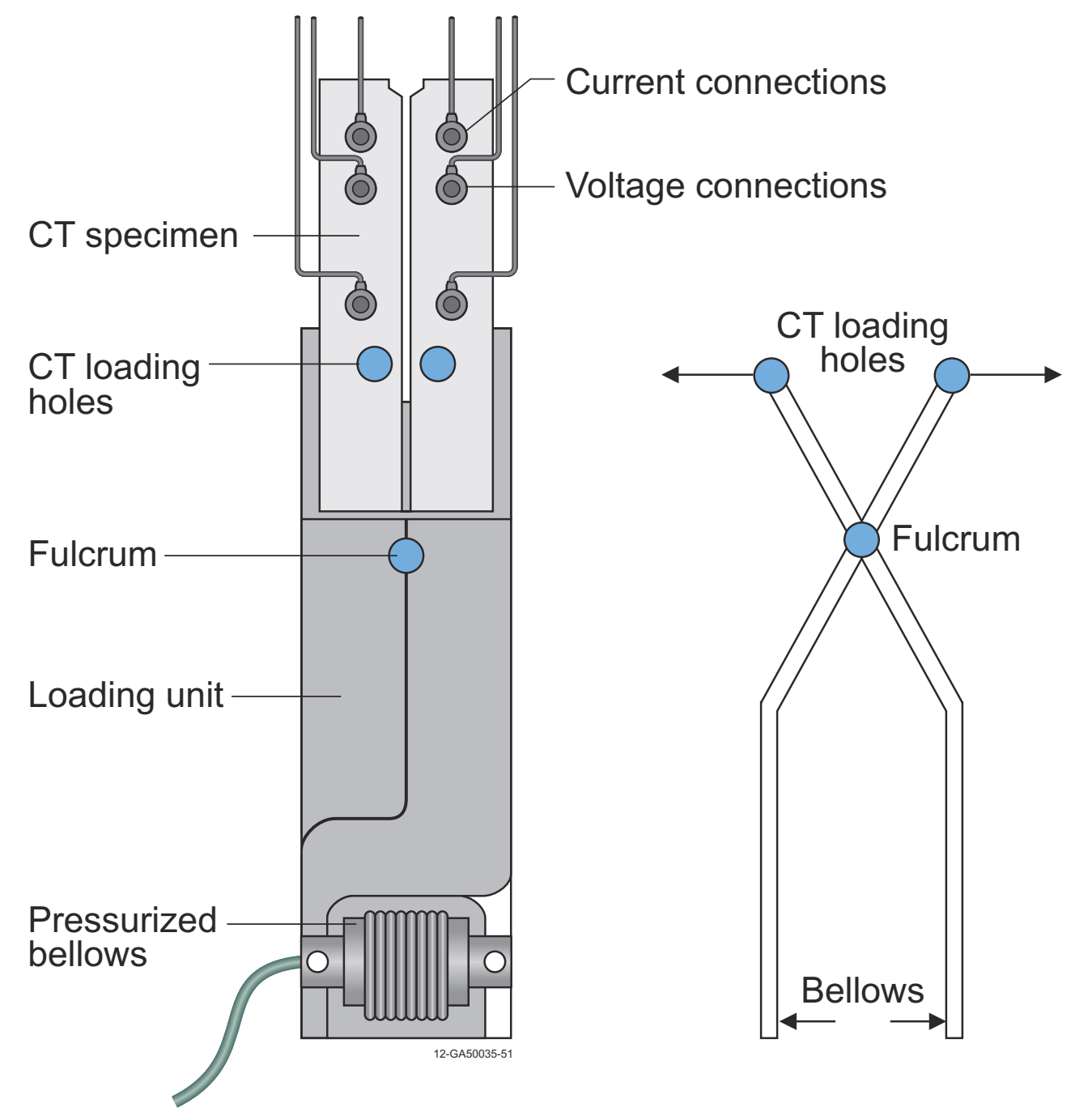

Figure 67. Essential hardware elements for implementing the DCPD method in-pile.

As a first step to implementing this technology, a prototype loading mechanism was constructed at INL based primarily on the HBWR design. Techniques were developed for making laser welds between the miniature bellows and the end fittings used to transfer the loads as shown in Figure 68. 


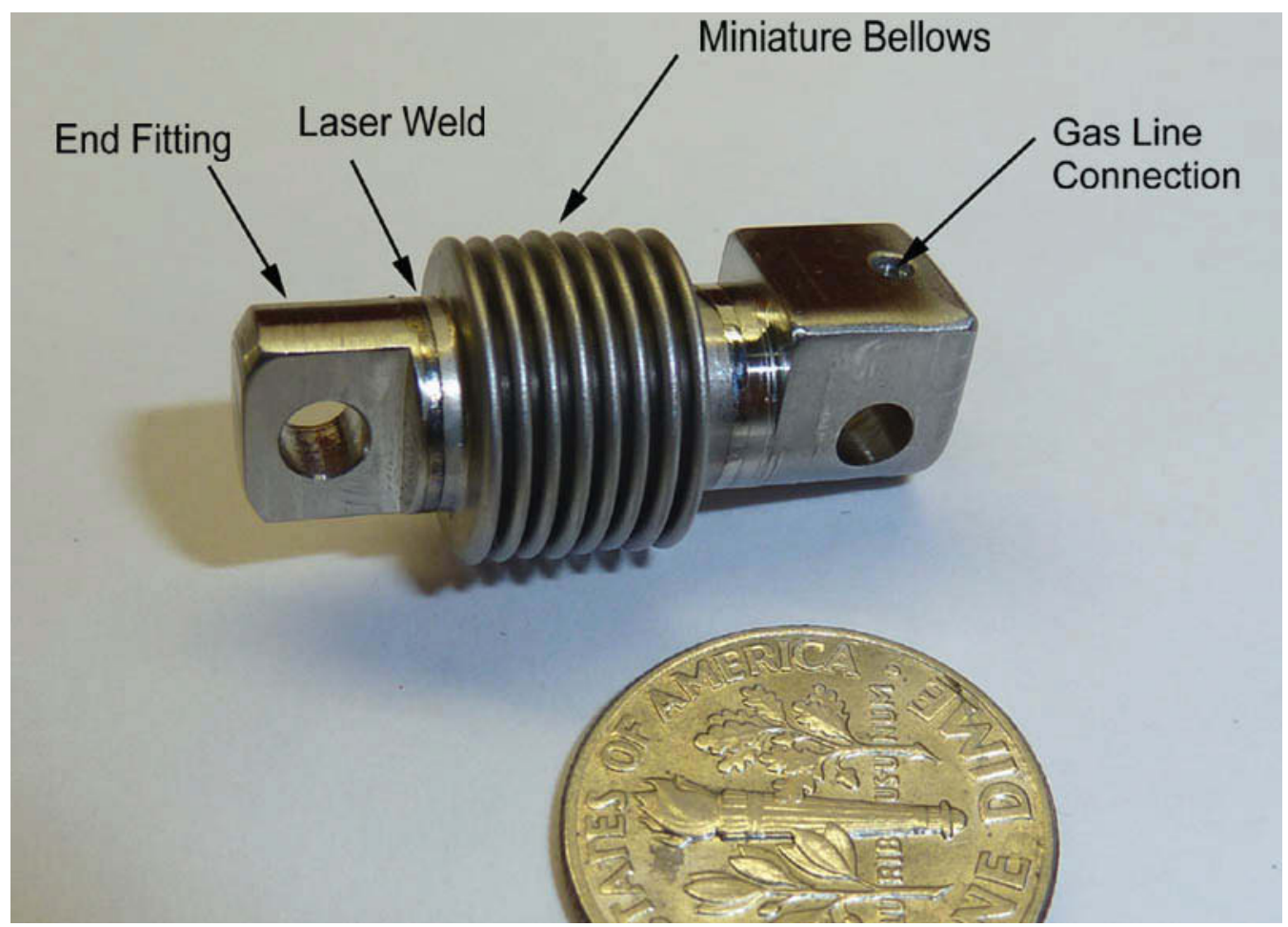

Figure 68. Example of end fittings laser welded to bellows.

The balance of the loading mechanism has been fabricated and assembled (see Figure 69). This work included developing techniques for brazing the small gas supply line to an end fitting. The mechanism has been pressure tested to 1000 psig and leak tested.

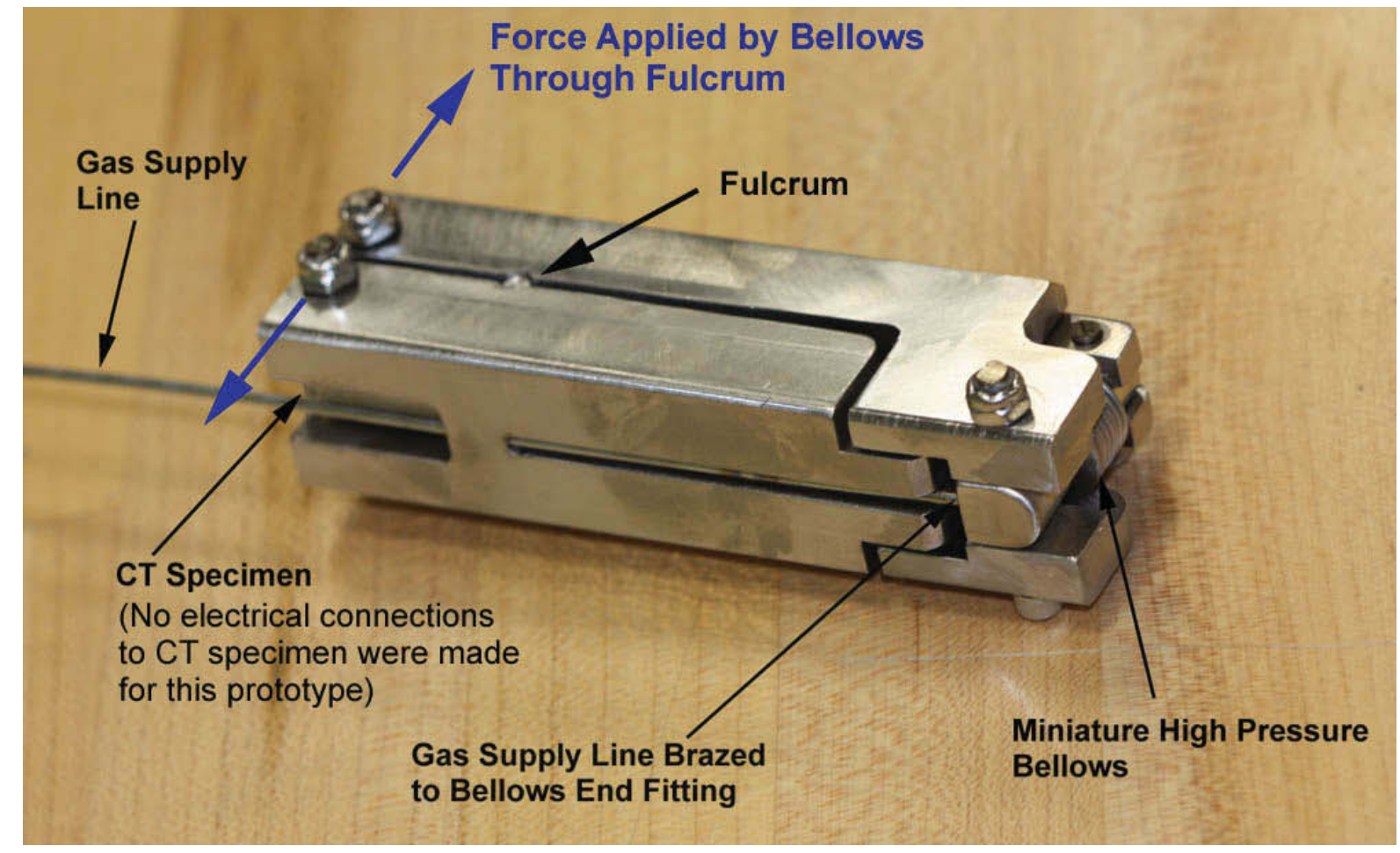

Figure 69. Prototype loading mechanism for in-pile DCPD testing - fabricated at INL. 
Future plans include bench top testing to first characterize the loading mechanism by creating an applied pressure versus resulting force curve, followed by a crack tip opening displacement versus load curve. After completion of bench top testing, a fully instrumented test rig will be placed in one of the HTTL autoclaves and tested in a PWR environment with correct water chemistry and pressure. This testing will include a fully functional DCPD measurement system, including the crack length measurement algorithm, and bellows pressurization system. As a final step before implementing this technology in ATR, a four month irradiation will be completed with the test rig installed in an existing autoclave in the MITR. Data obtained from this irradiation will demonstrate the in-pile performance of the test rig at a fraction of the cost of a similar irradiation in the ATR, but provide assurance of its performance to potential ATR customers. It is currently planned to irradiate a specimen for approximately 70 days, yielding an exposure of about $1 \times 10^{19} \mathrm{n} / \mathrm{cm}^{2}$. Post-irradiation examination will be performed to validate final crack growth estimates from the DCPD system.

\subsection{Summary}

As discussed in this section "Upgrade US MTR In-Pile Instrumentation" is a key objective needed to support FCRD irradiation testing. This section identified several types of sensor technologies that must be evaluated and enhanced, as needed, so that they can be deployed in higher temperature, higher flux US MTRs, such as ATR and HFIR. These sensors will allow detection of key parameters, such as geometry changes, thermal conductivity, flux, local power, and crack initiation and growth. Although FCRD funding is insufficient to address all of these sensors, there are other programs that also need enhanced in-pile instrumentation for irradiation testing at US MTRs. Hence, other on-going in-pile instrumentation research efforts are monitored to avoid duplication and ensure that all of the sensors technologies required for FCRD will ultimately be available. This report highlighted several research investigations of interest to the FCRD program that are underway including:

- LVDT-based methods to measure changes in diameter during irradiation testing;

- Thermal and fast flux measurement investigations, including development of the compact MPFDs that include sensors to simultaneously measure fast and thermal flux with temperature;

- Local power measurement investigations; and

- DCDP-based methods for crack measurement.

FY12 FCRD funding was used to complete efforts to support deployment of an enhanced creep test rig in Loop 2A of the ATR. Building upon results from prior INL and IFE/HRP collaborative efforts to develop a creep test rig for use in the new PWR loop at the ATR, an initial prototype of this creep test rig was evaluated using an HTTL autoclave. Test results indicate that this test rig can be used to measure elongations as small as $10 \mu \mathrm{m}$. Results from these FY11 test rig evaluations were used to finalize recommendations for an enhanced design and fabricate an improved prototype design. During FY12, this enhanced creep test rig design was fabricated, characterized, and calibrated. The rig is now ready for deployment to measure specimen elongation in real time during irradiation testing in ATR Loop 2A.

During FY12, efforts were also initiated to develop a creep irradiation test rig with the ability to apply a variable load to a specimen. Completion of this design for variable specimen loading, will position INL as the second organization in the world capable of real-time creep testing in reactor coolant. 
In-pile Instrumentation to Support Fuel Cycle Research and Development - FY12 Status Report

September 2012 


\section{SUMMARY}

A strategic research effort is underway to develop sensors of unprecedented accuracy and resolution for obtaining the data needed to characterize three-dimensional changes in fuel microstructure during irradiation testing. When implemented, this strategy will yield test capsule designs that are instrumented with new sensor technologies for irradiations at facilities primarily relied upon by the FCRD program, the ATR and the HFIR. As part of this effort, laboratory testing, and as needed, irradiation testing of sensors in these capsules will be completed to give sufficient confidence that the irradiation tests will yield the required data.

At the onset of this effort, a strategic plan was developed to provide necessary background information related to fuel irradiation testing, desired parameters for detection, and an overview of currently available in-pile instrumentation. As part of developing this strategic plan, a workshop was held in which US and foreign experts from fuels, irradiation, and instrumentation fields ranked candidate sensor technologies. The strategic plan describes the consensus reached during the workshop with respect to recommendations for the path forward for accomplishing the goals of this research program. This document reports the FY12 status of investigations in the sensor technologies identified by the expert panel as offering the most promise for meeting the FCRD objectives.

As noted within this report, FY12 research funding was limited. However, as summarized below, significant progress was still made in each technology area with respect to the developing and deploying new test rigs and sensors.

- Ultrasonics Based Sensors - During FY12, FCRD funding was primarily used to advance deployment of an UT and to support development of a successful ATR NSUF proposal for addressing a key issue related to ultrasonic sensor deployment for in-pile irradiation testing, ultrasonic transducer survivability.

Laboratory testing was completed to assess the viability of using ultrasonics thermometers for multipoint temperature detection during irradiation testing. Although the accuracy and resolution will depend on the sensor selected, prior evaluations indicate that temperature measurements can be obtained with the required accuracy $\left(2-3{ }^{\circ} \mathrm{C}\right)$ at multiple locations with a single small diameter probe $(1 \mathrm{~mm})$. Results from FY12 tests have identified appropriate UT probe materials, a new magnetostrictive transducer design, a new damping method to reduce signal noise, and an enhanced signal processing method. As indicated in Figure 70, temperature-dependent signal response evaluations indicate that stainless steel is the preferred probe for temperature measurements below $1000{ }^{\circ} \mathrm{C}$ and doped molybdenum (KW-Mo) is the preferred probe material for higher temperatures.

Interim results were documented in the paper, "Update on Ultrasonic Thermometry Development at Idaho National Laboratory," and presented at the 2012 Nuclear Plant Instrumentation, Control, and Human Machine Interface Technologies Conference. This paper received the "Innovations in Fuel Cycle Research Award." In addition, an IDR was filed related to the enhanced design for magnetostrictive transducers developed as part of this research.

FY12 funding allowed development of a collaborative proposal for addressing a key concern related to ultrasonic sensor deployment for irradiation testing, ultrasonic transducer survivability. This collaborative proposal, which was led by the PSU, has been selected by the ATR NSUF, and irradiation testing 


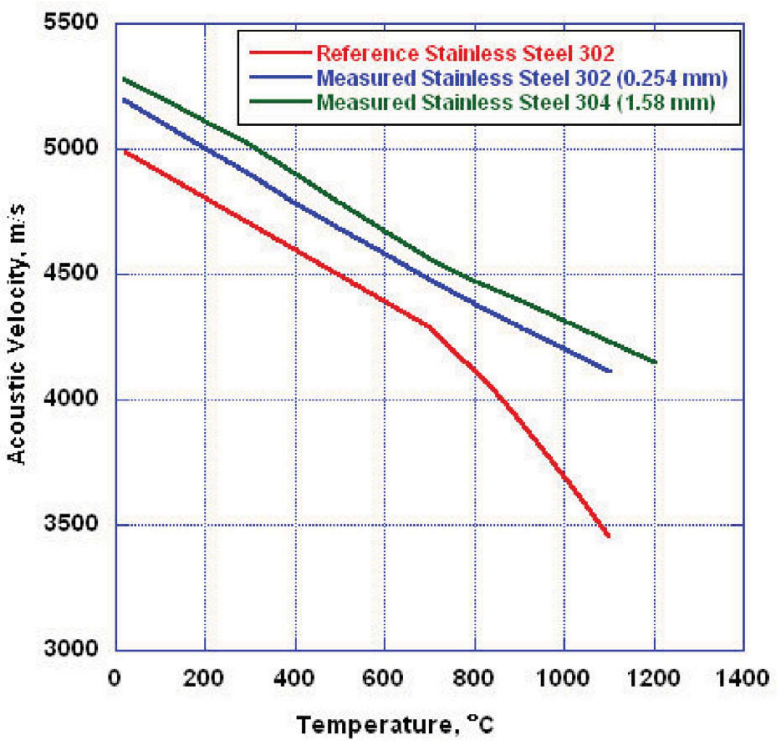

(a)

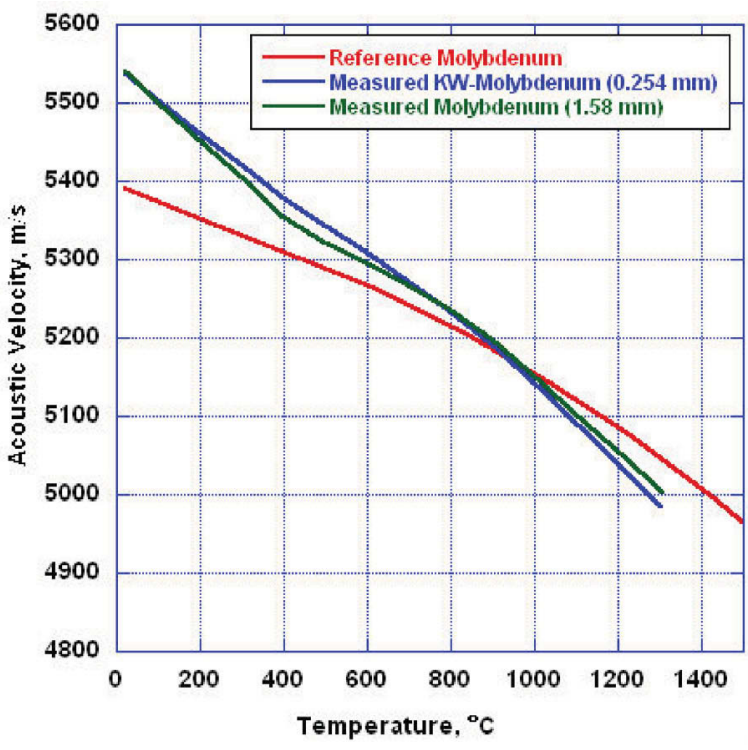

(b)

Figure 70. Response of probe materials exhibiting superior performance: (a) stainless steel for temperatures less than $1000{ }^{\circ} \mathrm{C}$ and (b) doped molybdenum (KW-Mo) for temperatures $>1000{ }^{\circ} \mathrm{C}$.

is expected to begin in FY13. Although details of the test are still being finalized, the irradiation capsule will include several piezoelectric and magnetostrictive transducers (see Figure 71). Finally, this document reports progress funded by other programs on the deployment of ultrasonics sensors for measuring other parameters, such as elongation.

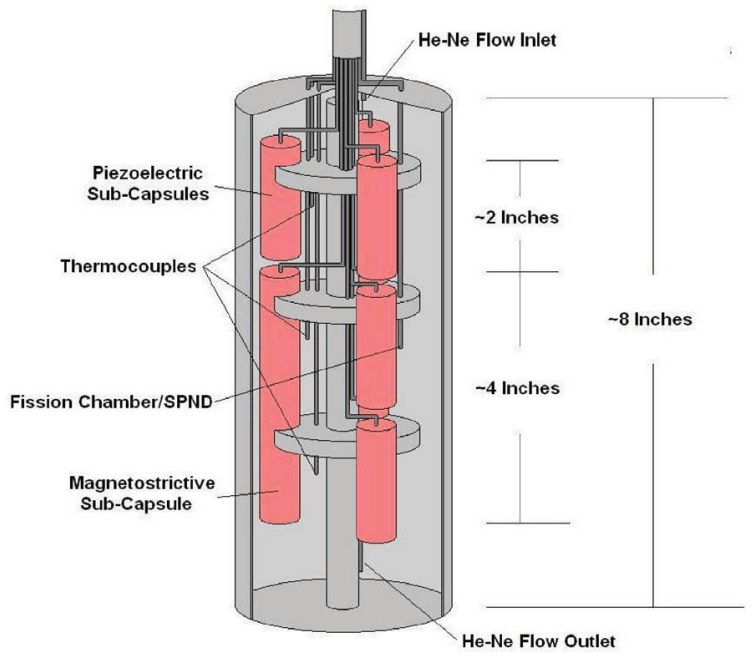

Figure 71. Conceptual design of proposed ultrasonics transducer test. 
- Fiber Optics-Based Sensors - During FY12, FCRD funding was primarily used to advance deployment of a fiber-optics based elongation sensor and to support development of an ATR NSUF proposal for addressing a key issue related to fiber optics-based sensor deployment for in-pile irradiation testing, fiber optics survivability. Fiber optic sensing technologies can be used to measure a number of parameters, such as elongation, temperature, pressure, and strain. Fiber optic sensors are small, and some techniques allow multiple sensing locations along the length of the fiber.

Initial efforts in the fiber optics area are focusing on a sensor for measuring length. During FY11, a measurement technique based on an EFPI was demonstrated in the laboratory. Measurements using this laboratory setup indicate elongations as small as $0.3 \mu \mathrm{m}$ can be detected for measurements ranging from 1.5 to $125 \mu \mathrm{m}$. Based on results from this technique demonstration, a conceptual probe design was developed and evaluated.

In FY12, efforts were focused on developing a sealed probe that could be deployed in an irradiation test. A probe design was developed that incorporated a bellows to provide isolation from the environment and allow expansion of the probe. A number of obstacles were resolved in fabricating this probe, such developing methods to bond inside the hypodermic tubing and developing methods to assemble and weld small probe components. An IDR was filed related to the design and fabrication methods developed for this sealed probe. A photo of the completed sensor is shown in Figure 72.

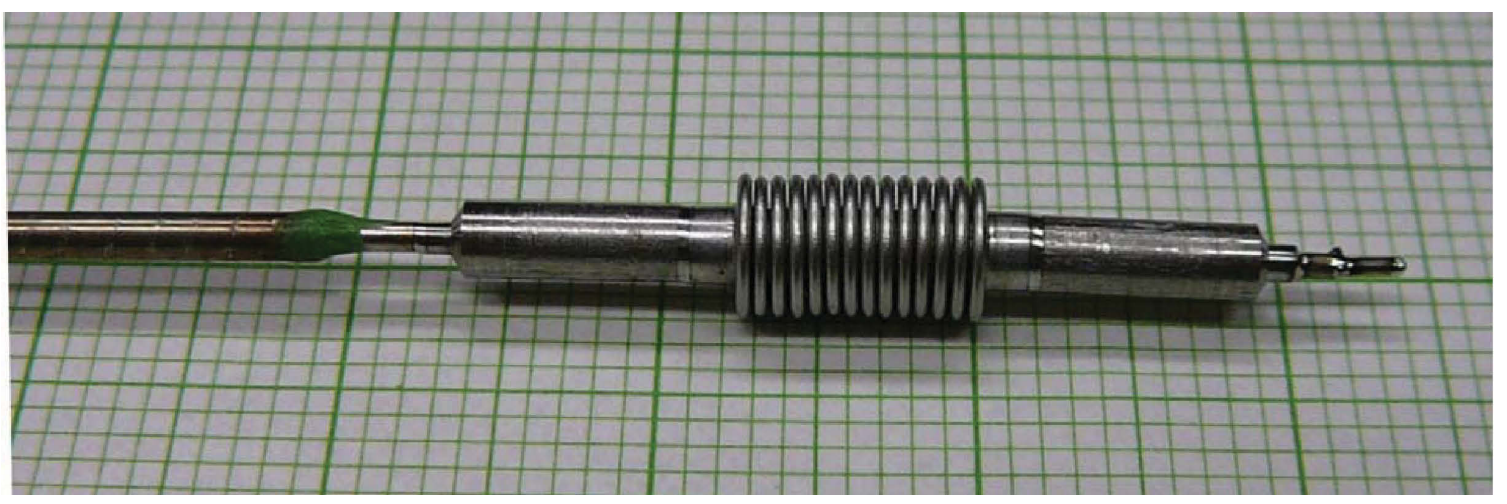

Figure 72. Welded elongation probe.

FY12 funding also allowed development of a collaborative proposal for addressing a key concern related to fiber optics-based sensor deployment for irradiation testing, optical fiber survivability. This university-led proposal was submitted to the ATR NSUF for consideration.

- Enhanced Existing US MTR Sensors - As discussed in Section 5, sensors for measuring several key parameters of interest during FCRD fuel irradiations are not currently available at US MTRs. To address this issue, FCRD funding is allocated for enhancing such instrumentation so that it can also be deployed at US MTRs. FY12 FCRD efforts in this area focused on completing characterization evaluations of a creep test rig that could be deployed in the newly reactivated ATR PWR Loop 2A for measuring elongation during irradiation. In addition, a conceptual design for a creep test rig with variable loading was developed. 
Building upon results from prior INL and IFE/HRP collaborative efforts to develop a creep test rig for use in the new PWR loop at the ATR, an initial prototype of this creep test rig was evaluated using an HTTL autoclave. Test results indicate that this test rig can be used to measure elongations as small as $10 \mu \mathrm{m}$. Results from these FY11 test rig evaluations were used to finalize recommendations for an enhanced design and fabricate an improved prototype design. During FY12, this enhanced creep test rig design was fabricated, characterized, and calibrated. The rig is now ready for deployment to measure specimen elongation in real time during irradiation testing in ATR Loop 2A.

As indicated in Figure 73, major components of the enhanced creep test rig design include a tensile specimen, a bellows, an LVDT, and the fixturing needed to connect these components within a supporting frame. (In a pressurized water environment [i.e., an autoclave or a PWR test loop], external water pressures tend to collapse the bellows producing a tensile load on the specimen.) IFE/HRP provided the LVDT and welded the LVDT, bellows, and the associated connecting fixturing in the test rig using e-beam welding techniques. Enhancements embodied in this test rig include an LVDT with silver alloy coil material (to eliminate inaccuracies that occur when the LVDT is heated near its Curie temperature), fixturing modifications to reduce inaccuracies associated with compliance issues and simplify assembly, and frame modifications to reduce gamma heating and increase compatibility with existing ATR PWR Loop 2A fixturing.

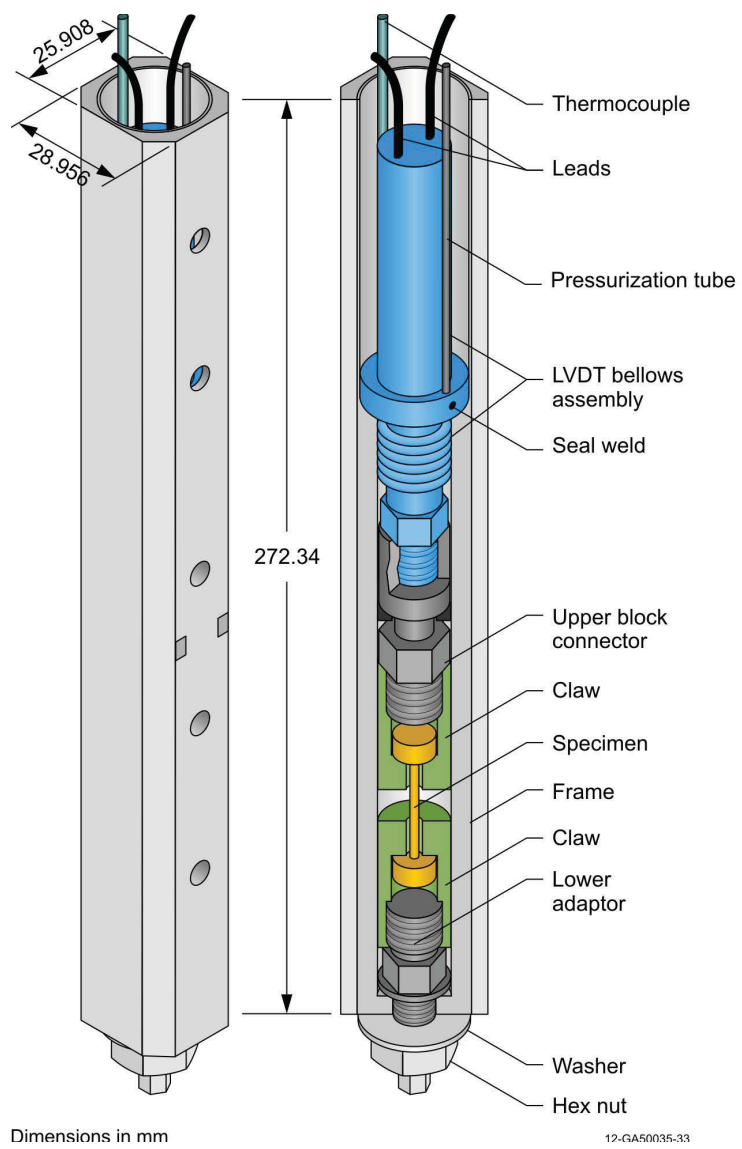

Figure 73. Enhanced creep test rig. 
During FY12, efforts were also initiated to develop a creep irradiation test rig with the ability to apply a variable load to a specimen. Like the enhanced creep test rig, this design will allow testing in reactor coolant at PWR conditions. (see Figure 74). Completion of this design for variable specimen loading, will position INL as the second organization in the world capable of real-time creep testing in reactor coolant.

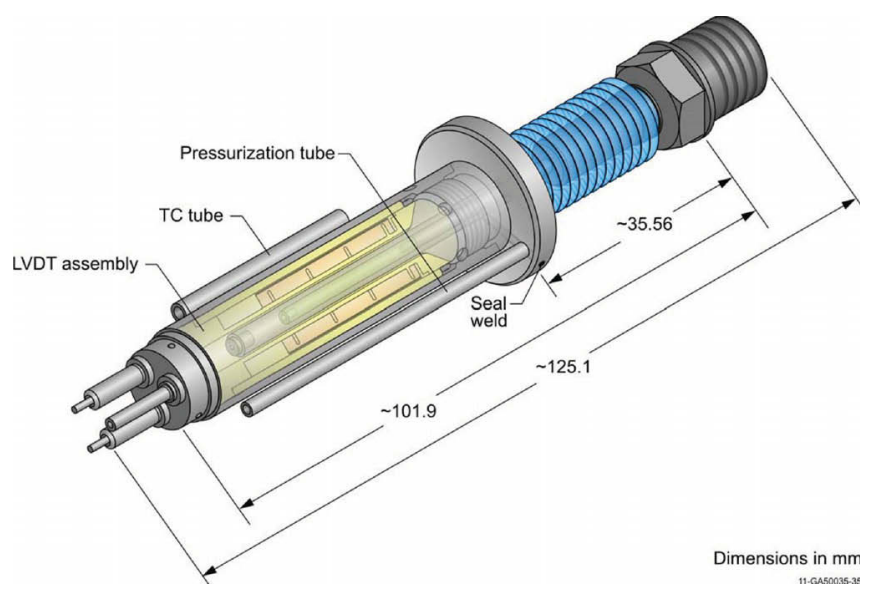

Figure 74. Conceptual design for variable load creep test rig.

In summary, significant progress was made in each technology area of interest with respect to in-pile instrumentation development for FCRD irradiation testing. A creep test rig is now available for measuring elongation. In addition, progress continues for developing new ultrasonics and fiber optics based sensors. 
In-pile Instrumentation to Support Fuel Cycle Research and Development - FY12 Status Report

September 2012 


\section{REFERENCES}

1. J. Rempe, H. MacLean, R. Schley, D. Hurley, J. Daw, S. Taylor, J. Smith, J. Svoboda, D. Kotter, D. Knudson, S.C. Wilkins, M. Guers, L. Bond, L. Ott, J. McDuffee, E. Parma, and G. Rochau, New In-Pile Instrumentation to Support Fuel Cycle Research and Development, FCRD-FUEL-2011-000033, (also issued as INL/EXT-10-19149), January 2011.

2. J. Rempe, J. Daw, D. Knudson, R. Schley, L. Bond, J. Coble, M. Good, and R. Meyer, In-pile Instrumentation to Support Fuel Cycle Research and Development - FY11 Status Report, FCRD-FUEL-2011-000307 (also issued as INL/EXT-11-23119), September 2011.

3. P. Miller, "DOE Nuclear Energy Programs: The Future of Nuclear Energy - Part 1," presentation to Nuclear Energy Advisory Committee, Washington, DC, December 18, 2009.

4. FY2009 Advanced Test Reactor National Scientific User Facility User's Guide, INL/EXT-08-14709, Idaho National Laboratory, 2009.

5. A.J. Palmer, G.L. McCormick, and S.J. Corrigan, "Hydraulic Shuttle Irradiation System (HSIS) Recently Installed in the Advanced Test Reactor (ATR)," Proceedings of ICAPP '10, Paper 10354, San Diego, CA, USA, June 13-17, 2010.

6. S. Solstad and H. Thorenson, personal communication with J. Rempe, Halden, Norway, August 2012.

7. H.A. Tasman, M. Campana, D. Pel, and J. Richter, "Ultrasonic Thin-Wire Thermometry for Nuclear Applications,” Temperature: Its Measurement and Control in Science and Industry, Vol. 5, Part 2, pp. 1191-1196, 1982.

8. R.J. Grossman, "Ultrasonic-Thermometry Development for In-Situ Measurement of Nuclear-Fuel Temperatures (AWBA Development Program)," KAPL-4160, General Electric Company Knolls Atomic Power Laboratory, 1982.

9. E.P. Papdakis, L.C. Lynnworth, D.R. Patch, and E.H. Carnevale, "Ultrasonic Thermometry in LMFBR Systems,” Final Report NYO-3906-13, Panametrics Inc., 1972.

10. Y. S. Touloukian, et al., Thermophysical Properties of Matter, IFI/Plenum Publishing, New York, New York, 1973.

11. S.A. Chavez, G.E. Korth, D.M. Harper, and T.J. Walker, "High-temperature tensile and creep data for Inconel 600, 304 stainless steel and SA106B carbon steel," Nuclear Engineering and Design, 148, pp. 351-363, 1994.

12. R. Syre, "Niobium, Molybdenum, Tantalum and Tungsten: a Summary of Their Properties with Recommendations for Research and Development," AGARDograph, 50, 1961.

13. G.A. Carlson, W.H. Sullivan, H.G. Plein, and T.M. Kerley, "An Ultrasonic Thermometry System for Measuring Very High Temperatures in Reactor Safety Experiments," SAND79-0621, Sandia Laboratories, 1979. 
14. R.J. Grossman, "Ultrasonic-Thermometry Development for In-Situ Measurement of Nuclear-Fuel Temperatures (AWBA Development Program)," KAPL-4160, General Electric Company Knolls Atomic Power Laboratory, 1982.

15. H.A. Tasman, M. Campana, D. Pel, and J. Richter, "Ultrasonic Thin-Wire Thermometry for Nuclear Applications," Temperature: Its Measurement and Control in Science and Industry, Vol. 5, Part 2, pp. 1191-1196, 1982.

16. D.J. Senor, J.K. Thomas, and K.L. Peddicord, "Thermophysical property correlations for the niobium-1\% zirconium alloy,” Journal of Nuclear Materials, 173, pp. 261-273, 1990.

17. C.G. Wojcik, "Processing, properties, and applications of high temperature niobium alloys," MRS Symposium, Materials Research Society, Pittsburgh, PA, 322: pp. 519-30, 1994.

18. M.J. Roberts, D.E. Holcomb, and R.A. Kisner, "Signal Processing Algorithm Implementation for In Vessel Level Measurement," https://inlportal.inl.gov/portal/server.pt/gateway/ PTARGS-0-2-3310-277-2604-43/http\%3B/inlpublisher\%3B7087/publishedcontent/publish/communities/inl-gov/ about-inl/gen-iv-technical-documents/signal-processing-algorighm.pdf, September 2006.

19. D.A. Parks and B.R. Tittmann, "Ultrasonic NDE in a Reactor Core," Presented at Review of Progress in Quantitative Nondestructive Evaluation, Burlington, VT, July 17-22, 2011.

20. R. Kazys, et al., "High Temperature Ultrasonic Transducers for Imaging and Measurements in a Liquid Pb/Bi Eutectic Alloy," IEEE Transactions on Ultrasonics, Ferroelectrics, and Frequency Control, Vol. 52, Issue 4, pp. 525-537, 2005.

21. N.D. Patel and P.S. Nicholson, "High Frequency - High Temperature Ultrasonic Transducers," NDT International, pp. 262-266, 1990.

22. D. Stubbs and R. Dutton, "High-Temperature Ultrasonic Sensor for in Situ Monitoring of Hot Isostatic Processing," SPIE, pp.164-172, 1996.

23. K. Trachenko, "Understanding resistance to amorphization by radiation damage," Journal of Physics: Condensed Matter, 16(49), pp. R1491-R1515, 2004.

24. T. Yano, K. Inokuchi, M. Shikama, and J. Ukai, "Neutron irradiation effects on isotope tailored aluminum nitride ceramics by a fast reactor up to $2 \cdot 10^{26} \mathrm{n} / \mathrm{m}^{2}$," Journal of Nuclear Materials, pp. 1471-1475, 2004.

25. Y. Ito, K. Yasuda, R. Ishigami, M. Sasase, S. Hatori, K. Ohashi, et al., "Radiation Damage of Materials Due to High Energy Ion Irradiation," Nuclear Instruments and Methods in Physics Research, Section B, Beam Interactions with Materials and Atoms, 191, pp. 530-535, 2002.

26. Y.P. Meleshko, S.G. Karpechko, G.K. Leont'ev, V.I. Nalivaev, A.D. Nikiforov, and V.M. Smirnov, "RADIATION RESISTANCE OF THE PIEZOELECTRIC CERAMICS TsTS-21 AND TNV-I," Translated from Atomnaya Energiya, pp. 50-52, 1986. 
27. E.P. Papdakis, L.C. Lynnworth, D.R. Patch, and E.H. Carnevale, "Ultrasonic Thermometry in LMFBR Systems,” Final Report NYO-3906-13, Panametrics Inc., 1972.

28. R.J. Grossman, "Ultrasonic-Thermometry Development for In-Situ Measurement of Nuclear-Fuel Temperatures (AWBA Development Program),” KAPL-4160, General Electric Company Knolls Atomic Power Laboratory, 1982.

29. G.A. Carlson, W.H. Sullivan, H.G. Plein, and T.M. Kerley, "An Ultrasonic Thermometry System for Measuring Very High Temperatures in Reactor Safety Experiments," SAND79-0621, Sandia Laboratories, 1979.

30. A.E. Arave, F.E. Panisko, and J.A. Christensen, "High-Temperature Ultrasonic Thermometer In-Reactor Fuel Rod Centerline Temperature Test Results,” ANCR-1091, Aerojet Nuclear Company, 1972.

31. G.A. Carlson, W.H. Sullivan, and H.G. Plein, "Application of Ultrasonic Thermometry in LMFBR Safety Research,” SAND-77 1157, Sandia Laboratories, 1977.

32. Vacuumschmelze, "SOFT MAGNETIC COBALT-IRON-ALLOYS," http://www.vacuumschmelze.com/fileadmin/Medienbiliothek_2010/Downloads /HT/PTH\%20004\%20Vacoflux-Vacodur\%20engl.pdf, accessed August 9, 2012.

33. M. Laurie, D. Magallon, J. Rempe, S. Wilkins, J. Pierre, C. Marquié, S. Eymery, and R. Morice, "Ultrasonic High Temperature Sensors: Past Experiments and Prospective for Future Use," International Journal of Thermophysics, 31 (8-9), pp. 1417-1427, Special Issue, September 2010.

34. Arnokrome 3 Datasheet Rev. 01-11-11,www.arnoldmagnetics.com/WorkArea/DownloadAsset.aspx?id=5262, accessed August 9, 2012.

35. Arnokrome 4 Specification Rev. 1/11/11,www.arnoldmagnetics.com/WorkArea/DownloadAsset.aspx?id=5263, accessed August 9, 2012.

36. Arnokrome 5 Specification Rev. 2/24/11,www.arnoldmagnetics.com/WorkArea/DownloadAsset.aspx?id=5328, accessed August 9, 2012.

37. “What is Galfenol?", Etrema Products, Inc., http://www.etrema-usa.com/core/galfenol/, accessed August 9, 2012.

38. R.S. Sery, et al., "Radiation Damage Thresholds for Permanent Magnets," NOLTR 61-45, 1961.

39. Liu, et al., "Thermal Stability and Radiation Resistance of Sm-Co Based Permanent Magnets," Paper 2036, Proceedings of Space Nuclear Conference, 2007.

40. J. Daw, J. Rempe, and J. Crepeau, "Update on Ultrasonic Thermometry Development at Idaho National Laboratory," 8th International Topical Meeting on Nuclear Plant Instrumentation, Control, and Human Machine Interface Technologies (NPIC\&HMIT 2012), San Diego, CA, July 22-26, 2012.

41. J.E. Daw, et al., "High Frequency Magnetostrictive Transducer for Waveguide Applications," Idaho National Laboratory Invention Disclosure Record 2257, Rev. 1, submitted August 8, 2012. 
42. G. Cheymol, H. Long, J.-F. Villard, and B. Brichard, "High Level Gamma and Neutron Irradiation of Silica Optical Fibers in CEA OSIRIS Nuclear Reactor," IEEE Trans. Nuc. Science, 55, 2252-2258, 2008.

43. K. Totsu, Y. Haga, and M. Esashi, "Ultra-miniature fiber-optic pressure sensor using white light interferometry," J. Micromech. Microeng. 15, 71-75, 2005.

44. R. Schley, J. Rempe, and D. Knudson, "Fiber Optic Elongation/Displacement Sensor," Idaho National Laboratory Invention Disclosure Record BA-725, 2219, Rev. 1, submitted February 29, 2012.

45. D. Klemer, R.S. Fielder, and K.L. Stinson-Bagby, "Test and Evaluation of Fiber Optic Sensors for High-Radiation Space Nuclear Power Applications,” Proc. ICAPP '04, Pittsburgh, PA, June 2004.

46. K.L Telschow, D.L. Cottle, and R.S. Schley, INL Letter Report on LDRD, completed 2005.

47. K.L. Stinson-Bagby and R.S. Fielder, "Fiber Bragg Gratings for High-Temperature Thermal Characterization," Proc. ICAPP '04, Pittsburgh, PA, Paper 4299, June 2004.

48. D. Knudson and J. Rempe, "Recommendations for Use of LVDTs in ATR High Temperature Irradiation Testing," 7th International Topical Meeting on Nuclear Plant Instrumentation, Control, and Human Machine Interface Technologies (NPIC\&HMIT 2010), Las Vegas, NV, Nov. 7-11, 2010.

49. P. Jorgensen, Mini-Flex Corporation, personal communication with D. Knudson, INL, Idaho Falls, ID, August 2011.

50. IFE/HRP Drawings No. 389588 (Bellows Assembly), June 27, 2011, and No. 389589 (INL Tensile Test Unit), June 28, 2011.

51. INL Drawings No. 603353 (Creep Test Experiment Assembly), No. 603354 (Creep Test Experiment Details), and No. 603355 (Creep Test Experiment Specimen Details), February 9, 2012.

52. D.L. Knudson, K.L. Davis, K.G. Condie, and J.L. Rempe, Qualification of an LVDT-Based Creep Test Rig for Use in ATR Loop 2A, INL/LTD-12-26173, Idaho National Laboratory, August 2012.

53. D.L. Knudson and J.L. Rempe, "LVDT-Based Elongation Measurements in Advanced Test Reactor High Temperature Irradiation Testing," Measurement Science and Technology, Vol. 23, 025604, 7 pp, January 2012.

54. B.G. Kim, J.L. Rempe, D.L. Knudson, K.G. Condie, and B.H. Sencer, "In-Situ Creep Testing Capability for the Advanced Test Reactor," Nuclear Technology, Vol. 179, No. 3, pp.417-428, September 2012.

55. P. Moilanen, S. Tähtinen, B.N. Singh, and P. Jacquet, "In-Situ Investigation of the Mechanical Performance and Life Time of Copper: Final report on Design, Construction, and Calibration of Test Module for In-Reactor Tensile Tests in BR2 Reactor," VTT Report BTUO 76-031127, October 27, 2004. 
56. N. Singh, S. Tähtinen, P. Moilanen, P. Jacquet, and J. Dekeyser, "In-Reactor Uniaxial Tensile Testing of Pure Copper at a Constant Strain Rate at $90{ }^{\circ}$ C," Journal of Nuclear Materials, 320, pp.299304, 2003.

57. R. Van Nieuwenhove, "Development and Testing of Instruments for Generation IV Fuel and Materials Research at the Halden Reactor Project," IAEA Technical Meeting on In-Pile Testing and Instrumentation for Development of Generation-IV Fuels and Materials, Halden, Norway, August 21-24, 2012.

58. R. Van Nieuwenhove and S. Solstad, "In-core fuel performance and material characterization in the Halden reactor," ANIMMA International Conference, Marseille, France, June 7-10, 2009.

59. R.H. Leyse and R.D. Smith, "Gamma Thermometers for Light Water Reactors," IEEE Transactions on Nuclear Science, NS-26, pp.934-943, February 1979.

60. H. Carcreff, V. Clouté-Cazalaa, and L. Salmon, "Development, calibration and experimental results obtained with an innovative calorimeter (CALMOS) for nuclear heating measurements," Proceedings of the Second International Conference on Advancements in Nuclear Instrumentation, Measurement Methods and their Applications (ANIMMA2011), Ghent, Belgium, June 2011.

61. H. Carcreff, Patent No. FR 1060068, December 3, 2010.

62. O. Aarrestad, "Instrumentation Capabilities at Halden," IFE/HRP Report HWR-351, February 1993.

63. R. Van Nieuwenhove, IFE/HRP, personal communication with J. Rempe, INL, Halden, Norway, August 2012. 
In-pile Instrumentation to Support Fuel Cycle Research and Development - FY12 Status Report

September 2012 